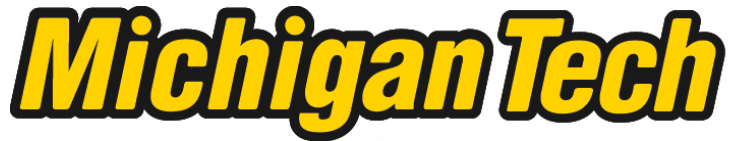 \\ Michigan Technological University Create the Future Digital Commons @ Michigan Tech
}

Development of measurement and modeling techniques to quantify atmospheric deposition of persistent, bioaccumulative and toxic chemicals in the Great Lakes

Mark D. Rowe

Michigan Technological University

Follow this and additional works at: https://digitalcommons.mtu.edu/etds

Part of the Environmental Engineering Commons, and the Environmental Sciences Commons Copyright 2009 Mark D. Rowe

\section{Recommended Citation}

Rowe, Mark D., "Development of measurement and modeling techniques to quantify atmospheric deposition of persistent, bioaccumulative and toxic chemicals in the Great Lakes", Dissertation, Michigan Technological University, 2009.

https://doi.org/10.37099/mtu.dc.etds/719

Follow this and additional works at: https://digitalcommons.mtu.edu/etds

Part of the Environmental Engineering Commons, and the Environmental Sciences Commons 


\title{
DEVELOPMENT OF MEASUREMENT AND MODELING TECHNIQUES TO QUANTIFY ATMOSPHERIC DEPOSITION OF PERSISTENT, BIOACCUMULATIVE AND TOXIC CHEMICALS IN THE GREAT LAKES
}

\author{
By \\ MARK D. ROWE \\ A DISSERTATION \\ Submitted in partial fulfillment of the requirements \\ for the degree of \\ DOCTOR OF PHILOSOPHY \\ Environmental Engineering \\ MICHIGAN TECHNOLOGICAL UNIVERSITY \\ 2009
}

Copyright @ Mark D. Rowe 2009 

This dissertation, "Development of measurement and modeling techniques to quantify atmospheric deposition of persistent, bioaccumulative and toxic chemicals in the Great Lakes", is hereby approved in partial fulfillment of the requirements for the degree of DOCTOR OF PHILOSOPHY in the field of Environmental Engineering.

\section{PROGRAM:}

\section{Environmental Engineering}

\section{Signatures:}

Judith A. Perlinger, Dissertation Advisor

Judith A. Perlinger, Graduate Program Director

January 7, 2010 



\section{Table of Contents}

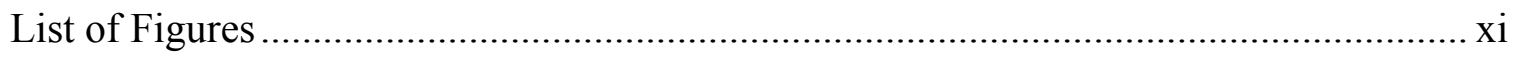

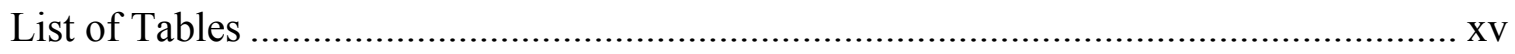

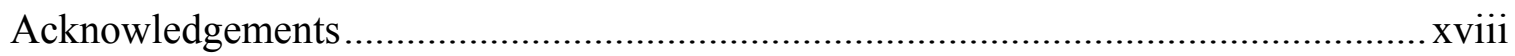

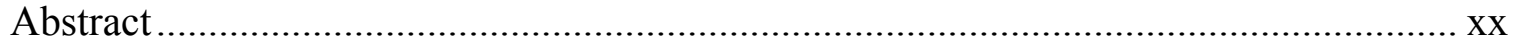

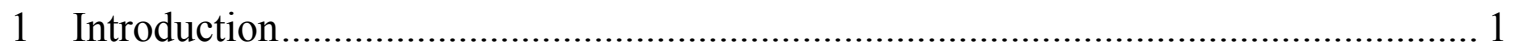

1.1 Sources of PBTs and health impacts of ecosystem contamination on humans and

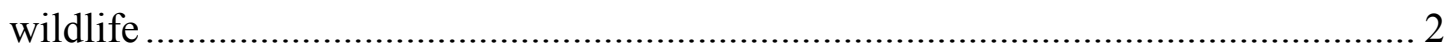

1.2 The role of gaseous air-water exchange in forecasting trends in ecosystem

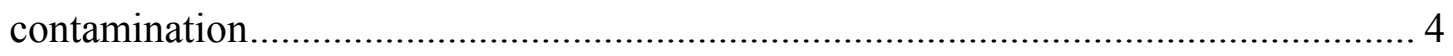

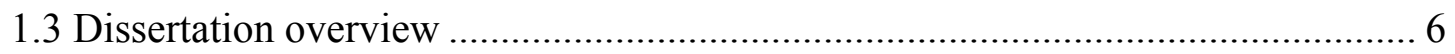

2 Gas-phase cleanup method for analysis of trace atmospheric semivolatile organic compounds by thermal desorption from diffusion denuders ....................................... 9

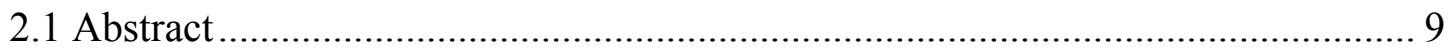

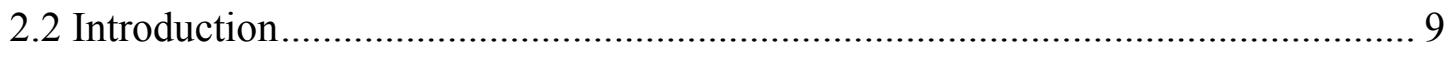

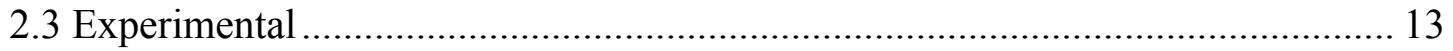

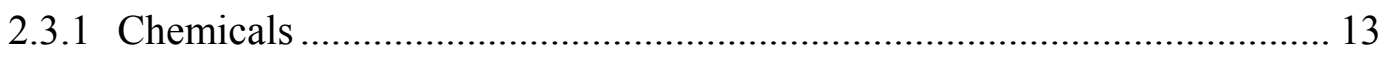

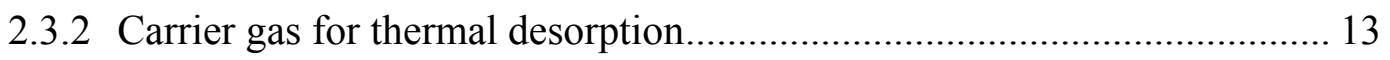

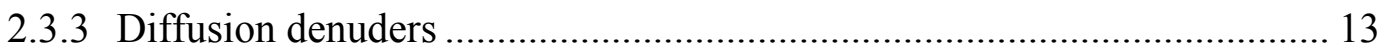

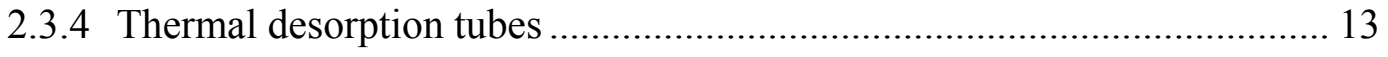

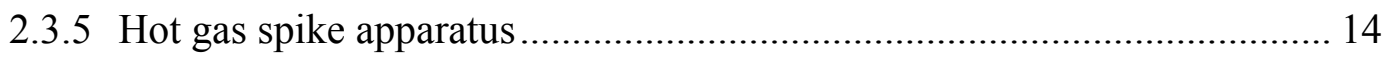

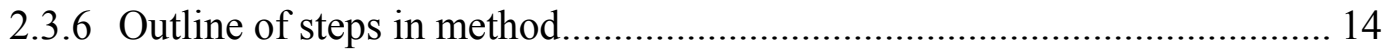

2.3.7 Air sample collection........................................................................ 15

2.3.8 Thermal transfer from low-flow denuder into TD tube ............................. 15 


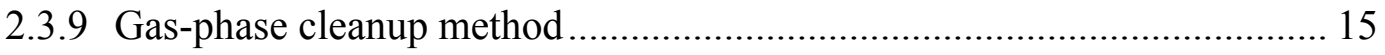

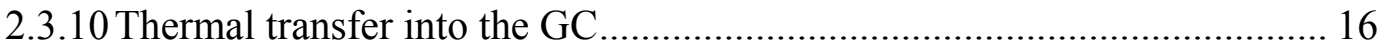

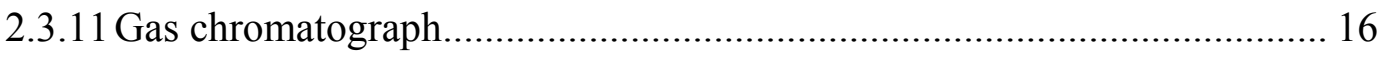

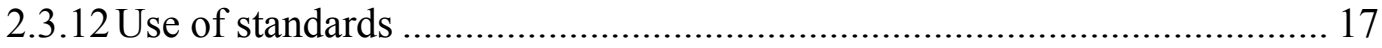

2.3.13 Air sample data processing and quality assurance ................................... 17

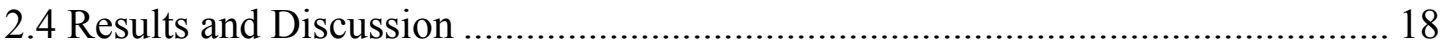

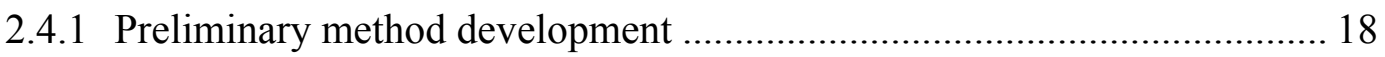

2.4.2 Selectivity of the gas-phase cleanup method ........................................... 20

2.4.3 Effect of the gas-phase cleanup on an ambient air sample chromatogram 24

2.4.4 Precision and sensitivity of the gas-phase cleanup method ........................ 26

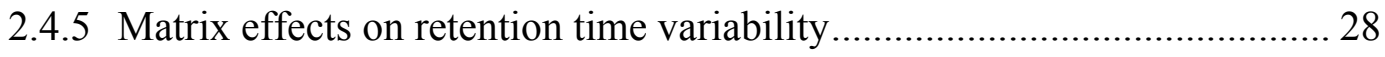

2.4.6 Comparison of PBT concentrations in indoor and outdoor air .................. 31

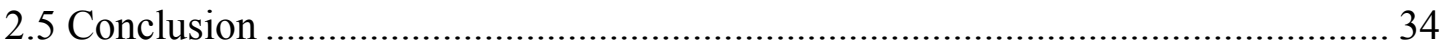

3 Prediction of gas collection efficiency and particle collection artifact for atmospheric semivolatile organic compounds in multicapillary denuders...................................... 35

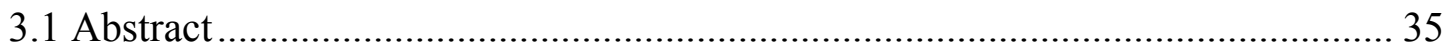

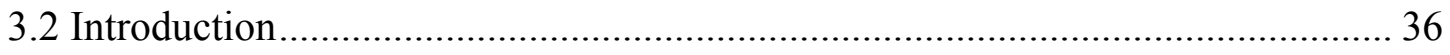

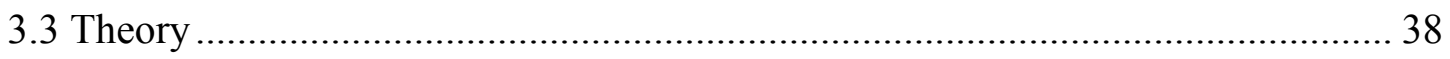

3.3.1 Prediction of gaseous collection efficiency .................................................. 38

3.3.2 Prediction of particle transmission efficiency ............................................ 41

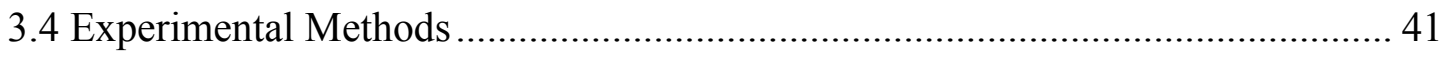

3.4.1 Low-flow and high-flow multicapillary diffusion denuders ..................... 41

3.4.2 Measurement of PDMS-gas partition coefficients by gas chromatography42

3.4.3 Measurement of breakthrough fraction for gaseous analytes 
3.4.4 Measurement of particle transmission efficiency................................. 44

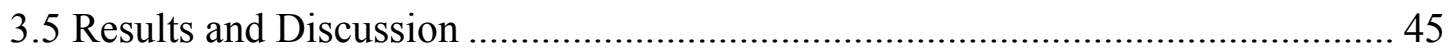

3.5.1 Measured and estimated PDMS-gas partition coefficients ..................... 45

3.5.2 Comparison of measured to predicted breakthrough fraction ................... 50

3.5.3 Comparison of measured to predicted particle transmission.................... 51

3.5.4 Application of the model to predict sampling artifacts ......................... 53

4 Performance of a high flow rate, thermally-extractable multicapillary denuder for atmospheric semivolatile organic compound concentration measurement ................58

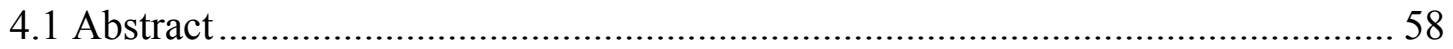

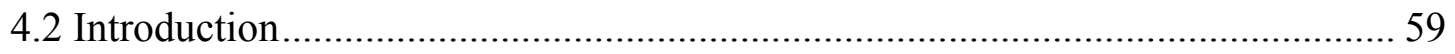

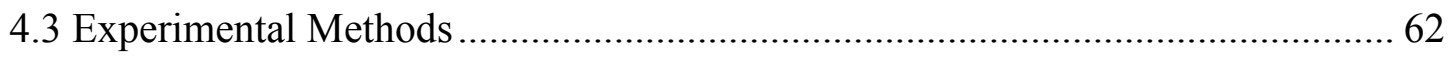

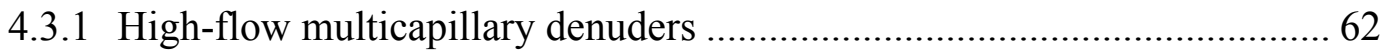

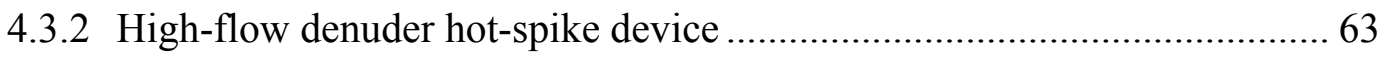

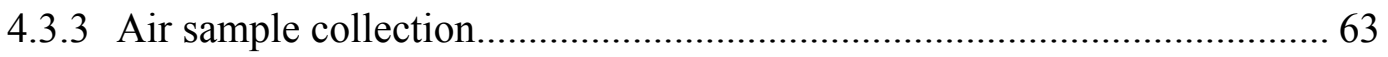

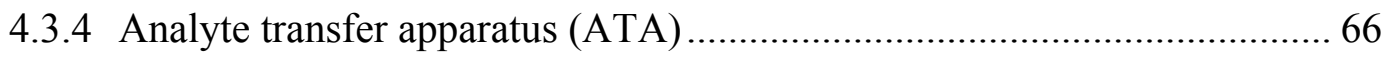

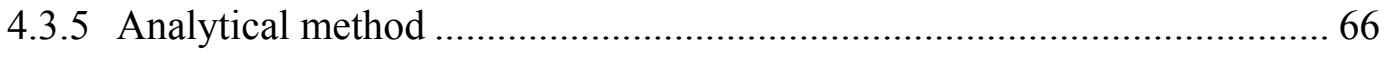

4.3.6 Bias and precision relative to high-volume sampling ............................ 67

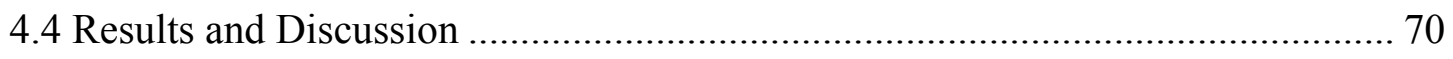

4.4.1 Surrogate recoveries and detectable analyte mass .............................. 70

4.4.2 Trace atmospheric PCB and HCB concentrations ............................... 72

4.4.3 Bias and precision relative to the high-volume sampler ........................ 75

4.4.4 High-flow denuder method performance .......................................... 77

5 Parameterization of internal boundary layer growth using an internal boundary layer

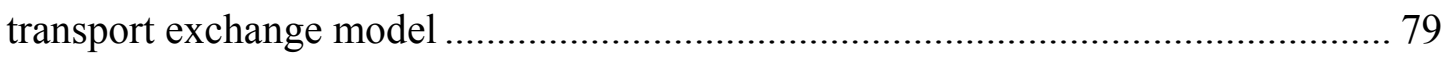


5.1 Abstract

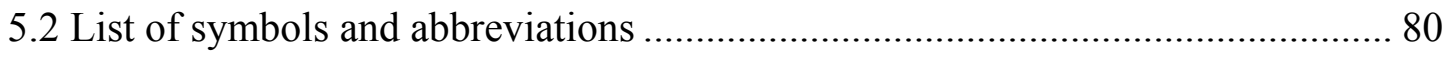

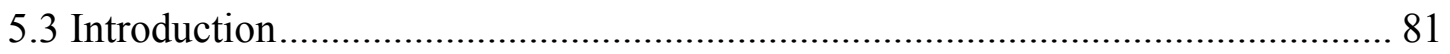

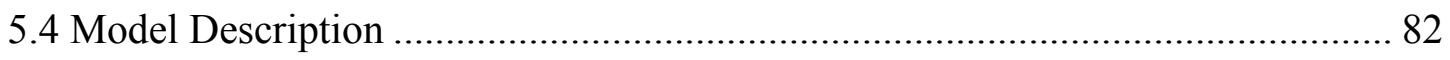

5.4.1 Mass balance over the internal boundary layer (IBL) ............................ 84

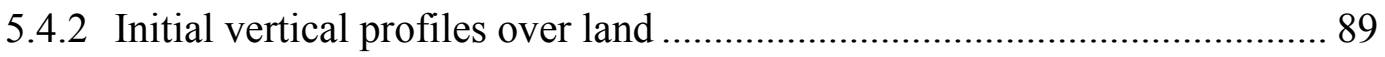

5.4.3 Mathematical approach to profile matching........................................ 90

5.4.4 Estimation of the IBL growth rate coefficient from air temperature and

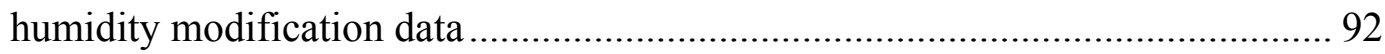

5.4.5 Estimation of the IBL growth rate coefficient from atmospheric soundings 100

5.4.6 Estimation of the IBL dimensionless profile shape from atmospheric

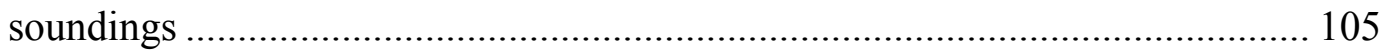

5.4.7 Parameterization of the IBL growth rate coefficient, $\alpha \ldots \ldots \ldots \ldots \ldots \ldots \ldots \ldots . . . . . . . . .107$

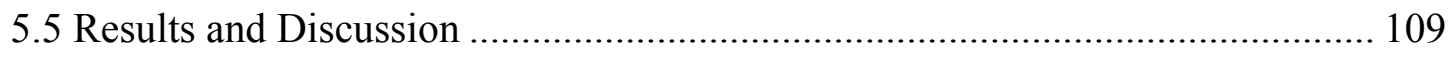

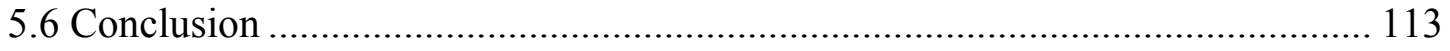

6 Application of an internal boundary layer transport exchange model to micrometeorological measurements of hexachlorobenzene and polychlorinated biphenyl gas transfer in Lake Superior ......................................................... 117

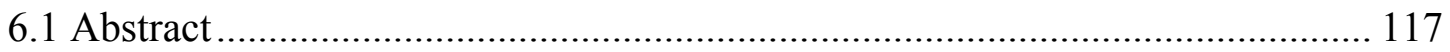

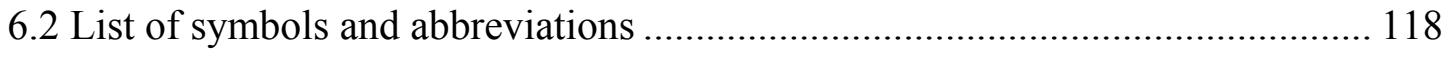

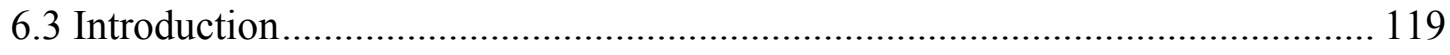

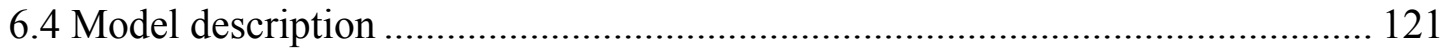

6.4.1 Internal Boundary Layer Transport Exchange (IBLTE) model .............. 121

6.4.2 Parameterization of air-water gas exchange flux ............................... 122 
6.4.3 Whitman Two-film (W2F) Model transfer velocity.

6.4.4 COARE Gas Transfer Model 126

6.4.5 Use of the COARE Gas Transfer Model with PBT organic compounds . 128

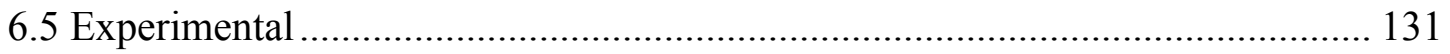

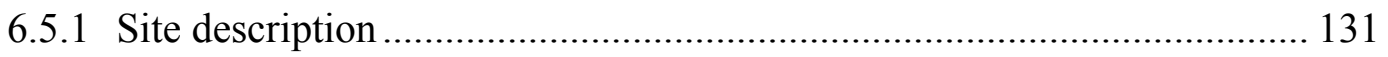

6.5.2 Modified Bowen Ratio (MBR) flux measurements ............................. 133

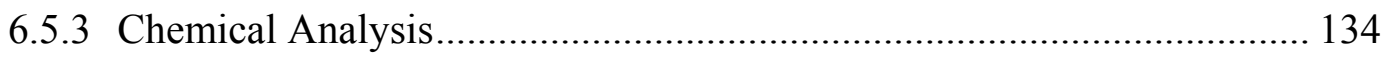

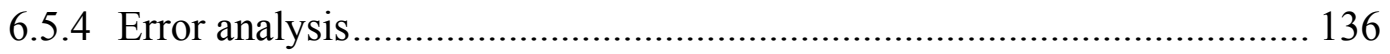

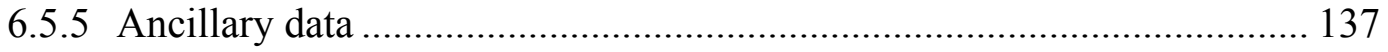

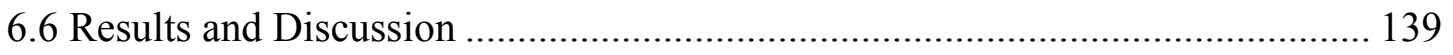

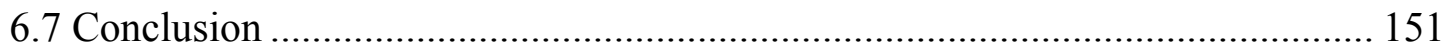

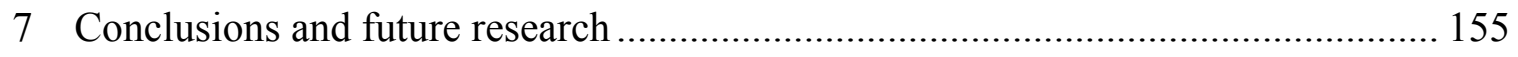

7.1 Methods for improved precision and temporal resolution for non-polar

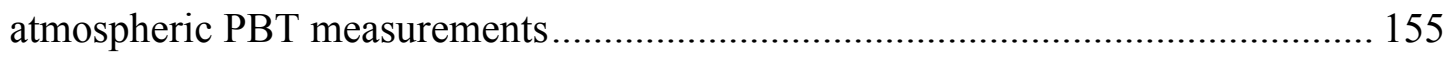

7.2 Atmosphere-surface exchange flux measurements for PBTs .......................... 156

7.3 Determination of the internal boundary layer growth rate coefficient by

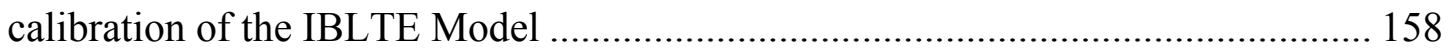

7.4 Application of the IBLTE and COARE gas transfer models to PBT air-water

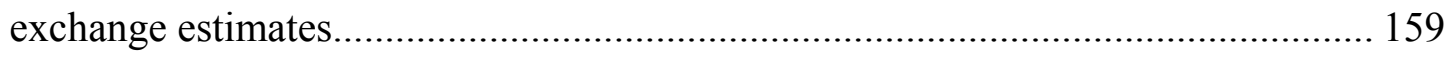

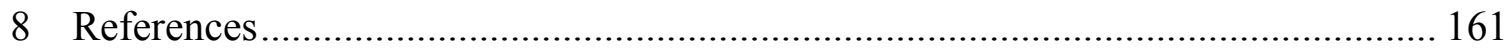

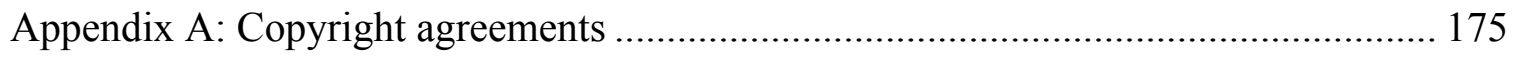

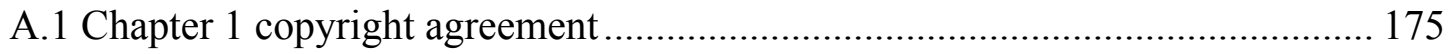

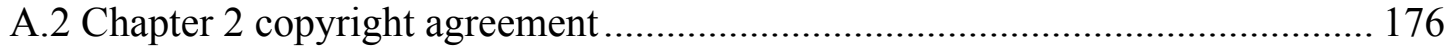

A.3 Journal of Chromatography A copyright agreement details. ........................... 177 
Appendix B: Chapter 2 supplemental information ............................................ 178

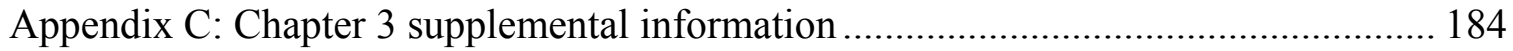

Detailed description of the collection efficiency model ...................................... 184

Prediction of gas-phase collection efficiency. .......................................... 184

Temperature-dependent $K_{\text {pdms }}$ from the solvation parameter model................. 186

Prediction of particle transmission efficiency.................................................. 187

Appendix D: Chapter 4 supplemental information.................................................. 195 


\section{List of Figures}

Figure 2.1: Recovery of analytes through the gas-phase cleanup method................ 22

Figure 2.2: Overlaid chromatograms of co-located outdoor low-flow air samples with one having been processed through the gas-phase cleanup method and the other having no cleanup.

Figure 2.3: Recovery and retention time variability for surrogate standards and internal standards.

Figure 3.1: Comparison of measured to predicted breakthrough fraction for low-flow and high-flow denuders. 50

Figure 3.2: Comparison of measured to predicted aerosol particle transmission through low-flow and high-flow denuders. 52

Figure 3.3: Predicted breakthrough volume and particle collection artifact, $f_{\mathrm{d}}$, for rural and urban aerosol particle size distributions in high-flow and low-flow denuders as a function of the octanol-air partition coefficient.

Figure 4.1: Two high-flow denuders in series and filter assembly inside the anodized aluminum sleeve.. 61

Figure 4.2: High-flow denuder sample collection at Eagle Harbor, MI 65

Figure 4.3: Recovery of surrogate standards hot-spiked into high-flow denuders with and without subsequent sample collection, and internal standards 71

Figure 4.4: Map showing sampling locations at Eagle Harbor and Houghton, Michigan. Air parcel back trajectories (24-hr) are indicated with the associated sample date and sum of PCB concentration. 73

Figure 5.1: Illustration of the modification of the vertical profile of gas mixing ratio with increasing fetch as a well-mixed atmospheric boundary layer is advected from land to water with a gas flux directed upward from the surface 83 
Figure 5.2: Illustration of the modification of the vertical profile of gas mixing ratio within the internal boundary layer in an air mass advected from land to water at a specific fetch, $X$.

Figure 5.3: Hourly air temperature, dewpoint temperature, and wind speed, from Toronto plotted with interpolated water surface temperature for Lake Ontario, 1973 ..... 94

Figure 5.4: Results of calibration of the IBL growth rate coefficient, $\alpha$, to air temperature and dewpoint temperature modification data using the IBLTE Model....... 96

Figure 5.5: Results of calibration of the IBL growth rate coefficient, $\alpha$, to air temperature and dewpoint temperature modification data using the IBLTE Model....... 98

Figure 5.6: Two maps of the East coast of North America showing a HYSPLIT backward air parcel trajectory starting at the rawinsonde launch location.................... 103

Figure 5.7: Sounding analysis plots for the maps shown in Figure 5.6................ 104

Figure 5.8: Vertical distribution of potential temperature and water vapor mixing ratio within the IBL from NEAQS soundings, plotted using the dimensionless profile function, Eq. (5.6). 106

Figure 5.9: The IBL growth rate coefficient, $\alpha \mathrm{m}^{0.5}$, versus the $10-\mathrm{m}$ bulk Richardson number. The calibrated values of $\alpha$ from the IBLTE Model calibration to the Phillips and Irbe (1978) data set are plotted as circles.

Figure 5.10: An enlarged view of the stable portion of Figure 5.9..................... 115

Figure 5.11: An enlarged view of the unstable portion of Figure 5.9................... 116

Figure 6.1: Molecular structures of $\alpha-\mathrm{HCH}, \mathrm{HCB}, \mathrm{PBDE} 47$, and PCB $18 \ldots$

Figure 6.2: Percent difference between COARE and W2F Model PBT transfer velocity for a water-side transfer resistance limited compound, $\mathrm{HCB}(\mathrm{A})$, and an air-side transfer resistance limited compound, $\alpha-\mathrm{HCH}$ (B), for 1973 hourly meteorological conditions for Lake Ontario. 130 
Figure 6.3: A map of Lake Superior showing the station locations, NOAA HYSPLIT air parcel backward trajectories, and NOAA GLSEA lake surface temperatures for 14 July 2006.

Figure 6.4: Sensible heat flux measured by eddy covariance and estimated by COARE Bulk Algorithm at the three stations in Lake Superior.

Figure 6.5: Overall mass transfer velocity, $k_{\mathrm{ol}}$, for each PBT at the 15, 30, and $60 \mathrm{~km}$ stations. Filled bars are from the COARE Algorithm with H Set 1 and H Set 2. Open bars are from the W2F model.

Figure 6.6: For each analyte the PBT flux and atmospheric concentration is plotted at the 15-, 30-, and 60-km stations.

Figure 6.7: Ratio of $15-\mathrm{km}$ station to $60-\mathrm{km}$ station (0620-0750 to $1318-1448$ local time) PBT concentration at $8.5 \mathrm{~m}$ height versus hydroxyl radical reaction rate constant for PBTs in air over Lake Superior at 8.5-m height on 14 July 2006.

Figure 6.8: Measured and IBLTE-Modeled air temperature at the 15-, 30-, and 60$\mathrm{km}$ stations. 152

Figure 6.9: Measured and IBLTE modeled HCB atmospheric concentration at the 15, 30-, and 60-km stations.

Figure 6.10: HCB flux versus fetch from the IBLTE Model for $15-\mathrm{km}, 30-\mathrm{km}$, and $60-\mathrm{km}$ stations.

Figure B.1: Chromatograms of co-located outdoor air samples. The upper chromatogram was processed through the gas-phase cleanup method while the lower chromatogram was not.

Figure C.1: $\log \left(K_{\text {pdms }}\right)$ measured using gas chromatography versus $\log \left(K_{\mathrm{oa}}\right)$ at $25^{\circ} \mathrm{C}$ for the compounds listed in Table 3.3. The relationship $\log \left(K_{\mathrm{pdms}}\right)=\log \left(K_{\mathrm{oa}}\right)-1$ is plotted using a dashed line. .194

Figure D.1: Schematic illustration of the high-flow denuder hot-spike device. .195 
Figure D.2: Schematic longitudinal cross-section of the analyte transfer apparatus

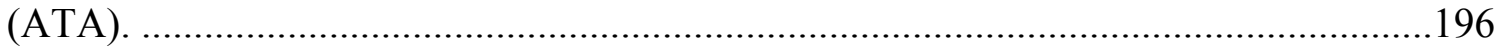




\section{List of Tables}

Table 2.1: Method detection limits (MDLs), pg, with and without the gas-phase cleanup method.

Table 2.2: Relative standard deviation, of surrogate and internal standard recoveries in indoor and outdoor air samples with gas-phase cleanup and without cleanup..... 30

Table 2.3: Observed concentration of selected persistent, bioaccumulative, and toxic chemicals $\left(\mathrm{pg} \mathrm{m}^{-3}\right)$ in duplicate outdoor and indoor air samples.

Table 3.1: Linear regression parameters (slope and intercept) used to estimate temperature-dependent solvent descriptors for polydimethylsiloxane stationary phase for estimation of the liquid-gas partition coefficient by the solvation parameter model ....... 39

Table 3.2: Regression parameters (slope and intercept) used to calculate temperature dependent liquid-gas partition coefficients for polydimethylsiloxane stationary phase derived from $\mathrm{GC}$ retention time measurements 48

Table 3.3: $\log \left(K_{\text {pdms }}\right)$ at $25{ }^{\circ} \mathrm{C}$ estimated from GC measurements and from PDMS solvent descriptors from two sources.

Table 4.1: Sample conditions, $\mathrm{HCB}$ and PCB concentrations for high-flow denuder samples collected at Eagle Harbor and Houghton, MI in 2008 74

Table 4.2: Summary statistics for comparison of $\mathrm{PCB}$ and $\mathrm{HCB}$ concentrations measured in co-located high-flow denuder and high-volume samplers, and field duplicate precision 75

Table 4.3: Between-method bias (high flow - high volume) as a function of relative PCB analyte volatility (GC elution order) and percent of total PCB concentration in air associated with particles over the sampling temperature range.

Table 5.1: Outline of IBLTE Model code 91

Table 5.2: Frequency distribution of the $10-\mathrm{m}$ bulk Richardson number based on hourly meteorological data from Toronto and interpolated water surface temperatures for Lake Ontario for 1 January to 31 December, 1973. 95 
Table 6.1: Conditions at the three sampling stations in eastern Lake Superior on 14 July 2006, and average temperature at the upper $(8.5 \mathrm{~m})$ and lower $(1 \mathrm{~m})$ platforms.... 131

Table 6.2: Overall method precision, expressed as the non-parametric coefficient of variation $(\mathrm{CoV})$ of field duplicates, using the same denuder sampling method as in the 14 July 2006 measurements. Relative difference in Henry's law constant from two sources (Set $2-$ Set 1$)$ is also reported.

Table 6.3: $\mathrm{PBT}$ concentration in filtered, near-surface Lake Superior water measured by Michigan Technological University and data compiled by the IADN Project. 138

Table 6.4: Atmospheric PBT concentration measured at the upper $(8.5-\mathrm{m})$ and lower (1-m) platforms at 15-, 30-, and 60-km stations in Lake Superior, 14 July $2006\left(\mathrm{pg} \mathrm{m}^{-3}\right.$ at $\left.25{ }^{\circ} \mathrm{C}, 1 \mathrm{~atm}\right)$ 143

Table 6.5: Contributions to the relative error in the MBR flux measurements given by the terms in Eq. (6.18)......

Table 6.6: Contributions to the relative error in the W2F flux estimates given by the terms in Eq. (6.19) 148

Table 6.7: Ratio of modeled to measured land-lake modification in PBT atmospheric concentration at 1-m height, 60-km fetch using Set 2 Henry's law constant and Michigan Tech aqueous concentration from Table 6.3. 151

Table B.1: Concentration of persistent, bioaccumulative, and toxic chemicals ( $\mathrm{pg} \mathrm{m}^{-}$ $\left.{ }^{3}\right)$ in duplicate outdoor and indoor air samples. .178

Table C.1: Solute descriptors for compounds used in GC measurements of $K_{\mathrm{pdms} . .189}$

Table C.2: Solvent descriptors for PDMS and dry octanol from several sources are presented, including the number of compounds in the calibration data set.

Table C.3: Sample collection conditions for gaseous breakthrough fraction measurements. 
Table C.4: Mean properties of log-normal ambient aerosol size distributions and predicted particle transmission for each aerosol mode through the high-flow and lowflow denuders.

Table C.5: Root mean square (RMS) error for comparison of predicted with measured breakthrough fraction, $b t$, for low-flow and high-flow diffusion denuders....193

Table D.1: Concentration of atmospheric persistent, bioaccumulative, and toxic chemicals (pg m ${ }^{-3}$ at $25^{\circ} \mathrm{C}, 1 \mathrm{~atm}$.)

Table D.2: Paired analyte groups for comparison of concentrations measured by high-flow denuder to IADN Project high-volume samples. 


\section{Acknowledgements}

I would like to thank my advisor, Judith Perlinger, for giving me an opportunity enter a new field, and for supporting me through our years of work together. I would like to thank the members of my committee - Christopher W. Fairall, Noel R. Urban, and Paul V. Doskey - for their role in bringing this work to completion. The contributions of Christopher Fairall of NOAA/ESRL were essential to the material presented in Chapters 5 and 6. Richard Honrath was a member of my committee until his death in 2009, and provided important insights in the early development of Chapters 5 and 6. Funding from the Great Lakes Commission, NSF Sustainable Futures IGERT program at Michigan Tech, a Michigan Tech Graduate School Doctoral Finishing Fellowship, and the NSF/ Michigan Tech Scholarships - Science, Technology, Engineering, and Mathematics (SSTEM) program (NSF Grant No. 0806569) are gratefully acknowledged. David Perram and David Tobias provided mentorship in the laboratory. My wife Lauren Fry provided invaluable support and encouragement. My parents gave me the opportunity of a university education, and my father was a role model to me as a professional scientist and amateur naturalist.

David Tobias provided data for method comparison for the work presented in Chapter 2, and Fritz Burt assisted in the laboratory. Fritz Burt and Juan Pablo Alvarez Rosario assisted with particle transmission measurements for the work presented in Chapter 3. Eric Bradfish, Shannon Flynn, Kenny Papes, and Lauren Fry each assisted at various times with flow rate calibration and field work for Chapters 3 and 4.

Provisional 2008 IADN Project data were provided by Ronald Hites of Indiana University. Helena Dryfhout-Clark of Environment Canada provided IADN Project data through 2007. Alice Dove and the IADN project provided PBT concentration data for Eagle Harbor, 2000-05, through the Canadian National Atmospheric Chemistry (NAtChem) Database. The comments of anonymous reviewers improved the quality of the material in Chapters 2 and 3. 
Reginald Hill of NOAA/ESRL provided example Matlab code for analysis of the NEAQS data presented in Chapter 5. David Tobias assisted with laboratory preparation and field work for the flux measurements presented in Chapter 6. Aqueous PBT concentration measurements were conducted by Micheal Eikenberry and David Tobias with funding through U.S. EPA GLNPO Grant No. GL-96520401-0. The U.S. EPA, and the captain and crew of the $R / V$ Lake Guardian are gratefully acknowledged for their support with the flux measurements. 


\section{Abstract}

Measurement and modeling techniques were developed to improve over-water gaseous air-water exchange measurements for persistent bioaccumulative and toxic chemicals (PBTs). Analytical methods were applied to atmospheric measurements of hexachlorobenzene (HCB), polychlorinated biphenyls (PCBs), and polybrominated diphenyl ethers (PBDEs). Additionally, the sampling and analytical methods are well suited to study semivolatile organic compounds (SOCs) in air with applications related to secondary organic aerosol formation, urban, and indoor air quality.

A novel gas-phase cleanup method is described for use with thermal desorption methods for analysis of atmospheric SOCs using multicapillary denuders. The cleanup selectively removed hydrogen-bonding chemicals from samples, including much of the background matrix of oxidized organic compounds in ambient air, and thereby improved precision and method detection limits for nonpolar analytes.

A model is presented that predicts gas collection efficiency and particle collection artifact for SOCs in multicapillary denuders using polydimethylsiloxane (PDMS) sorbent. An approach is presented to estimate the equilibrium PDMS-gas partition coefficient $\left(K_{\mathrm{pdms}}\right)$ from an Abraham solvation parameter model for any SOC.

A high flow rate $\left(300 \mathrm{~L} \mathrm{~min}^{-1}\right)$ multicapillary denuder was designed for measurement of trace atmospheric SOCs. Overall method precision and detection limits were determined using field duplicates and compared to the conventional high-volume sampler method. The high-flow denuder is an alternative to high-volume or passive samplers when separation of gas and particle-associated SOCs upstream of a filter and short sample collection time are advantageous.

A Lagrangian internal boundary layer transport exchange (IBLTE) Model is described. The model predicts the near-surface variation in several quantities with fetch in coastal, offshore flow: 1) modification in potential temperature and gas mixing ratio, 2) surface fluxes of sensible heat, water vapor, and trace gases using the NOAA COARE Bulk Algorithm and Gas Transfer Model, 3) vertical gradients in potential temperature 
and mixing ratio. The model was applied to interpret micrometeorological measurements of air-water exchange flux of HCB and several PCB congeners in Lake Superior. The IBLTE Model can be applied to any scalar, including water vapor, carbon dioxide, dimethyl sulfide, and other scalar quantities of interest with respect to hydrology, climate, and ecosystem science. 



\section{Introduction}

Contamination of ecosystems by atmospheric deposition of persisent, bioaccumulative and toxic (PBT) chemicals is a continuing concern for human and ecosystem health. Currently $43 \%$ of total lake acreage and $39 \%$ of total river miles in the United States are under fish consumption advisories, including 100\% of the Great Lakes and connecting waters. Seventy nine percent of U.S. coastal waters are under advisory, including nearly all of the East Coast and Gulf Coast. Mercury, dioxin, polychlorinated biphenyls (PCBs), DDT, and chlordane are responsible for most advisories (U.S. EPA 2008). While fish consumption advisories focus mainly on legacy chemicals, current use chemicals are also of concern (refer to, for example, Tuduri et al. 2006). Commercial as well as sport fisheries are affected (refer to, for example, Hites et al. 2004).

Societal and economic impacts of coastal ecosystem contamination are potentially significant. More than half of the world's population lives within $100 \mathrm{~km}$ of the coast, and that number is expected to increase by $25 \%$ over the next two decades. The coastal zone is the single most important region for fisheries and represents more than half the value of global ecological services (Niemi et al. 2004). United States statistics indicate that $20 \%$ of all males and $6 \%$ of all females (30 million anglers) spend 517 million days and $\$ 42.2$ billion on sport fishing and related activities annually. The federal taxes generated, $\$ 9$ billion, are equal to the annual budget of the U.S. EPA. In the Great Lakes, 1.3 million anglers spend $\$ 1.5$ billion (or $\$ 2.5$ to 7.1 billion (American Sportfishing Association 2008)) annually on sport fishing and related activities (U.S. Department of the Interior et al. 2006). It is difficult to measure cultural significance, but these statistics indicate that fishing is a valued activity for many Americans. Increasing pressure on coastal ecosystems can be anticipated in the future, both in terms of impacts on the ecosystems as well as demand for their services.

Worldwide, the poor are disproportionately dependent on ecosystem services. An estimated 250 million people in developing countries are directly dependent on smallscale fisheries for food and income. In East Asia and Africa fish provide more than 50 
percent of the animal protein intake in the diet of 400 million people. People dependent upon marine ecosystems in polar regions are particularly affected by atmospheric transport and bioaccumulation of PBTs. For example, 100\% of the human population in East Greenland has concentrations of mercury that are unacceptable, and reduced consumption of some traditional resources has been advised (Hassan et al. 2005, p. 730). While the potential implications of global contamination of fisheries by PBTs are profound, there is a great deal of uncertainty regarding the extent of contamination and the associated impacts. The recent and comprehensive Millenium Ecosystem Assessment had little to say regarding ecosystem contamination with PBTs, except that "Because of the poor monitoring of the long-term effects of xenobiotics [PBTs], the global and longterm implications of their use cannot be fully assessed" (Hassan et al. 2005, p. 181).

Gaseous exchange with the atmosphere is a dominant process in the mass balance for relatively volatile and water-insoluble chemicals such as PCBs and mercury (Jeremiason et al. 1994; Rowe et al. 2008), and an important contributing process for less volatile compounds such as polybrominated diphenyl ethers (Rowe et al. 2008) or more water soluble compounds such as some current use pesticides (Harman-Fetcho et al. 2000). Quantification of the rate of gaseous exchange with the atmosphere is critical to understand and predict the behavior of toxics in surface waters.

\subsection{Sources of PBTs and health impacts of ecosystem contamination on humans and wildlife}

The first restrictions on production and use of PBTs, including PCBs and several organochlorine pesticides OCPs, occurred in the 1970s. Since that time, concentrations of these chemicals have decreased in humans and wildlife, but are still widely present at detectable levels (Robinson et al. 1990; Smith 1999). While new production and use of PCBs has been banned for decades, existing stocks of PCBs continue to be emitted into the atmosphere. Urban areas are continuing sources of PCBs into the atmosphere (Blanchard et al. 2004; Harner et al. 2004). Building materials such as historical joint sealants (Kohler et al. 2005) and even new paint pigments are sources of PCBs (Hu et al. 2008). 
Other classes of chemicals, such as PBDEs and perfluorinated chemicals, are currently in use in the United States. PBDE concentrations in humans have increased rapidly in recent decades, and concentrations in the North American population are higher than in the European population (Hites 2004). Current PBDE concentrations in the North American population are similar to levels that cause reproductive effects in rodent studies (McDonald 2005). The built environment is a distributed source of PBDEs to the atmosphere (Harner et al. 2006). Recent developments in the science of PBTs have revealed new aspects of their behavior in the environment, wildlife, and in humans. For example, high production volume chemicals that were not previously known as PBTs have been recently discovered in environmental and biological samples (Hoh et al. 2006) or have been discovered to transform into known PBTs through atmospheric chemistry (Ellis et al. 2004).

Cancer and endocrine disruption are the negative health impacts of greatest concern with respect to PBT exposure. Direct causal associations between negative human health impacts and exposure to PBTs are difficult to establish in the general population because of the inherent challenges in epidemiological studies; however, causal associations between PBT exposure and negative health impacts in wildlife and laboratory animals have been established in numerous studies (WHO 2002). In a comprehensive review of the literature by the World Health Organization, the strength of evidence was judged to be moderate supporting the hypothesis that impaired neurobehavioral development in humans has been caused by exposure to PCBs, and that impaired immune function in humans has been caused by exposure to PCBs or 2,3,7,8-Tetrachlorodibenzyl- $p$-dioxin (TCDD). The evidence was judged to be weak supporting the hypothesis that endometriosis has been caused by exposure to TCDD or PCBs and that breast cancer has been caused by PCBs or DDT (WHO 2002, p. 125-126). A recent study has shown a correlation between human serum PBT concentrations and Type II diabetes (Lee et al. 2006). There is an ongoing debate regarding the neurodevelopmental effects of prenatal PCB exposure; some studies have correlated negative outcomes with PCB exposure while others have not (Gray et al. 2005). Regardless of the difficulties in proving causal associations between PBT exposure and health effects in the general population, 
concentrations of PBTs in humans and their trends over time continue to be of concern because of their known or suspected toxicity and their pervasive distribution, which is in part a result of atmospheric transport and deposition.

The Laurentian Great Lakes represent a system of great ecological and economic importance that has been impacted by atmospheric deposition of PBTs. Impaired reproduction in several species of wildlife in the Great Lakes has been linked to PBT exposure, including Chinook salmon, lake trout, herring gulls, Forster's terns, doublecrested cormorants, Caspian terns, and bald eagles (refs. cited in WHO 2002, p. 94). The 2002 Great Lakes Strategy set a goal of restoring the chemical integrity of the Great Lakes: "To reduce toxic substances in the Great Lakes Basin Ecosystem -- with an emphasis on persistent toxic substances -- so that all organisms are adequately protected. Over time, these substances will be virtually eliminated" (USEPA 2002). Specific goals were established, with respect to fish, that in the long-term all Great Lakes fish should be safe to eat without restriction, and a 25\% reduction in PCB concentrations should be achieved in whole lake trout and walleye samples over the period from 2000 to 2007 (USEPA 2002). A recent review of PCB concentrations in Great Lakes walleye and lake trout over the period from 2000 to 2007 revealed mixed results in achieving this goal. In Lake Huron, PCB concentrations decreased in both species of fish. In Lake Ontario concentrations in lake trout decreased while concentrations in walleye remained constant. In Lake Superior concentrations were constant in both species, and in Lake Erie PCB concentrations were actually increasing in walleye (Bhavsar et al. 2007). Continued reductions in PBT concentrations within the Great Lakes ecosystem will require identification and quantification of continuing, distributed sources of these substances as well as quantification of the major input and loss flows for the system.

\subsection{The role of gaseous air-water exchange in forecasting trends in ecosystem contamination}

Accurate models of PBT fate and transport have the ability to predict the time scale over which ecosystems respond to changes in PBT loading, as a result of regulatory or other forcings, and to predict the behavior of new chemicals in the environment before 
they become widely dispersed. For several important PBT classes, inputs (and losses) to the Great Lakes are dominated by air-water exchange. For example, a mass balance model for PCBs, mercury, and PBDEs in Lake Superior (Rowe et al. 2008; Rowe 2009) illustrates the impact of the rate of air-water exchange on the fate of these PBT classes in large lakes. In a system that is dominated by atmospheric deposition, loading processes include gaseous exchange, dry particulate deposition, and wet deposition. The processes that determine the total loss rate from the system, which determines the response time of the system to changes in loading, are gaseous exchange, sedimentation, and transformation. Because volatilization is a relatively rapid loss process for both mercury and the most abundant PCBs (tri- through penta-), the mass balance model (Rowe et al. 2008) predicts that similar times (from 2 - $10 \mathrm{yr}$ ) are required for the compounds to approach steady state in Lake Superior. The model predicts that if wet and dry deposition of oxidized mercury to the lake decrease in the future then concentrations of mercury in the lake will decrease at a rate similar to the historical decline in total PCB concentrations following the ban on production and most uses in the U.S. The decline in total PCB concentration in Lake Superior through the 1980s and 1990s has been documented in terms of aqueous concentrations (Jeremiason et al. 1994) and sediment core data (Song et al. 2004). In contrast, PBDEs are likely to respond more slowly if atmospheric concentrations are reduced in the future because loss by volatilization is a much slower process for PBDEs, leading to lesser overall loss rates for PBDEs in comparison to PCBs and mercury, and greater potential for concentrations to accumulate over time in the lake. In order to accurately predict the response of ecosystem contamination levels to future changes in PBT inputs and in climate variables, an accurate description of the rate of airwater exchange is needed.

An interesting outcome of the mass balance study of Rowe et al. (2008) was that it gave a volatilization rate that was 2.6 fold greater for PCBs than the volatilization rate estimated by other investigators using an empirical mass-balance approach (Jeremiason et al. 1994). This discrepancy underscores the difficulty in estimating air-water exchange of PBTs using the mass-balance or Whitman Two-film (W2F) Model approach. In the massbalance approach an attempt is made to quantify all other input/loss flows to the system 
and air-water exchange is estimated by difference. Chemical degradation is frequently ignored in this approach (Swackhamer et al. 1988; Jeremiason et al. 1994) in spite of the fact that chemical degradation rates are highly uncertain (Gouin et al. 2004), and may be a significant loss process (Rowe et al. 2008). On the other hand the W2F Model ignores the strong seasonal variation in atmospheric stability in the Great Lakes. Rates of airwater exchange are enhanced during the unstable season, fall and early winter when water is warmer than air, and reduced during the stable season, spring and early summer when water is colder than air. Correlation between seasonal modification of air-water exchange rate and seasonal variation in atmospheric PBT concentrations may have important impacts on the annual mass balance for some chemicals. The conventional W2F Model that is used to estimate air-water exchange does not account for effects of stability.

\subsection{Dissertation overview}

A means of direct measurement of PBT atmosphere-surface exchange fluxes would provide a much-needed opportunity to enhance our understanding of the fate and transport of these substances in the environment. Air-water exchange of PBTs is usually estimated using the equilibrium air-water concentration difference and a mass transfer velocity parameterization, for example in the Great Lakes by the Integrated Atmospheric Deposition Network (IADN) Project (Galarneau et al. 2000). Parameterizations of the mass transfer velocity are discussed in detail in Chapter 6. Technologies and methods for direct over-water measurement of air-water exchange fluxes from ships have been developed and improved in the past decade and applied to trace gases for which fastresponse $(10 \mathrm{~Hz})$ sensors are available, such as carbon dioxide (McGillis et al. 2004) and dimethyl sulfide (Blomquist et al. 2006). Current methods to measure atmospheric trace gas fluxes, for which fast response sensors are not available, include gradient methods, such as the modified Bowen ratio method (Perlinger et al. 2005), and relaxed eddy accumulation (Bowling et al. 1999). Both of these methods require a means to measure the gaseous concentration that meets three criteria: 1) sufficient precision to resolve a small difference in concentration between two heights or between two eddy-accumulation 
samplers, 2) sufficient method detection limit to achieve a measurement at ambient concentrations within a few hours (stationarity of meteorological conditions and fluxes is not generally maintained for more than a few hours), 3) accurate separation of gaseous from particle-associated semivolatile PBTs. Conventional methods to measure atmospheric concentration of PBTs have limited capabilities to meet one or more of these criteria.

Perlinger et al. (2005) reported the first measurements of PBT gaseous air-water exchange fluxes by the modified Bowen ratio method using a novel multicapillary denuder sampling device and thermal desorption method. Air-water exchange fluxes of $\alpha$-hexachlorocyclohexane $(\alpha-\mathrm{HCH})$ and hexachlorobenzene (HCB) were reported. Method detection limits were not sufficient to detect PCBs.

The work presented in Chapters 2 through 4 of this dissertation builds upon the work of Perlinger et al. (2005) through improvements to sampling devices and analytical methods. A novel gas-phase cleanup method for use with thermal desorption methods is presented in Chapter 2, which improved precision and method detection limits for the diffusion denuder method used by Perlinger et al. The cleanup method was used in the work presented in Chapters 3, 4, and 6. A model is presented in Chapter 3, with supporting measurements, that predicts gas collection efficiency and particle collection artifacts in multicapillary denuders as a function of design variables, analyte physicalchemical properties, and temperature. The model is a necessary tool for design of multicapillary denuders and for planning of field experiments. This model was applied to design, fabricate, and test a high flow rate multicapillary denuder with the objective of achieving improved detection limits relative to the low-flow denuder and conventional high-volume sampling method for samples of a few hour duration, with measurement precision that compares favorably to conventional methods. The performance of the highflow denuder is characterized in Chapter 4, in comparison to the high-volume sampler and low-flow denuder.

A challenge in interpretation of air-water exchange flux measurements is that the magnitude and direction of fluxes is expected to vary spatially on a scale of kilometers 
and temporally on a scale of hours as a function of meteorological variables, surface temperature, and PBT concentration. For example, Perlinger et al. (2005) reported PBT fluxes that differed by 1-2 orders of magnitude $(\alpha-\mathrm{HCH})$ or by 1 order of magnitude and the opposite direction (HCB) from the most recent monthly values estimated by the IADN Project. It is not known whether these discrepancies result from uncertainty in modified Bowen ratio measurements, uncertainty in the IADN flux estimates, or in smallscale spatio-temporal variability in PBT fluxes. Direct comparisons between estimated and measured fluxes require estimates of uncertainty and a model framework that can account for the effects of meteorological variables. A further complexity is that air flowing from land over water becomes increasingly modified with increasing travel distance over water (fetch) so that atmospheric concentrations and fluxes are also a function of fetch. The height in the atmosphere to which this modification occurs is referred to as the internal boundary layer (IBL). Chapter 4 describes development of an internal boundary layer transport exchange model in which a state-of-the-art, stability dependent algorithm for computation of surface fluxes and gas transfer is implemented. The IBLTE Model is applied to develop a parameterization of IBL growth as a function of the 10-m bulk Richardson number incident at the coast. Finally, in Chapter 5, the IBLTE Model is applied to interpret modified Bowen ratio flux measurements of HCB and PCBs in Lake Superior.

While measurement of PBT air-water exchange fluxes in the Great Lakes was a central motivation for the work described in this dissertation, these methods and models are expected to have additional applications. The sampling and analytical methods are well suited to study semivolatile organic compounds in air, including other PBTs and aside from PBTs, the latter of which are of interest for their role in formation of secondary organic aerosols with impacts on urban air quality and climate. The low-flow multicapillary denuders and cleanup method are of interest for indoor air quality studies where low pump power, short sample duration, small sample volume, and a relatively low-cost analytical method are of interest. The IBLTE Model can be applied to any gas, including water vapor, carbon dioxide, dimethyl sulfide, and other gases that are of interest with respect to hydrology, climate, and ecosystem science. 


\section{Gas-phase cleanup method for analysis of trace atmospheric semivolatile organic compounds by thermal desorption from diffusion denuders ${ }^{1}$}

\subsection{Abstract}

A novel gas-phase cleanup method was developed for use with a thermal desorption method for analysis of trace semivolatile organic compounds (SOCS) in the atmosphere using diffusion denuder samplers to separate gas-phase from particle-associated fractions. The cleanup selectively removed hydrogen-bonding chemicals from samples, including much of the background matrix of oxidized organic compounds that is present in ambient air samples. Abraham solvation parameters were found to be useful predictors of recovery of compounds through the cleanup method; most compounds with $A+B<0.3$ and $L \leq 12.3$ were fully recovered through the cleanup method. Addition of the cleanup method successfully produced baseline resolution in air samples and improved method precision. The utility of the method was demonstrated in an investigation of the built environment as a continuing source of semivolatile persistent, bioaccumulative, and toxic chemicals (PBTs) to the atmosphere.

\subsection{Introduction}

Semivolatile organic compounds (SOCs) in the atmosphere and in indoor air have important impacts on human health and climate. SOCs in the atmosphere have been implicated as a significant source of secondary organic aerosol particles that are not accounted for in current climate models (Robinson et al. 2007). Fine aerosol particles affect human health directly (Pope and Dockery 2006), and account for the greatest single

\footnotetext{
${ }^{1}$ This chapter is based on material that was previously published as M. D. Rowe and J. A. Perlinger (2009). Gas-phase cleanup method for analysis of trace atmospheric semivolatile organic compounds by thermal desorption from diffusion denuders. J. Chromatogr. A 1216: 5940-5948.
} 
contribution, among physical processes, to uncertainty in climate change predictions (IPCC 2007, Fig. 2.20). Many persistent, bioaccumulative, and toxic chemicals (PBTs) are SOCs, including polychlorinated biphenyls (PCBs), polybrominated diphenyl ethers (PBDEs), and some organochlorine pesticides (OCPs). The built environment is a continuing source of PBTs to the atmosphere (Farrar et al. 2005; Harner et al. 2006). Atmospheric transport and deposition of PBTs, followed by bioaccumulation is an important route of exposure to humans through fish and other foods. Direct exposure to humans in the built environment has been implicated as a significant contributing exposure route to PBTs in some cases (Harrad et al. 2004), but not in others (Drexler et al. 2004).

Sampling methods are needed to investigate the behavior of SOCs in the built and natural environment that can accurately separate gaseous and particle-associated SOCs, are low-cost, and that minimize the complexity of sample processing. Several technologies exist for sorptive sampling of SOCs including hi-vol samplers(Bidleman and Olney 1974; Doskey and Andren 1979), passive samplers (Harner et al. 2004), and low-volume sorbent tubes (Barro et al. 2009). We have designed, built, and tested lowflow rate $\left(13 \mathrm{~L} \mathrm{~min}^{-1}\right)$ (Tobias et al. 2007) and high-flow rate $\left(300 \mathrm{~L} \mathrm{~min}^{-1}\right)$ (Rowe and Perlinger 2009b) multicapillary diffusion denuders for collection of trace SOCs from ambient air and extraction using thermal desorption methods. These diffusion denuder methods offer advantages over existing methods in applications in which it is desirable to minimize detection limits with a relatively small sample volume and to separate gaseous from particle-associated SOCs. In conventional solvent-extraction methods, a small fraction of the concentrated extract is introduced into the gas chromatograph (GC). Extraction by thermal desorption allows introduction of the entire sample into the $\mathrm{GC}$ at one time, meaning that sample volume can be reduced by as much as a factor of 100 relative to conventional solvent extraction methods. The samplers may be used for short or long duration sampling depending on analyte, temperature, and temporal resolution desired. For example, short sampling times are necessary for micrometeorological SOC flux measurements because atmospheric stationarity must be maintained during sampling (Perlinger and Rowe 2008). For indoor air sampling it is advantageous to use quiet, low 
flow-rate diaphragm pumps and sample volumes much less than the room volume to avoid depletion of analytes and low-biased concentrations (Currado and Harrad 1998; Harrad et al. 2004). The low-flow and high-flow diffusion denuders were designed to be used within a multicapillary collection device (MCCD) sampling system. The MCCD consists of a diffusion denuder, followed by a filter, followed by an additional diffusion denuder or sorbent bed. This configuration is designed to avoid artifacts caused by adsorption of gas-phase analytes onto the filter and to capture analytes volatilized from particles captured on the filter. The use of polydimethylsiloxane (PDMS) stationary phase as a sorbent in our diffusion denuders enables extraction of captured gas-phase analytes by thermal desorption. A further advantage of PDMS samplers is that breakthrough can be predicted as a function of analyte properties and ambient temperature using GC retention time measurements and chromatographic theory (Rowe and Perlinger 2009c). This paper focuses on analysis of the gas-phase fraction of atmospheric SOCs using lowflow denuders.

Thermal desorption analysis of organic compounds extracted from air is usually limited to volatile organic compounds (not SOCs) and is performed without a cleanup step (Woolfenden 1997; Aragon et al. 2000; Dettmer and Engewald 2002; Dettmer and Engewald 2003; Barro et al. 2009). Analysis without a cleanup is only practical if the target analytes are more abundant or cause a greater response in the selected detector than the background matrix, which is composed of oxidized SOCs. Organic compounds in air are subject to photochemical reactions in the presence of oxidizers including hydroxyl radical, ozone, and nitrate radical. These reactions lead to the addition of oxygencontaining functional groups such as carbonyl, hydroxyl, carboxyl, and nitrate moieties to organic compounds (Atlas et al. 1993; Seinfeld and Pandis 1998). Addition of these functional groups increases the polar (importantly, hydrogen donor/acceptor) interaction capability of the molecule, which has a strong influence on its behavior in analytical separations. Addition of the electronegative element oxygen increases the response factor of the molecule in the electron capture detector (ECD). For example, organic nitrates are known to produce high response in an ECD (Fischer et al. 2002). The background matrix of polar organic compounds is collected in a sorptive sampler along with the target 
analytes. In 1-D chromatographic analysis of halogen-containing compounds by ECD, this oxidized organic background matrix must be separated from the analytes prior to the detector if an acceptable signal-to-noise ratio is to be obtained. In extreme cases, the background matrix of polar organic compounds forms an "unresolved complex matrix" or hump in the chromatogram if it is not removed (Stephanou and Stratigakis 1993). In conventional solvent-extraction methods for PCBs, the polar organic matrix is removed from the concentrated extract by liquid-solid column chromatography using silica gel, florisil, or alumina as the stationary phase, and solvents such as hexane or dichloromethane as the mobile phase (Barro et al. 2009). To maintain the advantages of a thermal desorption method (ease of sample handling, avoidance of solvent waste and cost, transfer of entire sample into the GC), it is desirable to perform a cleanup in the gas phase. A review of the literature has not revealed prior work on the topic of gas-phase cleanup methods for thermal desorption sample preparation. It has been demonstrated, however, that use of a silica- or alumina-PLOT column for analytical separation of ambient air samples in the GC greatly reduces the number of compounds eluted relative to a non-polar PDMS column, and that the eluted compounds are mostly non-polar (Dettmer and Engewald 2002). Use of the analytical column for the cleanup step would likely cause an accumulation of polar material in the column, causing column degradation, and for these reasons an offline, gas-phase cleanup step using a packed column was developed.

This paper describes the addition of a novel gas-phase cleanup method to diffusion denuder sampling and thermal desorption methods that have been described previously (Tobias et al. 2007). The cleanup method separates non-polar analytes from the ambient background matrix of oxidized organic compounds in ambient air. Offline thermal transfer steps and the use of hydrophobic, PDMS-based sorbent materials facilitate separation of water from ambient air samples without loss of analytes. A full description of the selectivity and precision of the new method are provided. The utility of the method is demonstrated with a comparative study of semivolatile PBT concentrations in indoor and outdoor air. 


\subsection{Experimental}

\subsubsection{Chemicals}

Individual compounds (PBDE and $\mathrm{PCB}$ congeners) or mixtures (PCB congeners) were purchased from Accustandard (New Haven, CT, USA) as solutions in isooctane. Pesticides were purchased as single-component solutions or mixtures of compounds in solution from Ultra Scientific (Kingstown, RI, USA). Multi-component standards were created through dilution in 99.9\%-pure "GC-grade" hexane (Burdick \& Jackson, Muskegon, MI, USA).

\subsubsection{Carrier gas for thermal desorption}

Ultra-high purity nitrogen (99.999\%) was used for all thermal desorption steps except for transfer into the GC for which the GC carrier gas was used. Semivolatile contaminants were removed from the carrier gas using a large glass column (60 mm I.D. $\times 300 \mathrm{~mm}$ long) packed with granular activated carbon. Freedom from contamination was confirmed using carrier gas blanks and field blanks associated with sampling events.

\subsubsection{Diffusion denuders}

The low-flow diffusion denuders described by Tobias et al. (2007) were used. Diffusion denuders consist of a 5/8-in. O.D. $\times 25.5 \mathrm{~cm}$ stainless steel tube treated with Silcosteel (Restek Corporation Bellefonte, PA, USA) containing 285-289 sections of 25 $\mathrm{cm} \times 530 \mu \mathrm{m}$ I.D. capillary columns with a 5 - $\mu \mathrm{m}$-thick film of $100 \%$ polydimethylsiloxane (Zebron ZB-1, Phenomenex, Torrance, CA, USA).

\subsubsection{Thermal desorption tubes}

Empty stainless steel thermal desorption tubes (Gerstel TDS2, 4 mm I.D., 6 mm O.D., 178 mm long, Supelco, Bellefonte, PA, USA) were Sulfinert coated (Restek Corporation Bellefonte, PA, USA), then packed with a 130 -mm bed length $(0.43 \mathrm{~g})$ of Chromosorb W coated with 3\%-polydimethylsiloxane (Rtx-1) stationary phase (acid washed, dimethyldichlorosilane deactivated, 40/60-mesh, Restek Corporation Bellefonte, PA, USA). The 
bed was held in place with Sulfinert coated stainless steel screens. TD tubes were capped with 1/4-inch Swagelok caps and PTFE ferrules when not in use. TD tubes were connected to thermal desorption systems using $1 / 4-$ inch Swagelok fittings with graphite ferrules. For use in the gas-phase cleanup, a Sulfinert-coated TD tube was packed with a $130-\mathrm{mm}$ (1.35 g) bed of silica gel (Davisil, 35/60-mesh, 150-Å pore, Supelco, Bellefonte, PA, USA). The bed was held in place with a Sulfinert-coated stainless steel screen at one end and Sulfinert-treated glass wool at the other end (Restek Corporation Bellefonte, PA, USA). Prior to use, both types of TD tubes were conditioned at $300^{\circ} \mathrm{C}$ for $20 \mathrm{~min}$., 160 $\mathrm{mL}$ min. $^{-1} \mathrm{~N}_{2}$. Silica gel packed TD tubes were re-packed with new silica gel after each use. PDMS-packed TD tubes were re-used after thermal desorption, but a separate population of TD tubes was used to handle the cleaned-up versus non cleaned-up samples.

\subsubsection{Hot gas spike apparatus}

The hot gas spike apparatus described by Tobias et al. (2007) was used to introduce surrogate standards into denuders, as well as internal standards and calibration standards into TD tubes. The hot gas spike apparatus temperature was $300{ }^{\circ} \mathrm{C}$.

\subsubsection{Outline of steps in method}

The following steps were used to collect atmospheric SOCs, cleanup the sample, and transfer the extract into the GC

1. Hot-spike surrogate standards into cooled denuder.

2. Collect sample by drawing air through denuder.

3. Thermal transfer from denuder into cooled PDMS-packed TD tube.

4. Thermal transfer from PDMS-packed TD tube into cooled silica gel-packed TD tube.

5. Gas-phase cleanup: thermal elution through silica gel-packed TD tube into a clean, cooled PDMS-packed TD tube.

6. Hot-spike internal standards into cooled TD tube.

7. Thermal transfer into the cooled PTV inlet of the GC. 


\subsubsection{Air sample collection}

The use of low-flow denuders for air sampling is described in detail by Tobias et al. (2007). A brief description is provided here with details specific to this study. Air flow through the samplers was set to $13 \mathrm{~L} \mathrm{~min}^{-1}$ using a mass air flow sensor (Micro Switch AWM5104V, Honeywell Inc., Freeport, IL, USA). Air flow rate was averaged over 1 min. intervals and recorded during sampling using a datalogger (CR5000, Cambell Scientific Inc., Logan, UT, USA). Sample volume was calculated from the flow rate record, and reported at standard conditions of $25^{\circ} \mathrm{C}, 1 \mathrm{~atm}$. Temperature and humidity were measured (HMP45C, Vaisala, Helsinki, Finland) and recorded during sampling (1 min. average). Denuders were capped using Swagelok fittings and stored at $4{ }^{\circ} \mathrm{C}$ until analysis. Outdoor air was sampled from the roof of the Dow Environmental Science and Engineering Building (DESEB). Indoor air was sampled in the DESEB and Dillman Hall. Both buildings are located on the campus of Michigan Technological University in Houghton, Michigan, USA.

\subsubsection{Thermal transfer from low-flow denuder into TD tube}

The inlet end of a PDMS-packed TD tube was connected to the inlet end of a denuder using a Sulfinert-coated 5/8-1/4-inch Swagelok reducing union. The denuder was inserted into the TD oven, and the carrier gas supply was connected to the outlet end of the denuder using a 5/8-inch Cajon fitting with a Viton O-ring. The TD oven described by Tobias et al. (Tobias et al. 2007) was modified to provide sufficient heat to the reducing union by adding wraps of heat tape to this region. The TD tube was maintained at $\sim 15^{\circ} \mathrm{C}$ using a water-cooled coil of copper tubing. Thermal desorption conditions were $230{ }^{\circ} \mathrm{C}$, $750 \mathrm{~mL} \mathrm{~min}^{-1} \mathrm{~N}_{2}$ flow, $30 \mathrm{~min}$.

\subsubsection{Gas-phase cleanup method}

The inlet end of a PDMS-packed TD tube was connected to the inlet end of a silica gel-packed TD tube using a Sulfinert-coated 1/4-inch Swagelok union. The PDMS-packed TD tube was inserted into an aluminum-block heater, then the carrier gas supply was connected to the outlet end. The silica gel-packed TD tube was maintained at $\sim 15{ }^{\circ} \mathrm{C}$ 
using a water-cooled coil of copper tubing. Thermal desorption conditions were $300{ }^{\circ} \mathrm{C}$, $80 \mathrm{~mL} \mathrm{~min}^{-1} \mathrm{~N}_{2}$ flow, $20 \mathrm{~min}$. Upon completion, the outlet of the silica gel-packed TD tube was capped and the system was allowed to cool below $40{ }^{\circ} \mathrm{C}$. The outlet of the silica gel-packed TD tube was connected to the inlet of a clean PDMS-packed TD tube using a Sulfinert-coated $1 / 4$-inch Swagelok union. The silica gel-packed TD tube was inserted into the aluminum-block heater and the PDMS-packed TD tube was inserted into the cooling coil. Conditions for thermal elution through the silica gel-packed TD tube were $270{ }^{\circ} \mathrm{C}$, $160 \mathrm{~mL} \mathrm{min.}^{-1}$, 30 min. Alumina (F1, 60/80 mesh, Alltech Associates Inc., Deerfield, IL) and Florisil (30/60 mesh, Sigma Aldrich, St. Louis, MO, USA) were also evaluated as adsorbents.

\subsubsection{Thermal transfer into the GC}

The TD oven described by Tobias et al. (2007) was used to transfer analytes from PDMS-packed TD tubes into the cooled PTV inlet of the GC. An aluminum sleeve was fabricated to fill the gap between the O.D. of the TD tube and the 5/8-inch I.D. of the TD oven. Thermal transfer conditions were $300{ }^{\circ} \mathrm{C}$ (TD oven and transfer line), $80 \mathrm{~mL} \mathrm{min.}{ }^{-1}$ $\mathrm{N}_{2}$ flow, 12 min., with the PTV inlet maintained at $30{ }^{\circ} \mathrm{C}$ using liquid nitrogen cooling. The inlet was flash-heated to $300{ }^{\circ} \mathrm{C}$ at the start of the $\mathrm{GC}$ run.

\subsubsection{Gas chromatograph}

The GC system, modifications to allow for thermal desorption transfer into the cooled PTV inlet, and capillary GC method were described by Tobias et al. (2007). Briefly, the analysis employed a 6890A Plus GC- micro-electron-capture detection ( $\mu \mathrm{ECD}$ ) system (Agilent Technologies, Palo Alto, CA, USA). The GC- $\mu$ ECD system was equipped with a PTV inlet with liquid nitrogen cryogenic cooling (CIS-4, Gerstel, Baltimore, MD, USA). The inlet liner used by Tobias et al. was replaced with a Siltek-coated inlet liner, packed with Siltek-treated glass wool (Restek Corporation Bellefonte, PA, USA), into which a 25-mm bed of the PDMS-coated Chromosorb W media described above was added, held in place with additional Siltek-treated glass wool. 


\subsubsection{Use of standards}

Prior to sample collection, denuders were spiked with a mixture containing surrogate standards (PCBs 14, 65, 166, $\delta-\mathrm{HCH}$, and dibutylchlorendate). After cleanup and prior to transfer into the GC, the TD tube containing the sample was spiked with an internal standard (IS) mixture (PCBs 30, 65, 155, and 204). Calibration standards were prepared that included 144 PCB congeners, including all significant constituents of the Aroclor mixtures, hexachlorobenzene, Aldrin, octachlorostyrene, trans-nonachlor, 4,4'-DDE, 2,4'-DDT, PBDE 47, PBDE 99, internal, and surrogate standards. Calibration standards at seven levels (nominally 3 to $1,700 \mathrm{pg}$ ) were introduced into the GC by hot-spiking into a TD tube, followed by thermal transfer into the GC. Recovery of internal standards and surrogate standards in samples, and recovery of analytes through the cleanup procedure for method development, were calculated by response relative to IS PCB 30 using a single-level calibration, with the calibration level corresponding to the compound mass spiked into samples.

\subsubsection{Air sample data processing and quality assurance}

Post-processing of GC data, including analyte identification and quantification, was carried out using offline processing software, the Macro for Organic Mass Determination (MOMD), a Visual Basic for Applications program created within our research group. The MOMD accepts raw GC output (retention time and peak area) from calibration standard runs and samples, and uses the data to create calibration curves, identify chromatogram peaks, and convert peak area to analyte mass. Analytes were identified by relative retention time (RRT) using RRT windows centered on the mean RRT of the analyte in the calibration standard, with a width of $\pm 0.125 \%$ of the RRT, as in (Basu 2000). Internal and surrogate standards PCB 30, 65, 155, and 166 were used as retention

time reference compounds. Peak area was converted to analyte mass by relative response with internal standard PCB 30 as the response reference compound. The calibration curves were fitted using a log-linear function that was found to give small, random residuals. Coefficient of determination values were $>0.90$ for all analytes (mean 0.99 for 128 resolved analytes or analyte groups). Two field blanks were collected with each 
sample. Field blanks were treated identically to samples, except that no air was drawn through the denuder. For all reported concentrations, the analyte mass in the blank was less than $20 \%$ of the analyte mass in the sample, and the analyte mass in the sample was greater than the method detection limit (MDL). Reported concentrations were field blanksubtracted. MDLs were determined by hot-spiking standards into denuders prepared for air sampling at $\sim 5$ times the instrument detection limit. The denuders were processed through the method, and analyte mass was determined using the MOMD. Standard deviations of mass determinations in seven replicates were calculated. The MDL for each analyte was determined by multiplying the standard deviation by the one-sided $99 \% \mathrm{t}$ statistic for $n=7$ (3.00). The quantification limit (QL) was three times the MDL.

\subsection{Results and Discussion}

\subsubsection{Preliminary method development}

Seven types of inlet liners were evaluated to determine the type that maximized analyte response factor (peak area / mass spiked) for a test mixture containing $\alpha$ hexachlorocyclohexane ( $\alpha-\mathrm{HCH}$ ), PCBs 30, and 204, PBDEs 47, 99, and 205. The relatively high inlet temperature of $30^{\circ} \mathrm{C}$ for preconcentration of analytes was selected to avoid difficulty with condensing water. Liners packed with deactivated glass wool did not fully retain more-volatile analytes such as $\alpha-\mathrm{HCH}$. The Tenax-TA packed liner used by Tobias et al. (2007) produced low response factors for PBDEs. The inlet liner that was selected gave greater response factors for PBDEs than liners packed with Tenax-TA or deactivated glass wool, while giving response factors for PCBs and $\alpha-\mathrm{HCH}$ that were as high as any of the inlet liners tested.

Three types of TD tubes were evaluated with the objective of maximizing response factor for PCBs, PBDEs, and $\alpha-\mathrm{HCH}$. Response factor was compared to direct hot-spike injection into the cooled PTV inlet. All TD tube shells were deactivated stainless steel. TD tubes packed with $0.21 \mathrm{~g}$ of Siltek-treated glass wool did not fully retain $\alpha-\mathrm{HCH}$. Tenax-TA and the PDMS packing provided response factors similar to direct hot-spike injection into the GC for all analytes in the test mixture. 
In prior work (Tobias et al. 2007), water in ambient air samples caused analytical difficulties if it was not eliminated prior to the GC, including a large water peak eluting at the column hold-up time and delay in elution of analytes. Tobias et al. (2007) minimized the influence of water by developing a five-step thermal desorption transfer into the GC in which analytes were retained in the cooled PTV inlet while water was vented out the split vent. In the method described here, it was desirable to eliminate water during the thermal desorption transfer from the denuder into the TD tube so that issues with water at subsequent steps in the method could be avoided. Preliminary experiments were conducted to determine the mass of water required to produce the effects observed by Tobias et al. (2007), and the mass of water that was retained in TD tubes in processing ambient air samples. Water was hot-spiked into TD tubes that had previously been hotspiked with analytes, and the amount of water retained in the TD tube was measured by mass gain. TD tube moisture in the range of 1.9 to $9.1 \mathrm{mg}$ of water mass gain did not produce a statistically significant shift in retention times for the analytes in the test mixture ( $95 \%$ confidence level, $n=5$ wet, 3 dry). Large water peaks were not visible in these chromatograms, but subsequent trials revealed small and large water peaks in runs in which TD tubes were hot-spiked with water masses of 8 and $23 \mathrm{mg}$, respectively. The PDMS packing retained less moisture than Tenax-TA; with a hot-spike of $5 \mathrm{mg}$ of water, PDMS packed TD tubes retained only $0.1 \mathrm{mg}$ of water after a five minute purge with $\mathrm{N}_{2}$ carrier gas $\left(160 \mathrm{~mL} \mathrm{min.}^{-1}\right)$, versus $1.0 \mathrm{mg}$ for a Tenax-TA packed TD tube. Greater mass of water was retained in TD tubes when the purge time was shortened, indicating that the dry carrier gas was able to effectively purge water from the tubes. Ambient air samples (18 m3) collected at $25.7^{\circ} \mathrm{C}, 38 \% \mathrm{RH}$ and $3.7^{\circ} \mathrm{C}, 59 \% \mathrm{RH}$ resulted in TD tube moisture of 0.04 and $0.4 \mathrm{mg}$, respectively, indicating that negligible quantities of water are retained in the PDMS-packed TD tube after sample transfer. Therefore, it was possible to greatly simplify the method for thermal transfer into the GC from the fivestep, 53 min. method of Tobias et al. (2007) to the one-step, 12 min. method described here. It is likely that use of the PDMS packing in the inlet liner, in place of the Tenax-TA packed liner used by Tobias et al. (2007), reduced retention of water in the inlet and 
further contributed to reduced sensitivity to water of the method described here compared to the method of Tobias et al.

Silica gel, alumina, and florisil were initially evaluated as adsorbent materials for the gas-phase cleanup. The adsorbents were evaluated by measuring recovery of the test mixture analytes after elution through the adsorbent into a PDMS-packed TD tube at temperatures of 200,250 , and $300^{\circ} \mathrm{C}$. An elution time of $30 \mathrm{~min}$. was selected along with a flow rate of $80 \mathrm{~mL} \mathrm{~min}^{-1}$, which is near the flow rate for maximum chromatographic efficiency of the TD tube packed column (Knox eqn. as in Lovkvist and Jonsson 1987). Alpha-HCH was not eluted under any conditions tested. The PCBs and PBDE 47 and 99 were eluted through silica gel at $300{ }^{\circ} \mathrm{C}$, while only PCB 30 was eluted through alumina and florisil at temperatures up to $300^{\circ} \mathrm{C}$. Alumina and florisil were not evaluated further owing to excessive retention of analytes. Further trials were conducted to optimize recovery of the analytes after elution through silica gel, which led to selection of $270^{\circ} \mathrm{C}$ and $160 \mathrm{~mL} \mathrm{min.}^{-1}$ in the final method.

\subsubsection{Selectivity of the gas-phase cleanup method}

A suite of 174 analytes, including OCPs, PCBs, and PBDEs was tested for recovery through the cleanup method. Standards were hot-spiked into PDMS-packed TD tubes, processed through the cleanup method, and transferred into the GC. Recovery was determined relative to instrument response from direct transfer of identically hot-spiked TD tubes into the GC (without cleanup). Results of these experiments are shown in

\section{Figure 2.1.}

The adsorption model described by Goss (2004) was employed in an effort to quantitatively predict recovery of analytes through the gas-phase cleanup method:

$$
\log (K)=a A+b B+l L-8.47
$$

where $K=$ adsorption constant for a given adsorbate $\left(\mathrm{m}^{3} / \mathrm{m}^{2}\right), a, A=$ adsorbent hydrogen bond base, adsorbate hydrogen bond acid interaction parameter, $b, B=$ adsorbent hydrogen bond acid, adsorbate hydrogen bond base interaction parameter, and $l, L=$ adsorbent, adsorbate Van der Waals interaction parameter. The constant -8.47 is derived 
from the standard state of adsorption. The constants $A, B$, and $L$ are the solute molecular interaction parameters used in the solvation model of Abraham et al. (1994). These temperature-independent molecular interaction parameters have been determined for many organic molecules. Experimentally-determined solvation parameters were available for all PCB congeners (Abraham and Al-Hussaini 2005), 2,4'DDT, heptachlor, endrin, dieldrin, and $\gamma-\mathrm{HCH}$ (refs. in Pharma Algorithms 2006), the remainder were estimated using the group contribution method of Platts et al. (1999) as implemented in (Pharma Algorithms 2006). Goss separated the adsorbent parameters ( $a, b$, and $l)$ into an adsorbent property and an empirical coefficient; here they are used simply as temperaturedependent empirical coefficients. 


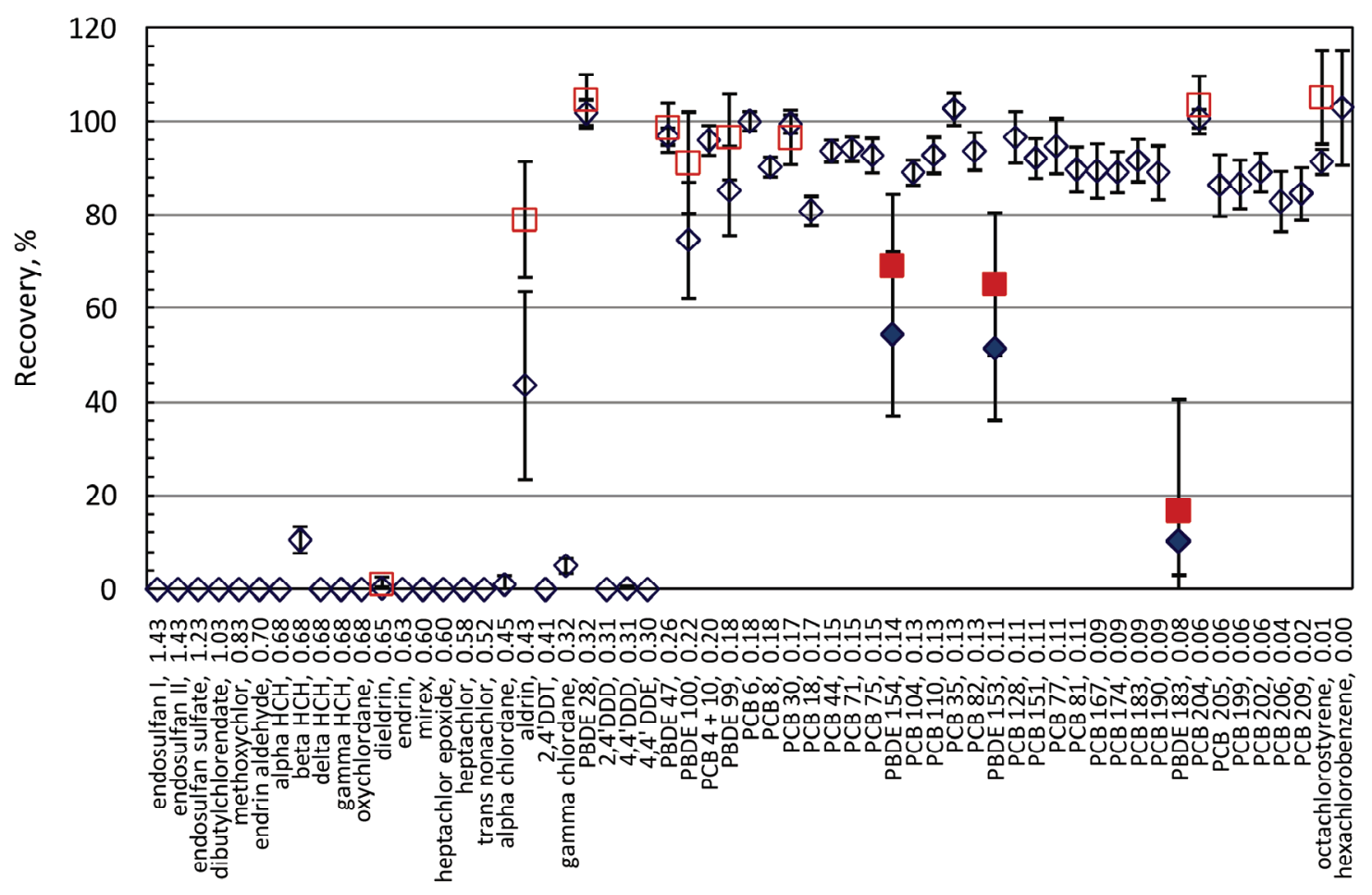

Figure 2.1: Recovery of analytes through the gas-phase cleanup method. Only a representative subset of the 144 PCB congeners tested is shown. An initial set of trials was conducted at an elution flow rate of $80 \mathrm{~mL} \mathrm{~min}^{-1}$ (diamond symbols, $n=7$ ). A second set of trials was conducted at an elution flow rate of $160 \mathrm{~mL} \mathrm{~min}^{-1}$ (square symbols, $n=3-4)$. Error bars indicate the $95 \%$ confidence interval on the mean. Analytes are listed in order of decreasing sum of hydrogen donor/acceptor parameters $(A+B, E q .1)$ from left to right, and the value is given after the analyte name. Filled symbols indicate PBDE compounds having $L>12.3$, Eq. (2.1). 
The values of the adsorbent parameters for silica gel were determined experimentally at 200,250 , and $300^{\circ} \mathrm{C}$ (Rowe and Perlinger 2008). Silica gel was found to be a bipolar hydrogen bonding adsorbent. The polar contribution to retention decreased with temperature over the range tested. It was also found that retention was concentrationdependent for polar molecules (stronger adsorption at low adsorbate concentration), and that the concentration-dependence increased with increasing sum of Abraham hydrogen donor/acceptor parameters $(\mathrm{A}+\mathrm{B})$ for the molecule.

Because of the concentration dependence of adsorption, Eq. 1 could not be used to quantitatively predict retention in the cleanup method. However, recovery through the cleanup method was qualitatively correlated to the Abraham solvation parameters of each compound. Compounds with a van der Waals interaction parameter, L, greater than 12.3 (PBDEs with $>5 \mathrm{Br}$ ) were not fully recovered (Figure 2.1). Among compounds with L $\leq 12.3$, recovery was correlated to the sum of hydrogen donor/acceptor parameters $(\mathrm{A}+$ B) for each analyte. Of 110 compounds tested with $\mathrm{A}+\mathrm{B}<0.3$ and $\mathrm{L} \leq 12.3,109$ had recoveries between 80 and $120 \%$ (mean 92\%). Non-ortho and mono-ortho (coplanar) PCBs did not behave differently from other PCBs; of the twelve coplanar PCBs used in dioxin-like toxic equivalency calculations (Rolaf van Leeuwen et al. 2000), eight were included in this study (PCBs 77, 81, 105, 114, 167, 118, 156, and 189) and had mean recovery of $91 \%$. PBDE 100 required an elution flow rate of $160 \mathrm{~mL}$ min.-1 to have a recovery greater than $80 \%$. The exception was the coeluting pair PCB $91+66$, which had a recovery of $70 \%$ at $80 \mathrm{~mL}$ min.-1 and was not tested at the higher elution flow rate. Of 25 compounds tested with $\mathrm{A}+\mathrm{B}>0.3$ and $\mathrm{L} \leq 12.3,23$ had recoveries less than $11 \%$ (mean $0.7 \%$ ). Exceptions were Aldrin and PBDE 28. It is possible that the Abraham solvation parameters calculated using the group contribution method were not accurate for these two compounds. Steric effects may also play a role. Setting aside a few exceptions, the criterion $[\mathrm{A}+\mathrm{B}<0.3$ and $\mathrm{L} \leq 12.3$ ] is a useful predictor of compounds that are fully recovered through the cleanup method. 


\subsubsection{Effect of the gas-phase cleanup on an ambient air sample chromatogram}

A pair of co-located low-flow samples was collected to show the effect of the gasphase cleanup on the chromatogram. The samples were collected over 24 hours, starting on 17 January, 2008. The sample volume was $22.0 \mathrm{~m} 3$, and the mean temperature and relative humidity were $-10{ }^{\circ} \mathrm{C}$, and $80.1 \%$. One sample was processed through the cleanup method, while the duplicate sample was transferred into the GC without cleanup. Addition of the cleanup dramatically reduced the noise level, as shown in Figure 2.2, which presents a portion of the chromatogram (complete chromatogram in Figure B.1). For example, PCBs 18 and 28 (identified in Figure 2.1 and Figure B.1), which are among the most abundant PCB congeners in ambient air, could be resolved in the cleaned-up sample, while it was not possible to resolve these peaks from background interferences without the cleanup. Baseline resolution was obtained in the cleaned-up chromatogram, while the chromatogram of the sample that was not cleaned up consisted of an unresolved complex matrix. In addition to lowering the baseline, many large peaks were removed from the chromatogram by the cleanup (Figure B.1). As an indication of the improvement in signal-to-noise, the total area under chromatogram was reduced by a factor of 15 in the cleaned-up sample while recovery of the surrogate standards was near $100 \%$. Specifically, recoveries of surrogate standards PCB 14, 65, and 166 were 102 , 101 , and $95 \%$ in the cleaned-up sample versus 151,96 , and $120 \%$ in the co-located, non-cleaned up sample, respectively. 


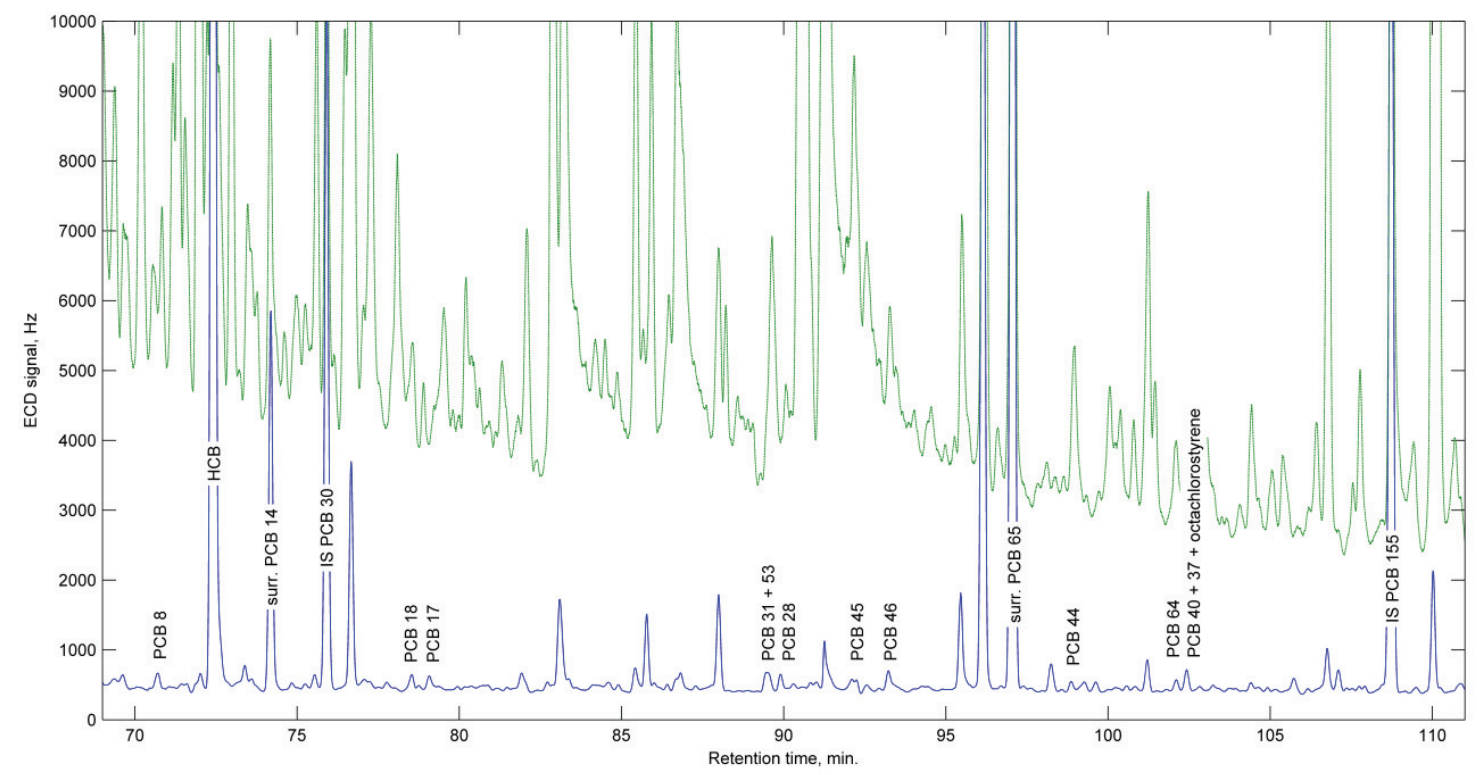

Figure 2.2: Overlaid chromatograms of co-located outdoor low-flow air samples with one having been processed through the gas-phase cleanup method (lower signal) and the other having no cleanup (upper signal). Analytes and co-eluting analyte groups are identified on the lower signal. 


\subsubsection{Precision and sensitivity of the gas-phase cleanup method}

Method sensitivity was evaluated by determination of MDLs. Addition of the cleanup improved MDLs relative to previously reported MDLs without the cleanup (Perlinger 2007) (Table 2.1). MDLs of some compounds improved more than others depending on the non-uniform distribution of interferences in the non-cleaned up chromatogram. The MDL of the co-eluting pair PCB $52+$ aldrin was greater with the cleanup because aldrin was partially removed by the cleanup (Figure 2.1). Some compounds could not be resolved from background interferences in the non-cleaned up chromatogram, but were resolved with the cleanup (Table 2.1). MDLs were greater for PBDEs than for PCBs because blank levels of PBDEs tended to be greater, which may be caused by their abundance in the indoor environment.

Method precision was evaluated by measuring the variability in field duplicates and in surrogate and internal standard recoveries in ambient air samples. Five air samples were collected in duplicate with backup denuders to capture breakthrough. Surrogate and internal standard recoveries were calculated to indicate the effects of sample matrix on measurement precision. Addition of the cleanup eliminated the need to use the background subtraction method of Tobias et al. (2007) to avoid background interference with surrogate and internal standard recoveries (Figure 2.3 A, vs. Tobias et al. Fig. 6). The majority of surrogate and internal standard recoveries were between 80 and $120 \%$ (Figure 2.3 A and B). Method precision was improved upon addition of the cleanup, as indicated by reduced variability in surrogate standard recoveries (Table 2.2). Surrogate standard PCB 14 recoveries were low for some samples in this study because the sample volume was intentionally made large enough to cause breakthrough for the more volatile analytes in order to validate a breakthrough prediction model (Rowe and Perlinger 2009c). Greater variability of the PCB 14 recovery in Table 2.2 and Figure 2.3 A is a result of breakthrough and not an indication of the cleanup method performance. 
Table 2.1: Method detection limits (MDLs), pg, with and without the gas-phase cleanup method.

\begin{tabular}{|c|c|c|c|c|c|c|c|c|c|}
\hline & $\mathrm{HCB}$ & $\begin{array}{l}\text { PCB } \\
28\end{array}$ & $\begin{array}{l}\text { PCB } 52+ \\
\text { aldrin }\end{array}$ & $\begin{array}{l}\text { PCB } 60+ \\
101+90\end{array}$ & $\begin{array}{l}\text { PCB } \\
153\end{array}$ & $\begin{array}{l}\text { PCB } \\
138\end{array}$ & $\begin{array}{l}\text { PCB } \\
180\end{array}$ & $\begin{array}{l}\text { PBDE } \\
47\end{array}$ & $\begin{array}{l}\text { PBDE } \\
99\end{array}$ \\
\hline With cleanup & 2.3 & 2.4 & 13.6 & 4.0 & 2.9 & 5.4 & 6.8 & 17.8 & 45.3 \\
\hline $\begin{array}{l}\text { Without } \\
\text { cleanup }^{\text {a }}\end{array}$ & 2.9 & 47.0 & 9.6 & 35.5 & 16.4 & 15.7 & NR & NR & NR \\
\hline
\end{tabular}

NR: compound not resolved 


\subsubsection{Matrix effects on retention time variability}

Retention times of early-eluting compounds were shifted later in air samples relative to retention times of the same compounds in standards, field blanks, and backup denuders (Figure 2.3 C and D). The fact that the shift did not occur in standards, field blanks, and backup denuders indicates a matrix effect. Furthermore, the shift was more pronounced in indoor air samples, which had greater concentrations of analytes and background matrix than outdoor air samples (Figure 2.3 E and F).

Tobias et al. (2007) attributed retention time shifts to water in samples, but water does not appear to be the cause of the observed variations in retention time here. Preliminary work, discussed previously, indicated that much greater quantities of water than were present in samples would be needed to cause retention time shifts. Furthermore retention time shifts were not observed in backup denuders (Figure 2.3 C vs. D), which were exposed to the same amount of water during sampling as the front denuders. The retention time shift was greatest for early eluting compounds, and decreased with increasing retention time (Figure 2.3 C). It seems likely that early-eluting compounds experience additional retention, especially in relatively high-mass indoor air samples, because the band of sample matrix focused at the head of the column acted as additional stationary phase at the start of the GC run. Experiments with a non-polar guard column and with a high-capacity pre-column were conducted in an effort to eliminate the retention time shift, but these efforts were not effective. The problem was addressed through the use of four retention time reference compounds distributed throughout the chromatogram for the purpose of identifying compounds by relative retention time; for surrogate standards PCB 14 and IS PCB 204, the range of absolute retention time variability in air samples was $0.42 \%$ and $0.07 \%$, respectively (Figure $2.3 \mathrm{~A}$ ), while the range of relative retention time variability for the same data set was $0.03 \%$ and $0.02 \%$, respectively, which is much less than the $\pm 0.125 \%$ RRT window definition for analyte identification. 

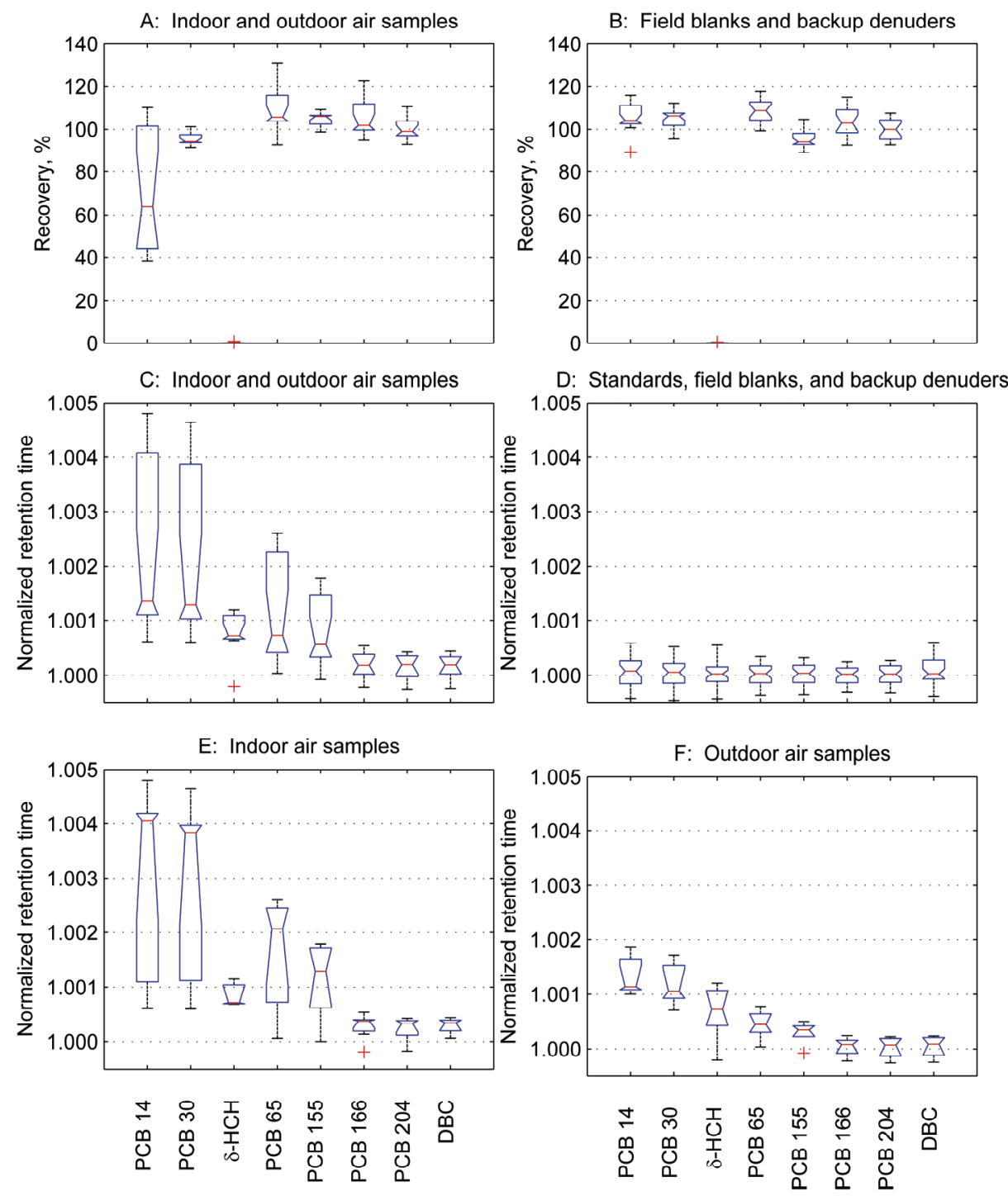

Figure 2.3: Recovery and retention time variability for surrogate standards (PCB 14, 65, $166, \delta-\mathrm{HCH}$, and dibutyl chlorendate) and internal standards (PCB 30, 155, and 166). Retention times are normalized to the mean retention time of the same compound in hot-spiked standards to show the variability. The plots show recovery in indoor and outdoor air samples $(A, n=12)$, recovery in field blanks and backup denuders $(B, n=20)$, retention time variability in indoor and outdoor air samples $(C, n=12)$, and retention time variability in hot-spiked standards, field blanks, and backup denuders $(D, n=34)$. The data in panel $\mathrm{C}$ are plotted separately in panels $\mathrm{E}$ and $\mathrm{F}$ to show the greater retention time variability in indoor versus outdoor samples. Each box has lines at the lower quartile, median, and upper quartile. Whiskers extend to the most extreme values within 1.5 times the interquartile range from the ends of the box. Outliers beyond the whiskers are indicated with the plus symbol. Boxes with notches that do not overlap have different medians at the $95 \%$ confidence level. 
Table 2.2: Relative standard deviation, $\%$, of surrogate and internal standard recoveries in indoor and outdoor air samples with gas-phase cleanup (this work, $n=12$ ) and without cleanup ((Tobias et al. 2007), $n=15$ for surr., 7 for IS). The $95 \%$ confidence interval on the relative standard deviation is given in parentheses.

$\begin{array}{lrlllll} & \text { PCB 14 } & \text { PCB 30 } & \text { PCB 65 } & \text { PCB 155 } & \text { PCB 166 } & \text { PCB 204 } \\ \text { With cleanup } & 40(29-68)^{\mathrm{a}} & 3(2-5) & 10(7-18) & 3(2-5) & 8(6-14) & 5(4-9) \\ \text { Without } & & & & & & \\ \text { cleanup } & 19(14-30) & 6(4-13) & 17(12-26) & 6(4-14) & 31(23-49) & 29(19-64)\end{array}$

${ }^{a}$ Greater variability caused by breakthrough in some samples. 


\subsubsection{Comparison of PBT concentrations in indoor and outdoor air}

Concentrations of HCB, commonly-reported PCBs, and PBDEs are reported in Table 2.3. Samples were collected in duplicate, and the individual measurements are given in

Table 2.3 to provide an indication of measurement precision. The sum of analyte mass on front and backup denuders was used to calculate concentrations so that analyte mass that broke through from the front denuder into the backup denuder was included.

Breakthrough into the backup denuder ranged from 4 to $39 \%$ for $\mathrm{HCB}$, and was less than $12 \%$ for the other analytes reported in Table 2.3. The absolute value of the percent difference between measured concentrations in duplicate samples was calculated to quantify method precision. In the five duplicate samples, there was a total of 203 observations that met the quality criteria (>MDL, not flagged for blank), and the median percent difference was $14 \%$ (mean $21 \%$ ). Among measurements that exceeded the QL, the median percent difference was $13 \%($ mean $21 \%, n=170)$.

Indoor air samples were collected in the two buildings on the campus of Michigan Technological University to investigate the effect of age of construction on the concentration of PCBs and PBDEs in indoor air. Concentrations of selected analytes in air are given in Table 2.3, while concentrations for all analytes are given in Supporting Information. Dillman Hall was built in 1957, a time when PCBs were in common use but prior to the adoption of PBDEs in many products, while the DESEB was built in 1998, well after the manufacture of PCBs was banned and PBDEs were in common use. Concentrations of PBDE 47 and 99 were similar in the two buildings, and within the range of concentrations reported for office buildings in other studies (Harrad et al. 2004; Destaillats et al. 2008). Sources of PBDEs include personal computers (Destaillats et al. 2008) and possibly polyurethane foam in furniture. Thus, it is not surprising that the two buildings have similar concentrations because this type of equipment has been updated regularly in Dillman Hall since construction. PCB concentrations were on the order of ten fold greater in Dillman Hall than in DESEB, which is consistent with the fact that Dillman Hall was in use over a time period when PCBs were common in many products. Correlation between age of construction and PCB concentration in indoor air has been reported in previous investigations (Wallace et al. 1996). 
Table 2.3: Observed concentration of selected persistent, bioaccumulative, and toxic chemicals $\left(\mathrm{pg} \mathrm{m}^{-3}\right)$ in duplicate outdoor and indoor air samples.

\begin{tabular}{|c|c|c|c|c|c|}
\hline Sample location & $\begin{array}{l}\text { Outdoor } \\
4 \text { Dec. }\end{array}$ & $\begin{array}{l}\text { Outdoor } \\
19 \mathrm{Dec} .\end{array}$ & $\begin{array}{l}\text { DESEB } \\
\text { laboratory } \\
29 \text { Nov. }\end{array}$ & $\begin{array}{l}\text { DESEB } \\
\text { hallway } \\
11 \text { Dec. }\end{array}$ & $\begin{array}{l}\text { Dillman } \\
\text { hallway } \\
4 \text { Jan. }\end{array}$ \\
\hline Date & 2007 & 2007 & 2007 & 2007 & 2008 \\
\hline Volume, $\mathrm{m}^{3}$ & 20.8 & 19.5 & 5.1 & 3.8 & 2.6 \\
\hline Temp., ${ }^{\circ} \mathrm{C}$ & -9.2 & -4.2 & 17.4 & 19.9 & 21.9 \\
\hline Rel. humidity, \% & 75.7 & 83.6 & 28.2 & 24.4 & 11.0 \\
\hline \multirow[t]{2}{*}{$\mathrm{HCB}$} & 54.0 & 55.7 & 49.6 & 101.6 & 174.4 \\
\hline & 63.3 & 69.2 & 51.0 & 96.6 & 181.2 \\
\hline \multirow[t]{2}{*}{ РCB 28} & & 1.4 & 6.6 & 31.8 & 516.1 \\
\hline & 0.6 & 1.7 & 6.5 & 30.6 & 576.5 \\
\hline \multirow[t]{2}{*}{ РCB 52} & 1.4 & 2.0 & & & 127.3 \\
\hline & & 2.0 & & & 143.6 \\
\hline \multirow[t]{2}{*}{ РCB 101} & $<0.2$ & $<0.2$ & 4.6 & 16.5 & 93.7 \\
\hline & $<0.2$ & 0.8 & 3.2 & 17.4 & 107.9 \\
\hline \multirow[t]{2}{*}{ PCB 153} & $<0.1$ & 0.3 & 1.6 & 4.0 & 45.5 \\
\hline & $<0.1$ & 0.3 & 1.1 & 3.9 & 55.2 \\
\hline \multirow[t]{2}{*}{ РCВ 138} & $<0.3$ & 0.7 & 1.8 & 3.5 & 27.4 \\
\hline & $<0.3$ & $<0.3$ & 1.6 & 3.3 & 34.8 \\
\hline \multirow[t]{2}{*}{ PCB 180} & $<0.3$ & $<0.3$ & $<1.3$ & $<1.8$ & 45.8 \\
\hline & $<0.3$ & $<0.4$ & $<1.3$ & $<1.8$ & 59.6 \\
\hline *sum of six PCBs $\times 5$ & 4.9 & 23.2 & 67.3 & 278.0 & 4583.3 \\
\hline sum of 139 PCBs & 28.9 & 88.5 & 551.0 & 866.8 & 7183.4 \\
\hline \multirow[t]{2}{*}{ PBDE 47} & 8.4 & 6.4 & 537.6 & 509.9 & 485.3 \\
\hline & 14.3 & 8.3 & 387.0 & 549.8 & 616.9 \\
\hline \multirow[t]{2}{*}{ PBDE 99} & & $<2.3$ & 461.4 & 119.5 & 27.1 \\
\hline & 3.8 & $<2.3$ & 295.0 & 209.6 & 45.8 \\
\hline
\end{tabular}

Notes: Sample volumes and concentrations are referenced to standard conditions of 25 ${ }^{\circ} \mathrm{C}, 1 \mathrm{~atm}$. Observations that fell between the MDL and QL are reported in italicized font. In the case of non-detect, the MDL is given in boldface font preceded by the symbol " $<$ ". Missing values indicate observations that failed the blank criterion. PCB 52 co-eluted with aldrin. PCB 101 co-eluted with PCBs 60 and 90. Air temperature and relative humidity reported in the table are means over the sample collection period. *In this case, the sum of PCB concentrations was estimated as the sum of the six PCB congener concentrations listed included in this table, multiplied by five, after (Gabrio et al. 2000; Kohler et al. 2002; Kohler et al. 2005). 
PBT concentrations in the two buildings were not high compared to those reported in other investigations. Both buildings had total PCB concentrations that were a thousandfold less than concentrations in buildings that were investigated because of contamination by PCBs used in joint sealants (Gabrio et al. 2000; Drexler et al. 2004), and within the range of recent concentrations compiled for offices and homes that were not selected for study because of known contamination (Barro et al. 2009). The approach of estimating sum of PCBs in indoor air by adding the concentrations of the six congeners listed in Table 2.3, multiplied by five, has been used in some investigations (Gabrio et al. 2000; Kohler et al. 2002; Kohler et al. 2005). It is apparent that this approximation is only reasonable when all six congeners are above the detection limit (Table 2.3). The sample collected in a DESEB laboratory had lower concentrations of PBTs than either of the hallway locations in the DESEB, which likely resulted from a greater rate of air exchange in the laboratory by the fume hood and independent air source.

Comparison of PBT concentrations in indoor and outdoor air is limited by the fact that the outdoor measurements reported in Table 2.3 and Table B. were collected during cold weather when gaseous SOC concentrations are expected to be relatively low. However, a comparison can be made by reference to additional measurements from the DESEB roof in summer (Rowe and Perlinger 2009b) and to measurements made at Eagle Harbor, MI (Strandberg et al. 2001; Environment Canada 2009a), a rural site located 35 miles northeast of Houghton, MI. Atmospheric PBDE 47 and 99 concentrations less than 10 pg m-3 were reported for Eagle Harbor (1997 to 1999, air temp. $20 \pm 3{ }^{\circ} \mathrm{C}$ ) (Strandberg et al. 2001) and the rural site of Sleeping Bear Dunes, MI (2000 to 2004, adjusted to air temp of $15^{\circ} \mathrm{C}$ ) (Hoh and Hites 2005). PBDE concentrations in both buildings were on the order of one hundred fold greater than concentrations in outdoor air (Strandberg et al. 2001; Hoh and Hites 2005) (Table 2.3). PCB and HCB concentrations in outdoor air reported in Table 2.3 were within the range of values reported at Eagle Harbor for November and December (2000 to 2005). PCB and HCB concentrations in Dillman Hall were greater than the maximum concentrations reported at Eagle Harbor for June, July, and August, 2000 to 2005, or 2.4, 26, 12, 22, and 217-fold greater than the Eagle Harbor median for HCB, PCB 28, 52, 101, 138, and 180, respectively. HCB and PCB 
concentrations in the DESEB hallway were greater than the median but within the range of summer concentrations reported at Eagle Harbor. Outdoor air concentrations measured on the DESEB roof in June and August, 2008, were 67 to 96 pg m-3 for HCB and less than 10 pg m-3 for PCBs listed in Table 2.3 (Rowe and Perlinger 2009b), which is within the range of the summer Eagle Harbor concentrations. These results suggest that both buildings are a source of PBDEs to the atmosphere and Dillman Hall is a source of PCBs to the atmosphere. Neither building appears to be a strong source of HCB, and it cannot be concluded that DESEB is a source of PCBs to the atmosphere.

\subsection{Conclusion}

A novel gas-phase cleanup method was developed for use with a thermal desorption method for analysis of trace SOCs in air using diffusion denuder samplers to separate gas-phase from particle-associated fractions. The cleanup selectively removed hydrogen-bonding chemicals from samples, including much of the background matrix of oxidized organic compounds that is present in ambient air samples. Abraham solvation parameters were found to be a useful predictor of recovery through the cleanup method;

most compounds with $\mathrm{A}+\mathrm{B}<0.3$ and $\mathrm{L} \leq 12.3$ were fully recovered through the cleanup method. Addition of the cleanup method resulted in baseline resolution in air samples and improved method precision and sensitivity. The utility of the method was demonstrated in an investigation of the built environment as a continuing source of PBTs to the atmosphere. The method offers an alternative to high-volume and passive samplers with solvent extraction for non-polar compounds in some applications where accurate separation of gaseous and particle-associated fractions, rapid low-cost sample processing, short sample collection time, and quiet light-weight sampling equipment are of interest. 


\section{Prediction of gas collection efficiency and particle collection artifact for atmospheric semivolatile organic compounds in multicapillary denuders $^{2}$}

\subsection{Abstract}

A modeling approach is presented to predict the sorptive sampling collection efficiency of gaseous semivolatile organic compounds (SOCs) and the artifact caused by collection of particle-associated SOCs in multicapillary diffusion denuders containing polydimethylsiloxane (PDMS) stationary phase. Approaches are presented to estimate the equilibrium PDMS-gas partition coefficient $\left(K_{\mathrm{pdms}}\right)$ from a solvation parameter model for any compound, and, for nonpolar compounds, from the octanol-air partition coefficient $\left(K_{\mathrm{oa}}\right)$ if measured $K_{\text {pdms }}$ values are not available. These estimated $K_{\text {pdms }}$ values are compared with $K_{\text {pdms }}$ measured by gas chromatography. Breakthrough fraction was measured for SOCs collected from ambient air using high-flow (300 $\left.\mathrm{L} \mathrm{min}^{-1}\right)$ and lowflow $\left(13 \mathrm{~L} \mathrm{~min}^{-1}\right)$ denuders under a range of sampling conditions $\left(-10\right.$ to $25^{\circ} \mathrm{C} ; 11$ to 100 $\%$ relative humidity). Measured breakthrough fraction agreed with predictions based on frontal chromatography theory using $K_{\mathrm{pdms}}$ and equations of Golay and Lövkvist and Jönsson within measurement precision. Analytes included hexachlorobenzene, 144 polychlorinated biphenyl congeners, and polybrominated diphenyl ethers 47 and 99. Atmospheric particle transmission efficiency was measured for the high-flow denuder (0.037 to $6.3 \mu \mathrm{m}$ diameter), and low-flow denuder (0.015 to $3.1 \mu \mathrm{m}$ diameter). Particle transmission predicted using equations of Gormley and Kennedy, Pich, and a modified filter model, agreed within measurement precision (high-flow denuder) or were slightly greater than (low-flow denuder) measured particle transmission. As an example application of the model, breakthrough volume and particle collection artifact for the two

\footnotetext{
${ }^{2}$ This chapter is based on material that was previously published as M. D. Rowe and J. A. Perlinger (2009). Prediction of gas collection efficiency and particle collection artifact for atmospheric semivolatile organic compounds in multicapillary denuders. J. Chromatogr. A 1217: 256-263. 10.1016/j.chroma.2009.11.049
} 
denuder designs were predicted as a function of $K_{\mathrm{oa}}$ for nonpolar SOCs. The modeling approach is a necessary tool for the design and use of denuders for sorptive sampling with PDMS stationary phase.

\subsection{Introduction}

Semivolatile organic compounds (SOCs) partition between a gaseous fraction and a particle-associated fraction in the atmosphere. The SOCs include chemicals from a wide range of classes that originate from natural and anthropogenic sources, or are produced in the atmosphere as a result of oxidation processes, for example alkanes, alkenes, aromatic hydrocarbons, carbonyls, carboxylic acids, and organic nitrates (Atlas et al. 1993; Fischer et al. 2002). These compounds are of current scientific interest for their participation in photochemical reactions that lead to formation of ozone and fine particulate matter (Fuzzi et al. 2006). SOCs have been implicated as a significant source of secondary organic aerosol particles that is not accounted for in current models (Robinson et al. 2007). Fine aerosol particles affect human health directly (Pope and Dockery 2006), and account for the greatest single contribution, among physical processes, to uncertainty in climate change predictions (IPCC 2007, Fig. 2.20). The SOCs also include chemicals that are persistent, bioaccumulative, and toxic (PBT), such as polycyclic aromatic hydrocarbons (PAHs), polybrominated diphenyl ethers (PBDEs), organochlorine pesticides (OCPs), and polychlorinated biphenyls (PCBs). Gas-particle partitioning behavior plays an important role in prediction of fate and transport of SOCs in indoor (Weschler and Nazaroff 2008) and outdoor (Atlas et al. 1993) environments; deposition rates tend to be greater for the particle-associated fraction, while chemical transformation rates tend to be greater for the gaseous fraction. Sample collection techniques that can accurately separate gaseous from particle-associated SOCs are needed to monitor concentrations and predict behavior of SOCs in outdoor and indoor environments.

Conventional sampling techniques for SOCs, including the widely used high-volume sampler (Bidleman and Olney 1974; Doskey and Andren 1979), involve collection of the particle-associated fraction on a filter located upstream of a sorbent bed that collects the gaseous fraction. This approach suffers from both positive and negative artifacts caused 
by volatilization of SOCs from particles on the filter, adsorption of gaseous SOCs onto the filter, or reaction of collected SOCs with atmospheric oxidizing species (Mader et al. 2001; Goriaux et al. 2006; Arp et al. 2007). Diffusion denuders followed by filters in the sampling path have been developed as an alternative to avoid artifacts produced by the conventional filter-sorbent bed sampler (Krieger and Hites 1992; Gundel et al. 1995; Eatough 1999; Mader et al. 2001; Tobias et al. 2007). Separation of gaseous and particulate analytes in a diffusion denuder is based on the greater diffusivity of gases compared to particles.

The two most common artifacts associated with denuder samplers are breakthrough of gaseous analytes from the denuder and particle collection within the denuder (Volckens and Leith 2003). In fact, a small amount of breakthrough from the denuder can significantly bias a particulate-fraction measurement for SOCs that are lightly-retained in the denuder and partition weakly to particles (Bidleman et al. 1999). Similarly, collection of a small fraction of particles within the denuder can significantly bias the gaseous fraction for predominantly particle-associated analytes. Breakthrough artifacts can be avoided by selecting a sample volume that is less than the temperature- and analytespecific breakthrough volume. The artifact due to particle collection within the denuder is a function of denuder design, analyte volatility, and ambient particle size distribution. It is necessary to predict the occurrence of these artifacts as a function of denuder design and sampling variables to minimize their impacts on data quality.

In this chapter, a practical approach is presented to predict gaseous collection efficiency and particle collection artifact in multicapillary diffusion denuders that contain polydimethylsiloxane (PDMS) as sorbent. PDMS offers several advantages for sorptive sampling: 1) PDMS is a re-usable coating that is durable in both thermal desorption and solvent extraction methods, 2) PDMS collects analytes by non-selective absorption resulting in low risk of irreversible adsorption and catalytic surface reaction, 3) PDMS retains little water in sampling of humid air (Rowe and Perlinger 2009a), thus minimizing difficulties caused by water in sample processing and analysis, 4) Diffusivity in PDMS is high compared to other sorptive sampling polymers (Rusina et al. 2007), leading to rapid uptake kinetics, and 5) PDMS coating has a smooth surface, compared to particulate 
coatings such as XAD, which may lower its potential to trap particles. In prior literature, measured gas collection efficiency has been reported under specific conditions (Krieger and Hites 1994; Mader et al. 2001), but an approach to predict collection efficiency in the denuder as a function of analyte properties, design, and sampling variables was not developed. Volckens and Leith (2003) considered the effects of assumed gas and particle collection artifacts on measured gas-particle partition coefficients, but did not attempt to predict the magnitude of collection efficiency artifacts in the denuder. Baltussen et al. (2002) described the application of chromatographic theory to predict gaseous collection efficiency in sorptive samplers, but use of this method is limited in practice because values of the temperature-dependent equilibrium stationary phase-gas partition coefficient are generally not available. We present two methods to estimate the PDMSgas partition coefficient $\left(K_{\mathrm{pdms}}\right)$ and compare estimated to measured $K_{\mathrm{pdms}}$ values for several SOCs. Additionally, an approach to predict gaseous SOC and particle collection efficiency is described, and predictions are compared to measured collection efficiencies for two denuder designs. Finally, an application of the model is presented in which the range of volatility over which sampling is predicted to be artifact-free is compared for the two denuder designs.

\subsection{Theory}

\subsubsection{Prediction of gaseous collection efficiency}

To predict gaseous collection efficiency using chromatographic theory, it is necessary to know the temperature-dependent $K_{\text {pdms }}$ for each analyte of interest. It is desirable to estimate this parameter to avoid the need to measure $K_{\text {pdms }}$ for each analyte. Using the solvation parameter model of Abraham et al. (1994), an equilibrium liquid-gas partition coefficient is obtained by adding the contributions of the various molecular interactions:

$$
\log (K)=c+e E+s S+a A+b B+l L
$$

where $K=$ liquid-gas partition coefficient, $c=$ intercept, $e, E=$ solvent, solute $n$ - and $p i$ electron pair interaction descriptor, $s, S=$ solvent, solute dipole/polarizability interaction descriptor, $a, A=$ solvent hydrogen bond base, solute hydrogen bond acid interaction 
descriptor, $b, B=$ solvent hydrogen bond acid, solute hydrogen bond base interaction descriptor, and $l, L=$ solvent, solute cavity formation/dispersive interaction descriptor. In this model, the temperature dependence of $K$ is addressed through the use of temperaturedependent solvent descriptors, while solute descriptors are not varied with temperature. Measured solute descriptors are available for many compounds of interest (for example, Abraham et al. 1994; Abraham and Al-Hussaini 2005), and a group contribution method can be used to estimate solute descriptors for any compound (Platts et al. (2000) as implemented in (Pharma Algorithms 2006)) if measured values are not available. We obtained temperature-dependent solvent descriptors for PDMS by linear regression of solvent parameters determined by Li et al. (2000) at five temperatures. Regression parameters and statistics are reported in Table 3.1, and details of the calculations are given in Supplemental Information. $K_{\text {pdms }}$ estimated using the parameters in Table 3.1 is compared to other estimates of $K_{\mathrm{pdms}}$ in Results and Discussion.

Table 3.1: Linear regression parameters (slope and intercept) used to estimate temperature-dependent solvent descriptors for polydimethylsiloxane stationary phase for estimation of the liquid-gas partition coefficient by the solvation parameter model, Eq. (3.1).

\begin{tabular}{llllll} 
& \multicolumn{3}{l}{ Std. } & Std. \\
& Slope $^{\text {a }}$ & Error & Intercept $^{\text {a }}$ & Error & $\mathrm{R}^{2}$ \\
C & 121.9 & 8.6 & -0.445 & 0.023 & 0.9854 \\
S & -- & -- & 0.209 & 0.001 & - \\
a & 273.5 & 15.8 & -0.509 & 0.043 & 0.9901 \\
I & 439.1 & 0.6 & -0.613 & 0.002 & 1.0000
\end{tabular}

${ }^{\mathrm{a}} c, a, I=$ slope $/ \mathrm{T}+$ intercept, derived from the data of Li et al. (2000), $\mathrm{n}=5$, temperature range $60-140^{\circ} \mathrm{C}$. Descriptors $e$ and $b$ were equal to zero. 
A brief description of the approach to predict gaseous collection efficiency is provided here with a detailed description and equations provided in Appendix C. Sorptive sampling of gases into a liquid phase in open tubular samplers can be described using chromatographic theory (for example, Baltussen et al. 2002). Thermodynamic equilibrium between the two phases is described using the gas-liquid partition coefficient. PDMS may be treated as a liquid here, even though it is a cross linked polymer, because chromatographic retention in PDMS is dominated by dissolution of analytes into the bulk phase rather than by interfacial adsorption. Interfacial adsorption can contribute significantly to retention at low temperatures and for analytes that differ significantly in polarity from the stationary phase (Poole and Poole 2009). For nonpolar stationary phases such as PDMS, adsorption at the substrate dominates over adsorption at the air-PDMS surface, and is greater if the substrate is not well deactivated. Therefore, interfacial adsorption may contribute to retention in sorptive samplers at ambient temperature. However, retention by adsorption is additive to retention by dissolution (Poole and Poole 2009, Eq. 9); thus prediction of retention by partitioning into the bulk phase alone may be considered a lower bound to predicted retention. The lower limit of expected retention is of interest for the purpose of predicting collection efficiency.

The extent to which the collection efficiency is limited by longitudinal diffusion in the gas and the rate of mass transfer in gas and liquid is taken into account through the theoretical plate height, $H$, a length scale that is used to estimate the length of sampler over which equilibrium between the two phases is reached. $H$ is given as a function of flow velocity, diffusivity in the two phases, capillary diameter, and film thickness in the Golay equation (as in Poole 2003, p. 34). Diffusivity in PDMS was estimated using the empirical correlation of Malcolm et al. (2003). As the sampler reaches equilibrium with the incoming concentration, the analyte will eventually begin to break through. The integral breakthrough fraction, $b t$, is defined as the ratio of analyte mass that passed through the denuder to analyte mass that entered the denuder over the sampling period. To predict $b t$ as a function of sample volume, $H$, and sampler length, we used the expression of Lövkvist and Jönsson (1987, Eq. 8), which was derived for conditions of 
constant inlet concentration and samplers with small numbers of theoretical plates $(<$ $100)$.

\subsubsection{Prediction of particle transmission efficiency}

Unintentional particle collection within the multicapillary denuder by diffusion and gravitational sedimentation along the length of the capillaries was modeled after Gormley and Kennedy (1949), and Pich (1972), respectively. Flow was assumed to be laminar within the denuder. Reynolds numbers were 46 and 119 for the high-flow and low-flow denuders, respectively, compared to a minimum value of approximately 2300 for turbulent flow in a tube (White 1999, p.330). Particle collection can occur at the entrance of the denuder where flow is split by the capillary walls through impaction, interception, and diffusion. Particle collection on the ends of the capillary tubes was estimated by modification of the single-fiber filter collection efficiency model described by Hinds (1999, p.190). An equivalent fiber diameter was defined as the ratio of solid area of the denuder cross-section to the summed length of capillary walls. The expression for overall collection efficiency was modified to represent collection on a two-dimensional surface (the capillary ends). Details are provided in Appendix C. Particle collection by electrophoresis and thermophoresis was neglected.

\subsection{Experimental Methods}

\subsubsection{Low-flow and high-flow multicapillary diffusion denuders}

Low-flow (13 $\mathrm{L} \mathrm{min}^{-1}$ ) denuders consisted of 289 sections of capillary GC columns (ZB-1, 0.530-mm inside dia., $100 \%$ PDMS, 5- $\mu \mathrm{m}$ film, Phenomenex) packed into a deactivated stainless steel tube (250-mm long, 13-mm inside dia.). Details of design, construction, and application of the low-flow denuders are given elsewhere (Tobias et al. 2007; Rowe and Perlinger 2009a). A high-flow denuder was designed using the modeling approach described here with the goal of achieving 2- to 3-hour breakthrough-limited sampling times at $300 \mathrm{~L} \mathrm{~min}^{-1}$ for relatively low $K_{\text {pdms }}$ PBTs such as $\alpha-\mathrm{HCH}$ and HCB. Details of fabrication of the high-flow denuder and associated equipment are presented elsewhere (Rowe and Perlinger 2009b). Briefly, the high-flow denuders were constructed 
of welded stainless steel honeycombs (102-mm outside dia., 1.04-mm cell dia., 51-mm depth, Quality Honeycomb, Arlington, TX). The honeycombs were deactivated using the Sulfinert process (Restek, Bellefonte, PA), then coated in our lab with a $5-\mu \mathrm{m}$ film of cross-linked and bonded PDMS stationary phase (Rtx-1, Restek). Two honeycomb disks were stacked in stainless steel sleeves to make an overall denuder length of $102 \mathrm{~mm}$. One denuder was fabricated using a cordierite ceramic honeycomb (1.3 mm square cell, 76mm deep, Applied Ceramics, Doraville, GA), which was also Sulfinert deactivated and coated with PDMS. Anodized aluminum sampler housings held the denuders and filter holder in place and sealed the flow path with PTFE and Viton gaskets. A mass-flow controlled blower motor (Tisch Environmental, Cleves, $\mathrm{OH}$ ) provided flow. Inlets were designed after those of Liu and Pui (1981) to protect the samplers from rain during sampling as well as to maximize coarse particle transmission.

\subsubsection{Measurement of PDMS-gas partition coefficients by gas chromatography}

$K_{\text {pdms }}$ values were determined by a series of GC retention time measurements collected at a minimum of four temperatures for relatively low $K_{\mathrm{pdms}}$ PCBs, OCPs, and PBDEs. In practice, the sample volume that can be collected without breakthrough is limited by the lowest $K_{\text {pdms }}$ analyte of interest. The retention factor, $k$, can be determined from retention time measurements as $k=\left(t_{\mathrm{r}}-t_{\mathrm{m}}\right) / t_{\mathrm{m}}$, where $t_{\mathrm{r}}$ is the retention time, $t_{\mathrm{m}}$ is the column holdup time, and $K_{\mathrm{pdms}}=k \beta$. Column holdup time was determined using detector response from the trace quantity of air that is introduced with a blank injection. In practice, retention times are converted to volumes using flow rate measured at the column outlet, corrected for pressure drop over the column and evaporation of water in the soap film flow meter. We followed the correction procedure of Poole $(2003$, p. 10). $\beta$ was calculated from capillary column dimensions and film thickness provided by the manufacturer. Measurements were conducted at a column flow velocity equal to the denuder sampling flow velocity, and also at one half and one tenth of the sampling flow velocity to confirm that measured $K_{\text {pdms }}$ was not affected by limited mass transport. The GC was an HP 5890 Plus with an electron capture detector $\left(\mathrm{H}_{2}\right.$ carrier gas, $300{ }^{\circ} \mathrm{C}$ inlet, 5 
m column). The column was the same as that used to construct the low-flow denuders. The oven temperature was held constant during the GC run, and confirmed with an independent thermocouple.

\subsubsection{Measurement of breakthrough fraction for gaseous analytes}

Sample collection conditions spanned the range of anticipated sampling conditions (from -10 to $25{ }^{\circ} \mathrm{C}$, from 11 to $100 \%$ relative humidity, from 2.7 to $111.6 \mathrm{~m}^{3}$ sample volume; Table C3). Outdoor air samples were collected at two locations: at the Integrated Atmospheric Deposition Network (IADN) monitoring site at Eagle Harbor, MI and on the roof of the Dow Environmental Sciences and Engineering Building (DESEB), Michigan Technological University, Houghton, MI. Indoor air samples were collected in the DESEB and adjacent Dillman Hall.

Breakthrough samples were collected in duplicate (co-located samplers), and two field blanks were included with each experiment. Field blanks were subjected to identical processing steps as samples, including assembly and disassembly at the sample collection site, with the exception that air was not drawn through field blank denuders. Each breakthrough sample consisted of two denuders connected in series, with the backup denuder intended to capture breakthrough of ambient SOCs from the front denuder. The experimental breakthrough fraction, $b t$, was calculated as

$$
b t=\frac{M_{b}}{M_{f}+M_{b}}
$$

where $M_{\mathrm{f}}$ and $M_{\mathrm{b}}$ are the mass of analyte on the front and back denuders, respectively. Temperature and relative humidity were measured using a model HMP45C sensor (Vaisala). Flow rate, temperature, and relative humidity were recorded at 1-min. intervals. Sample volume was calculated from the flow rate record and reported at standard conditions of $25^{\circ} \mathrm{C}, 1 \mathrm{~atm}$. Sample extraction, cleanup, GC analysis, and quality assurance procedures are described in detail elsewhere (Rowe and Perlinger 2009a; Rowe and Perlinger 2009b). A gas-phase cleanup method (Rowe and Perlinger 2009a), described in Chapter 2, was used to remove the polar background matrix of oxidized 
organic compounds in air prior to analysis in order to improve signal-to-noise ratio and selectivity in analysis by electron capture detection. Polar organochlorine compounds, including $\mathrm{HCH}$ isomers, were removed by the cleanup method; therefore, breakthrough fraction measurements are not presented for these compounds. Analytes included hexachlorobenzene, 144 PCB congeners, and PBDEs 47 and 99. The following quality criteria were applied in breakthrough fraction measurements: 1) $M_{\mathrm{f}}$ greater than nine times method detection limit, 2) $M_{\mathrm{f}}$ greater than five times the field blank concentration. The first criterion ensures that a non-detect in the backup denuder indicates a breakthrough fraction less than 0.1. Analyte masses were blank subtracted.

\subsubsection{Measurement of particle transmission efficiency}

A scanning mobility particle sizer (SMPS) optical particle counting instrument (Model 3071A-3025A, TSI) was used to measure fine particle size distributions (from $0.01-0.5 \mu \mathrm{m}$ ) downstream of the low-flow and high-flow denuders during sampling of ambient atmospheric aerosol on the DESEB roof. Coarse particle size distributions (from $0.5-20 \mu \mathrm{m}$ ) were measured using an aerodynamic particle sizer (APS; Model 3320, TSI). The aerosol sample flow of $1 \mathrm{~L} \mathrm{~min}^{-1}$ and $5 \mathrm{~L} \mathrm{~min}^{-1}$ for the SMPS and APS, respectively, was drawn just downstream of the high-flow and low-flow denuders using isokinetic inlets in order to avoid artifacts associated with flow distortion at the aerosol sample inlet.

To measure particle transmission, ambient aerosol particle size distributions were collected alternately with the denuder and with a blank denuder in the sampling train without changing the inlet geometry (3-min. samples, SMPS; 5-min. samples, APS). The blank denuder consisted of the outer stainless steel tube of a denuder not containing any capillaries. The fractional particle transmission through the denuder, $f_{\mathrm{t}}$, was measured as

$$
f_{t}=\frac{N_{d}}{N_{b}}
$$

where $N_{\mathrm{d}}$ is the particle count recorded during a sample with the denuder in place, and $N_{\mathrm{b}}$ is the particle count recorded during a subsequent sample with the blank denuder in place. Samples with fewer than 25 counts were discarded to ensure that the Poisson error 
of the particle count was less than $20 \%$. A series of $24 f_{\mathrm{t}}$ measurements was conducted to obtain a mean and $95 \%$ confidence interval for comparison with the predicted $f_{\mathrm{t}}$.

\subsection{Results and Discussion}

\subsubsection{Measured and estimated PDMS-gas partition coefficients}

$K_{\text {pdms }}$ at $25^{\circ} \mathrm{C}$ estimated from $\mathrm{GC}$ measurements and from solvent descriptors from several sources were compared to determine whether consistent estimates were obtained. Solvent descriptors for PDMS were available from four investigations, each relying on a distinctly different experimental method: 1) Li et al. (2000) measured $K_{\text {pdms }}$ for a diverse set of 41 to 63 compounds at $60,80,100,120$, and $140^{\circ} \mathrm{C}$ by open tubular column $\mathrm{GC}$; 2) Poole and Poole (1995) measured $K_{\mathrm{pdms}}$ at $121.4^{\circ} \mathrm{C}$ by packed column GC at several levels of stationary phase loading to correct for effects of interfacial adsorption. Phase ratio was measured by exhaustive Soxhlet extraction; 3) Sprunger et al. (2007) compiled literature values of $K_{\text {pdms-gas }}$ and $K_{\text {pdms-water from static equilibrium experiments using }}$ PDMS-coated solid phase microextraction (SPME) fibers near $25^{\circ} \mathrm{C}$. Solvent descriptors were reported for the "dry" data set ( $K_{\text {pdms-gas }}, 64$ compounds) and the "wet" data set (78 compounds $)$, in which $K_{\text {pdms }}$ was calculated from $\log \left(K_{\text {pdms-gas }}\right)=\log \left(K_{\text {pdms-water }}\right)-$ $\log \left(K_{\text {air-water }}\right)$; 4) Hierlemann et al. (2001) measured $K_{\text {pdms }}$ for 33 compounds at $25^{\circ} \mathrm{C}$ using polymer coated acoustic wave vapor sensors.

Interfacial adsorption is expected to be more significant for polar compounds in PDMS and at low temperatures (Poole and Poole 2009); thus, dipole/polarizability and hydrogen bonding descriptors $(s, a$, and $b)$ may be expected to have higher values in experiments that were affected by interfacial adsorption. Solvent descriptors from the above four investigations are presented in Table $\mathbf{C 2}$ along with $25^{\circ} \mathrm{C}$ descriptors estimated from the data of $\mathrm{Li}$ et al. using the regression of Table 3.1, and for dry octanol. The descriptors of Li et al. at $120^{\circ} \mathrm{C}$ are in close agreement with those of Poole and Poole, which were corrected for effects of interfacial adsorption, thus it is likely that the descriptors of $\mathrm{Li}$ et al. were minimally affected by interfacial adsorption. The $e, s, b$, and $l$ descriptors of Hierlemann et al. are in close agreement with the $25^{\circ} \mathrm{C}$ descriptors derived 
from Li et al., while Hierlemann et al. reported a higher $a$ descriptor. Hierlemann et al. suspected substrate effects as the cause of their high $a$ descriptor.

Sprunger et al. found higher values of polar descriptors for PDMS than prior investigations. The difference between the dry and wet descriptors of Sprunger et al. is greater than the reported uncertainties for all descriptors except $c$, suggesting that the solvation characteristics of PDMS are affected by water or that error was introduced through estimation of $K_{\text {pdms-gas }}$ from $K_{\text {pdms-water }}$. The descriptors of Sprunger et al. indicate stronger dipole/polarizability $(s)$ and hydrogen bonding $(a, b)$ interactions than Li et al. and Hierlemann, in fact the wet hydrogen bond acid $(b)$ descriptor of Sprunger et al. (0.650) is comparable to that of octanol (0.702) within the stated uncertainty. PDMS contains no acidic hydrogens, unless silanol groups are present, and several investigators have found $b=0$ for PDMS and similar polysiloxane stationary phases (Poole and Poole 1995; Li et al. 2000; Hierlemann et al. 2001; Li and Poole 2001).

Polysiloxane-coated GC columns have been shown to become more polar through use. Li and Poole (2001) determined solvent descriptors for a performance-degraded PDMS-5 \% diphenylsiloxane column and found increased $s, a$, and decreased $l$ relative to a new column of the same type ( $b=0$ for both), which they attributed to greater analytesubstrate interaction in the degraded column.

Comparison of PDMS solvent descriptors determined by various methods leads to the interpretation that the descriptors of $\mathrm{Li}$ et al. are representative of dissolution into pure PDMS, while those of Sprunger et al. may be more representative of PDMS in the presence of moisture, silanol, or other polar contaminants. The latter conditions may occur in a denuder during sampling or after a denuder has experienced several thermal desorption cycles, which may cause greater retention for polar compounds than predicted by the descriptors of Li et al. However, this hypothesis cannot be tested here because measurement of breakthrough for polar compounds in denuders was not included in this study. The descriptors of Li et al. likely represent a lower limit for retention of polar compounds in these denuders. 
Regression parameters to calculate $K_{\text {pdms }}$ values as a function of temperature, derived from GC measurements, are presented in Table 3.2. $\log \left(K_{\mathrm{pdms}}\right)$ values at $25^{\circ} \mathrm{C}$ estimated from GC measurements (using Table 3.2) and the solvent descriptors of Li et al. (using Table 3.1) are compared to $\log \left(K_{\mathrm{pdms}}\right)$ estimated using the solvent descriptors of Sprunger et al. in Table 3.3. The octanol-air partition coefficient, $\log \left(K_{\text {oa }}\right)$, is presented for comparison (Beyer et al. 2002; Harner and Shoeib 2002; Li et al. 2003). $K_{\mathrm{pdms}}$ derived from $\mathrm{Li}$ et al. and from Sprunger et al. are equally comparable to $K_{\mathrm{pdms}}$ derived from GC measurements for the relatively nonpolar HCB and PCBs. For the hydrogen bond basic $\mathrm{HCHs}, K_{\text {pdms }}$ from Sprunger et al. is greater than both the $K_{\text {pdms }}$ derived from Li et al. and the GC measurements, which stems from the non-zero hydrogen bond acid descriptor, $b$, of Sprunger et al. Neither source of solvent descriptors produced $K_{\mathrm{pdms}}$ in good agreement with GC measurements for PBDE 28, although the value of Li et al. was closest, which may stem from the fact that solute descriptors for PBDE 28 were estimated from a group contribution method (Pharma Algorithms 2006). The root mean square (RMS) error between $K_{\text {pdms }} 25^{\circ} \mathrm{C}$ derived from GC measurements and from Li et al. was $36 \%$ relative to the GC value and excluding PBDE 28, while $K_{\mathrm{pdms}}$ varies over more than three orders of magnitude for the analytes included in Table 3.3 over typical sample collection temperatures (Table C3).

$\log \left(K_{\text {pdms }}\right)$ values derived from GC measurements were approximately one log unit less than $\log \left(K_{\text {oa }}\right)$ at $25^{\circ} \mathrm{C}$ (mean 1.03 , std. error $0.07, \mathrm{n}=7$ ) for the analytes tested, consistent with greater ease of cavity formation, $l$, dipole interactions, $s$, and hydrogen bond acid interactions, $b$, indicated by the solvent descriptors of octanol relative to those of PDMS (Table C2). Thus, an approximate value of $K_{\text {pdms }}$ at $25^{\circ} \mathrm{C}$ for relatively nonpolar compounds similar to those listed in Table $\mathbf{3 . 3}$ may be obtained through the relationship $\log \left(K_{\text {pdms }}\right) \approx \log \left(K_{\text {oa }}\right)-1$, which is plotted along with measured $K_{\text {pdms }}$ in Figure C1. This relationship is not expected to hold for compounds more polar than those listed in Table 3.3; thus $K_{\text {pdms }}$ derived from measurements or estimated by the solvation parameter model should be used whenever possible. 
Table 3.2: Regression parameters (slope and intercept) used to calculate temperature dependent liquid-gas partition coefficients for polydimethylsiloxane stationary phase derived from GC retention time measurements. Standard errors of estimation of the slope and intercept by regression are given along with the coefficient of determination $\left(R^{2}\right)$, number of observations $(n)$, and the temperature range of the measurements.

\begin{tabular}{|c|c|c|c|c|c|c|c|}
\hline & Slope ${ }^{a}$ & $\begin{array}{l}\text { Std. } \\
\text { Error }\end{array}$ & Intercept $^{a}$ & $\begin{array}{l}\text { Std. } \\
\text { Error }\end{array}$ & $R^{2}$ & $\mathrm{n}$ & $\begin{array}{l}\text { Temp. } \\
\text { range, }{ }^{\circ} \mathrm{C}\end{array}$ \\
\hline $\mathrm{HCB}$ & 3131 & 11 & -4.08 & 0.030 & 0.9998 & 21 & $60-140$ \\
\hline$\alpha-\mathrm{HCH}$ & 3132 & 13 & -4.15 & 0.034 & 0.9997 & 21 & $60-140$ \\
\hline $\mathrm{\gamma}-\mathrm{HCH}$ & 3220 & 13 & -4.25 & 0.034 & 0.9997 & 21 & $60-140$ \\
\hline РСB 18 & 3270 & 15 & -4.26 & 0.038 & 0.9995 & 26 & $80-180$ \\
\hline РCB 44 & 3580 & 18 & -4.64 & 0.045 & 0.9994 & 25 & $80-180$ \\
\hline РCB 65 & 3517 & 17 & -4.51 & 0.043 & 0.9994 & 25 & $80-180$ \\
\hline PBDE 28 & 3852 & 20 & -4.83 & 0.049 & 0.9995 & 20 & $100-180$ \\
\hline
\end{tabular}


Table 3.3: $\log \left(K_{\text {pdms }}\right)$ at $25{ }^{\circ} \mathrm{C}$ estimated from GC measurements and from PDMS solvent descriptors from two sources. Percent difference is given between $K_{\text {pdms }}$ estimated from $\mathrm{GC}$ measurements and the various solvent descriptors. $\log \left(K_{\mathrm{oa}}\right)$ at $25{ }^{\circ} \mathrm{C}$ is shown for comparison

\begin{tabular}{|c|c|c|c|c|c|c|c|}
\hline Source & $\mathrm{HCB}$ & $\alpha-\mathrm{HCH}$ & $\gamma-\mathrm{HCH}$ & PCB 18 & PCB 44 & PCB 65 & PBDE 28 \\
\hline GC (Table 3.2) ${ }^{a}$ & 6.42 & 6.35 & 6.55 & 6.70 & 7.37 & 7.28 & 8.09 \\
\hline Li et al. (Table 3.1) ${ }^{b}$ & 6.53 & 6.53 & 6.75 & 6.68 & 7.43 & 7.40 & 8.87 \\
\hline Pct. diff. Li et al. - GC & 29 & 50 & 58 & -5 & 14 & 33 & 501 \\
\hline Dry PDMS-gas ${ }^{c}$ & 6.48 & 6.71 & 6.95 & 6.74 & 7.48 & 7.46 & 9.01 \\
\hline Pct. diff. dry - GC & 14 & 126 & 154 & 8 & 28 & 50 & 730 \\
\hline Wet PDMS-gas ${ }^{c}$ & 6.31 & 6.70 & 6.95 & 6.73 & 7.44 & 7.42 & 8.98 \\
\hline Pct. diff. wet - GC & -23 & 124 & 153 & 6 & 18 & 38 & 679 \\
\hline $\log \left(K_{\mathrm{oa}}\right)$ & 7.35 & 7.37 & 7.83 & 7.49 & 8.29 & 8.23 & 9.41 \\
\hline
\end{tabular}



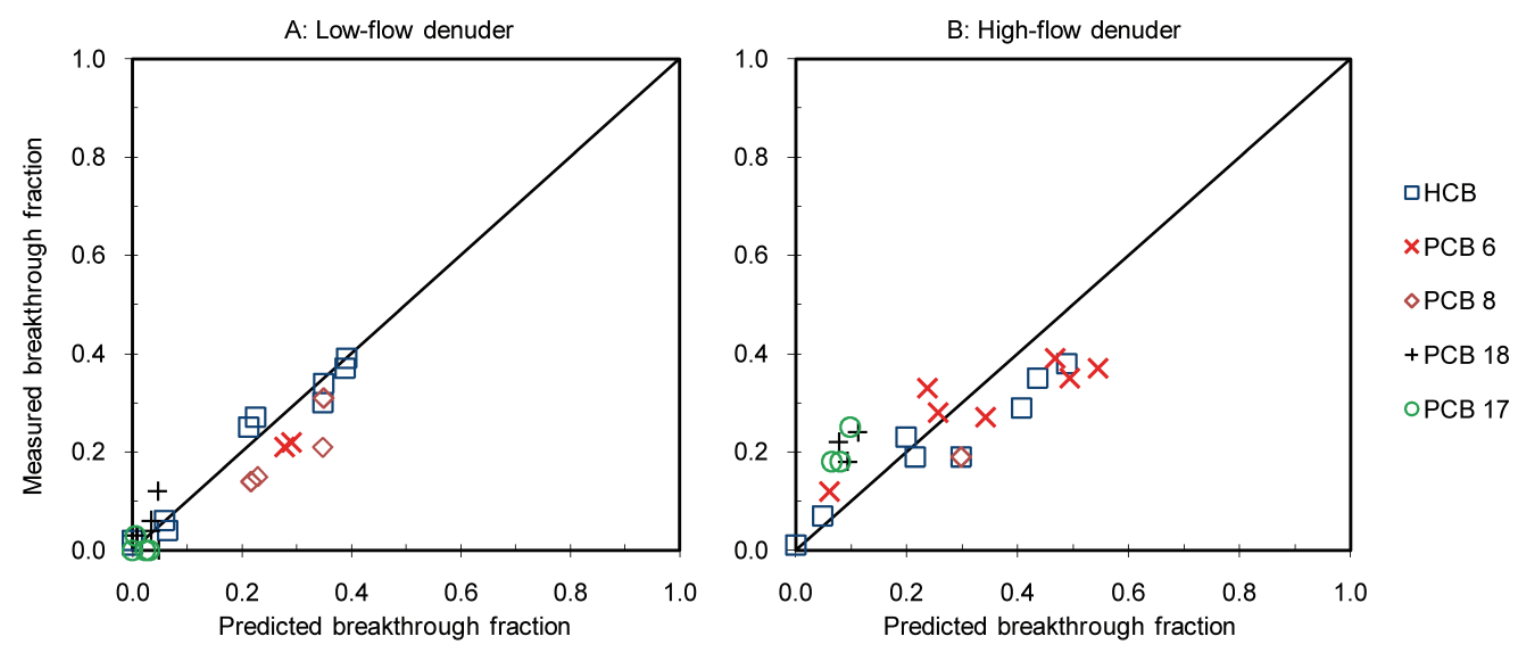

Figure 3.1: Comparison of measured to predicted breakthrough fraction for low-flow (A) and high-flow denuders (B).

\subsubsection{Comparison of measured to predicted breakthrough fraction}

The performance of the model for gaseous collection efficiency was evaluated by comparison of modeled to measured breakthrough fraction for low-flow and high-flow denuders under the sampling conditions listed in Table C3. Samples were collected in relatively pristine rural environments as well as in indoor environments having 10 to 100 times greater concentrations of SOCs (Rowe and Perlinger 2009a). Sample volumes were selected using the breakthrough model to give a value of $b t$ in Eq. (3.2) of $\sim 0.25$ for $\mathrm{HCB}$ at the anticipated sample collection temperature; thus, breakthrough was expected only for analytes with relatively low $K_{\text {pdms. }}$ Valid measurements of $b t$ values (non-zero breakthrough and meeting the quality criteria) were obtained for $\mathrm{HCB}$ and PCBs $6,8,17$, and 18. Zero breakthrough fraction was predicted for compounds with greater $K_{\mathrm{pdms}}$ than PCB $17\left(\log \left(K_{\text {pdms }}\right) 25^{\circ} \mathrm{C}=6.71\right.$ using Table 3.1 $)$ under all conditions tested. For analytes with predicted $b t=0$, measured $b t>0.1$ was observed for only 11 of 243 and 12 of 58 measurements for low-flow and high-flow denuders, respectively. 
Measured and predicted $b t$ values are compared in Figure 3.1. The solvation model was used to estimate $K_{\text {pdms }}$ values for PCBs 6,8 , and 17 . In these experiments, the model was effectively used to select sample volumes that resulted in $b t<0.4$ for $\mathrm{HCB}$ (Figure 3.1) under all conditions. The RMS error between predicted and measured $b t$ was 0.05 ( $n$ $=28)$ for the low-flow denuder, compared to a RMS difference of $0.05(n=13)$ between duplicate measurements, indicating that the model predicted breakthrough as well as can be evaluated given the precision of the measurements. The model predicted $b t$ slightly less accurately for the high-flow denuder (RMS of $0.10, n=23$ vs. $0.05, n=7$ for duplicates). Several factors may have contributed, including less chromatographic efficiency of the high-flow denuders (6.5 theoretical plates vs. 12 for low-flow), band broadening caused by the gap between the two honeycombs that make up a metallic honeycomb high-flow denuder, non-uniform flow across the 102-mm dia. denuder, or non-uniform stationary phase coating. Breakthrough was predicted as well for the ceramic honeycomb (RMS 0.10, $n=7$ ) as for the metallic honeycombs (RMS 0.10, $n=$ 16), and for high humidity (RH $>70 \%$ ) as for low humidity samples (Table C5).

\subsubsection{Comparison of measured to predicted particle transmission}

Predicted coarse particle transmission was much less for the low-flow than for the high-flow denuder (Figure 3.2), primarily due to the gravitational sedimentation term. The low-flow denuder has previously been used for analytes that have a negligible particle-associated fraction, thus it was evaluated in a horizontally-oriented aspirated sampler housing with an inlet that is designed to exclude coarse particles consisting of a 25-mm dia. pipe with a $90^{\circ}$ bend (Perlinger et al. 2005). Denuders should be oriented vertically for applications in which coarse particle transmission is of concern. Predicted impaction and interception losses on the capillary ends were enhanced in the low-flow denuder relative to the high-flow denuder due to higher face velocity ( $\left.1.7 \mathrm{vs} .0 .7 \mathrm{~m} \mathrm{~s}^{-1}\right)$ and greater capillary wall thickness (180 vs. $68 \mu \mathrm{m})$. The discontinuity in the modeled coarse particle transmission (visible in Figure 3.2) occurs at the particle diameter for which the sum of interception and impaction collection efficiency reaches its theoretical maximum. In the low-flow denuder, measured particle transmission was slightly less than 
predicted for most size classes (Figure 3.2), however mean particle transmission generally followed the decreasing trends in predicted transmission for fine particles (collection by diffusion) and coarse particles (sedimentation, impaction, and interception).

Measured particle transmission did not differ significantly from predicted particle transmission for nearly all size classes in the high-flow denuder (Figure 3.2). High-flow fine particle transmission measurements were combined for the ceramic honeycomb and stainless steel honeycomb $(\mathrm{n}=24$ each); the two honeycomb support materials behaved similarly with respect to fine particle transmission.
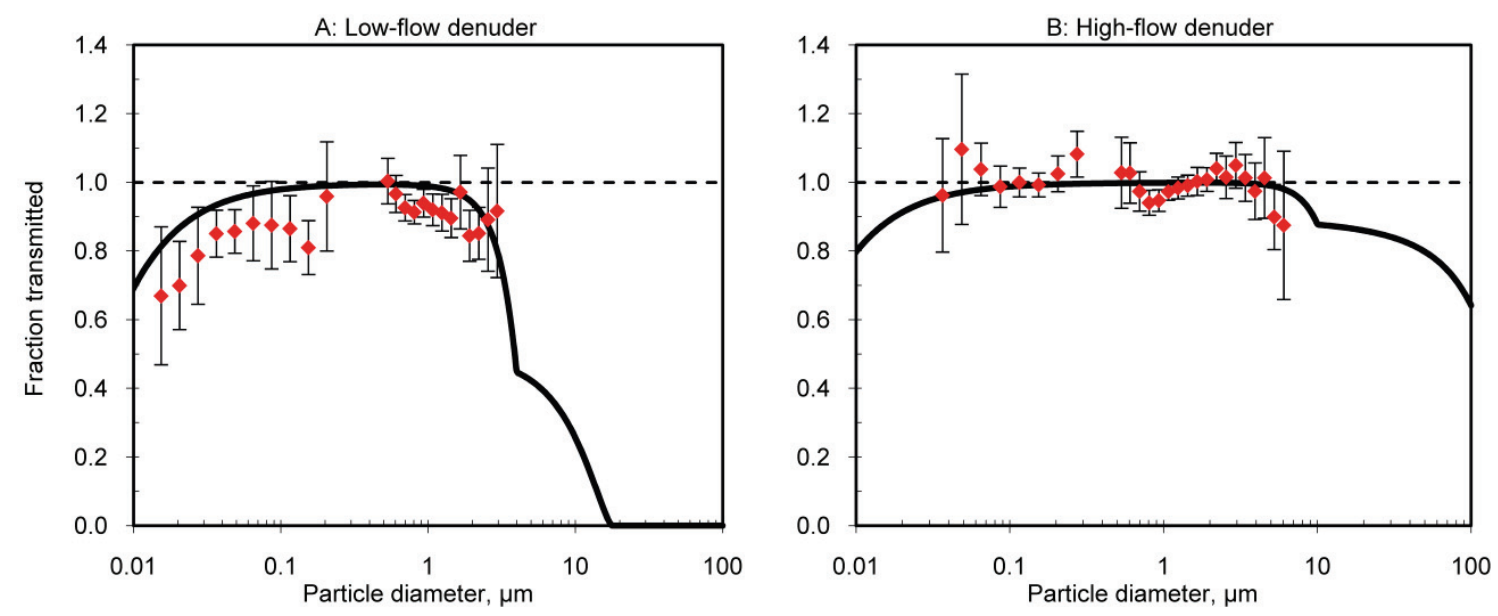

Figure 3.2: Comparison of measured (symbols) to predicted (line) aerosol particle transmission through low-flow (A) and high-flow (B) denuders. Error bars represent the $95 \%$ confidence interval for the mean value, with $n=24$ in most cases. 
The experimental method that we used to measure particle transmission allowed us to measure transmission of actual ambient aerosol particles under realistic sampling conditions over the particle diameter range in which ambient aerosol particles are most numerous. However, the method had limited ability to verify model predictions for coarse particle transmission. Coarse particle number concentrations are relatively low, thus few of the samples had statistically significant numbers in size classes $>\sim 2 \mu \mathrm{m}$. Coarse particles were detected in significant numbers up to $6.3 \mu \mathrm{m}$ in the high-flow denuder vs. $3.1 \mu \mathrm{m}$ in the low-flow denuder, reflecting the fact that the high-flow sampler inlet was designed to maximize coarse particle transmission while the low-flow inlet was designed to exclude coarse particles.

\subsubsection{Application of the model to predict sampling artifacts}

To estimate the magnitude of the artifact caused by unintentional particle collection in the denuder, model rural and urban log-normal aerosol particle size distributions were considered having properties given in Table C4 (Whitby 1978). Predicted particle transmission efficiency through high-flow or low-flow denuders for each of the three aerosol modes (nucleation, accumulation, and coarse) was calculated.

$$
f_{t j}=\sum_{i=1}^{n} C_{p i} f_{t i}
$$

where $f_{\mathrm{tj}}$ is the mass fraction of particles transmitted through the denuder for a given aerosol mode $j, C_{\mathrm{pi}}$ is the mass concentration of particles within a particle size class from the model distribution, and $f_{\mathrm{ti}}$ is the fractional transmission for the size class from the model described above. The subscript $i$ indicates summation over particle diameter classes in an aerosol mode. The magnitude of the artifact caused by collection of particleassociated SOCs was then calculated.

$$
f_{d}=\frac{\sum_{j=1}^{3} K_{p j} C_{p j}\left(1-f_{t j}\right)}{\sum_{j=1}^{3} K_{p j} C_{p j}\left(1-f_{t j}\right)+1}
$$

where $f_{\mathrm{d}}$ is the mass fraction of SOC in the denuder sample associated with particles, $C_{\mathrm{pj}}$ is the mass concentration of particles within aerosol mode $j$, and $f_{\mathrm{tj}}$ is the fractional 
transmission for the aerosol mode, Eq. (3.4). For the three aerosol modes, $f_{\mathrm{tj}}$ was 0.93 , 0.90 (nucleation), 0.98, 0.97, (accumulation), and 0.93, 0.40 (coarse) for high-flow and low-flow denuders, respectively, for the urban aerosol $\left(f_{\mathrm{tj}}\right.$ values were similar for rural aerosol, Table C4).

The particle-gas partition coefficient, $K_{\mathrm{p}}$, was calculated after Harner and Shoeib (2002), as a function of $K_{\mathrm{oa}}$ and the fraction organic matter, $f_{\mathrm{om}}$, of the aerosol particles. Arp et al. (2008) calibrated a modified Abraham solvation parameter model to predict $K_{\mathrm{p}}$, and found that under dry conditions for nonpolar and most polar compounds, sorption is dominated by absorption into a water-insoluble organic phase, while under moist conditions polar and ionized compounds can partition additionally into a mixed-aqueous phase. The model of Harner and Shoeib was selected because it is consistent with the mechanism identified by Arp et al. for nonpolar compounds, and facilitates the comparison of predicted performance for two denuder designs presented in Figure 3.3 for the relatively nonpolar analytes considered here. The model of Arp et al. could be substituted for that of Harner and Shoeib in the approach presented here if a more mechanistically-realistic prediction of particle collection artifact is desired for polar and ionized organic compounds under moist conditions.

Figure 3.3: (next page) Predicted breakthrough volume and particle collection artifact, $f_{\mathrm{d}}$, for rural $(A, B)$ and urban $(C, D)$ aerosol particle size distributions in high-flow $(A, C)$ and low-flow $(B, D)$ denuders as a function of the octanol-air partition coefficient. Breakthrough volume is defined as the sample volume at which fractional breakthrough, $b t,=0.1$. The cumulative contribution of each aerosol mode to $f_{d}$ is plotted individually. The artifact-free operation range for the denuder is the region between the "Breakthrough volume" and "Nucleation + Accumulation + Coarse" lines in the figure. Ranges of $\log \left(K_{\text {oa }}\right)$ for classes of SOCs are shown for reference (bottom). 


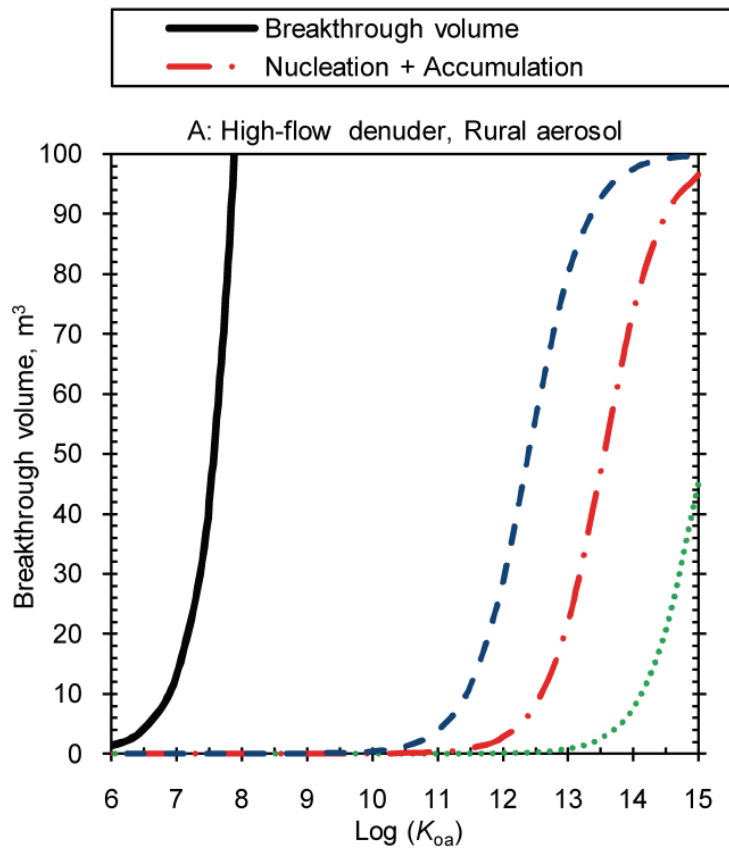

....... Nucleation

- - Nucleation + Accumulation + Coarse
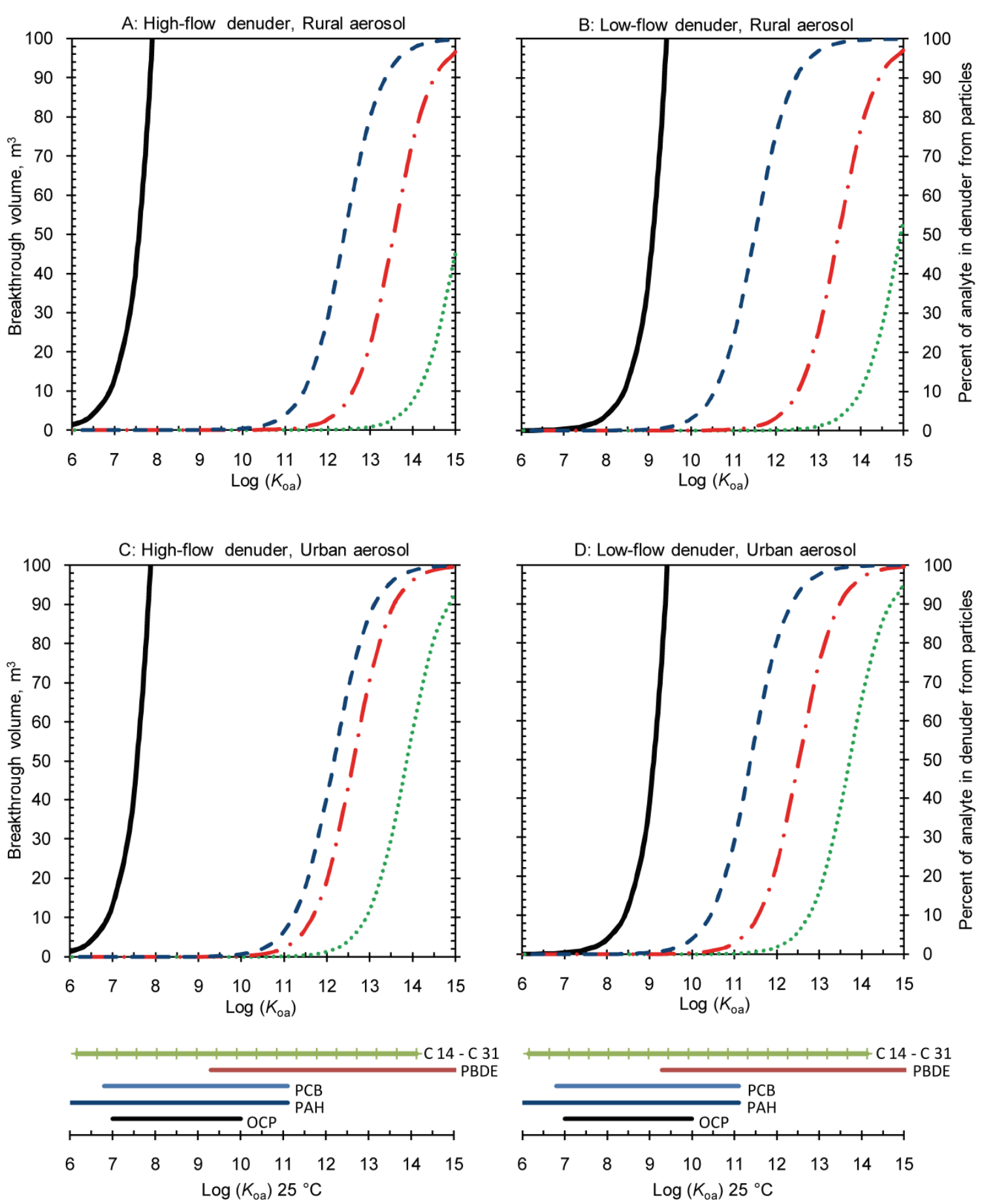
In the Harner and Shoeib model, $f_{\text {om }}$ was assumed to be $0.23,0.20$, and 0.18 for the nucleation, accumulation, and coarse aerosol modes (Offenberg and Baker 1999). These values of $f_{\text {om }}$ result in a relatively uniform distribution of SOC mass fraction over fine and coarse particle modes, although $f_{\text {om }}$ could be manipulated in the model to estimate $f_{\mathrm{d}}$ for SOCs that are not uniformly distributed among fine and coarse particles. The various classes of SOCs may favor either fine or coarse particles, depending on their source and $K_{\mathrm{p}}$. SOCs that actively partition between the gas and particle fractions (low $K_{\mathrm{p}}$ ) are likely to be found in both fine and coarse particle modes (Holsen et al. 1991; Kaupp and McLaughlan 2000). SOCs that are almost entirely particle associated are likely to remain with their original source particles, for example association of PBDE 209 with coarse dust particles (Wilford et al. 2008) and association of large molecular mass PAH and PCDD/F with fine combustion particles (Kaupp and McLaughlan 2000).

Breakthrough volume and $f_{\mathrm{d}}$ values are a function of SOC $K_{\mathrm{pdms}}$ and $K_{\mathrm{p}}$, respectively, which are related to the common scale of $K_{\mathrm{oa}}$ here (a relationship that is expected to hold for nonpolar SOCs only). The SOC volatility range over which a denuder can be used to separate gaseous and particle-associated SOCs and to collect gaseous SOCs is limited in the low- $K_{\text {pdms }}$ extreme by breakthrough volume and in the high- $K_{\mathrm{p}}$ extreme by $f_{\mathrm{d}}$. This relationship can be used to create a window of effective phase separation and gaseous SOC collection with a particular denuder, as illustrated in Figure 3.3 for the high- and low-flow denuders. In Figure 3.3, the relationship $\log \left(K_{\text {pdms }}\right) \approx \log \left(K_{\text {oa }}\right)-1$ was assumed for breakthrough volume calculation. The breakthrough volume curve is shifted to the left for the high-flow denuder, relative to the low-flow denuder, while $f_{\mathrm{d}}$ values are similar for the two, meaning that the high-flow denuder can sample over a wider range of SOC $K_{\text {pdms }}$ and $K_{\mathrm{p}}$ values. Ranges of $K_{\mathrm{oa}}$ values for classes of SOCs are shown in Figure 3.3 for reference (C14 - C31 n-alkanes (Pharma Algorithms 2006), mono - octa CBs, OCPs, one to five ring PAHs (Beyer et al. 2002), and tri-deca BDE (Harner and Shoeib 2002; Rowe 2009, p.30).

At $25^{\circ} \mathrm{C}$, the high-flow denuder can sample most PCBs, OCPs, PAHs, and lower- $K_{\mathrm{p}}$ PBDEs at $20 \mathrm{~m}^{3}$ breakthrough volume or higher and less than $10 \% f_{\mathrm{d}}$. The low-flow denuder is more limited in terms of breakthrough volume for lower- $K_{\mathrm{pdms}} \mathrm{SOCs}$. The 
low-flow denuder is best applied when SOC mass is measurable in a sample of a few cubic meters, or when higher- $K_{\text {pdms }}$ SOCs are the target analytes and $f_{\mathrm{d}}$ is not a concern. The cumulative contribution of each aerosol mode to $f_{\mathrm{d}}$ is plotted separately in Figure 3.3. It is apparent that the SOC volatility range over which artifact-free sampling can be conducted with the denuders can be expanded by excluding the coarse aerosol mode with an impactor or appropriate inlet design; however, a fraction of analyte in the sample may be lost unless the contents of the impactor are included in the analysis. 


\section{Performance of a high flow rate, thermally-extractable multicapillary denuder for atmospheric semivolatile organic compound concentration measurement $^{3}$}

\subsection{Abstract}

A high flow rate $\left(300 \mathrm{~L} \mathrm{~min}^{-1}\right)$ multicapillary denuder was designed for measurement of trace atmospheric semivolatile organic compounds (SOCs). The denuder is coated with a re-usable, cross-linked and bonded polydimethylsiloxane stationary phase as a nonselective absorbent for SOCs. A solvent-free thermal desorption method was developed, including sample cleanup, that transfers the entire sample into the gas chromatograph to minimize the sampling time required to collect a detectable analyte mass. Trace concentrations $\left(0.1-100 \mathrm{pg} \mathrm{m}^{-3}\right)$ of polychlorinated biphenyls and hexachlorobenzene were measured in the atmosphere at a rural location near Lake Superior in sample times of 3.2 to $6.2 \mathrm{hr}$. Overall method precision was determined using field duplicates and compared to the conventional high-volume sampler method. Method precision (coefficient of variation) of $16 \%$ was found for the high-flow denuder compared to $21 \%$ for the high-volume method. The relative difference between the two methods was $25 \%$, with the high-flow denuder method giving generally lower concentrations. The high-flow denuder is an alternative to high-volume or passive samplers when it is desirable to separate gaseous from particle-associated SOCs upstream of a filter. Sample collection times comparable to, or shorter than, high volume sampling are possible, which is advantageous for studies that require high temporal resolution.

\footnotetext{
3 This chapter is based on material that was submitted for publication as M. D. Rowe and J. A. Perlinger (2009). Performance of a high flow rate, thermally-extractable multicapillary denuder for atmospheric semivolatile organic compound concentration measurement. Environ. Sci. Technol. in review.
} 


\subsection{Introduction}

Semivolatile organic compounds (SOCs) partition between gas and particleassociated fractions in the atmosphere. SOCs include chemicals that originate from natural and anthropogenic surface sources, or that are produced in the atmosphere as a result of oxidation processes, for example alkanes, alkenes, aromatic hydrocarbons, carbonyls, carboxylic acids, and organic nitrates (Atlas et al. 1993; Fischer et al. 2002). SOCs also include chemicals that are persistent, bioaccumulative, and toxic (PBT), such as polycyclic aromatic hydrocarbons (PAHs), polybrominated diphenyl ethers (PBDEs), organochlorine pesticides (OCPs), and polychlorinated biphenyls (PCBs). Atmospheric SOCs are of current scientific interest not only for their participation in secondary organic aerosol formation (Robinson et al. 2007), with implications for human health and climate (Fuzzi et al. 2006), but also with respect to transport and deposition of PBTs.

Conventional sampling methods for trace atmospheric SOCs, such as high-volume air sampling (Bidleman and Olney 1974; Doskey and Andren 1979),collect the particleassociated fraction on a filter upstream of a sorbent bed that collects the gaseous fraction. This approach suffers from artifacts caused by volatilization of SOCs from particles on the filter, adsorption of gaseous SOCs onto the filter, or reaction of collected SOCs with oxidizing species (Mader et al. 2001; Goriaux et al. 2006; Arp et al. 2007). Polyurethane foam passive samplers have become established as an alternative to high-volume samplers for sampling periods of weeks to months. Quantitative determination of concentrations using passive samplers is complicated by the fact that gaseous and fine particle-associated analytes are sampled at different rates, which depend on meteorological variables, while coarse particles are excluded (Klanova et al. 2008). Denuders followed by filters have been developed as an alternative to minimize artifacts produced by the conventional filter-sorbent bed sampler (Krieger and Hites 1992; Gundel et al. 1995; Eatough 1999; Mader et al. 2001; Tobias et al. 2007; Rowe and Perlinger 2009c).

Here, development of a high flow rate (high-flow) multicapillary diffusion denuder (Figure 4.1) is described, along with associated devices, and methods for measurement 
of trace atmospheric SOC concentrations that offer several advantages over existing technology (Perlinger and Rowe 2009). Some sorbents used in denuders are not amenable to analysis of gaseous analytes, for example charcoal (Eatough 1999), while XAD resin requires solvent extraction and is not compatible with thermal desorption (Mader et al. 2001; Goriaux et al. 2006). We used cross linked and bonded polydimethylsiloxane (PDMS) as a non-selective absorbent in the denuder, which offers several advantages over adsorbents such as carbon or XAD: 1) analytes are lightly-bound and can be extracted by thermal desorption, 2) the denuder can be re-used many times without recoating, 3) collection of water is minimized because PDMS is very hydrophobic (Baltussen et al. 2002; Rowe and Perlinger 2009a), 4) analytes absorbed into PDMS are better protected from atmospheric oxidants than analytes collected on adsorbents (Baltussen et al. 2002), and 5) competition for limited surface sites and non-linear isotherms complicate breakthrough prediction for adsorbents, while retention in a liquid phase such as PDMS can be modeled using chromatographic theory (Baltussen et al. 2002; Rowe and Perlinger 2009c). Thermal desorption avoids the use of expensive, highpurity solvents and associated waste generation during sample preparation. Thermal desorption enables transfer of the entire sample into the gas chromatograph (GC), resulting in reduced sampling times to collect a detectable analyte mass relative to samplers that require solvent extraction; in solvent extraction, only a small fraction $(1 / 10$ to $1 / 100$ ) of the sample extract is typically injected into the GC at a time. Reduced sample collection time enables experimental flexibility to study phenomena at time scales comparable to (Rowe and Perlinger 2009a) or shorter than (Perlinger et al. 2005; Perlinger and Rowe 2008) the typical 12 to 24 hour sample times of high-volume samplers. 


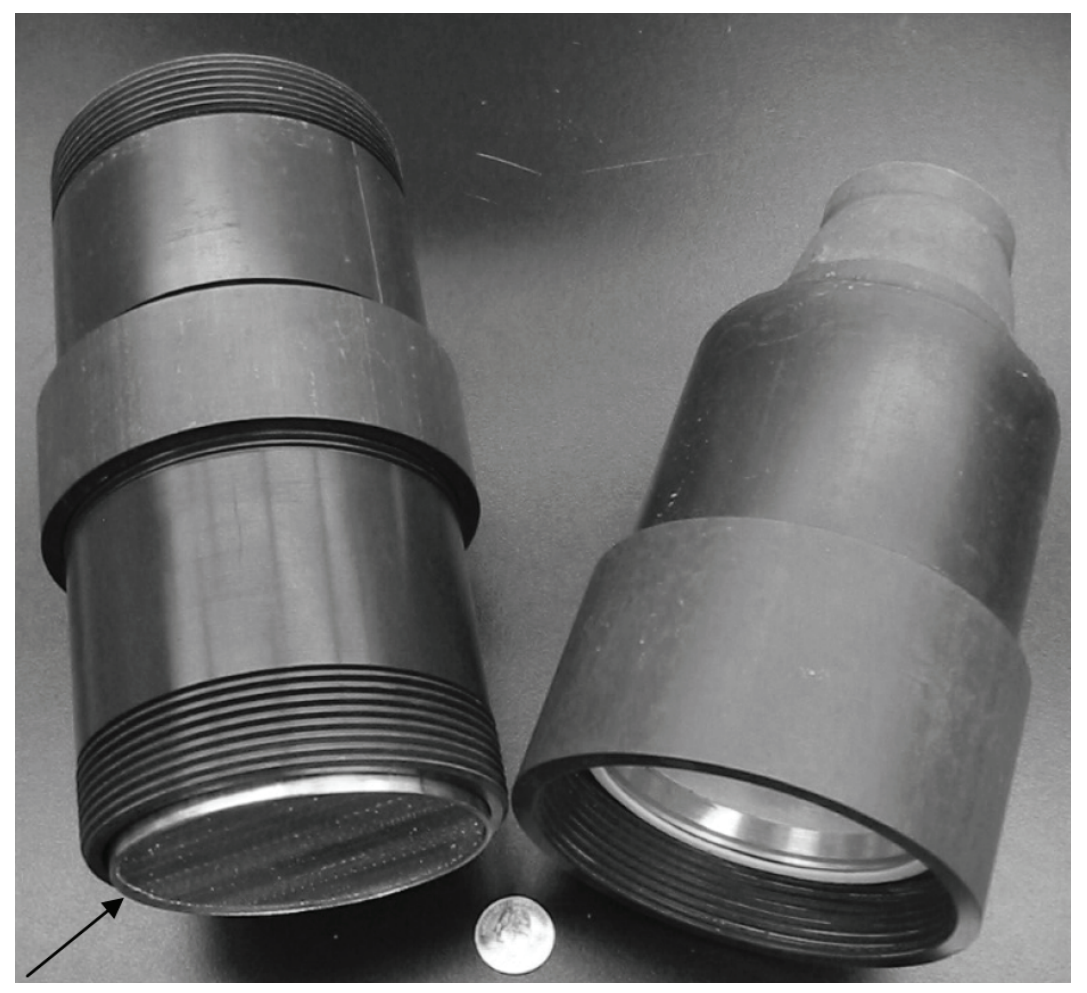

Figure 4.1: Two high-flow denuders in series (left) and filter assembly (right) inside the anodized aluminum sleeve. The $102-\mathrm{mm}$ dia. high-flow denuder is indicated by the arrow. 
In this paper, methods are described for fabrication of the high-flow denuder, as well as extraction and analysis of high-flow denuder samples. The level of data quality that was achieved in measurement of trace atmospheric PBT concentrations in a rural location is reported, and method performance relative to co-located samples collected independently by the Integrated Atmospheric Deposition Network (IADN) Project by high-volume air sampling is evaluated. In Chapter 4, a method is described to predict gas and particle collection efficiency for multicapillary denuders and measured gaseous breakthrough and particle transmission are reported for the high-flow and previouslydeveloped low-flow denuder (Rowe and Perlinger 2009c).

\subsection{Experimental Methods}

\subsubsection{High-flow multicapillary denuders}

High-flow denuders were fabricated by pressing a honeycomb (welded type 304 stainless steel, 0.05-mm foil, 1.04-mm largest-dimension hexagonal cell dia., 51-mm deep, 100-mm dia., Quality Honeycomb, Arlington, TX) into a stainless steel tube (54mm deep, 102-mm dia., 1.59-mm wall thickness). After assembly, the honeycombs were deactivated (Sulfinert, Restek, Bellefonte, PA). Two honeycomb assemblies were stacked in the sampler to make one 102-mm.-deep denuder. One denuder was fabricated using a cordierite ceramic honeycomb (1.3 mm square cell, 76-mm deep, Applied Ceramics, Doraville, GA), which was inserted into a stainless steel sleeve and Sulfinert deactivated.

The denuders were coated with PDMS (RTX-1, Restek). A $0.1 \mathrm{~g} \mathrm{~mL}^{-1}$ solution of PDMS was prepared in a 1-L volumetric flask by dilution with pentane (B\&J 99.9 \%, VWR). Dicumyl peroxide (98\%, Sigma-Aldrich) was added to the pentane solution at $2.5 \mathrm{mg} \mathrm{mL}^{-1}$ as a crosslinking agent just prior to coating. Denuders were coated in a dry glovebox ( $<10 \%$ relative humidity). Prior to coating, denuders were heated under flowing helium $\left(320^{\circ} \mathrm{C}, 20 \mathrm{~min}\right.$.) to remove adsorbed moisture, then transferred into the glovebox without exposure to the atmosphere. Helium (99.999\%) was purified using a water, oxygen, and hydrocarbon trap (RMSHY-4, Agilent Technologies). Denuders were dipped into the PDMS solution. Excess solution was blown out of the honeycomb cells 
with a jet of nitrogen. Two dips were needed to obtain the target $5-\mu \mathrm{m}$ coating thickness, determined by mass gain and an estimated surface area of $1.48 \mathrm{~m}^{2}$ for the $51-\mathrm{mm}$ deep honeycomb. PDMS was removed from the outside surface of the honeycomb by wiping with a pentane-soaked tissue. Denuders were cured under flowing helium $\left(2 \mathrm{~L} \mathrm{~min}^{-1}\right)$ in a stainless steel foil bag for $20 \mathrm{~min}$. at room temperature, $2 \mathrm{hr}$. at $40{ }^{\circ} \mathrm{C}, 1.5 \mathrm{hr}$. at $140{ }^{\circ} \mathrm{C}$, $12-16 \mathrm{hr}$. at $320^{\circ} \mathrm{C}$, and cooled under helium purge. To remove non-crosslinked polymer residue, each honeycomb was placed in a metal can with $750 \mathrm{~mL}$ of dichloromethane (B\&J 99.9\%, VWR Scientific), then turned end-over-end for ten minutes. Excess solution was removed with a jet of nitrogen. Prior to use, denuders were thermally extracted and checked for blank response levels. Denuders were stored in sealed metal cans that had been combusted in air at $450{ }^{\circ} \mathrm{C}$ for $6 \mathrm{hr}$.

\subsubsection{High-flow denuder hot-spike device}

A hot-spike device was designed to introduce surrogate standards into the high-flow denuders. Use of hot-spike devices has been described previously (Tobias et al. 2007; Rowe and Perlinger 2009a). It was necessary to modify the design used with low-flow denuders to include a mixing chamber to distribute analytes uniformly over the $102-\mathrm{mm}$ dia. denuder and to cool the gas from the injection zone by dilution (Figure D1). All surfaces upstream of the denuder were deactivated stainless steel (Sulfinert, Restek), and were heated to prevent condensation of analytes. The carrier gas was nitrogen (99.999\%) and contamination in the gas system was minimized using procedures described elsewhere (Rowe and Perlinger 2009a). A 10-mm thick aluminum sleeve held the denuder in place below the hot-spike device and was a heat sink. Hot-spike procedure: injection zone at $300{ }^{\circ} \mathrm{C}$ and flow rate of $160 \mathrm{~mL} \mathrm{~min}^{-1}$, mixing chamber at $230{ }^{\circ} \mathrm{C}$ and flow rate of $4 \mathrm{~L} \mathrm{~min}^{-1}$, flush device for $30 \mathrm{~s}$, load denuders and flush for $1 \mathrm{~min}$., inject standards and flush for $5 \mathrm{~min}$., return denuders to sealed metal can.

\subsubsection{Air sample collection}

Denuders were assembled for sample collection in anodized aluminum sampler sleeves (Figure 4.1). Rain cover inlets (Figure 4.2) were designed after Liu and Pui 
(1981) to maximize coarse-particle transmission. A custom-fabricated aluminum filter holder held the 102-mm dia. quartz fiber filter (Tisch Environmental, Cleves, OH). Filters were pre-combusted at $450{ }^{\circ} \mathrm{C}$ for $6 \mathrm{hr}$. In this investigation, two 102-mm deep denuders in series, placed upstream of the filter, were used to investigate denuder collection efficiency. Filters were not analyzed as part of this investigation. The sampling train was sealed using PTFE and Viton gaskets under compression from the threaded aluminum sampler sleeves. Prior to sampling, the sampler sleeves were cleaned by sonication in a dilute detergent solution (Cole Parmer Micro-90) followed by triple rinse in hot water. Sampler sleeves were sealed in clean polyethylene bags prior to use.

A sample flow rate of $300 \mathrm{~L} \mathrm{~min}^{-1}$ was provided using a mass-flow controlled vacuum motor assembly that was calibrated using a calibrated orifice (Tisch Environmental, TE1004 vacuum, TE300-313 controller, and TE5040A orifice). After assembly, the sample train was checked for leakage by measuring the flow rate with the vacuum on and the sampler inlet capped. Temperature and relative humidity were measured (HMP45C, Vaisala), and recorded at the same 1-min averages as flow rate during sampling. Sample volume was calculated from the flow rate record, and reported at standard conditions of $25^{\circ} \mathrm{C}, 1 \mathrm{~atm}$. Samples were stored at $4{ }^{\circ} \mathrm{C}$ after collection in pre-combusted, sealed metal cans.

Samples were collected at two locations: the IADN Project monitoring site at Eagle Harbor, MI and the roof of the Dow Environmental Sciences and Engineering Building (DESE Bldg.) on the campus of Michigan Technological University in Houghton, MI. Samples were collected in duplicate and two field blanks were included with each field experiment. Field blanks were subjected to identical processing steps as samples, including assembly and disassembly at the sampling site, with the exception that air was not drawn through the blank denuders. 


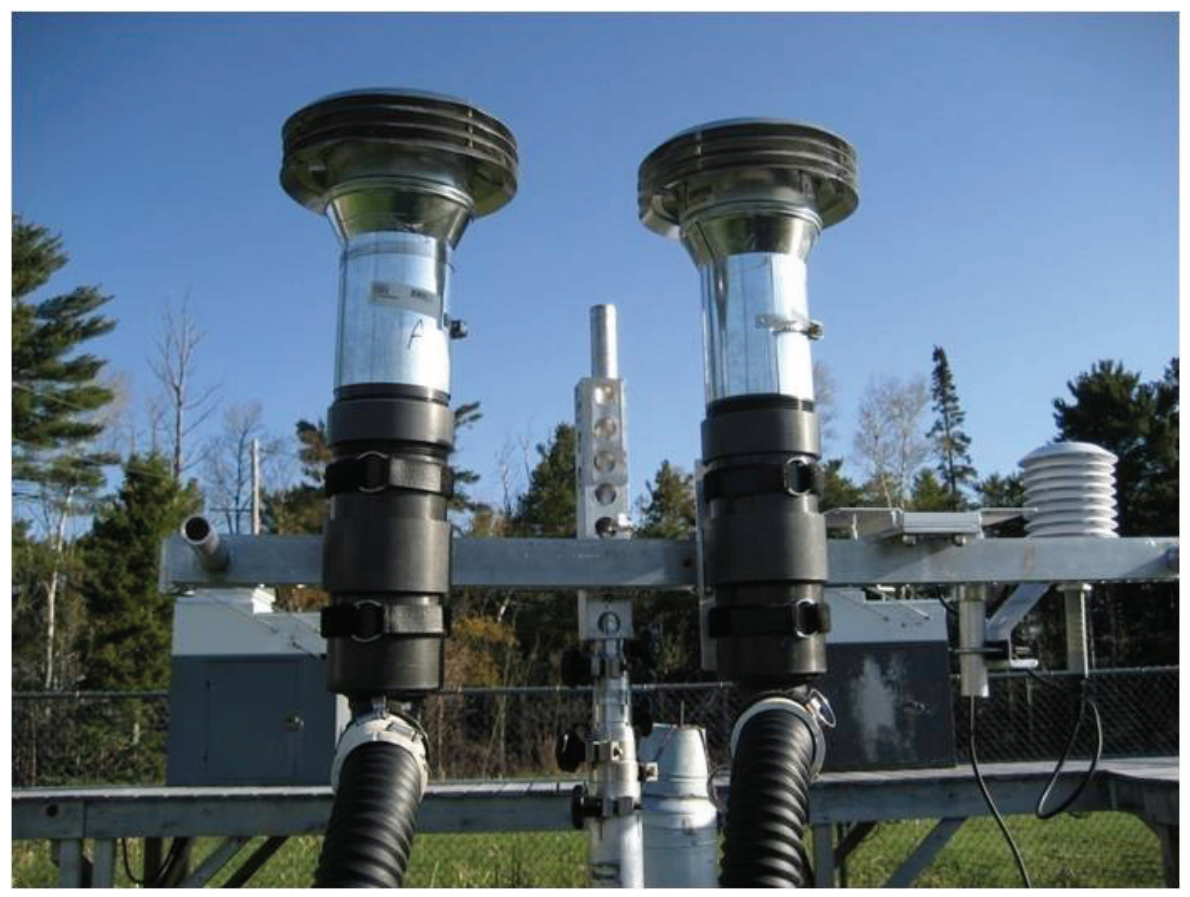

Figure 4.2: High-flow denuder sample collection at Eagle Harbor, MI 


\subsubsection{Analyte transfer apparatus (ATA)}

The ATA was designed to perform a quantitative thermal extraction of analytes from the high-flow denuders and transfer them into a cooled thermal desorption (TD) tube. The ATA consists of a cylindrical pressure vessel made of deactivated (Sulfinert, Restek) stainless steel (Figure D2). A denuder is loaded into the ATA using a flange at the top of the ATA. The flange is extended outside of the heated zone to minimize the thermal mass of the heated zone and to allow use of an elastomer seal (Viton O-ring) in the flange. Carrier gas flows downward through a narrow annular section to minimize upward migration of analytes, cool the flange, and preheat carrier gas. Carrier gas flows through the denuder and carries analytes into a water-cooled $\left(15^{\circ} \mathrm{C}\right)$ thermal desorption (TD) tube attached to the ATA outlet. Residual moisture collected with the sample passes through the TD tube during the ATA transfer, and is not significantly retained (Rowe and Perlinger 2009a).

ATA transfer was initiated by loading a denuder into the ATA so that the flow direction was opposite that of sample collection. The ATA was purged with nitrogen carrier gas $\left(2 \mathrm{~L} \mathrm{min.}{ }^{-1}\right)$ at room temperature for $15 \mathrm{~min}$. to remove oxygen. With gas flowing, a TD tube was attached to the ATA outlet using a union fitting and graphite ferrule. The union was wrapped with insulation to avoid condensation of analytes. Temperature controllers for the heating mantles were set to $250^{\circ} \mathrm{C}$ for the upper (inner and outer) zones, while the lower zone surrounding the denuder was set to $230^{\circ} \mathrm{C}$. The extraction was conducted for $30 \mathrm{~min}$. from the time the heaters were turned on. With the gas still flowing, the TD tube was removed and capped, the ATA outlet was capped, and the outer heating mantle was removed from the ATA to accelerate cooling.

\subsubsection{Analytical method}

The analytical method, TD tube, instrument calibration, data post-processing and quality assurance were described in detail elsewhere (Rowe and Perlinger 2009c). Briefly, the sample was processed through a novel gas-phase cleanup method consisting of thermal elution through silica gel to remove the atmospheric background matrix of oxidized organic compounds while nonpolar analytes were quantitatively transferred into 
a cooled TD tube. Analysis was conducted by $\mathrm{GC}-\mu \mathrm{ECD}$. Prior to sample collection, denuders were spiked with a solution containing surrogate standards (PCBs 14, 65, 166, and PBDE 104) in hexane. After cleanup and prior to transfer into the GC, the TD tube containing the sample was hot-spiked with an internal standard (IS) mixture (PCBs 30, 155, and 204). For all reported concentrations, the analyte mass in the blank was less than $20 \%$ of the analyte mass in the sample, and the analyte mass in the sample was greater than the method detection limit (MDL). Reported concentrations were field blanksubtracted. MDLs were determined by hot-spiking standards into denuders prepared for air sampling at $\sim 5$ times the instrument detection limit. The denuders were processed through the method, and analyte mass was determined as for a sample. Standard deviations of mass determinations in seven replicates were calculated. The MDL for each analyte was determined by multiplying the standard deviation by the one-sided $99 \% \mathrm{t}$ statistic for $\mathrm{n}=7$ (3.00). The quantification limit (QL) was three times the MDL.

\subsubsection{Bias and precision relative to high-volume sampling}

The IADN Project provided 2008 data for the Eagle Harbor station prior to completion of their normal quality assurance analysis. To ensure the quality of these data, we verified that surrogate recoveries met the $50-130 \%$ IADN Project objective (Wu et al. 2009), and we excluded concentrations less than the limit of detection (LOD $=$ mean + $3 \times$ std. dev. of field blanks for the station and year; U.S. EPA and Environment Canada 2001, App. G Eq. 3-11). We adjusted IADN Project sample volumes to standard conditions of $25^{\circ} \mathrm{C}, 1 \mathrm{~atm}$. prior to calculation of concentration from the reported mass.

To compare high-flow denuder concentrations to those obtained by the high-volume sampler method of the IADN Project, it was necessary to match common analytes between the two methods. The IADN Project monitors 84 PCB congeners that are considered to make up the majority of PCB mass in air (Blanchard et al. 2004). The highflow denuder method included 130 PCB congeners selected to represent the major constituents of the Aroclor products (Table D.1). All but seven of the IADN PCB analytes (PCBs 47, 76, 89, 126, 169, 171, and 201) were included in the high-flow

method. None of these seven had $>30 \%$ frequency of detection ( $>$ LOD), and none had 
an annual geometric mean concentration $>1 \mathrm{pg} \mathrm{m}^{-3}$, compared to an annual geometric mean sum of PCB concentration of 34 to $50 \mathrm{pg} \mathrm{m}^{-3}$ for the same time period (Eagle Harbor 2003 to 2007, annual statistics provided by the IADN Project). HCB and individual PCB congeners that were resolved in both methods, and resolved congeners that could be added to match a co-eluting group, were selected for comparison $(n=30)$. In addition, ten analyte groups were included that were frequently detected in the IADN Project data, but co-eluted with one or two congeners in the high-flow method that were not included in the IADN Project method. The IADN Project suite was selected to represent the most abundant congeners in air, so it was assumed that the additional congeners included in the high-flow suite were relatively less abundant and would have minimal influence on the comparison. The paired analyte groups are listed in Table D.2.

Bias and precision were evaluated using statistical methods that have been used by others to assess air quality measurement methods (Sirois and Vet 1999; Allan 2004; Wu et al. 2009). High-flow denuder samples were collected concurrently with IADN Project high-volume samples on three dates (19 May, 17 July, and 29 July, 2008) at Eagle Harbor, MI. High-flow samples were collected in duplicate on all three dates, but one of the 29 July samples was lost due to a laboratory error. Five paired high-flow, highvolume samples were made by pairing the single high-volume sample with each of the duplicate high-flow samples on 19 May and 17 July and pairing the two single samples on 29 July. Between method bias was evaluated after the procedure described by Allan (2004, p. 96). The difference in concentration for paired analyte groups between colocated high-flow denuder and high-volume samplers was calculated as $\Delta C_{\mathrm{i}}=C_{D \mathrm{i}}-C_{H \mathrm{i}}$, where $C_{D \mathrm{i}}$ is the high-flow denuder concentration, and $C_{H \mathrm{i}}$ is the high-volume sampler concentration for analyte $i$ in a paired sample. The frequency distribution of $\Delta C_{\mathrm{i}}$ for all samples and analytes was tested for normality using the Lilliefors test. The distributions were found to be non-normal, so the non-parametric sign test was used to determine whether the median of $\Delta C_{\mathrm{i}}$ was significantly different from zero. The bias was then expressed as the relative difference: median $\left(\Delta C_{\mathrm{i}}, \ldots, \Delta C_{\mathrm{n}}\right) / \operatorname{median}\left(\left(C_{D \mathrm{i}}+C_{H \mathrm{i}}\right) / 2, \ldots,\left(C_{D \mathrm{n}}\right.\right.$ $\left.\left.+C_{H \mathrm{n}}\right) / 2\right) \times 100 \%$. 
The overall precision for each method was determined after the procedure described by Allan (2004, p. 92) using field duplicate samples (two identical samplers operated side-by-side using the same method). Three pairs of field duplicates were available for the high-flow denuder and 17 pairs of duplicates, representing the most recent five years at Eagle Harbor, MI (2003 to 2007), were selected from the data provided by the IADN Project. The between sampler error was calculated as $e_{\mathrm{i}}=1 / \sqrt{ } 2 \times\left(C_{1 \mathrm{i}}-C_{2 \mathrm{i}}\right)$ where $C_{1 \mathrm{i}}$ and $C_{2 \mathrm{i}}$ are the Sampler 1 and Sampler 2 concentrations for analyte $i$ in a field duplicate sample. The overall precision, defined as the spread of the $e_{\mathrm{i}}$ values was quantified using the modified median absolute deviation, $\operatorname{MMAD}=\operatorname{median}\left(\left|e_{\mathrm{i}}-\mathrm{M}\right|, \ldots,\left|e_{\mathrm{n}}-\mathrm{M}\right|\right) / 0.6745$, where $\mathrm{M}=\operatorname{median}\left(e_{\mathrm{i}}, \ldots, e_{\mathrm{n}}\right)$. The MMAD is a robust non-parametric estimator of the spread of a distribution that is a consistent estimator of the standard deviation if the data are normally distributed, and is relatively insensitive to extreme values for non-normally distributed data (Sirois and Vet 1999). The overall precision was also expressed in a normalized form as the non-parametric coefficient of variation, $\mathrm{CoV}=100 \% \times \mathrm{MMAD} /$ median $\left(\left(C_{1 \mathrm{i}}+C_{2 \mathrm{i}}\right) / 2, \ldots,\left(C_{1 \mathrm{n}}+C_{2 \mathrm{n}}\right) / 2\right)$, a measure of the spread of $e_{\mathrm{i}}$ at the median concentration.

For the purpose of statistical comparison, each analyte within each sample was treated as an independent measurement. SOC concentration measurement error originates from three contributions: 1) analytical method and calibration, 2) chemical interferences, and 3 ) sampling differences (Wu et al. 2009). Differences in analytical method and chemical interferences can be expected to affect each analyte independently, while sampling errors, such as error in the sample volume, may affect all analytes in a sample similarly. Thus, treating each analyte in each sample as an independent measurement is equivalent to the assumption that the majority of measurement error originates from variables that affect each analyte independently; we discuss the validity of this assumption further below. 


\subsection{Results and Discussion}

\subsubsection{Surrogate recoveries and detectable analyte mass}

With only a few exceptions, surrogate recoveries for standards hot-spiked into highflow denuders and field blanks were between 80 and $120 \%$ (Figure 4.3 A, B), indicating that analytes can be quantitatively recovered through the method. There was greater variability in surrogate recoveries in the presence of the sample matrix; however, all surrogate recoveries were within the 50 to $130 \%$ data quality objective of the IADN Project high-volume sampling method (Wu et al. 2009), except for PBDE 104 in some back denuders (Figure 4.3 C, D), and 27 out of 33 PCB surrogate recovery values met the 75 to $125 \%$ data quality objective of this study (Perlinger 2008). Median surrogate recoveries for samples were 94, 88, 91, and $74 \%$ for PCBs 14, 65, 166, and PBDE 104, respectively (Figure $4.3 \mathrm{C}$ ).

A design objective of the high-flow denuder was the ability to collect a sample in a shorter period of time than existing methods. To evaluate performance relative to this objective, the number of analytes detectable in a two-hour sample was estimated for three methods. Median concentrations of PCBs and HCB measured by the IADN Project for 2000 to 2005 at Eagle Harbor, MI, were assumed. Method detection limits for highvolume sampling (567 L min ${ }^{-1}$ flow rate) reported by Bandemehr et al. (1997, Table II-2), and by Rowe and Perlinger (2009a) for the high-flow denuder (300 L min ${ }^{-1}$ flow rate), and low-flow denuder (13 L min ${ }^{-1}$ flow rate), respectively, were applied. Under these conditions, the high-flow denuder would collect a detectable mass of 35 analytes, versus 24 for the high-volume sampler, and 5 for the low-flow denuder. 

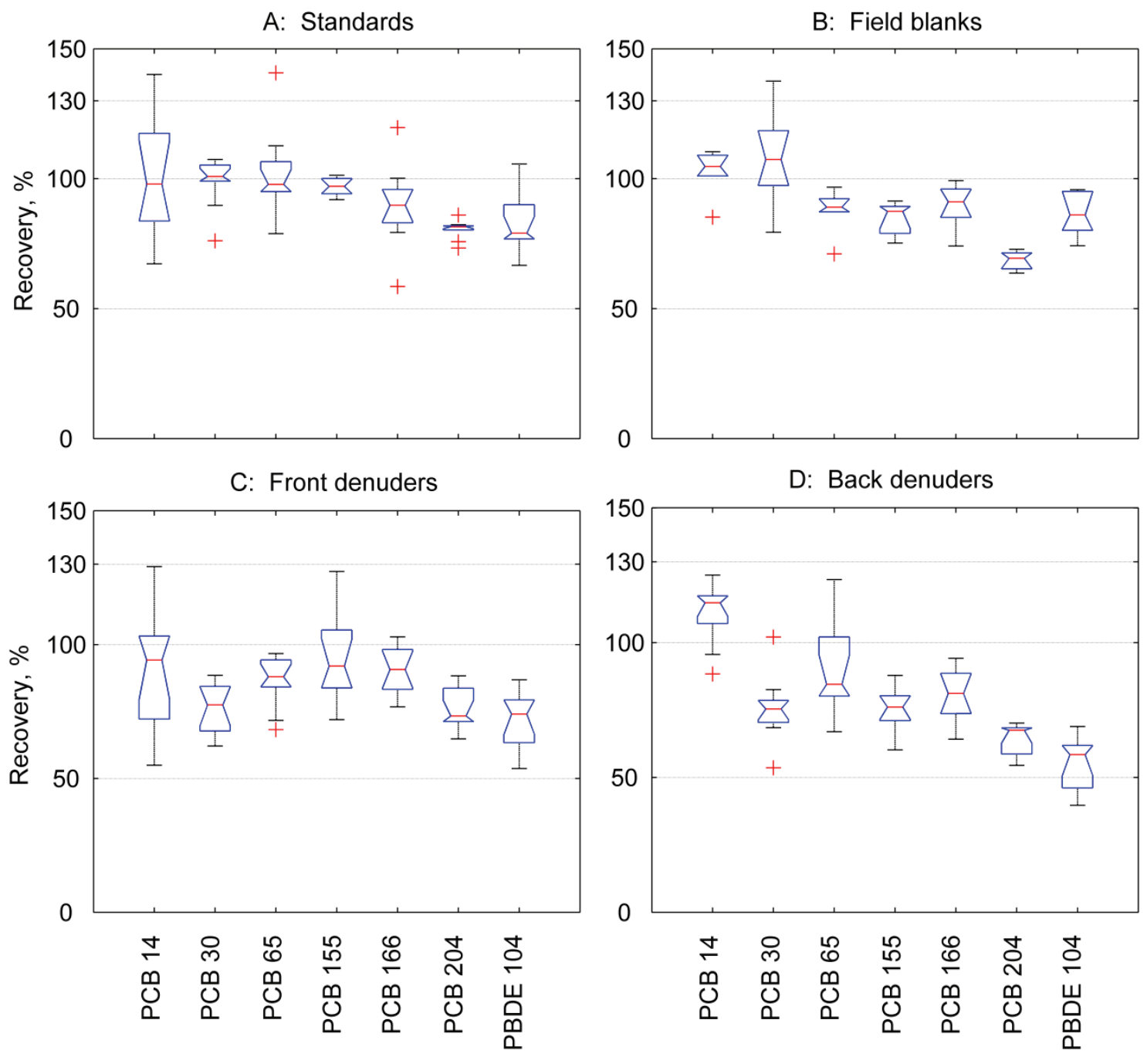

Figure 4.3: Recovery of surrogate standards (PCBs 14, 65, 166, and PBDE 104) hot-spiked into high-flow denuders with $(C, n=11 ; D, n=10)$ and without $(A, n=10 ; B, n=6)$ subsequent sample collection, and internal standards (PCBs 30,155, and 204) hotspiked subsequent to sample collection. The y-axis scales were set to indicate data quality objectives for surrogate recoveries of $50-130 \%$ for similar samples collected by high-volume sampler (Wu et al. 2009). 


\subsubsection{Trace atmospheric PCB and HCB concentrations}

The performance of the high-flow denuder was evaluated by measuring trace atmospheric PCB and HCB concentrations at the rural site of Eagle Harbor and the nearby city of Houghton (county population 30 000), both located in Northern Michigan (Figure 4.4). Samples were collected on six dates, three at each location, in May through August of 2008. The analytes were ranked in order of decreasing median concentration, and those having median concentrations $\geq 1.0 \mathrm{pg} \mathrm{m}^{-3}$ are included in Table 4.1. Concentrations for all analytes are presented in Table D.1.

The mean sum of PCB concentration was greater at Houghton than at Eagle Harbor (t-test assuming log-normal distribution, $P=0.02$ ), while the mean HCB concentration was not significantly different for the two locations $(P=0.92)$. Older buildings in the area are a continuing source of PCBs to the atmosphere (Rowe and Perlinger 2009a), which may contribute to the greater PCB concentrations observed at Houghton than at Eagle Harbor. Air parcel back-trajectories (Draxler et al. 2009) indicated that sampled air originated from the North on two dates and from the South on one date at each location. At both sites, air originating from more highly-populated areas to the South was associated with greater PCB concentrations than air originating from less-populated areas to the North (Figure 4.4). 


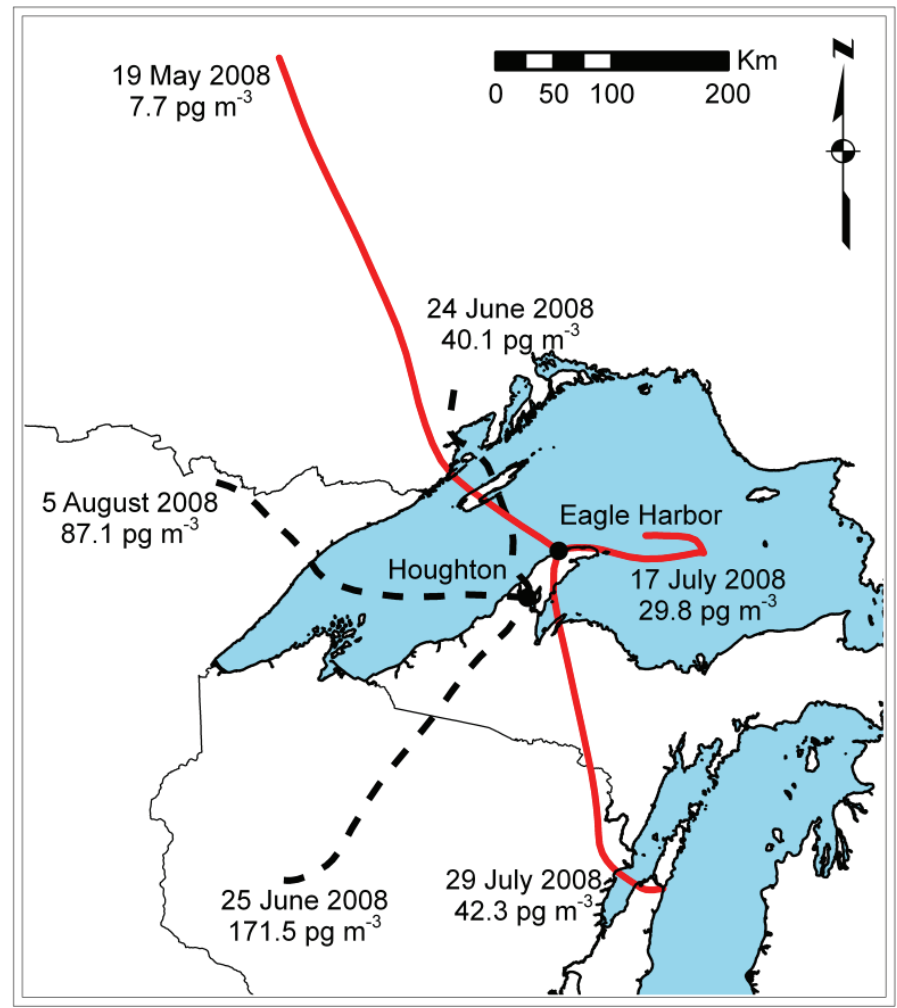

Figure 4.4: Map showing Lake Superior, Northern Lake Michigan, and sampling locations at Eagle Harbor and Houghton, Michigan. Air parcel back trajectories (24-hr) are indicated with the associated sample date and sum of PCB concentration. 
Table 4.1: Sample conditions, $\mathrm{HCB}$ and PCB concentrations ${ }^{\mathrm{a}}$ (pg m $\mathrm{pt}^{-3}$ at $25^{\circ} \mathrm{C}, 1 \mathrm{~atm}$.) for high-flow denuder samples collected at Eagle Harbor (EH) and Houghton (H), MI in 2008

\begin{tabular}{|c|c|c|c|c|c|c|c|c|c|}
\hline Sample location & $\mathrm{EH}$ & EH & H & H & $\mathrm{EH}$ & EH & EH & H & H \\
\hline \multirow[t]{2}{*}{ Date } & 19 & 19 & 24 & 25 & 17 & 17 & 29 & & \\
\hline & May & May & Jun. & Jun. & Jul. & Jul. & Jul. & 5 Aug. & 5 Aug. \\
\hline Volume, $\mathrm{m}^{3}$ & 56.8 & 59.0 & 67.9 & 76.8 & 109.4 & 111.6 & 73.1 & 70.1 & 66.3 \\
\hline Sample time, $\mathrm{hr}$ & 3.2 & 3.3 & 3.8 & 4.3 & 6.1 & 6.2 & 4.1 & 3.9 & 3.7 \\
\hline Start time, EDT & 0600 & 0600 & 1430 & 1430 & 2340 & 2230 & 1600 & 1530 & 1530 \\
\hline Temp., o-C & 4.5 & 4.5 & 11.8 & 20.0 & 13.6 & 13.6 & 24.9 & 24.1 & 24.1 \\
\hline Rel. humid., \% & 79.3 & 79.3 & 94.6 & 74.2 & 99.7 & 99.7 & 71.8 & 52.5 & 52.5 \\
\hline $\mathrm{HCB}$ & 55.7 & 69.2 & 68.5 & 95.9 & 104.9 & 78.0 & 66.4 & 66.7 & 69.0 \\
\hline РСB 18 & $<0.9$ & & 7.6 & 19.2 & 4.1 & 2.6 & 5.6 & 9.0 & 9.0 \\
\hline PCB 6 & $<0.4$ & $<0.4$ & 6.6 & 10.9 & 10.1 & 7.9 & 5.1 & 6.1 & 6.8 \\
\hline РCB 48 & 5.9 & $<0.2$ & $<0.2$ & $<0.2$ & 4.1 & 3.5 & $<0.2$ & $<0.2$ & 0.5 \\
\hline РСB 22 & $<1.0$ & $<1.0$ & 0.7 & 4.2 & $<0.5$ & $<0.5$ & 1.3 & 3.0 & 2.9 \\
\hline РCB 52 & $<0.2$ & $<0.2$ & 1.1 & 6.3 & $<0.1$ & $<0.1$ & 1.1 & $<0.2$ & 3.7 \\
\hline PCB 8 & $<0.7$ & $<0.6$ & 2.2 & 12.2 & 0.9 & 0.7 & 2.2 & 4.1 & 4.1 \\
\hline PCB $131+118^{b}$ & $<1.6$ & $<1.6$ & 1.7 & 4.1 & 2.0 & $<0.8$ & 2.2 & $<1.3$ & $<1.4$ \\
\hline PCB $31+53$ & $<0.4$ & $<0.4$ & 2.1 & 13.1 & $<0.2$ & 0.8 & 2.0 & $<0.3$ & 7.2 \\
\hline PCB 17 & $<0.2$ & $<0.2$ & 2.0 & 6.5 & 1.0 & 0.8 & 2.0 & 3.4 & 3.3 \\
\hline PCB 28 & & $<0.2$ & 1.5 & 8.6 & 0.7 & 0.5 & 1.4 & $<0.1$ & 5.2 \\
\hline РCB 95 & $<0.2$ & 0.3 & 1.4 & 7.8 & 0.5 & & 1.3 & 5.2 & 5.5 \\
\hline РСB 70 & $<0.2$ & $<0.2$ & 1.2 & 6.3 & 0.2 & $<0.1$ & $<0.1$ & 1.0 & 1.8 \\
\hline РСB 44 & $<0.7$ & $<0.6$ & 1.1 & 6.6 & 0.8 & 0.4 & $<0.5$ & 3.8 & $<0.6$ \\
\hline PCB $59+42$ & $<0.2$ & 0.4 & 0.7 & 3.3 & 0.3 & $<0.1$ & 1.0 & 2.2 & 2.1 \\
\hline PCB $33+20$ & $<0.5$ & $<0.5$ & 1.1 & 6.0 & 0.4 & $<0.3$ & 0.9 & $<0.4$ & $<0.4$ \\
\hline PCB $40+37^{c}$ & 0.5 & 0.8 & 1.0 & 2.5 & 1.1 & 0.7 & 1.5 & $<0.2$ & 1.6 \\
\hline PCB 136 & $<0.2$ & 0.4 & 0.3 & 0.3 & 1.0 & $<0.1$ & 7.5 & 4.6 & 5.0 \\
\hline РСB 149 & $<0.2$ & 0.4 & 0.6 & 2.7 & $<0.1$ & $<0.1$ & 1.0 & $<0.1$ & 3.1 \\
\hline sum of $P C B{ }^{d}$ & 9.0 & 6.4 & 40.1 & 171.5 & 32.3 & 27.3 & 42.3 & 67.3 & 106.9 \\
\hline
\end{tabular}




\subsubsection{Bias and precision relative to the high-volume sampler}

Bias of the high-flow denuder method relative to the high-volume sampler method was evaluated by comparison of concentrations measured by co-located samplers at Eagle Harbor, MI. PCB and HCB concentrations measured by high-flow denuder tended to be lower than concentrations measured by the high-volume method. The relative difference was $25 \%$, which was significantly different from zero (Table 4.2). Similarly, a previous co-located sampler comparison between the two labs that analyze samples for the IADN Project found gas-phase PCB concentrations measured by the USA laboratory to be higher than (relative difference of $21 \%$ ) concentrations measured by the Canadian laboratory (Wu et al. 2009). This level of agreement is considered to be good in comparison to the data quality objective of the IADN Project of $<100 \%$ overall method relative difference between laboratories (Wu et al. 2009).

Table 4.2: Summary statistics for comparison of PCB and HCB concentrations measured in co-located high-flow denuder and high-volume samplers, and field duplicate precision

\begin{tabular}{|c|c|c|c|c|}
\hline & Units & $\begin{array}{l}\text { High flow - } \\
\text { high volume }\end{array}$ & $\begin{array}{l}\text { High flow - } \\
\text { high flow }\end{array}$ & $\begin{array}{l}\text { High volume - } \\
\text { high volume }\end{array}$ \\
\hline No. of paired samples & -- & 5 & 3 & 17 \\
\hline No. of paired measurements & -- & 70 & 67 & 532 \\
\hline Median concentration & $\mathrm{pg} \mathrm{\textrm {m } ^ { - 3 }}$ & 1.6 & 0.7 & 0.5 \\
\hline Median difference & $\mathrm{pg} \mathrm{\textrm {m } ^ { - 3 }}$ & -0.39 & 0.02 & 0.00 \\
\hline Relative difference & $\%$ & -25.1 & 3.5 & -0.7 \\
\hline Sign test ${ }^{a}$ & $P$ value & $<0.001$ & 0.050 & 0.208 \\
\hline MMAD & $\mathrm{pg} \mathrm{m}^{-3}$ & 1.5 & 0.1 & 0.1 \\
\hline CoV & $\%$ & 97.0 & 16.4 & 21.0 \\
\hline
\end{tabular}


High-flow denuder samples were collected over a subset of the high-volume sample collection period (3.2 to $6.2 \mathrm{hr}$. vs. $24 \mathrm{hr}$.), which may have contributed to lack of agreement if a significant diel trend in concentration occurred. Eagle Harbor high-flow denuder samples were collected in the early morning, night, and afternoon (Table 4.1). Varying sample collection time over hour of the day would have minimized the amount of bias introduced if a consistent diel trend in concentration existed. The magnitude of diel trend in concentration has been observed to decrease with increasing PCB chlorination because both hydroxyl radical reactivity and mass transfer rate coefficient for air-surface exchange decrease with increasing chlorination (Lee et al. 1998; Totten et al. 2002). Thus, if bias was introduced by diel variation in concentration, the magnitude of bias is expected to decrease with increasing PCB chlorination. The opposite trend was observed; relative difference between the two methods increased with decreasing volatility (Table 4.3), providing evidence that bias was not introduced by a diel trend in concentration. It is not likely that the trend in relative difference between methods with volatility was caused by particle-associated artifacts because only the least-volatile class in Table 4.3 was estimated to have a significant particle-associated fraction. The trend is much more apparent in terms of relative difference than in terms of median difference, thus the trend in bias may be a statistical artifact introduced by the decreasing median concentration with decreasing volatility.

Table 4.3: Between-method bias (high flow - high volume) as a function of relative PCB analyte volatility (GC elution order) and percent of total PCB concentration in air associated with particles over the sampling temperature range.

$\begin{array}{llllll} & \begin{array}{l}\text { Median } \\ \text { conc., } \\ \text { pg }^{-3}\end{array} & \begin{array}{l}\text { Median } \\ \text { difference, } \\ \text { pg m }^{-3}\end{array} & \begin{array}{l}\text { Relative } \\ \text { difference, }\end{array} & \begin{array}{l}\text { \% } \\ \text { Earlier-eluting than first tetraCB }\end{array} & \begin{array}{l}\text { Percent } \\ \text { particle- } \\ \text { associated }^{\text {a }}\end{array} \\ \text { TetraCB } & 1.7 & -0.14 & -5.1 & 24 & <1 \\ \text { PentaCB and hexaCB } & 1.0 & -0.45 & -25.2 & 21 & <1 \\ \text { Later-eluting than first heptaCB } & 0.6 & -0.48 & -45.4 & 14 & 3-<1 \\ & \\ & \end{array}$


Overall precision for high-flow denuder and high-volume sampler methods was compared using field duplicate samples. Overall precision, expressed by CoV, was $16 \%$ for high-flow denuder and $21 \%$ for high-volume samples (Table 4.2). This result indicates that high-flow denuder method precision compares favorably to the established high-volume sampler method. In comparison of field duplicates from the same method, the relative bias is expected to be zero if the differences were caused by random error. The relative difference was small for both methods, and not significantly different from zero (high-volume), or marginally significant (high-flow, Table 4.2). These results suggest that random error contributions to each analyte in each sample were dominant over error contributions that systematically biased all analytes in one sample relative to the duplicate, and supports the treatment of each analyte in each sample as an independent measurement.

\subsubsection{High-flow denuder method performance}

The purpose of this investigation was to characterize the performance of the highflow denuder in measurement of trace gas-phase atmospheric SOCs. Precision and bias of the high-flow denuder method were reported to facilitate design of experiments using this method, and in order to consider the method as an alternative to existing methods. Highflow denuder field replicate precision compared favorably to the high-volume sampling method, which is of interest in investigations of atmosphere-surface exchange fluxes and in other applications in which it is necessary to resolve a difference in concentration between two samples. The method presented here offers the possibility to measure trace SOC concentrations in sample times that are comparable (12-24 hours) to or shorter than (minutes to a few hours) high-volume sampling because the entire sample is transferred into the GC, which is advantageous for measurement of surface fluxes, diel trends in concentration, location of sources by air-parcel back-trajectory analysis, or other phenomena in which high temporal resolution is needed. An associated disadvantage is that replicate samples must be collected if multiple instrumental analyses or archived extracts are desired. The pressure drop across the high-flow denuder is low $(0.15 \mathrm{kPa}$ without the filter, $10 \mathrm{kPa}$ with the filter) compared to a high-volume sampler with the 
filter and XAD cartridge (14 to $16 \mathrm{kPa}$ ), an advantage where low pump power is desired. Relatively inexpensive consumables are required, namely nitrogen gas and silica gel, compared to high-purity solvents required by conventional solvent-extraction and cleanup methods. In this study, the high-flow denuder thermal extraction, cleanup, and analysis method required 5 hours of labor and $\$ 5$ in consumables per sample compared to 20 hours and $\$ 44$ for XAD pre-cleaning, Soxhlet extraction, solvent exchange, and column cleanup of high-volume samples. Additional work is needed to develop methods for analysis of polar and thermally-labile compounds collected by the high-flow denuder. 


\section{Parameterization of internal boundary layer growth using an internal boundary layer transport exchange model ${ }^{4}$}

\subsection{Abstract}

A Lagrangian Internal Boundary Layer Transport Exchange (IBLTE) Model is described, which predicts the modification with fetch in offshore flow of gas mixing ratio, air-water exchange flux, and near-surface vertical gradients in mixing ratio. The internal boundary layer (IBL) is defined as the height to which the air mass has been modified by interaction with the water surface. A mass balance is conducted over the IBL using the integral depth scale approach. Surface fluxes and vertical profiles in the surface layer (the lowest 1/10 of the IBL) are calculated using the NOAA COARE bulk algorithm and gas transfer model. The IBL growth rate constant, $\alpha$, was obtained by calibrating the model to a large data set of air temperature and humidity modification over Lake Ontario, 1973. For the calibrated model, root mean square errors for air temperature and dewpoint temperature modification were 1.3 and $1.6^{\circ} \mathrm{C}$, respectively. Values of $\alpha$ were obtained from the 2004 New England Air Quality Study atmospheric soundings, and from solution of a simplified diffusion equation and an estimate of eddy diffusivity from Monin Obukhov similarity theory (MOST). Calibrated and MOST values of $\alpha$ were consistent with prior literature for stable conditions. Reasonable agreement was obtained between calibrated and MOST values of $\alpha$ for stable, neutral, and unstable conditions. Through use of the parameterization described here, IBL height can be estimated as a function of fetch over a wide range of stability using readily available inputs (air temperature, humidity, and wind speed incident at the coast, and water temperature).

\footnotetext{
${ }^{4}$ This chapter is based on material that is intended for publication as M. D. Rowe, J. A. Perlinger, and C. W. Fairall. (2009). Parameterization of internal boundary layer growth using an internal boundary layer transport exchange model.
} 


\subsection{List of symbols and abbreviations}

$d T a \quad$ Land-lake air temperature modification $[\mathrm{K}]$

$d T d \quad$ Land-lake dewpoint temperature modification [K]

$f \quad$ fraction of $h_{\mathrm{ibl}}$ that defines the top of the surface layer [-]

$F_{\mathrm{s}} \quad$ flux per unit area at the surface $\left[\mathrm{M} \mathrm{L}^{-2} \mathrm{~T}^{-1}\right]$

$g \quad$ acceleration due to gravity $\left[\mathrm{L}^{1} \mathrm{~T}^{-2}\right]$

$H(x) \quad$ integral depth scale [L]

$H(x)_{\mathrm{u}}$ upper, portion of the integral depth scale above the surface layer [L]

$H(x)_{1}$ lower, surface layer portion of the integral depth scale [L]

$h_{\mathrm{ibl}} \quad$ height of the internal boundary layer [L]

IBL internal boundary layer

$K \quad$ turbulent eddy diffusivity $\left[\mathrm{M}^{2} \mathrm{~T}^{-1}\right]$

$k_{\mathrm{a}} \quad$ air-side gas transfer velocity $\left[\mathrm{L} \mathrm{T}^{-1}\right]$

$L \quad$ Obukhov length [L]

MOST Monin-Obukhov similarity theory

$n \quad$ exponent that determines the shape of the mixing ratio profile in the IBL [-]

$P \quad$ atmospheric pressure $\left[\mathrm{M} \mathrm{L}^{-1} \mathrm{~T}^{-2}\right]$

$R \quad$ gas constant $\left[\mathrm{L}^{2} \mathrm{M} \mathrm{T}^{-2} \mathrm{~K}^{-1} \mathrm{~mol}^{-1}\right]$

$R i_{b} \quad$ bulk Richardson number [-]

$R i_{\mathrm{b} 10}$ bulk Richardson number defined using upstream, over-land meteorological variables at 10-m reference height [-]

$r(z) \quad$ gas mixing ratio as a function of height [-]

$r_{1} \quad$ upstream, over-land mixed layer gas mixing ratio [-]

$r_{\mathrm{s}} \quad$ gas mixing ratio at the surface [-]

$T \quad$ absolute temperature $[\mathrm{K}]$

$U \quad$ mean wind speed in the $x$ direction $\left[\mathrm{L} \mathrm{T}^{-1}\right]$

$U_{10} \quad$ wind speed at $10-\mathrm{m}$ height $\left[\mathrm{L} \mathrm{T}^{-1}\right]$

$U_{\text {avg }} \quad$ wind speed averaged vertically over the IBL $\left[\mathrm{L} \mathrm{T}^{-1}\right]$

$u * \quad$ friction velocity $\left[\mathrm{L} \mathrm{T}^{-1}\right]$

$x \quad$ horizontal dimension aligned with the mean wind [L] 
$X \quad$ fetch: distance travelled by the air mass over water from the coast [L]

$z \quad$ vertical dimension, positive upward [L]

$z_{\mathrm{m}} \quad$ profile matching height; border between surface layer and IBL [L]

$z_{\mathrm{o}} \quad$ aerodynamic roughness length [L]

$z_{\mathrm{r}} \quad$ reference height at which wind speed or scalar has a known value [L]

$\alpha \quad$ IBL growth rate coefficient $\left[\mathrm{L}^{0.5}\right]$

$\gamma \quad$ lapse rate: deviation of temperature or mixing ratio vertical profile from wellmixed condition $\left[\mathrm{K} \mathrm{L}^{-1}\right]$ or $\left[\mathrm{L}^{-1}\right]$.

$\gamma_{\mathrm{d}} \quad$ dry adiabatic lapse rate, $\gamma_{\mathrm{d}}=-0.0098 \mathrm{~K} \mathrm{~m}^{-1}$

$\gamma_{\mathrm{e}}$ environmental lapse rate $\left[\mathrm{K} \mathrm{L}^{-1}\right]$

$\theta \quad$ potential temperature $[\mathrm{K}]$

$\theta_{\mathrm{v}} \quad$ virtual potential temperature $[\mathrm{K}]$

$\theta_{\mathrm{vl}} \quad$ upstream, over-land mixed layer virtual potential temperature [K]

$\theta_{\mathrm{vs}} \quad$ virtual potential temperature of air at equilibrium with the water surface $[\mathrm{K}]$

$\kappa \quad$ von Kármán constant, assumed to have a value of 0.4 [-]

$\Phi_{\mathrm{H}}(z / L) \quad$ MOST gradient profile function for potential temperature [-]

$\Psi_{\mathrm{M}}(z / L) \quad$ MOST integral profile function for wind speed [-]

\subsection{Introduction}

Flux measurement from ships using eddy covariance and gradient techniques has become more common in recent decades due to development and refinement of technologies for direct measurement of air-water exchange fluxes and correction for ship motion. Quantification of air-water exchange fluxes of trace gases such as carbon dioxide (McGillis et al. 2004), dimethyl sulfide (Blomquist et al. 2006), and toxic substances (Perlinger et al. 2005; Perlinger and Rowe 2008) are important to understand and predict climate change and ecosystem health. Fluxes of sensible heat, water vapor, and trace gases, vary spatially and temporally as a function of meteorological variables. A model framework is necessary to interpret and evaluate the reasonableness of flux measurements, as well as to predict the values of fluxes. 
A physics-based gas transfer model, such as the COARE Gas Transfer Model (Fairall et al. 2000), accounts for the effects of atmospheric stability on fluxes in the constant-flux surface layer. In this investigation, the COARE bulk algorithm and gas transfer model are applied within a Lagrangian framework that estimates the height to which the air mass is modified by the water surface in offshore flow (i.e., the height of the internal boundary layer (IBL)), and estimates the modification of gas mixing ratio, potential temperature, surface fluxes, and near-surface vertical gradients with fetch. The model is applied to develop a parameterization for the IBL growth rate coefficient for stable, neutral, and unstable conditions. In the coastal zone during offshore flow, conditions of horizontal homogeneity may be compromised to the extent that the constant flux layer is below the measurement height, causing flux at the measurement platform to be not representative of the surface flux (Fairall et al. 2006). Predictions of the IBL height as well as fetch dependence of fluxes and gradients are useful for planning and interpretation of flux measurements in the coastal zone.

\subsection{Model Description}

An IBL forms in the atmosphere whenever flow passes over a change in surface properties such as roughness, temperature, or moisture (Garratt 1990). The influence of the new surface is propagated upward by turbulent diffusion more slowly than it is advected horizontally, thus some time (distance) is required to establish new steady-state vertical profiles of temperature and mixing ratio (Figure 5.1). In the case of cool air flowing over a warmer surface, a statically unstable, or convective IBL is formed. Turbulence is enhanced by convection, thus the convective IBL grows rapidly and reaches equilibrium in tens of kilometers (Garratt 1987). In contrast, when warm air flows over a cooler surface, turbulence is suppressed by thermal stratification and a statically stable IBL is formed. The growth rate of a stable IBL is low, and fetches of several hundred kilometers are required to develop an IBL of several hundreds of meters deep (Garratt 1987).

The development of internal boundary layers has been studied with respect to pollutant dispersion in coastal regions and meteorological forecasting. Models of IBL 
development range from complex numerical turbulence models (Garratt 1987; Smedman et al. 1997; Angevine et al. 2006b) to relatively simple 2-D Lagrangian models (Garratt 1987; Hsu 1989; Melas 1989). Angevine et al. (2006b) applied a high-resolution numerical model to investigate pollutant transport in offshore, coastal flow associated with the 2002 New England Air Quality Study, and found that some, but not all, of the important phenomena were captured: the stable boundary layer in the model formed further from shore, was less stable, and thicker than observations. Thus, fine-scale phenomena near the coast can be challenging for current numerical models to capture. Here, the objective is to provide an easy to use tool that can aid in interpretation of micrometeorological flux measurements of trace gases in the coastal zone. The 2-D Lagrangian framework is selected because it enables investigation at a fine spatial scale: full representation of vertical gradients using surface layer similarity theory, and $<1 \mathrm{~km}$ horizontal resolution.

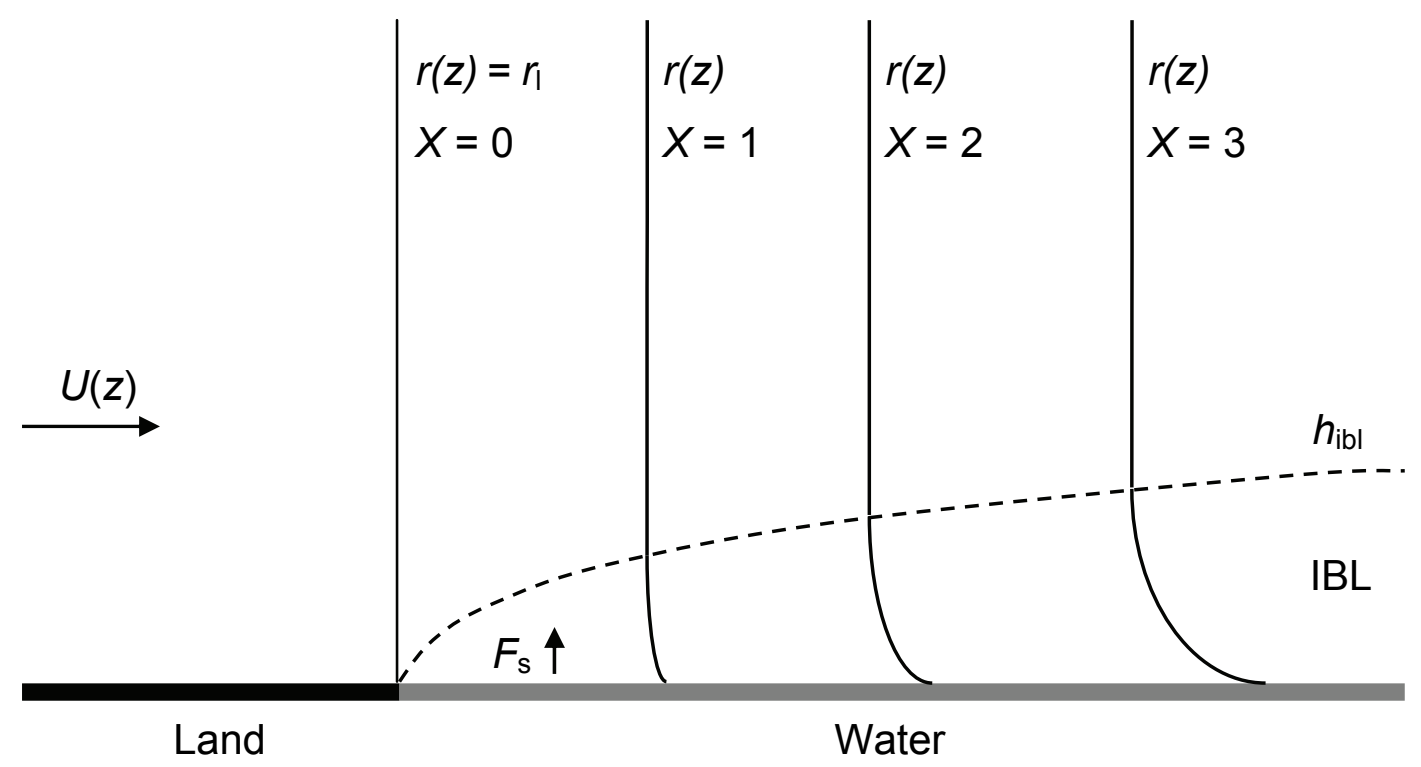

Figure 5.1: Illustration of the modification of the vertical profile of gas mixing ratio, $r$, with increasing fetch, $X$, as a well-mixed atmospheric boundary layer is advected from land to water with a gas flux directed upward from the surface. The internal boundary layer is defined as the height to which mixing ratio is modified by exchange with the surface. 


\subsubsection{Mass balance over the internal boundary layer (IBL).}

A mass balance is performed over the IBL taking a Lagrangian perspective, moving along with an air mass that leaves the land and travels over the water in a direction aligned with the mean wind. For the purpose of this model, the IBL is defined as the vertical distance above the water surface that is affected by exchange with the surface; thus the flux is zero at the top of the IBL and all mass and sensible heat exchanged with the surface is contained within the IBL. For the case of a mixed layer advected from land to water, fluxes of conserved scalars are expected to decrease with height and approach zero at $h_{\mathrm{ibl}}$ because vertical gradients approach zero at $h_{\mathrm{ibl}}$ and are equal to zero in the residual mixed layer above $h_{\mathrm{ibl}}$. For example, a quasi-linear decrease in flux with height has been observed in the stable, nocturnal IBL over land (Nieuwstadt 1984). Because $h_{\text {ibl }}$ is practically defined at a point where vertical gradients have approached, but are not equal to zero, there is a finite flux at $h_{\mathrm{ibl}}$ - the IBL grows by entrainment of air from above - but because $h_{\mathrm{ibl}}$ increases by definition as this occurs, the flux at $h_{\mathrm{ibl}}$ is considered to be zero. The IBLTE Model framework assumes a well-mixed layer is advected from land, neglects directional wind shear, and subsidence. These effects may be important in some cases.

The mass balance is written by setting the vertical integral of the profile modification equal to the horizontal integral of flux through the surface at the fetch of interest. This approach yields a quantity with units of length, $H(x)$, which is called the integral depth scale (Stull 1988):

$$
H_{(x)} \equiv \int_{0}^{h_{i b l}}\left(r_{(z)}-r_{l}\right) d z=\int_{0}^{X} \frac{F_{s}}{U_{a v g}} \frac{R T}{P} d x
$$

where $h_{\mathrm{ibl}}$ is the height of the internal boundary layer, $r(z)$ is the mixing ratio as a function of height at the fetch of interest, $r_{1}$ is the mixing ratio over land (assumed to be independent of $z$ ), $F_{\mathrm{s}}$ is the flux at the surface, $U_{\mathrm{avg}}$ is the wind speed averaged vertically over the IBL, $R$ is the gas constant, $T$ is the average absolute air temperature, $P$ is the atmospheric pressure, and $x$ is the horizontal dimension aligned with fetch. The concept 
of performing a mass balance over the IBL by integrating the profile modification over the IBL is illustrated in Figure 5.2.

The wind speed determines the time required to travel a given fetch, and is therefore an important parameter in the integral depth scale. The 10-m wind speed over land is input into the model. Wind speed over water at 3-m height is determined using the empirical correlations for wind ratio of Phillips and Irbe (1978) as a function of fetch and initial air-water temperature difference. $U_{\text {avg }}$ is evaluated at each fetch increment by numerically integrating (five-point Gauss quadrature) the vertical profile of wind speed, $U_{\text {(z) }}$ (roughness and stability dependent), given by the COARE Algorithm:

$$
U_{a v g}=\frac{1}{h_{i b l}} \int_{0}^{h_{i b l}} U_{(z)} d z
$$

The horizontal integral in Equation (5.1) is evaluated numerically, using the trapezoid rule, at each fetch increment using the COARE Algorithm to estimate the sensible and latent heat flux, and the COARE Gas Transfer Model to estimate gas flux. The model is written here for a trace gas mixing ratio, but it is similarly applied to potential temperature. It is necessary to model potential temperature to account for varying stability with fetch and also to calibrate $h_{\mathrm{ibl}}$ parameterization using temperature and humidity modification data. 


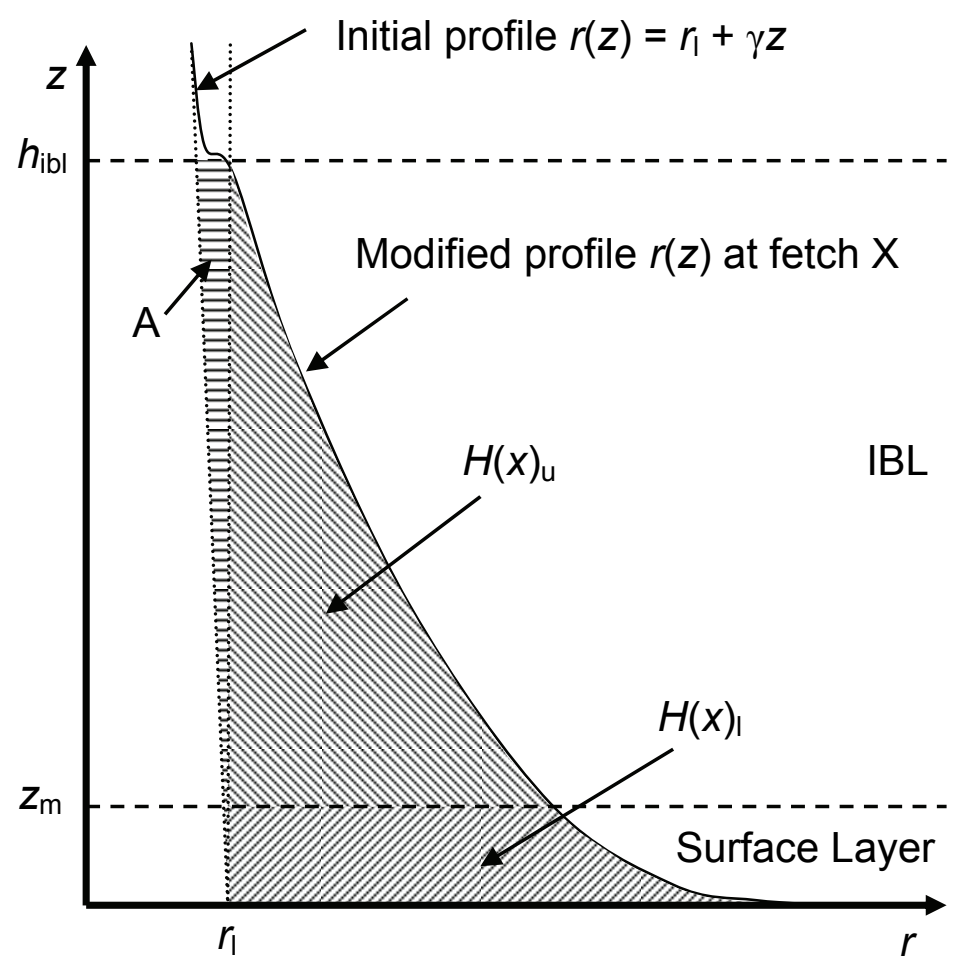

Figure 5.2: Illustration of the modification of the vertical profile of gas mixing ratio within the internal boundary layer in an air mass advected from land to water at a specific fetch, $X$. In this scenario, the initial mixing ratio profile over land is $r(z)=r_{1}+y z$ and there is an upward gas flux from the water. The areas $H(x)_{\mathrm{u}}, H(x)_{1}$, and $A$ correspond to components of the mass balance discussed in the text. 
Once the integral depth scale has been determined by evaluating the horizontal integral in Equation (5.1), the modification to the mixing ratio as a function of height can be found if profile functions are defined. To this end, the IBL is divided into a relatively thin surface layer, where the flux can be assumed to depart minimally from the surface value, $F_{\mathrm{s}}$, and the remainder of the IBL in which the flux decreases with height, approaching zero at $h_{\mathrm{ibl}}$. In the constant-flux surface layer, the stability-dependent MoninObukhov similarity theory (MOST) profile functions used in the COARE Algorithm are applied. This approach is loosely modeled after the concept of Mahrt (1999, Fig. 1), which indicates that the height within the IBL over which $z / L$ (MOST) scaling is appropriate decreases with increasing stability. Here, the IBL profile function of Garratt (1990), $\left(z / h_{\text {ibl }}\right)$ scaling, is applied above the surface layer, as illustrated in Figure 5.2.

The approach to evaluate the vertical integral in Equation (5.1) begins with specifying $h_{\mathrm{ibl}}$. The $h_{\mathrm{ibl}}$ is assumed to increase as the square root of fetch, $X$ :

$$
h_{i b l}=\alpha X^{0.5}
$$

Garratt (1990) reported that the square-root-of-fetch dependence is a reasonable approximation for both stable and unstable IBLs. Parameterization of $\alpha$ as a function of the bulk Richardson number is discussed subsequently.

The constant-flux surface layer is defined as a constant fraction of $h_{\mathrm{ibl}}$ :

$$
z_{m}=f h_{i b l}
$$

where $z_{\mathrm{m}}$ is the matching height at which the surface layer and IBL profile functions match, and $f$ is a fraction of the IBL height. A value of 0.1 was selected for $f$. Evidence for $f=0.1$ can be found in the manuscript by Fairall et al. (2006, Fig. 9), where it is shown that momentum flux measured at 18-m height is representative of the expected surface flux when $h_{\mathrm{ibl}}$ exceeds $200 \mathrm{~m}$.

Within the surface layer, vertical profiles of potential temperature and specific humidity are obtained from the MOST profile functions in the COARE Algorithm. For gas mixing ratio, a vertical profile is constructed through use of the air-side transfer 
velocity given by the COARE Gas Transfer Model (after Fairall et al. 2000; Blomquist et al. 2006):

$$
r_{(z)}=r_{\left(z_{r}\right)}+\frac{R T}{P} F_{s}\left[\frac{1}{k_{a\left(z_{r}\right)}}-\frac{1}{k_{a(z)}}\right]
$$

where $r(z)$ is the mixing ratio at the height of interest, $r_{\left(z_{r}\right)}$ is the known value of the mixing ratio at some reference height, and $k_{a\left(z_{r}\right)}$ and $k_{a(z)}$ are the air-side transfer velocities for the gas of interest at the reference height and the height of interest, respectively.

Within the range $z_{\mathrm{m}}<z<h_{\mathrm{ib}}$, the vertical profile of mixing ratio or potential temperature is described by the IBL dimensionless profile function of Mulhearn (1981):

$$
\frac{\left(r-r_{s}\right)}{\left(r_{l}-r_{s}\right)}=\left(\frac{z}{h_{i b l}}\right)^{n}
$$

where $r_{\mathrm{s}}$ is the mixing ratio at the surface. As it is applied here, $r_{\mathrm{s}}$ is simply used to construct the profile as a function of $\left(z / h_{\mathrm{ibl}}\right)$, but has no physical significance because the $\left(z / h_{\mathrm{ibl}}\right)$ profile is only applied above $z_{\mathrm{m}}$, as illustrated in Figure 5.2. The exponent $n$ is a constant that determines the shape of the profile. A value of $n=1$ was selected for stable and neutral conditions, while a value of $n=10$ was found to give a slightly better fit to air temperature and humidity modification data for unstable conditions in the calibration. Vertical profiles of potential temperature and water vapor mixing ratio were analyzed to assist in selecting a value of $n$, which is discussed subsequently. The IBLTE Model is intended for application to surface-based measurements, thus the measurement height will usually be within the surface layer. For prediction of fetch-dependent vertical gradients in mixing ratio near the surface, the gradients will be given by the surface layer similarity relations, which have a sound theoretical and empirical foundation. The IBL profile function, Eq. (5.6), simply provides a means to close the mass balance over the IBL so that the variation in mixing ratio with fetch at $z_{\mathrm{m}}$ can be estimated and the resultant variation in fluxes and gradients with fetch can be estimated using conventional surface layer similarity theory. 


\subsubsection{Initial vertical profiles over land}

The IBLTE Model is intended to be implemented using surface-based measurements of over-land temperature, humidity, and gas mixing ratio; therefore it is necessary to make assumptions regarding the initial vertical profiles of these variables over land. The simplest approach is to assume a well-mixed initial profile over land (mixing ratio and potential temperature constant with height). For a mixed layer, temperature is expected to decrease with height according to the dry adiabatic lapse rate, which results in potential temperature constant with height. If the actual lapse rate is more stable than the dry adiabatic lapse rate, heat will be added to the IBL as it grows. This effect can be important, particularly in the convective IBL case (Chang and Braham 1991). In the case of water vapor, specific humidity generally decreases with height over the atmospheric boundary layer, which causes drying of the air within the IBL as the IBL grows owing to entrainment of dry air. A lapse rate, $\gamma$, was added to allow for a non-adiabatic initial lapse rate for potential temperature or a slight gradient in mixing ratio across the mixed layer, as illustrated in Figure 5.2:

$$
\gamma=\gamma_{e}-\gamma_{d}
$$

where $\gamma_{\mathrm{e}}$ is the environmental lapse rate and $\gamma_{\mathrm{d}}$ is dry adiabatic lapse rate. For the general case where soundings over land are not available, it is more reasonable to assume $\gamma_{\mathrm{e}}=-0.006 \mathrm{~K} \mathrm{~m}^{-1}$ for potential temperature and $\gamma=-0.001 \mathrm{~kg} \mathrm{~g}^{-1} \mathrm{~m}^{-1}$ for specific humidity, after the lowest two kilometers of the U.S. Standard Atmosphere, which is derived from many averaged soundings (reported in Seinfeld and Pandis 1998), than to assume the dry adiabatic lapse rate and a constant specific humidity with height. This change was important to obtain a good fit to both temperature and humidity modification when $\alpha$ was calibrated to temperature and humidity modification data. In application of the IBLTE Model to other gases, a non-zero value of $\gamma$ may be used, as for the example of water vapor, when the initial mixing ratio of the gas is height-dependent. 


\subsubsection{Mathematical approach to profile matching}

The integral depth scale was divided into two parts, a lower and upper profile contribution (illustrated as the lower and upper shaded areas in Figure 5.2).

$$
H_{(x)}=H_{(x) l}+H_{(x) u}
$$

The MOST profile contribution to the integral depth scale (lower shaded area in Figure 5.2) is

$$
H_{(x) l}=\int_{0}^{z_{m}}\left(r_{(z)}-r_{l}\right) d z+\frac{1}{2} \gamma z_{m}^{2}
$$

in which the integral term was evaluated by numerical integration (Gauss quadrature) of the MOST profile. The term containing $\gamma$ comes from the shaded are $A$ in Figure 5.2.

The upper profile contribution is evaluated by re-arranging the $\left(z / h_{\mathrm{ibl}}\right)$ profile function and integrating:

$$
H_{(x) u}=h_{i b l}\left(r_{s}-r_{l}\right) \int_{z_{m}}^{h_{i b l}}\left[1-\left(\frac{z}{h_{i b l}}\right)^{n}\right] d\left(\frac{z}{h_{i b l}}\right)
$$

which yields the following, after adding the lapse rate contribution:

$$
H_{(x) u}=h_{i b l}\left(r_{s}-r_{l}\right)\left[\frac{n-n f-f+f^{n+1}}{n+1}\right]+\frac{1}{2} \gamma\left(h_{i b l}^{2}-z_{m}^{2}\right)
$$

The above expression can be re-arranged to obtain $r_{\mathrm{s}}$ as a function of $H(x)_{\mathrm{u}}$ and known variables. The flow of the model code is outlined in Table 5.1. 
Table 5.1: Outline of IBLTE Model code

1) Inputs: over-land air temperature, wind speed, and humidity; water surface temperature.

a) Trace gas inputs: over-land mixing ratio, aqueous concentration, Henry's Law constant, molecular mass, molar volume.

2) Additional estimated inputs: downwelling long-wave and short-wave irradiance, environmental lapse rate.

3) The Phillips and Irbe wind speed and stability classifications are selected based upon the initial air-water temperature difference and wind speed.

4) The IBL growth rate constant, $\alpha$, is selected by the calibration routine, from previously-calibrated values, or from a parameterization.

5) Start the fetch loop:

a) Fetch $=$ fetch + fetch increment

b) Update the height of the IBL, Eq. (5.3)

c) Adjust the over-land wind speed to over-water wind speed using the Phillips and Irbe empirical correlations.

d) Call the COARE Algorithm to determine the sensible and latent heat fluxes, friction velocity, Obukhov length, and roughness length.

e) Evaluate the layer-averaged wind speed, Eq. (5.2).

f) Evaluate the integral depth scales for temperature, water vapor, and gas mixing ratio (evaluate the horizontal integral in Eq. (5.1) using the trapezoid rule).

g) Profile matching loop:

i) Evaluate the lower contribution to the integral depth scale; integrate Eq. (5.9) by Gauss quadrature.

ii) Determine the upper contribution to the integral depth scale by difference, Eq. (5.8).

iii) Determine $r_{s}$, Eq. (5.11).

iv) Calculate the potential temperature at the profile matching height, Eq. (5.6).

v) Repeat steps i through iv for specific humidity and gas mixing ratio.

vi) Call the COARE Algorithm using the updated temperature and humidity at the profile matching height.

h) Iterate the profile matching loop until the modeled variable (temperature and gas mixing ratio) converges at the matching height.

i) Update the temperature and gas mixing ratios at the reference height using the MOST profile functions (the reference height is usually below the matching height).

6) Loop for next fetch increment 


\subsubsection{Estimation of the IBL growth rate coefficient from air temperature and humidity modification data}

The IBL growth rate coefficient, $\alpha$, was calibrated using a large data set of over-water temperature and humidity modification (Phillips and Irbe 1978). The data set, derived from 6,926 pairs of land and over-water measurements of temperature, dewpoint temperature, and wind speed, was collected over the 12-month period of the International Field Year of the Great Lakes, 1973, using an array of 20 data buoys installed in Lake Ontario especially for the purpose. The data cover a range of wind speed, air-water temperature difference, and stability that is representative of an annual cycle over the Great Lakes. The data were reported in the form of the average, standard deviation, and number of measurements of air temperature and dewpoint temperature modification for measurements grouped into classifications of over-land wind speed, over-land air-water temperature difference, and fetch. Empirical correlations derived from the same data set are currently used to adjust over-land meteorological data for over-water modification in an evaporation model for the Great Lakes (Croley II 1989).

To calibrate $\alpha$ using the IBLTE Model, it was necessary to compile a set of over-land meteorological data that was representative of the over-land meteorological data of Phillips and Irbe, which are no longer available. Phillips and Irbe classified the data into classes based on stability, characterized by air-lake temperature difference at the coast, and wind speed. Stability is more accurately indicated by the Richardson number than by land-lake temperature difference alone. Some of the Phillips and Irbe classes contained a wide range of Richardson number. The 10-m bulk Richardson number was used here to characterize stability at the coast:

$$
R i_{b 10}=\frac{g 10\left(\theta_{v l}-\theta_{v s}\right)}{\theta_{v l} U_{10}^{2}}
$$

where $\theta_{\mathrm{vl}}$ and $\theta_{\mathrm{vs}}$ are the virtual potential temperature of the mixed-layer over land and of air at equilibrium with the water surface, respectively, $U_{10}$ is the $10-\mathrm{m}$ wind speed over land and $g$ is the acceleration due to gravity. 
An objective in compiling the calibration set of meteorological conditions was to simulate as closely as possible the distribution of Richardson numbers, as well as the actual ranges of meteorological conditions, within each of the Phillips and Irbe classes. To this end, historical data for Lake Ontario, 1973, were obtained from the Toronto International Airport (Environment Canada 2009b), one of the stations used by Phillips and Irbe, to obtain over-land air temperature, dewpoint temperature, and wind speed. Monthly mean water-surface temperatures (Croley and Hunter 1996) for Lake Ontario, 1973, were interpolated to the hourly data from Toronto. The time series is shown in

\section{Figure 5.3.}

A calibration set of 937 sets of input data was compiled by randomly selecting records from the time series on the synoptic hours $(06,12,18$, and $00 \mathrm{UTC})$, then assigning them to the 30 Phillips and Irbe classes. Phillips and Irbe also sampled their data only on the synoptic hours. The number of records assigned to a class was arbitrarily capped at 50, which was considered to produce a representative sample while maintaining a reasonable model calibration time ( $\sim 6 \mathrm{hr})$. The median $R i_{\mathrm{b} 10}$ value and calibrated value of $\alpha$ for each class was not sensitive to repeated random samples. All records in the time series were used for 22 of 30 classes because the time series, sampled on the synoptic hours, contained fewer than 50 records that fell within the class for 22 of the 30 classes. These classes represent relatively infrequent meteorological events. Thus, the cap of 50 records per class only affected 8 of 30 classes. Furthermore, since all of the synoptic hour records were used for 22 of the 30 classes, it is likely that many of these records represent the same relatively infrequent metorological events from 1973 that were sampled by Phillips and Irbe.

To provide a sense of the frequency of occurrence of the values of $R i_{\mathrm{b} 10}$, frequency distributions of $R i_{\mathrm{b} 10}$ from the time series are presented in Table 5.2. The frequency of occurence of $R i_{\mathrm{b} 10}$ values decreases rapidly with increasing absolute value of $R i_{\mathrm{b} 10}$. Sampling the time series on the synoptic hours resulted in a similar frequency distribution to the full data set. The calibration set captured all of the extreme values of the synoptic hour sample, and a random sub-sample of the frequently-occurring values. 


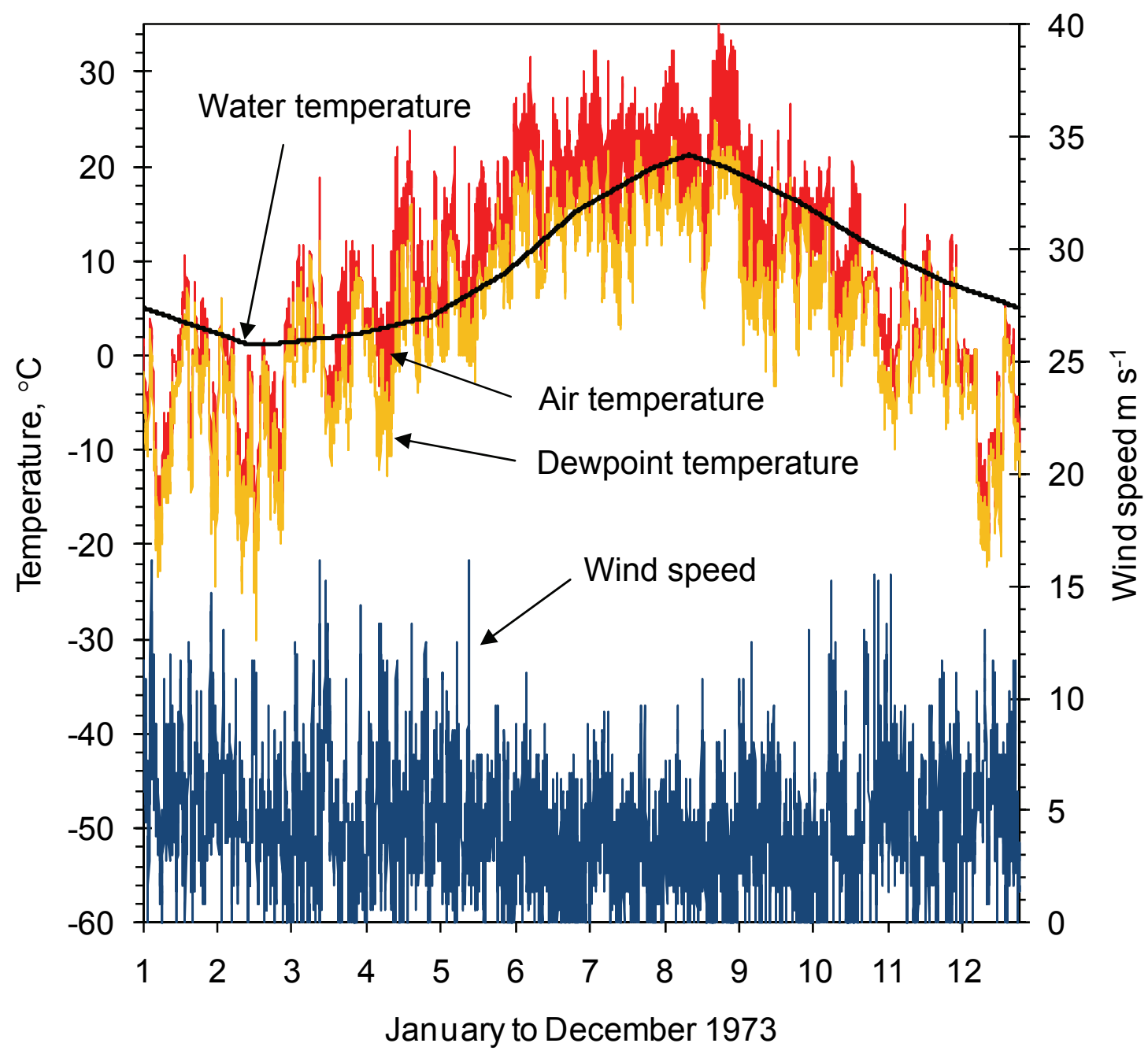

Figure 5.3: Hourly air temperature $\left(-22.2\right.$ to $\left.35.6{ }^{\circ} \mathrm{C}\right)$, dewpoint temperature $(-30$ to 25 ${ }^{\circ} \mathrm{C}$ ), and wind speed (0.6 to $16.1 \mathrm{~m} \mathrm{~s}^{-1}$, zero values were excluded from the analysis) from Toronto plotted with interpolated water surface temperature ( 1.1 to $21.2^{\circ} \mathrm{C}$ ) for Lake Ontario, 1973. 
Table 5.2: Frequency distribution of the 10-m bulk Richardson number based on hourly meteorological data from Toronto and interpolated water surface temperatures for Lake Ontario for 1 January to 31 December, 1973.

$\begin{array}{lccc}\begin{array}{l}\text { Percentile rank } \\ \text { Maximum }\end{array} & \begin{array}{c}\text { Toronto 1973 } \\ \text { all hours }\end{array} & \begin{array}{c}\text { Toronto 1973 } \\ \text { synoptic hours } \\ 13.7581\end{array} & \begin{array}{c}\text { Calibration set } \\ 13.7581\end{array} \\ 99 & 1.8349 & 1.7648 & 2.2766 \\ 95 & 0.3904 & 0.4509 & 0.6666 \\ 75 & 0.0652 & 0.0590 & 0.0578 \\ \text { Median } & -0.0080 & -0.0087 & -0.0200 \\ 25 & -0.1172 & -0.1250 & -0.1462 \\ 5 & -0.7822 & -0.8339 & -1.1797 \\ 1 & -2.7514 & -3.3262 & -4.9556 \\ \text { Minimum } & -22.0428 & -11.4121 & -11.4122 \\ \mathrm{n} & 8760 & 1759 & 937\end{array}$

To obtain a calibrated value of $\alpha$ for each class, the model was run repeatedly for each record in the calibration data set using a routine to find the value of $\alpha$ that minimized the sum of squared error, inverse weighted by the standard error of the Phillips and Irbe data, between the modeled and measured air temperature and dewpoint temperature modification. Upon completion of the calibration, the median of the several values of $\alpha$ within each class was taken to obtain a single value of $\alpha$ for each class.

To verify the calibration, the model was run for the calibration data set, using the median values of $\alpha$ for each class, and the RMS errors for air temperature and dewpoint temperature modification were calculated; the RMS errors were 1.3 and $1.6^{\circ} \mathrm{C}$, respectively. Modeled and measured air temperature and humidity modification for the 30 Phillips and Irbe classes and for each record in the calibration set are shown in Figures 5.4 and 5.5 . 
Figure 5.4: (next page) Results of calibration of the IBL growth rate coefficient, $\alpha$, to air temperature and dewpoint temperature modification data using the IBLTE Model. Landlake air-temperature modification, $\mathrm{dTa}^{\circ} \mathrm{C}$, versus fetch, $\mathrm{km}$, for the thirty classes of Phillips and Irbe. Lines represent model output for each record in the calibration set of over-land meteorological conditions. Circles and error bars represent the mean and standard error of the data from Phillips and Irbe (1978). 

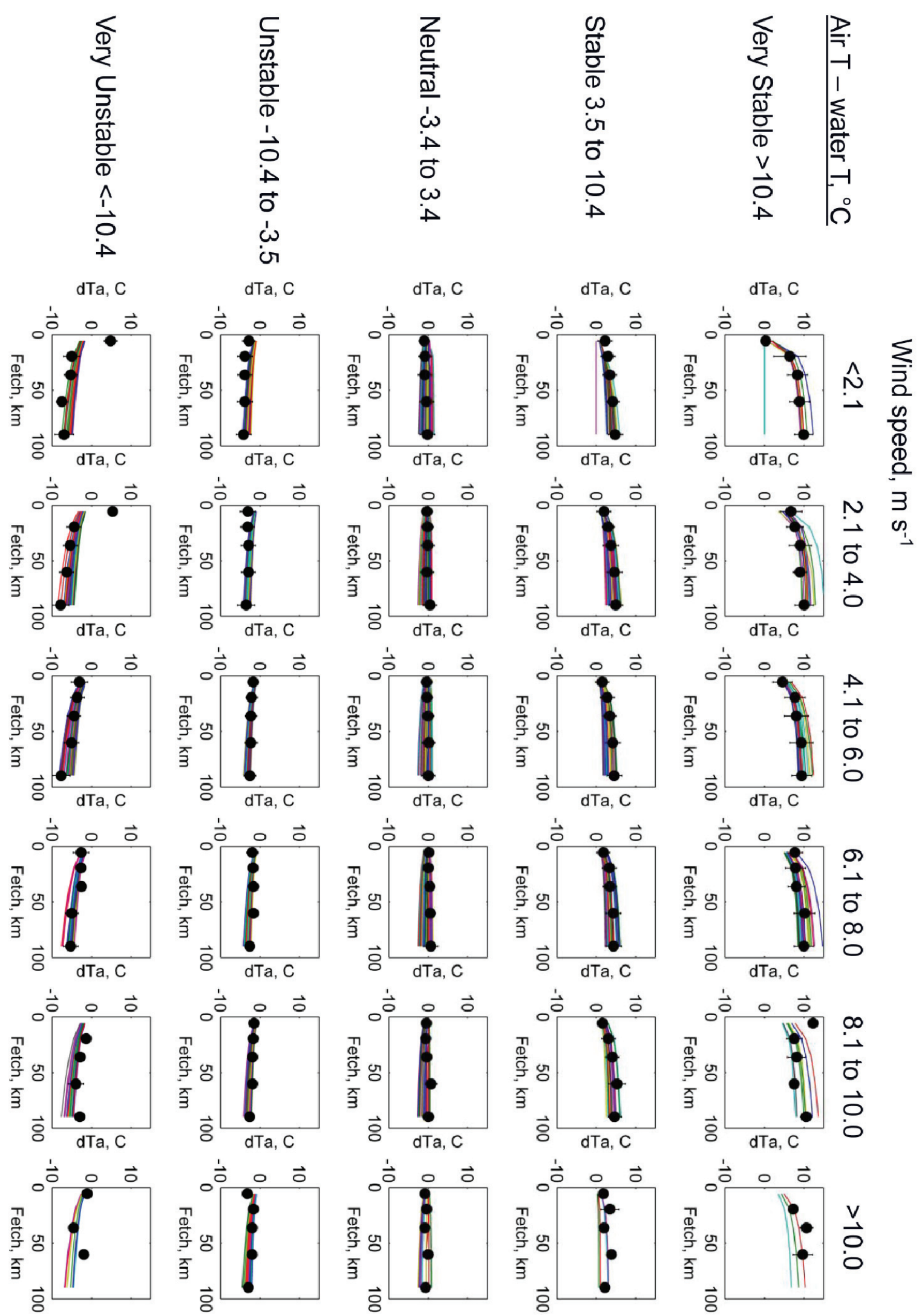
Figure 5.5: (next page) Results of calibration of the IBL growth rate coefficient, $\alpha$, to air temperature and dewpoint temperature modification data using the IBLTE Model. Landlake dewpoint-temperature modification, $\mathrm{dTd}^{\circ} \mathrm{C}$, versus fetch, $\mathrm{km}$, for the thirty classes of Phillips and Irbe. Lines represent model output for each record in the calibration set of over-land meteorological conditions. Circles and error bars represent the mean and standard error of the data from Phillips and Irbe (1978). 

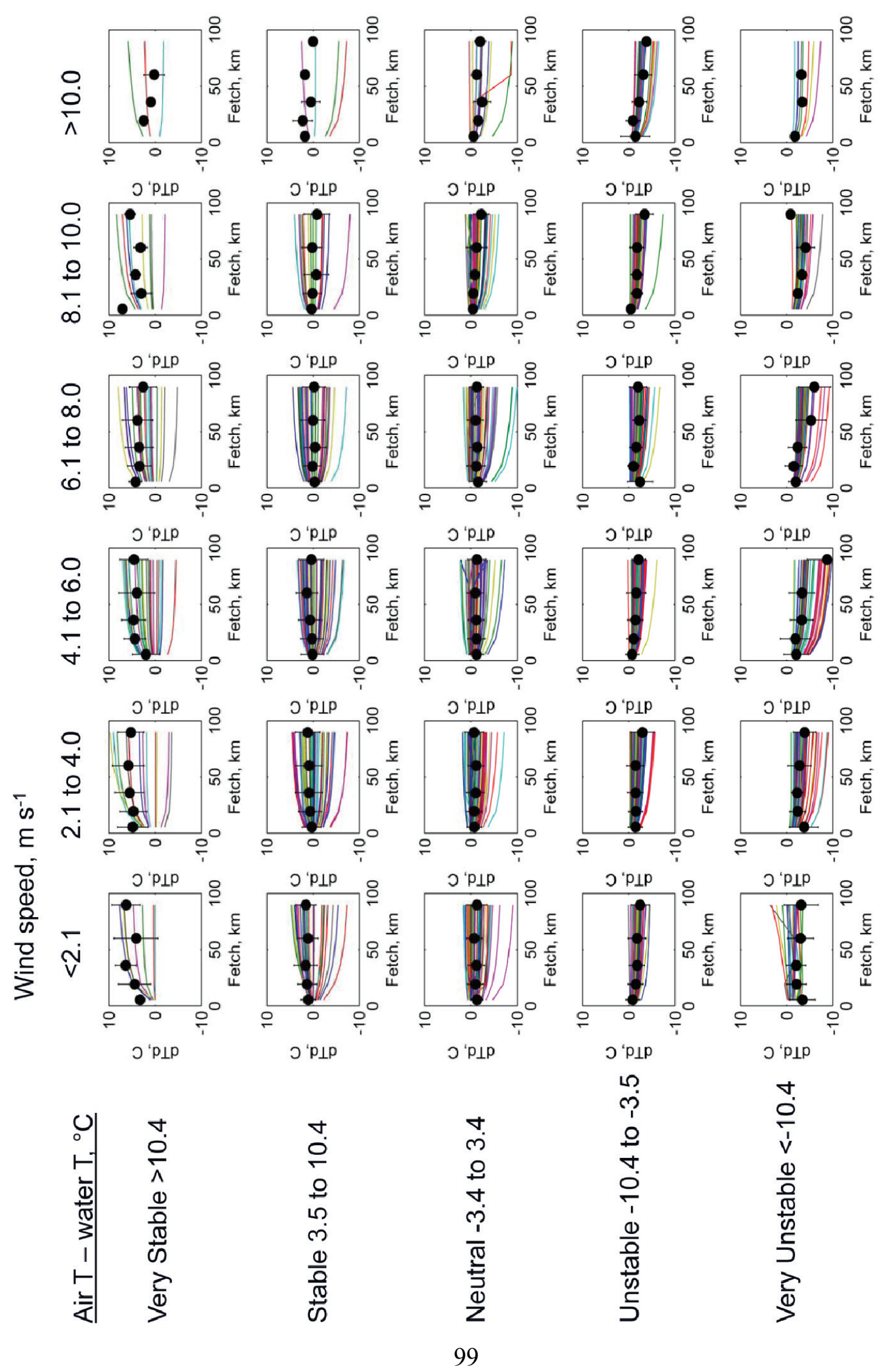


\subsubsection{Estimation of the IBL growth rate coefficient from atmospheric soundings}

Rawinsonde profiles collected off the East Coast of North America as part of the 2004 New England Air Quality Study (NEAQS) (Angevine et al. 2006a; Fairall et al. 2006) provide an additional opportunity to investigate shallow stable boundary layers in coastal offshore flow with detailed, over-water measurements. The shipboard NEAQS rawinsonde profiles were used to estimate values of $\alpha$ using Eq. (5.3) with $h_{\mathrm{ibl}}$ estimated from the sounding and fetch estimated using a HYSPLIT model backward air parcel trajectory (Draxler et al. 2009). First, 48 soundings were selected from the maps described in Fairall et al. (2006) that had wind vectors at 17.5 and $250 \mathrm{~m}$ that both indicated flow from land. HYSPLIT backward trajectories were run for each of these soundings ( $24 \mathrm{hr}$, 10-m starting height, constant pressure height, FNL archive meteorological data). Several soundings were then eliminated because flow from the sea was indicated by the back trajectory, leaving 35 soundings. Fetch was summed along the back trajectory from the location where it crossed the coast. Two examples of the trajectory analysis are shown in Figure 5.6. In the figure, the trajectory is plotted as circles at each hour of transport time, starting at the rawinsonde launch location (plus). The location where the trajectory crossed the coast is indicated with a red asterisk. In the plot title, the latitude, longitude, year, day, and hour of the rawinsonde launch are indicated along with the local hour that the air parcel trajectory left the coast, the quality indicator of the sounding, and $\alpha$ calculated from the IBL height and fetch of the sounding.

Upstream, over-land meteorology to calculate $R i_{\mathrm{b} 10}$ values for the NEAQS soundings was estimated from the sounding data using temperature and humidity taken from the next level above $h_{\mathrm{ibl}}$ in the sounding (assumed to be unmodified over the fetch), and the 10-m wind speed was estimated using the stability-dependent MOST relationship after calling the COARE Algorithm with inputs from the second level in the rawinsonde data (change in wind speed on movement of the air mass from land to sea was neglected). The first level in the rawinsonde data was considered to be unreliable because it may have been affected by the ship's wake. Over-land meteorology was also estimated using HYSPLIT model output and nearby meteorological stations, but in many cases this 
estimation procedure produced results that were not consistent with the same air mass as the sounding. The IBL height was estimated from the sounding by the mixing diagram approach (Craig 1946; Angevine et al. 2006a) as well as by using an $R i_{\mathrm{b}}$ threshold of $0.10,0.25$, and 0.50, as was done by Fairall et al. (2006).

The soundings were given a subjective quality classification based upon the extent to which they conformed to the assumption of a mixed layer being advected from land to water. The quality of a sounding was considered good (qual $=1)$ if it appeared to represent a well-mixed layer above the IBL, and bad (qual $=0)$ if there was evidence that a stable layer already existed when the air mass left the land (gradients in potential temperature and humidity above $h_{\mathrm{ibl}}$, or leaving the coast between midnight and 0600 EST) or if $h_{\mathrm{ibl}}$ was not well defined in the mixing diagram.

Two examples of the sounding analysis are shown in Figure 5.7, which correspond to the maps in Figure 5.8. Sounding analysis plots are shown that were considered to be representative (top, qual $=1$ ), and not representative (bottom, qual $=0$ ) of a mixed layer advected from the land. Rawinsonde data are plotted as blue points. The right panel is the mixing diagram plot. The sea surface temperature and saturation mixing ratio from the ship data are plotted as green circles. The dashed line on the mixing diagram plot extends from the surface temperature and mixing ratio to the assumed upstream, over-land temperature and mixing ratio at the top of the IBL. Potential temperature and mixing ratio are plotted from the backward trajectory at the coast (light blue plus) and from the ship (red $\mathrm{x})$. Horizontal lines represent various estimates of $h_{\mathrm{ibl}}: R i_{\mathrm{b}}=0.10,0.25,0.50$ (dashed lines) and from the mixing diagram (solid line). The potential temperature and mixing ratio similarity theory profiles are plotted from 0 to $30 \mathrm{~m}$ (solid line). One-tenth of the IBL height from the mixing diagram is indicated with a red asterisk.

On the mixing diagram plot, a mixed layer plots as a series of overlaid points, while potential temperature and water vapor mixing ratio within the IBL are expected to lie along a straight line connecting the mixed layer potential temperature and mixing ratio to the water surface potential temperature and mixing ratio. Deviations from this ideal behavior occur if the air mass was not well-mixed upon leaving the coast, if modification 
in potential temperature and humidity within the IBL occurred by means other than the influence of the water surface, if the water surface properties were fetch-dependent, or if directional wind shear caused air masses with different backward trajectories to converge. 

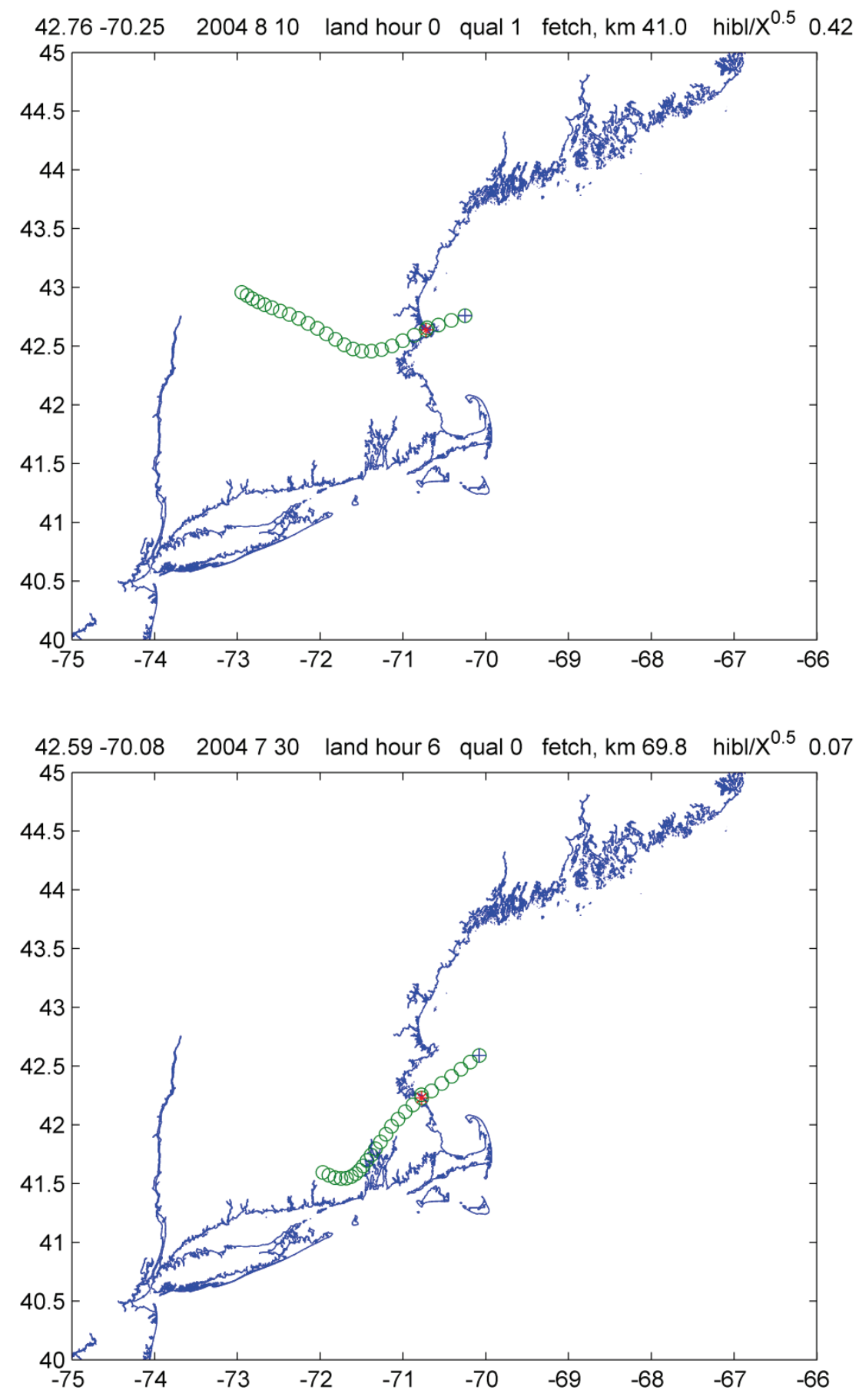

Figure 5.6: Two maps of the East coast of North America showing a HYSPLIT backward air parcel trajectory starting at the rawinsonde launch location. Axes are degrees latitude and longitude. Additional details are provided in the text. 

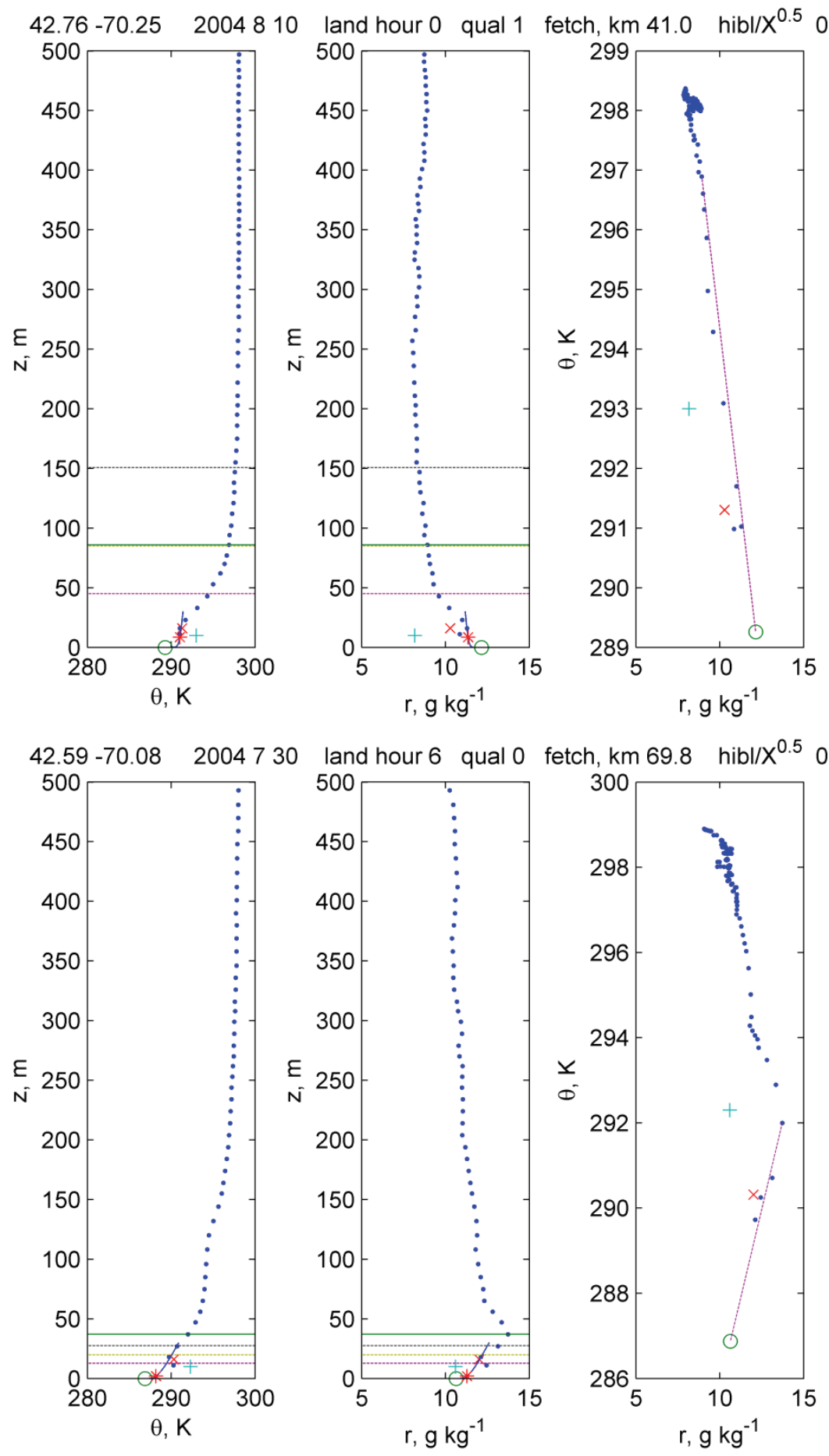

Figure 5.7: Sounding analysis plots for the maps shown in Figure 5.6. Additional details are provided in the text. 


\subsubsection{Estimation of the IBL dimensionless profile shape from atmospheric soundings}

The NEAQS soundings were compared to the dimensionless profile function that was used in the IBLTE Model to give mixing ratio as a function of height within the IBL and above the surface layer, Eq. (5.6) (after Mulhearn 1981; Garratt 1990). To plot the dimensionless profile function for the NEAQS soundings, it was necessary to estimate the potential temperature and water vapor mixing ratio at $0.1 h_{\mathrm{ibl}}$. In cases for which 0.1 $h_{\mathrm{ibl}}$ was lower than the second level in the NEAQS sounding, the potential temperature and mixing ratio at $0.1 h_{\mathrm{ibl}}$ were estimated from the MOST profiles after calling the COARE Algorithm for the conditions at the second level $(\approx 22 \mathrm{~m})$, of the rawinsonde data.

The exponent, $n$, in Eq. (5.6) determines the shape of the profile. Mulhearn (1981) found $n=0.25$ to be a good fit to the Craig (1946) soundings collected off the east coast of North America, while Garratt and Ryan (1989) found $n=2$ for soundings off the coast of southeastern Australia. In contrast to these previous investigations, the NEAQS soundings did not conform to a single value of $n$; most fell between $n=0.25$ and $n=2$, with $n=1$ providing a reasonable approximation (Figure 5.8). It should be noted that $r_{s}$ equal to the surface value in Eq. (5.6) was used in the prior investigations cited, as opposed to $r_{s}=r$ at $0.1 h_{\mathrm{ibl}}$ here, which would produce a greater tendency toward $n<1$ in Figure 5.8. The NEAQS soundings exhibited a range of shapes with no apparent trend in $n$ with fetch (2 to $189 \mathrm{~km})$ or stability for stable and near neutral conditions $\left(R i_{\mathrm{b} 10}=0.006\right.$ to 0.8 ). Figure 5.8 supports use of $n=1$ in the IBLTE Model for stable and neutral conditions. Insufficient data for unstable conditions were available from NEAQS to provide insight into a value of $n$ for unstable conditions. 

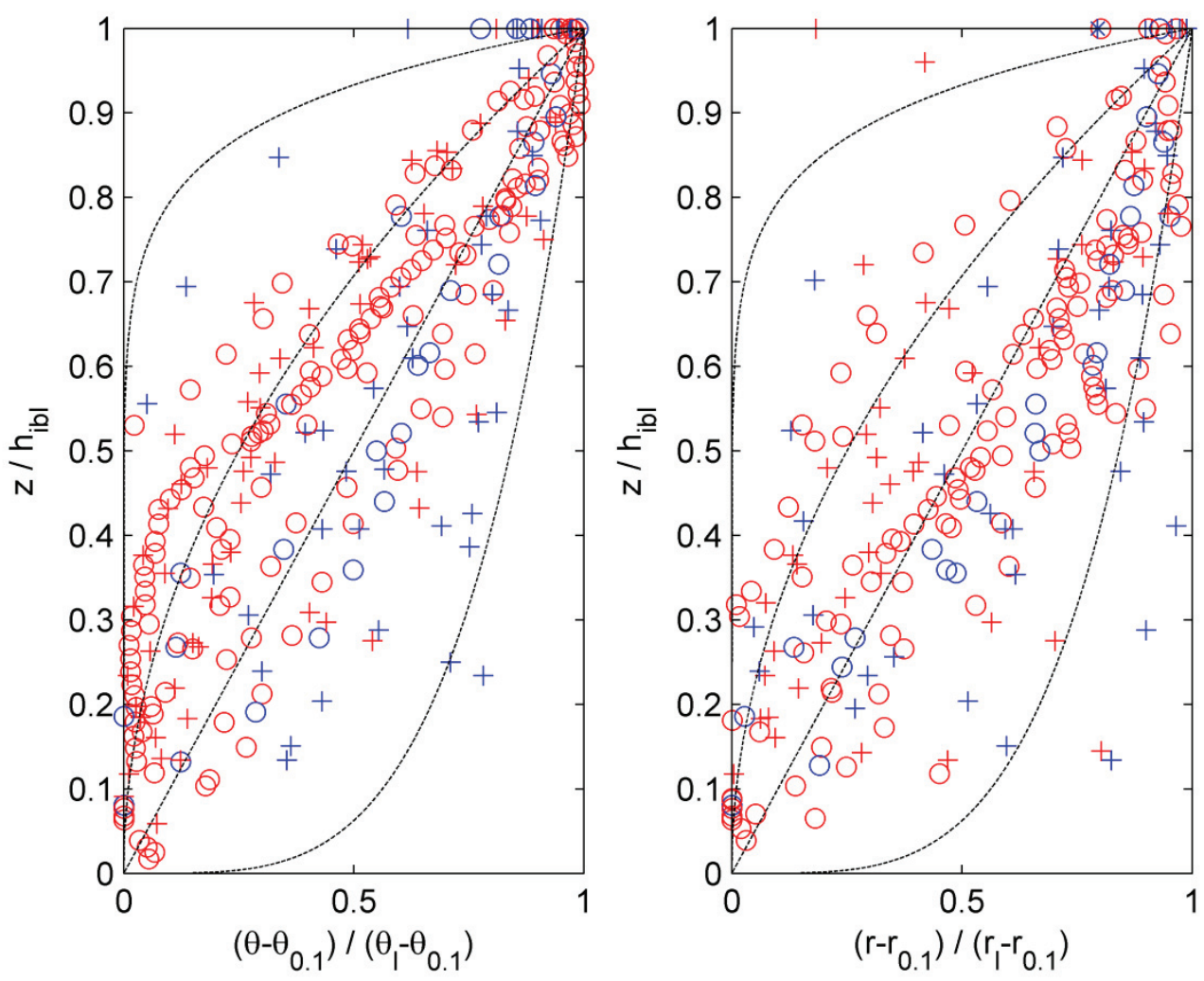

Figure 5.8: Vertical distribution of potential temperature (left) and water vapor mixing ratio (right) within the IBL from NEAQS soundings, plotted using the dimensionless profile function, Eq. (5.6). Dashed lines in the plot indicate profile shapes for (from right to left) $n=0.25,1,2$, and 10 in Eq. (5.6). The symbol type indicates neutral, $R i_{b 10}=+/-$ 0.05 (plotted as circles), or stable, $R i_{\mathrm{b} 10}>0.05$ (plotted as plus). Soundings taken at greater than the median fetch, $41 \mathrm{~km}$, are colored red, while less than median fetch is colored blue. 


\subsubsection{Parameterization of the IBL growth rate coefficient, $\alpha$}

A parameterization of $\alpha$ is derived here by drawing upon estimates of eddy diffusivity from MOST. There are reasons why MOST may have limited application in the coastal IBL, which are discussed in detail subsequently. Even so, it is interesting to investigate to what extent the state of turbulence at equilibrium with the water surface can explain estimates of $\alpha$ from observations.

In the simplest case, modification of temperature or mixing ratio in the IBL can be considered as a function of the rate of horizontal advection and the rate of vertical transport of the thin layer of air equilibrated with the surface. Fick's second law of diffusion is written with the Lagrangian transformation of time to distance as a function of wind speed, $U$, and turbulent diffusion coefficient, $K$ :

$$
U \frac{\partial\left(\theta-\theta_{s}\right)}{\partial x}=K \frac{\partial^{2}\left(\theta-\theta_{s}\right)}{\partial z^{2}}
$$

A solution to this equation for $K$ and $U$ constant in $x$ and $z$, and for initial and boundary conditions of a uniform mixed layer temperature advected from land, $\theta_{1}$, and $\theta=\theta_{\mathrm{s}}$ at the surface (Taylor 1915; Garratt 1987), is:

$$
\left(\theta-\theta_{s}\right)=\left(\theta_{l}-\theta_{s}\right) \operatorname{erf}\left(z\left(\frac{U}{4 K x}\right)^{\frac{1}{2}}\right)
$$

If the internal boundary layer height, $h_{\mathrm{ibl}}$, is defined at height $z$ where

$$
\frac{\left(\theta-\theta_{s}\right)}{\left(\theta_{l}-\theta_{s}\right)}=0.9
$$

Then Eq. (5.14) can be re-written as

$$
h_{i b l}=2 e r f^{-1}(0.9)\left(\frac{K}{U}\right)^{\frac{1}{2}} x^{\frac{1}{2}}
$$

or as Eq. (5.3), where 


$$
\alpha=2.3\left(\frac{K}{U}\right)^{\frac{1}{2}}
$$

in which the substitution, $2 \operatorname{erf}^{-1}(0.9)=2.3$ has been made. To estimate the dependence of $\alpha$ on stability, the stability-dependent forms of the MOST similarity relations are inserted:

$$
\begin{gathered}
K=\frac{\kappa z u_{*}}{\phi_{H}\left(\frac{z}{L}\right)} \\
\frac{u_{*}}{U}=\frac{\kappa}{\left[\ln \left(\frac{Z}{z_{0}}\right)-\Psi_{\mathrm{M}}\left(\frac{Z}{L}\right)\right]}
\end{gathered}
$$

Combining Eqs. (5.17), (5.18), and (5.19)

$$
\alpha=2.3 \kappa\left(\frac{z}{\phi_{H}\left(\frac{z}{L}\right)\left[\ln \left(\frac{z}{z_{0}}\right)-\Psi_{\mathrm{M}}\left(\frac{z}{L}\right)\right]}\right)^{\frac{1}{2}}
$$

The gradient profile function for potential temperature, $\phi_{H}\left(\frac{z}{L}\right)$, is used in Eq. (5.18) because an eddy diffusivity for potential temperature and gas mixing ratio is needed. Eddy diffusivity for potential temperature is greater than eddy diffusivity for momentum under unstable conditions (Kaimal and Finnigan 1994, Fig. 1.8). It is often assumed that $K_{\mathrm{H}}$ and $\phi_{H}\left(\frac{z}{L}\right)$ apply to water vapor and pollutants as well as to potential temperature (Stull 1988, p. 384). The integral profile function for wind speed, $\Psi_{\mathrm{M}}\left(\frac{z}{L}\right)$, is used in Eq. (5.19) because this is a re-arrangement of the stability-dependent logarithmic wind speed profile function, used here to obtain a relationship between the 10-m wind speed and the friction velocity. In Eq. (5.19), it is appropriate to use $z=10 \mathrm{~m}$ if $U_{10}$ is used. In Eq. (5.18), $z$ should be selected for the height that produces a representative, effective $K$ for the IBL growth, which is unknown, so $z=10 \mathrm{~m}$ is used throughout Eq. (5.20) for the purposes of these calculations. 


\subsection{Results and Discussion}

The various estimates of $\alpha$ are all plotted together as a function of $R i_{\mathrm{b} 10}$ in Figure $\mathbf{5 . 9}$ for comparison. Enlarged portions of the stable and unstable regions of Figure 5.9 are shown in Figure 5.10 and Figure 5.11, respectively. The MOST estimate of $\alpha$ was calculated using Eq. (5.20) for the calibration set of meteorological conditions that was used to obtain the calibrated values of $\alpha$ from the Phillips and Irbe (1978) data. The COARE 3.0 Algorithm was used to obtain $L$ and $z_{0}$ in Eq. (5.20). The calibrated values of $\alpha$ obtained from application of IBLTE Model to the Phillips and Irbe data are also plotted along with the Mulhearn (1981) parameterization of $\alpha$, with a constant of 0.02 (Garratt 1990):

$$
h_{i b l}=0.02 U\left(\frac{g}{\theta_{v}} \Delta \theta_{v}\right)^{-0.5} X^{0.5}=0.02 z^{0.5} R i_{b z}^{-0.5} X^{0.5}
$$

Empirical functions having the form of Eq. (5.22) were fitted to the calibrated values of $\alpha$ (in units of $\mathrm{m}^{0.5}$ ) for stable and unstable conditions.

$$
\alpha=0.86\left(\frac{B}{B+R i_{b 10}}\right)^{C}+\left(D R i_{b 10}+E\right)\left[1-\left(\frac{B}{B+R i_{b 10}}\right)^{C}\right]
$$

where $0.86 \mathrm{~m}^{0.5}$ is the value of Eq. (5.20) at the limit of neutral stability $\left(R i_{\mathrm{b} 10}=z / L=0\right)$ and $B, C, D$, and $E$ are fitting coefficients. For stable conditions $\left(R i_{\mathrm{b} 10}>0\right), B=0.0167, C$ $=0.635, D=-5.410^{-4}$, and $E=0$ provided a good fit to $\alpha$ calculated from Eq. (5.20) for the calibration set $\left(R^{2}=0.982\right)$. For unstable conditions $\left(R i_{\mathrm{b} 10}<0\right), B=-0.0212, C=$ 0.0957, $D=0$, and $E=7.248 \mathrm{~m}^{0.5}$ provided a good fit to $\alpha$ calculated from Eq. (5.20) for the calibration set $\left(R^{2}=0.998\right)$. Eq. (5.22) provides a simple means to calculate the MOST estimation of $\alpha$ if it is not convenient to run a bulk algorithm such as COARE to determine $z / L$ and to evaluate the $\Phi$ and $\Psi$ functions.

For stable values of $R i_{\mathrm{b} 10}$, there is good agreement between the calibrated values of $\alpha$, the Mulhearn parameterization, and the MOST estimation of $\alpha$. Fitting the Mulhearn parameterization to the calibrated values of $\alpha$ results in a coefficient of 0.02 , identical to that of Garratt (1990), Eq. (5.21). The coefficient of determination, $R^{2}$, was 0.586 , indicating that $59 \%$ of the variance in the calibrated values of $\alpha$ was explained by the 
Mulhearn parameterization, and the probability of obtaining an equally high correlation by chance, $P$, was 0.001 . Thus, the approach of obtaining $\alpha$ by calibration of the IBLTE Model to the Phillips and Irbe data produced values of $\alpha$ that are consistent with previous investigations in which $h_{\mathrm{ibl}}$ was measured from interpretation of soundings.

While Mulhearn and others were primarily interested in the thermal IBL, which does not exist at the neutral stability limit, the focus here is on estimation of $\alpha$ for gas mixing ratio, which means that the entire range of stability is of interest for this investigation. The Mulhearn (1981) expression approaches infinity as $R i_{\mathrm{b} 10}$ approaches zero, which reduced the value of $R^{2}$ for the correlation between the Mulhearn expression and the calibrated values of $\alpha$. Based on interpretation of $\alpha$ as a function of the eddy diffusivity (Eq. (5.17)) it is intuitive that $\alpha$ should have a finite value at the neutral limit. The average ( \pm std. error) of the median values of $\alpha$ calibrated to the neutral Phillips and Irbe classes was $0.87 \pm 0.06 \mathrm{~m}^{0.5}$, which is nearly identical to the value of $0.86 \mathrm{~m}^{0.5}$ that results when Eq. (5.20) is evaluated at $z / L=0$. The MOST estimation of $\alpha$ was more highly correlated to the calibrated values of $\alpha$ than the Mulhearn parameterization for stable conditions, $R i_{\mathrm{b} 10}>0\left(R^{2}=0.785 P<0.001\right)$.

Prior literature on development of the IBL in coastal offshore flow has focused on the stable IBL, in which modification of temperature and humidity are most dramatic. The approach of estimating $\alpha$ by calibration of the IBLTE Model to the Phillips and Irbe data also allows estimation of $\alpha$ over the unstable range of $R i_{\mathrm{b} 10}$. Very unstable conditions occur in the Great Lakes in late fall and winter under conditions that are not favorable for field measurements over water, so the Phillips and Irbe data represent a rare and valuable data set to investigate these conditions. For unstable conditions, the MOST estimation of $\alpha$ was less highly correlated to the calibrated values of $\alpha$ than for stable conditions, but the correlation was still significant $\left(R^{2}=0.607 P<0.001\right)$.

Values of $\alpha$ estimated from the NEAQS data were weakly correlated to the Mulhearn and MOST estimates of $\alpha$. The most significant correlation was found when $h_{\mathrm{ibl}}$ was determined from the mixing diagram approach, as shown in Figure $5.7\left(R^{2}=0.340 P\right.$ $<0.001)$. When $h_{\mathrm{ibl}}$ was defined at a critical bulk Richardson number from the sounding, 
$h_{\mathrm{ibl}}$ at $R i_{\mathrm{b}}=0.10$ produced $\alpha$ that was consistently below the Mulhearn and MOST parameterizations $\left(R^{2}=0.101 P=0.063\right)$. When $h_{\mathrm{ibl}}$ was defined at $R i_{\mathrm{b}}=0.25, \alpha$ was on the same scale as the Mulhearn and MOST parameterizations, but the correlation was very weak $\left(R^{2}=0.054 P=0.178\right)$. The correlation was not improved by using only soundings that were subjectively rated as high quality, in terms of conforming to the assumption of a mixed layer advected from land. The NEAQS data presented new challenges in defining $h_{\mathrm{ibl}}$ from the rawinsonde profiles and in estimating the upstream meteorological variables over land to calculate $R i_{\mathrm{b} 10}$. The data set was not as large as that of Phillips and Irbe, and represented individual measurements rather than binned and averaged values that might display less variability. Furthermore, directional wind shear was observed in many of the NEAQS soundings (Fairall et al. 2006), which cannot be simulated using the Lagrangian framework of the IBLTE Model. It is possible that directional wind shear is more common or stronger off New England than for the Great Lakes because of thermal wind caused by the large scale land-sea temperature difference on the East Coast, which is of greater spatial extent than for the Great Lakes.

A reasonbly good correlation was observed between the MOST and Mulhearn parameterizations of $\alpha$ and the calibrated values of $\alpha$, but there were large discrepancies for some of the Phillips and Irbe classes. The discrepancies could be an artifact resulting from the classification scheme of Phillips and Irbe, or could result from contributions to IBL growth that are not accounted for by the turbulent flow at steady state with the water surface described by MOST. There are several reasons why observed IBL growth rate may differ from the MOST parameterization: 1) the assumption of $U$ and $K$ constant with $z$ is not realistic, and may be less appropriate for unstable than stable conditions because of greater $h_{\mathrm{ibl}} ; 2$ ) at short fetch, turbulence advected from the land may be more or less intense than the turbulence at steady state with the water surface that is assumed in the MOST estimation of $K ; 3)$ turbulence at $h_{\mathrm{ibl}}$ may be decoupled from the surface under stable conditions; 4) selection of $z=10 \mathrm{~m}$ to calculate the eddy diffusivity may be less appropriate for unstable than for stable conditions, 5) dependence of $h_{\mathrm{ibl}}$ on square root of fetch is expected to be valid over a limited range of fetch because $h_{\mathrm{ibl}}$ approaches a steady-state value at some fetch, which likely occurs at a shorter fetch under unstable 
conditions than for stable conditions. With these considerations in mind, it is interesting that the MOST parameterization of $\alpha$ is in reasonably good agreement with observations. This suggests that bottom-up turbulence generation from the water surface is capable of explaining much of the observed variation in IBL growth rate.

In an effort to investigate whether discrepancies between MOST and calibrated $\alpha$ were caused by the classification scheme of Phillips and Irbe or by variables not accounted for in derivation of the MOST parameterization, the relative error between MOST and calibrated $\alpha$ was analyzed for correlation to other variables. The Phillips and Irbe data were classified by wind speed and air-water temperature difference at the coast, then averaged. Some of the classes include a wide range of $R i_{\mathrm{b} 10}$, which may have corrupted the dependence of the calibrated $\alpha$ values on $R i_{\mathrm{b} 10}$, particularly for classes in which $\alpha$ has a non-linear $R i_{\mathrm{b} 10}$ dependence over the range of $R i_{\mathrm{b} 10}$. There was a weak but signficant correlation between relative error in $\alpha$ estimation and the range in $R i_{\mathrm{b} 10}$ normalized to the median $R i_{\mathrm{b} 10}$ of the class $\left(R^{2}=0.392 P=0.050\right)$. The relative error in $\alpha$ estimation was not significantly correlated to the midpoint wind speed $\left(R^{2}=0.032 P=\right.$ $0.405)$ or air-water temperature difference $\left(R^{2}=0.037 P=0.370\right)$ of the Phillips and Irbe classes $\left(R^{2}<0.04 P>0.37\right)$. This suggests that discrepancies between MOST and calibrated $\alpha$ may have been at least partially caused by the classification scheme of Phillips and Irbe. Their classification scheme could have been improved using classes based on $R i_{\mathrm{b} 10}$, and by using as the dependent variable temperature and dewpoint temperature modification relative to the initial air-water temperature or dewpoint temperature difference, as in Eq. (5.15). Even so, the data of Phillips and Irbe represent an intensive field investigation of air temperature and humidity modification in the Great Lakes that is unique in its spatial and seasonal coverage, and it was possible to extract useful information on IBL development from it through application of the IBLTE Model. It may be possible to obtain a more accurate parameterization of $\alpha$ by applying the approach described here if a similar data set should become available in the future. 


\subsection{Conclusion}

An internal boundary layer transport exchange model was developed and applied to measurements of air temperature and humidity modification over water to obtain estimates of the internal boundary layer growth rate coefficient, $\alpha$, in coastal offshore flow under stable, neutral, and unstable conditions. A parameterization for $\alpha$ was developed using Monin-Obukhov similarity theory. The MOST parameterization of $\alpha$ explained $79 \%$ and $61 \%$ of the variation in $\alpha$ obtained from the model under stable and unstable conditions, respectively, and was in close agreement under neutral conditions. Under stable conditions, $\alpha$ obtained from both the model and the MOST parameterization were consistent with the Mulhearn (1981) parameterization.

The MOST parameterization of $\alpha$ provides a means to estimate $h_{\mathrm{ibl}}$ in applications in which the complexity of a high-resolution numerical turbulence model is not warranted, or when the spatial resolution of a numerical scheme is too coarse to resolve the fine spatial scale of IBL development. For example, when making flux measurements in the coastal zone it is useful to estimate whether the measurement platform is at a significant fraction of the IBL height to ensure that the flux is representative of the surface flux. Additionally, parameterization of $\alpha$ in a model such as the IBLTE can be used to estimate near-surface modification of gas mixing ratio and temperature as well as the variation of surface fluxes and vertical gradients of gas mixing ratio and temperature in coastal offshore flow. 


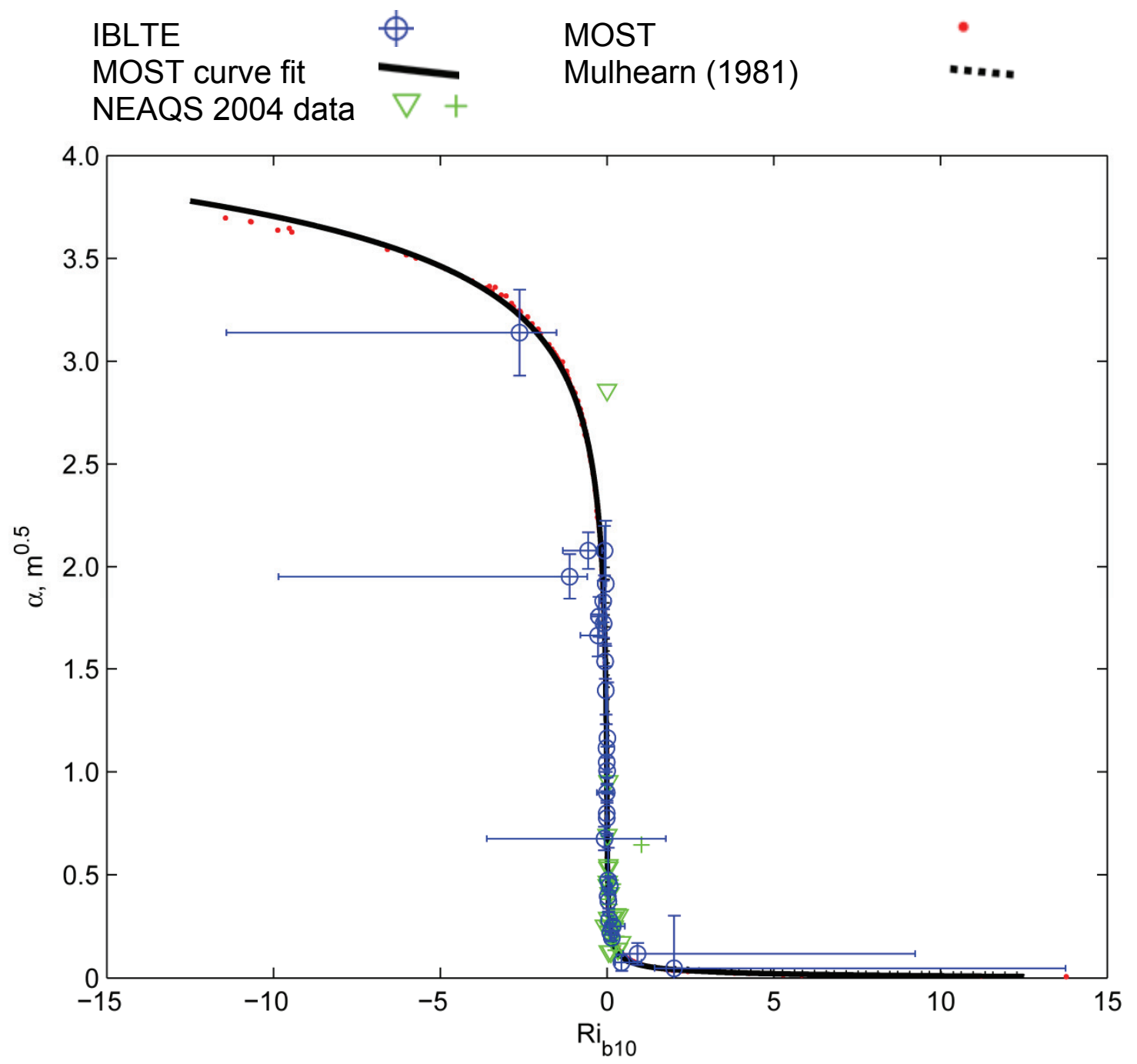

Figure 5.9: The IBL growth rate coefficient, $\alpha \mathrm{m}^{0.5}$, versus the $10-\mathrm{m}$ bulk Richardson number. The calibrated values of $\alpha$ from the IBLTE Model calibration to the Phillips and Irbe (1978) data set are plotted as circles. Vertical error bars indicate the standard error of the $\alpha$ values resulting from the range of meteorological conditions in the calibration set. The horizontal error bar represents the range of $R i_{b 10}$ from the calibration set that fell within the Phillips and Irbe class. The symbol is plotted at the median $R i_{b 10}$. Red points are the MOST estimation of $\alpha$, Eq. (5.20) calculated for each record in the calibration set. The solid black line is a curve fit to the MOST values of $\alpha$, Eq. (5.22). The dotted black line is the Mulhearn (1981) parameterization of $\alpha$, Eq. (5.21). Green symbols (triangle and plus) are $\alpha$ from the NEAQS profile data. Triangles indicate low quality profiles and pluses indicate high quality profiles. 

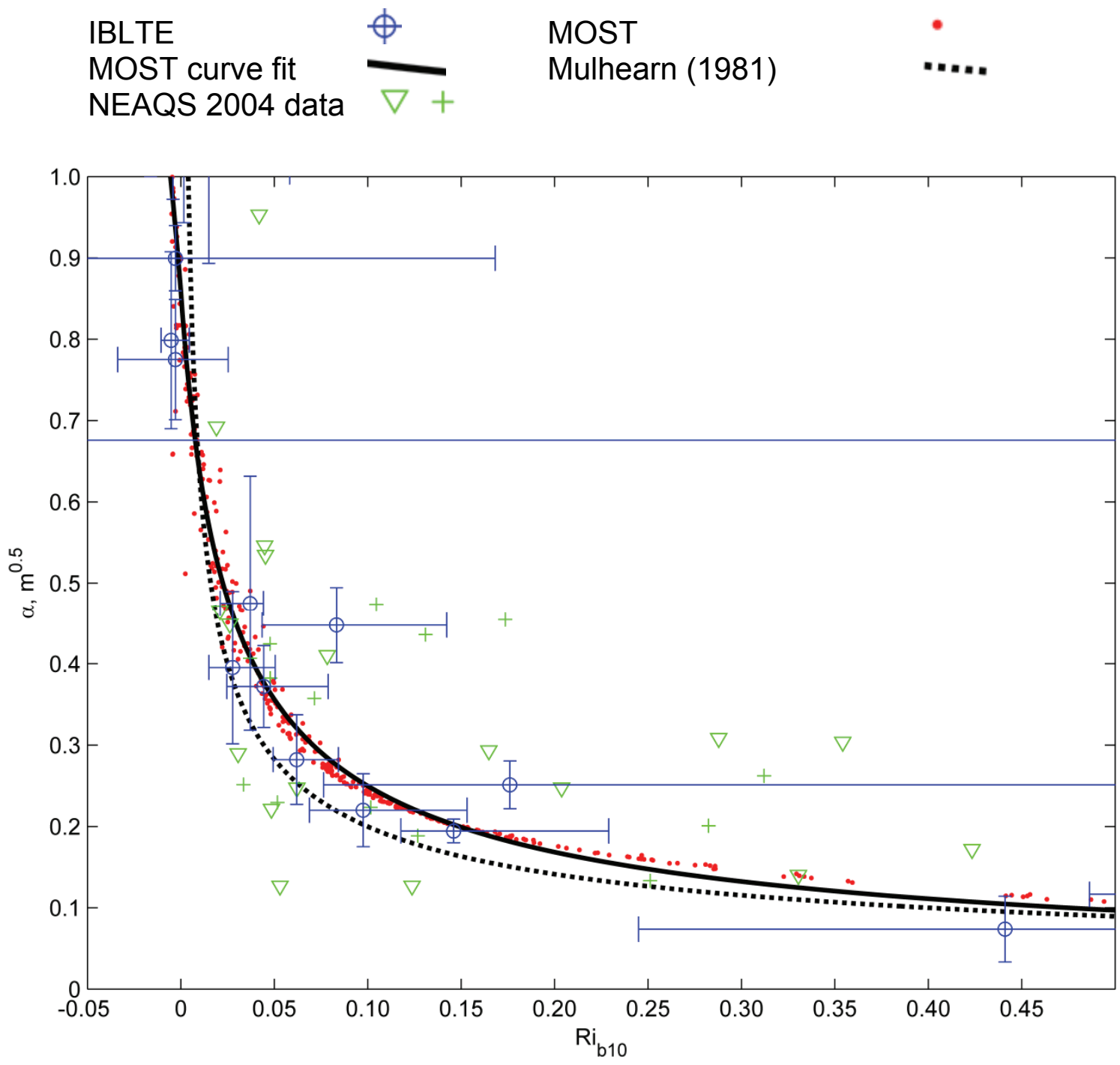

Figure 5.10: An enlarged view of the stable portion of Figure 5.9. 
IBLTE $\quad \phi \quad$ MOST

$\begin{array}{ll}\text { MOST curve fit } & \\ \text { NEAQS } 2004 \text { data } & \text { Mulhearn (1981) }\end{array}$

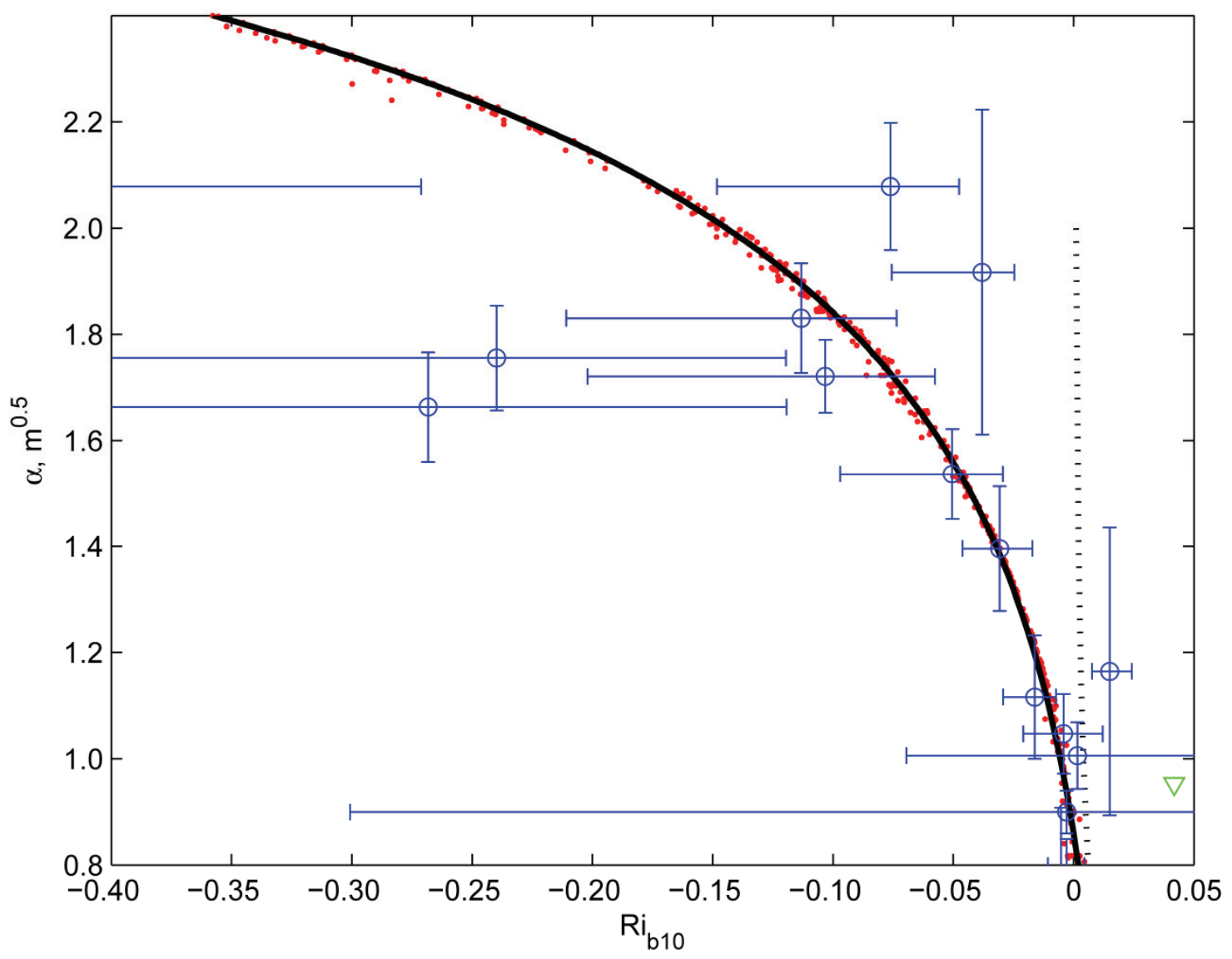

Figure 5.11: An enlarged view of the unstable portion of Figure 5.9. 


\section{Application of an internal boundary layer transport exchange model to micrometeorological measurements of hexachlorobenzene and polychlorinated biphenyl gas transfer in Lake Superior ${ }^{5}$}

\subsection{Abstract}

An Internal Boundary Layer Transport Exchange (IBLTE) Model was used to interpret modified Bowen ratio (MBR) air-water exchange flux measurements for hexachlorobenzene and polychlorinated biphenyls conducted on 14 July, 2006 in Lake Superior. Flux measurements were conducted at three stations with increasing fetch in offshore flow $(15,30$, and $60 \mathrm{~km})$. This allowed comparison of measured and predicted modification in near-surface atmospheric concentration with fetch to measured and predicted flux direction using the IBLTE Model. Fluxes estimated using the Whitman Two-Film (W2F) Model were compared to fluxes measured by MBR with propagated error for both. Most MBR and W2F fluxes were upward (volatilization), which was qualitatively consistent with increasing atmospheric concentration with fetch at 1-m height. MBR and W2F fluxes agreed within estimated uncertainty for several cases, while W2F fluxes were significantly greater in other cases. Analysis with the IBLTE Model indicated that the MBR fluxes were in better agreement with the observed modification in concentration with fetch at 1-m height than W2F fluxes for cases in which the W2F fluxes were significantly greater than MBR fluxes. Uncertainties in the aqueous concentrations were likely responsible for the significant discrepancies between MBR and W2F fluxes in some cases. Comparison of PBT transfer velocities predicted by W2F and COARE gas transfer models revealed significant differences between the two for hourly meteorological conditions representative of an annual cycle over the Great Lakes.

\footnotetext{
${ }^{5}$ This chapter is based on material that is intended for publication as M. D. Rowe, J. A. Perlinger, and C. W. Fairall. (2009). Application of an internal boundary layer transport exchange model to micrometeorological measurements of hexachlorobenzene and polychlorinated biphenyl gas transfer in Lake Superior.
} 
The COARE Model may be considered as an alternative to the W2F Model for PBT airwater exchange estimates.

\subsection{List of symbols and abbreviations}

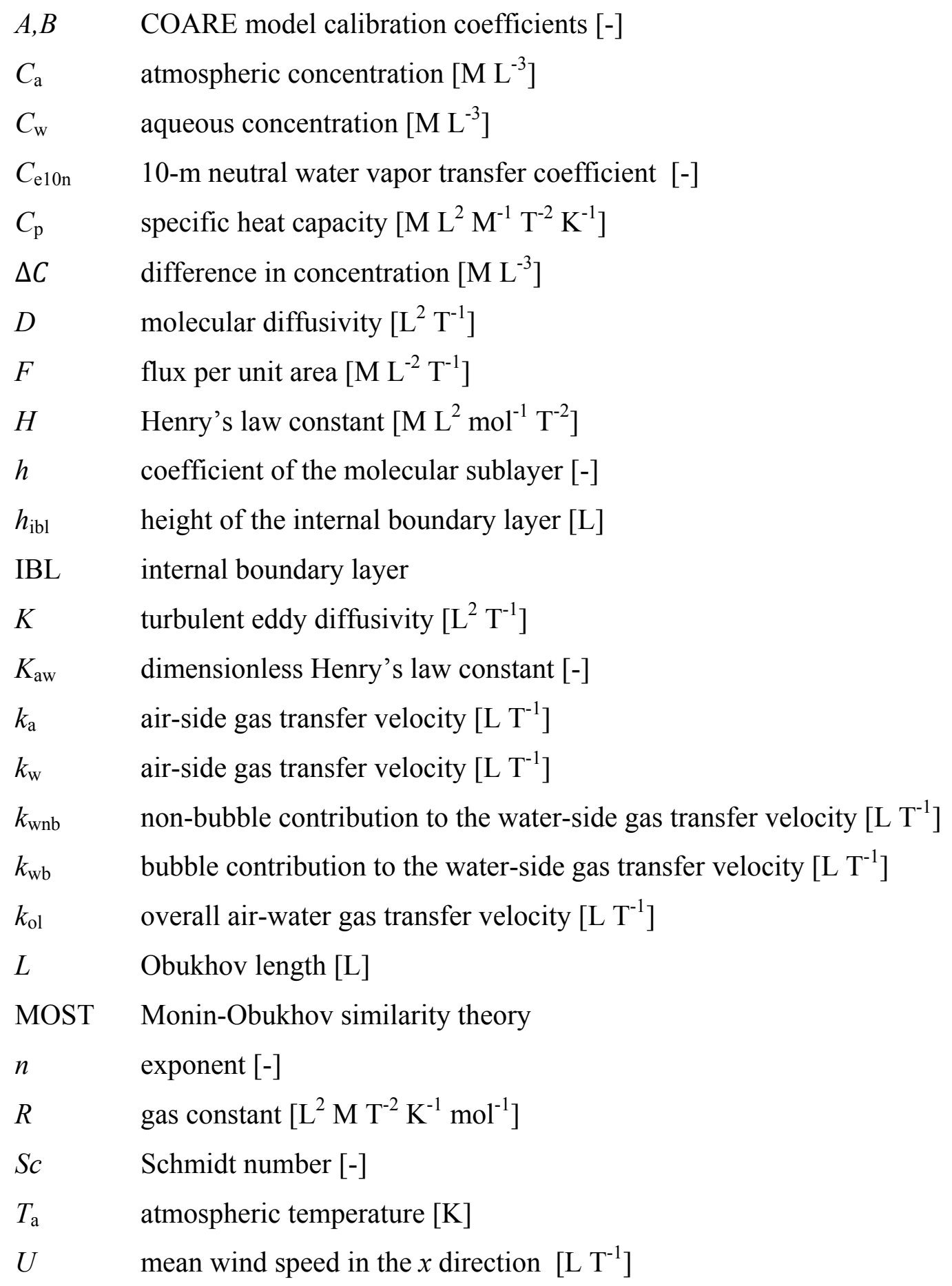




\begin{tabular}{ll}
$U_{10}$ & mean wind speed at 10-m height $\left[\mathrm{L} \mathrm{T}^{-1}\right]$ \\
$u *$ & friction velocity $\left[\mathrm{L} \mathrm{T}^{-1}\right]$ \\
$V$ & molar volume $\left[\mathrm{L}^{3} \mathrm{~mol}^{-1}\right]$ \\
$v_{\mathrm{CO}_{2}}$ & $k_{\mathrm{ol}}$ for carbon dioxide $\left[\mathrm{L} \mathrm{T}^{-1}\right]$ \\
$v_{w}$ & $k_{\mathrm{ol}}$ for water vapor $\left[\mathrm{L} \mathrm{T}^{-1}\right]$ \\
\hline$w^{\prime} \theta$ & kinematic sensible heat flux [K $\left.\mathrm{L} \mathrm{T}^{-1}\right]$ \\
$x$ & horizontal dimension aligned with the mean wind [L] \\
$z$ & vertical dimension, positive upward [L] \\
$z_{\mathrm{o}}$ & aerodynamic roughness length [L] \\
$z_{\mathrm{r}}$ & reference height at which wind speed or scalar has a known value [L] \\
$\alpha$ & dimensionless solubility, [-] \\
$\delta_{u w}$ & thickness of the water-side molecular sublayer for momentum [L] \\
$\delta()$ & estimated uncertainty in a quantity [same units as the quantity] \\
$\theta$ & potential temperature, $\mathrm{K}$ \\
$\Delta \theta$ & change in $\theta$ between two heights in the atmosphere [K] \\
$\kappa$ & von Kármán constant, assumed to have a value of $0.4[-]$ \\
$\rho$ & fluid density [M L $\left.\mathrm{L}^{-3}\right]$ \\
$\Psi_{\mathrm{H}}(z / L)$ & MOST integral profile function for potential temperature [-]
\end{tabular}

\subsection{Introduction}

Contamination of ecosystems by atmospheric deposition of persisent, bioaccumulative and toxic (PBT) substances is a continuing concern for human and ecosystem health. Currently $43 \%$ of total lake acreage and $39 \%$ of total river miles in the United States are under fish consumption advisories, including $100 \%$ of the Great Lakes and connecting waters. Seventy nine percent of U.S. coastal waters are under advisory, including nearly all of the East Coast and Gulf Coast. Mercury, dioxins, polychlorinated biphenyls (PCBs), DDT, and chlordane are responsible for most advisories (U.S. EPA 2008). While fish consumption advisories focus mainly on legacy chemicals, current use chemicals are also of concern (Tuduri et al. 2006). For large bodies of water, gaseous 
exchange with the atmosphere is a dominant process in the mass balance for relatively volatile and water-insoluble chemicals such as PCBs and mercury (Jeremiason et al. 1994; Rowe et al. 2008), and an important contributing process for less volatile or more water soluble compounds such as polybrominated diphenyl ethers (Rowe et al. 2008) and some current use pesticides (Harman-Fetcho et al. 2000). Quantification of the rate of gaseous exchange with the atmosphere is critical to understanding and predicting the behavior of toxics in surface waters.

Gaseous exchange fluxes of PBTs are usually estimated from measurements of atmospheric and aqueous concentration using the W2F Model (for example, Blanchard et al. 2008) but over-water measurements of fluxes are rarely attempted. W2F flux estimates are subject to uncertainty in concentration measurements, Henry's law constant, and mass transfer velocity parameterization. Micrometeorological methods, such as the modified Bowen ratio (MBR) method (Wesely et al. 1987; Perlinger et al. 2005), can be used to measure the flux directly, and thus provide a means to evaluate gas transfer parameterizations.

Air-water exchange flux varies spatially and temporally as a function of meteorological variables. A model framework is necessary to interpret and evaluate the reasonableness of flux measurements, as well as to predict the values of fluxes. A mechanistic parameterization of mass transfer velocity, as in the COARE Gas Transfer Model (Fairall et al. 2000), accounts for the effects of atmospheric stability on fluxes in the constant-flux surface layer. In the coastal zone during offshore flow, conditions of horizontal homogeneity may be compromised to the extent that on-shore gas mixing ratios are unrepresentative of over-water mixing ratios, or that the constant flux layer is below the measurement height, causing flux at the measurement platform to be not representative of the surface flux.

Here, the COARE Gas Transfer Model is applied within the internal boundary layer transport exchange (IBLTE) Model (described in Chapter 5) to estimate the modification of PBT gaseous concentration, surface fluxes, and near-surface vertical gradients with fetch, and to make comparison to measurements. The IBLTE Model is applied to aid in 
understanding and interpretation of MBR flux measurements of hexachlorobenzene (HCB) and PCBs in Lake Superior conducted on 14 July 2006. Use of a novel gas-phase cleanup method in the PBT concentration measurements improved precision in the concentration measurement and allowed measurement of fluxes for HCB and some PCBs. MBR flux measurements are reported with error estimates for HCB and several PCB congeners at three stations in Lake Superior with increasing fetch in offshore flow. The PCB fluxes reported likely represent the first over-water MBR measurements for these compounds.

\subsection{Model description}

\subsubsection{Internal Boundary Layer Transport Exchange (IBLTE) model}

The IBLTE Model, described in Chapter 5, takes a Lagrangian perspective following an air mass as it flows from the coast with increasing fetch over the water. Exchange of mass and sensible heat with the water causes gas mixing ratio and potential temperature within the air mass to become increasingly modified from the over-land values. The height to which this modification occurs increases with fetch, as a function of the vertical eddy diffusivity, and this height is defined as the internal boundary layer height $\left(h_{\mathrm{ibl}}\right)$. A mass balance is conducted by vertically integrating the modification in mixing ratio from the surface to $h_{\mathrm{ibl}}$ and this quantity is assumed to be equal to the air-water exchange flux at the surface integrated over the fetch. The vertical profiles of potential temperature and mixing ratio are assumed to be the stability-dependent Monin-Obukhov similarity profiles up to $0.1 \times h_{\mathrm{ibl}}$, linear over the remainder of the IBL for stable and neutral conditions and a mixed-layer profile for unstable conditions. The $h_{\mathrm{ibl}}$ is assumed to grow proportional to square-root of fetch with a growth rate coefficient that has been parameterized and calibrated as a function of the 10-m bulk Richardson number incident at the coast. The IBLTE Model framework assumes a well-mixed layer is advected from land, neglects directional wind shear, and subsidence. These effects may be important in some cases. 
The model is intended to be used with inputs that are available from surface measurements: wind speed, air temperature, humidity, and mixing ratio incident upon the coast, as well as water temperature and aqueous concentration. The model can be used to predict the variation in several quantities with fetch within the surface layer, defined as $\left.0.1 \times h_{\mathrm{ibl}}: 1\right)$ modification in potential temperature and gas mixing ratio from the over-land values, 2) surface fluxes of sensible heat, latent heat, and trace gases, and 3) vertical gradients in potential temperature and mixing ratio.

\subsubsection{Parameterization of air-water gas exchange flux}

Air-water exchange flux is commonly estimated using a bulk relationship:

$$
F=k_{o l}\left(C_{w}-\frac{C_{a}}{K_{a w}}\right)
$$

where $F$ is the flux, $C_{\mathrm{w}}$ and $C_{\mathrm{a}}$ are the concentration of the chemical of interest in water and air, respectively, and $K_{\text {aw }}$ is the dimensionless Henry's Law constant at the water surface temperature. Equilibrium solubility can be expressed in several ways:

$$
\frac{C_{a}}{C_{w}}=\frac{H}{R T_{a}}=K_{a w}=\frac{1}{\alpha}
$$

where $H$ is Henry's Law constant at the water surface temperature, $T_{\mathrm{a}}$ is the reference temperature for the gaseous concentration, and $R$ is the gas constant. In oceanic and atmospheric sciences, it is common to use the dimensionless solubility, $\alpha$, (for example, Fairall et al. 2000) while $H$ and $K_{\text {aw }}$ are common in environmental organic chemistry. The overall mass transfer coefficient, $k_{\mathrm{ol}}$, is a function of air-side, $k_{\mathrm{a}}$, water-side, $k_{\mathrm{w}}$, transfer velocities and solubility:

$$
\frac{1}{k_{o l}}=\left(\frac{1}{k_{w}}+\frac{1}{K_{a w} k_{a}}\right)
$$

$k_{\mathrm{a}}$ is about one thousand fold greater than $k_{\mathrm{w}}$, so for soluble gases $\left(K_{\mathrm{aw}}<10^{-3}\right)$, the airside transfer velocity dominates $k_{\mathrm{ol}}$, while for sparingly soluble gases $\left(K_{\mathrm{aw}}>10^{-3}\right)$ waterside transfer velocity is controlling (Schwarzenbach et al. 2003). PBTs of environmental interest span the range from air-side to water-side transfer control. For example, 
hexachlorobenzene ( $\mathrm{HCB})$ and $\alpha-\mathrm{HCH}$ are PBTs for which gaseous exchange is a dominant mode of entry into surface waters. The structure of these compounds is shown in Figure 6.1. The two compounds have similar molecular mass but $\mathrm{HCH}$ has a $K_{a w}$ that is one-hundred-fold less than that of HCB because of its greater capability for hydrogenbonding interaction with water.
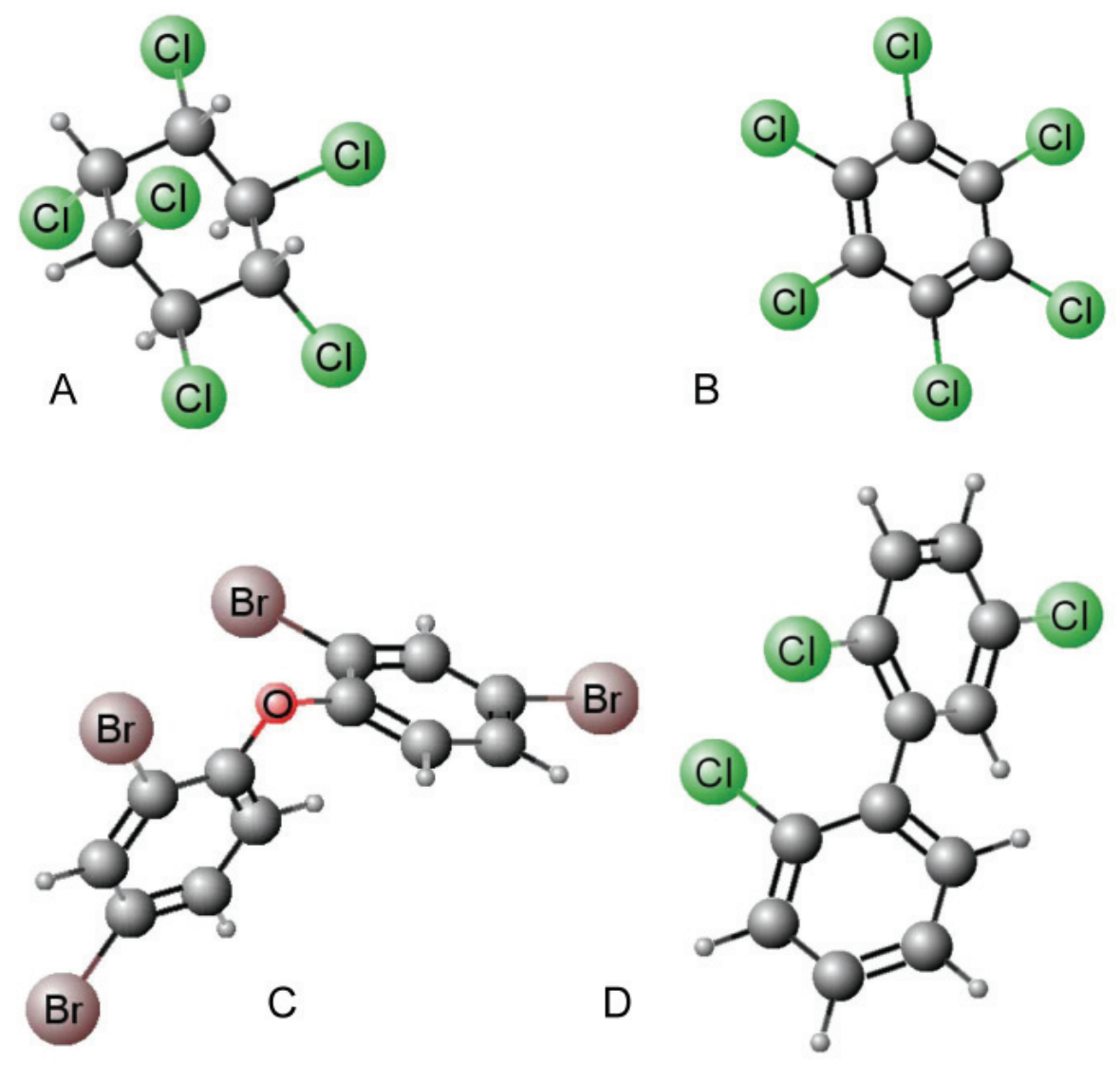

Figure 6.1: Molecular structures of $\alpha-\mathrm{HCH}(\mathrm{A}), \mathrm{HCB}(\mathrm{B}), \mathrm{PBDE} 47$ (C), and PCB 18 (D). 
The air-side and water-side transfer velocities are a function of the molecular diffusivity of the chemical of interest in air or water, $D$, the height and stabilitydependent turbulent diffusivity, $K(z)$, and the reference height (or depth) at which the concentration is measured (Fairall et al. 2000):

$$
\frac{\Delta C}{F}=\int_{0}^{z_{r}} \frac{d z}{(D+K(z))}=\frac{1}{k_{a, w}}
$$

where $\Delta C$ is the concentration difference between the surface and the reference height. Turbulent diffusivity increases as an approximately linear function of distance away from the surface, thus most of the transfer resistance given by the integral term in Eq. (6.4) for the air-side occurs within the first $0.5 \mathrm{~mm}$ above the air-water interface in which molecular diffusion controls transport (Fairall et al. 2000). In the W2F parameterization that is commonly used in environmental organic chemistry literature, all transfer resistance is assumed to occur within the air-side and water-side molecular sublayers, the turbulent and molecular diffusion contributions are lumped together in empirical parameterizations of water vapor and carbon dioxide transfer velocity as a function of 10$\mathrm{m}$ wind speed, and gradients above and below the surfaces are neglected (measurement height is not explicitly represented). Effects of atmospheric stability are neglected in the W2F Model. In the COARE Gas Transfer Model, height-dependent transfer velocity is parameterized as a function of the air-side and water-side Schmidt numbers, and turbulence scaling parameters. Effects of atmospheric stability and water side buoyancy are included, along with disruption of the molecular sublayers by breaking bubbles at high wind speeds.

\subsubsection{Whitman Two-film (W2F) Model transfer velocity}

The concept of modeling gas transfer in terms of thin air-side and water-side films in which mass transfer is limited by molecular diffusion and concentration gradients in the bulk fluid are neglected is usually attributed to Whitman (1923). The concept has been widely applied to gas transfer problems in the natural environment (for example, Liss and Slater 1974). The following simplified W2F transfer velocity parameterizations are used 
by the IADN Project to estimate PBT gas transfer in the Great Lakes (Hornbuckle et al. 1994; Galarneau et al. 2000).

$$
\begin{gathered}
k_{w}=v_{C O_{2}}\left(\left(\frac{V_{P B T}}{V_{C O_{2}}}\right)^{0.6}\right)^{-n} \\
k_{a}=v_{w}\left(\frac{D_{P B T}}{D_{w}}\right)^{0.61}
\end{gathered}
$$

where $n=2 / 3$ for $U_{10}<3.6 \mathrm{~m} \mathrm{~s}^{-1}$, and $n=0.5$ otherwise (Bidleman and McConnell 1995), $V_{P B T}$ and $V_{\mathrm{CO}_{2}}$ are the molar volumes for PBT and carbon dioxide, respectively. In these equations, $k_{\mathrm{a}}$ and $k_{\mathrm{w}}$ are related to the transfer velocity of a reference gas by the ratio of Schmidt numbers. Reference gases were selected that are water-side transfer resistance limited $\left(\mathrm{CO}_{2}\right)$ or air-side transfer resistance limited (water vapor). The equations are further simplified by observing that the Schmidt number ratio of PBT and reference gas is equal to the diffusivity ratio because viscosity of the common solvent cancels out. In Eq. (6.5), diffusivity is estimated using the Wilke Chang method, resulting in the ratio of molar volumes raised to the power 0.6 . A molar volume of $29.6 \mathrm{~cm}^{3} \mathrm{~mol}^{-1}$ for $\mathrm{CO}_{2}$ is used. In Eq. (6.6), the method of Fuller et al. is used to calculate the gas-phase diffusivities. These diffusivity estimation methods are described elsewhere (Schwarzenbach et al. 2003).

Hornbuckle et al. (1994) used the following expressions to estimate transfer velocity for water vapor and carbon dioxide:

$$
\begin{gathered}
v_{w}\left(c m s^{-1}\right)=0.2 U_{10}+0.3 \\
v_{\mathrm{CO}_{2}}\left(\mathrm{~cm} \mathrm{~h}^{-1}\right)=0.45 U_{10}^{1.65}
\end{gathered}
$$

where $U_{10}$ has units of $\mathrm{m} \mathrm{s}^{-1}$. Eq. (6.7) was originally published in the 1993 edition of the Schwarzenbach et al. (2003) environmental organic chemistry text. Eq. (6.8) is from Wanninkhof et al. (1991). These expressions have become almost universally adopted to estimate air-water exchange of PBTs (for example, Galarneau et al. 2000; Totten et al. 2001; Dachs et al. 2002; Rowe et al. 2007; Gioia et al. 2008; Yan et al. 2008; Zhang et al. 
2008). An earlier expression is sometimes used (for example, Meng et al. 2008) that gives $k_{\mathrm{a}}$ as a function of $U_{10}$ and Schmidt number, derived from measurements of volatilization of organic compounds from a wind-wave tank (Mackay and Yeun 1983).

A factor of two discrepancy exists between Eq. (6.7) and ship-based micrometeorological measurements of water vapor transfer velocity. Eq. (6.7) was proposed as a function that reasonably approximated a set of $v_{\mathrm{w}}$ measurements collected from six literature sources, after adjusting them to 10-m height using an assumed roughness length. The data set included wind tunnel, evaporation pan, and field measurements at reference heights of $0.075,0.1,2,6$, and $10 \mathrm{~m}$. Eq. (6.7) gives $v_{\mathrm{w}}$ of $0.013 \mathrm{~m} \mathrm{~s}^{-1}$ at $U_{10}=5 \mathrm{~m} \mathrm{~s}^{-1}$, or a $10-\mathrm{m}$ neutral water vapor transfer coefficient, $C_{\mathrm{e} 10 \mathrm{n}} \equiv v_{\mathrm{w}} /$ $U_{10}$, of $2.6 \times 10^{-3}$. In contrast, Fairall et al. (2003) present data over the $U_{10}$ range from 1 to $19 \mathrm{~m} \mathrm{~s}^{-1}$ and cite several supporting data sources, indicating that $C_{\mathrm{e} 10 \mathrm{n}}=1.15 \times 10^{-3}$ within $5.3 \%$. Thus, the transfer velocity parameterization described by Eqs. (6.5) to (6.8) could be improved by adopting the more accepted value for $C_{\mathrm{e} 10 \mathrm{n}}$. However, the W2F method neglects the influence of atmospheric stability on $k_{\mathrm{a}}$, buoyancy effects on $k_{\mathrm{w}}$, and does not explicitly account for film disruption by breaking bubbles at higher wind speeds. These phenomena are explicitly parameterized in the COARE Gas Transfer Model.

\subsubsection{COARE Gas Transfer Model}

A shortcoming of $U_{10}$ as a turbulence scaling parameter, as in Eqs. (6.7) and (6.8) is that there is not a one-to-one relationship between $U_{10}$ and the turbulent stress at the surface. The relationship between $U_{10}$ and friction velocity, a measure of the turbulent stress at the surface, depends on atmospheric stability and the aerodynamic roughness of the surface.

In the COARE Gas Transfer Model (Fairall et al. 2000) $k_{\mathrm{a}}$ and $k_{\mathrm{w}}$ are functions of the fundamental turbulence scaling parameters: friction velocity, $u_{*}$, roughness length $z_{o}$, and Obukhov length, $L$, and the Schmidt numbers of the compound of interest $S c$ in air and water. The turbulence scaling parameters are obtained from bulk meteorological parameters using the COARE Bulk Algorithm (Fairall et al. 2003). The bubble-mediated transfer is parameterized separately and uses a $U_{10}$ correlation for the white-cap fraction. 


$$
\begin{gathered}
k_{a}=\frac{u_{*}}{\left[h_{a} S c_{a}^{1 / 2}+\kappa^{-1}\left[\ln \left(\frac{z_{r a}}{z_{0}}\right)-\Psi_{H}\left(\frac{z_{r a}}{L}\right)\right]-5+\frac{\ln \left(S c_{a}\right)}{2 \kappa}\right]} \\
k_{w n b}=\frac{u_{*}}{\sqrt{\frac{\rho_{w}}{\rho_{a}}}\left[h_{w} S c_{w}^{1 / 2}+\kappa^{-1} \ln \left(\frac{z_{r w}}{\delta_{u w}}\right)\right]} \\
k_{w b}=0.0068 B K_{a w} U_{10}^{3.41}\left[1+\left(\frac{14 S c_{w}^{1 / 2}}{K_{a w}}\right)^{\frac{-1}{1.2}}\right]^{-1.2} \\
k_{w}=k_{w n b}+k_{w b}
\end{gathered}
$$

where $k_{\mathrm{wnb}}$, and $k_{\mathrm{wb}}$ are the water-side non-bubble and bubble-mediated transfer velocities, respectively. The remaining variables are described elsewhere (Fairall et al. 2000; Blomquist et al. 2006), including the von Kármán constant, $\kappa=0.4$, air-side friction velocity, $\mathrm{u} *$, densities of air and water, $\rho_{\mathrm{a}}$, and $\rho_{\mathrm{w}}$, respectively, reference depth below the water surface $\left(z_{r w}=0.5 \mathrm{~m}\right)$, reference height above the water surface, $z_{r a}$, and the Monin-Obukhov similarity theory integral profile function for potential temperature, $\Psi_{\mathrm{H}}\left(\frac{z}{L}\right)$, which is used to describe the stability and heigh-dependent turbulent diffusivity for sensible heat and gas mixing ratio. The second term in the denominator of Eq. (6.9) replaces $C d^{-1 / 2}$ in Eq. (5a) in the manuscript by Blomquist et al. (2006) because stability was neglected in the original derivation (Fairall 2007). The water-side molecular sublayer thickness, $\delta_{\mathrm{uw}}$, is parameterized as in the COARE cool skin calculation. The coefficients of the molecular sublayers, $h_{\mathrm{a}}$ and $h_{\mathrm{w}}$, are estimated as $h_{\mathrm{a}}=13.3$, neglecting sublayer buoyancy effects, and $h_{\mathrm{w}}=13.3 / \mathrm{A} / \varphi$, where $\varphi$ is a function describing sublayer buoyancy effects as in the COARE cool skin calculation. The empirical constants were $A=1.2$ and $B=1.0$ after the best fit to the University of Hawaii TAO and BIO eddy covariance data.

The COARE Gas Transfer Model was calibrated to over-water eddy covariance $\mathrm{CO}_{2}$ flux measurements (Fairall et al. 2003; Hare et al. 2004). The model calibrated to the GasEx $2001 \mathrm{CO}_{2}$ data was found to adequately describe dimethylsulfide fluxes measured by eddy covariance (Blomquist et al. 2006). In a more recent study (Marandino et al. 
2009), the COARE Gas Transfer Model was shown to give $k_{\mathrm{ol}}$ at the low end of values measured for dimethlysulfide by eddy covariance, which displayed considerable variability. There is current debate on the significance of variables such as biological surfactants, wave age, and diel effects on the water-side sublayer. While it is likely that the COARE Gas Transfer Model model will be further modified and improved as additional data become available, it currently has a more sound theoretical and empirical basis than the W2F Model embodied in Eqs. (6.5) to (6.8) and is a good candidate to replace that model for estimates of PBT air-water exchange.

\subsubsection{Use of the COARE Gas Transfer Model with PBT organic compounds}

C.W. Fairall provided MATLAB code for the COARE 3.0 Bulk Algorithm and the COARE 3.0 DMS gas transfer model used by Blomquist et al. (2006). COARE 3.0 PBT was created by modification of COARE 3.0 DMS. The equation for $k_{\mathrm{a}}$ was modified as in Eq. (6.9). Values of Henry's law constant for PBTs have been cited as a dominant source of uncertainty in W2F Model flux estimates (Hoff 1994), therefore two sets of $H$ values were considered to give a sense of the level of agreement between current estimates: 1) HCB from Jantunen and Bidleman (2006), PCBs from Bamford et al. (2002), and 2) the values used by the IADN Project: HCB from Ten Hulscher et al. (1992), PCB 110 from Beyer et al. (2002), other PCBs from Li et al. (2003). Henry's law constant for PBDEs was obtained from the paper by Cetin and Odabasi (2005). COARE 3.0 PBT accepts an identification number for the organic molecule of interest, which is linked to a data file containing three compound specific properties: Henry's Law slope and intercept, as in:

$$
\log (H)=\frac{A}{T_{w}}+B
$$

molecular mass, and Le Bas molar volume. Dimensionless solubility was calculated from Eq. (6.2). Compound diffusivity in air was calculated using the Fuller equation, and in water using the Hayduk Laudie Equation (as in the text by, Schwarzenbach et al. 2003). Schmidt numbers in air and water were calculated using temperature dependent 
expressions for viscosity obtained from the COARE 3.0 Algorithm (air) and the text by White (1999) (water).

Notable differences exist between PBT transfer velocities predicted by the W2F Model and COARE Models. A comparison of $k_{\mathrm{ol}}$ given by the two models is shown in Figure 6.2, in which percent difference, (COARE-W2F)/W2F $\times 100 \%$, is plotted for hourly meteorological conditions for Lake Ontario, 1973, providing an example of an annual cycle over the Great Lakes. Records with zero wind speed were excluded from the analysis. The structure of the compounds whose $k_{\mathrm{ol}}$ values are compared in Figure 6.2 was shown in Figure 6.1. For the values shown by box and whisker plots, water vapor transfer velocity in the W2F Model was calculated using $C_{\mathrm{e} 10 \mathrm{n}}=1.15 \times 10^{-3}$, in place of Eq. (6.7). The median percent difference between transfer velocities given by the two models using Eq. (6.7) in the W2F model is plotted with circles. Stability-dependent differences between the two models result from the stability-dependent relationship between $U_{10}$ and $u_{*}$, the turbulent contribution to the air-side transfer resistance, and buoyancy effects in the water-side film; the latter two contributions cause differing behavior for the selected water-side and air-side transfer resistance limited compounds. For the water-side transfer resistance limited compound (HCB), the median percent difference varied from -32 (June) to $61 \%$ (September) depending upon the dominant atmospheric stability of the month. However, both stable and unstable conditions occured within every month due to variation in air temperature over diurnal and synoptic time scales. A wide range of percent difference occurred within each month, including extreme values up to $760-2900 \%$, which are beyond the scale of Figure 6.2. For the air-side transfer resistance limited compound $(\alpha-\mathrm{HCH})$ median percent difference varied from $-53 \%$ (June) to $90 \%$ (February), with the unstable enhancement of the COARE model extending over a greater number of months than for HCB. Again a large range of percent difference occurred within each month. The W2F Model is biased high relative to the COARE Model for the air-side limited compound when Eq. (6.7) is used to calculate water vapor transfer velocity in the W2F model, as indicated by the distance of the circles below the median lines of the boxes in Figue 6.2. 


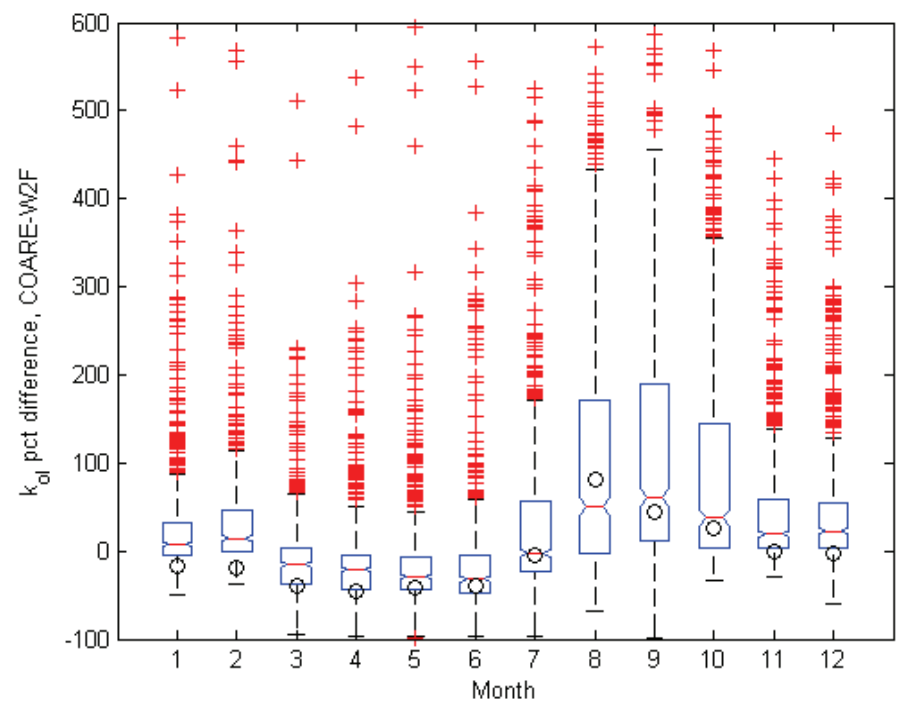

A

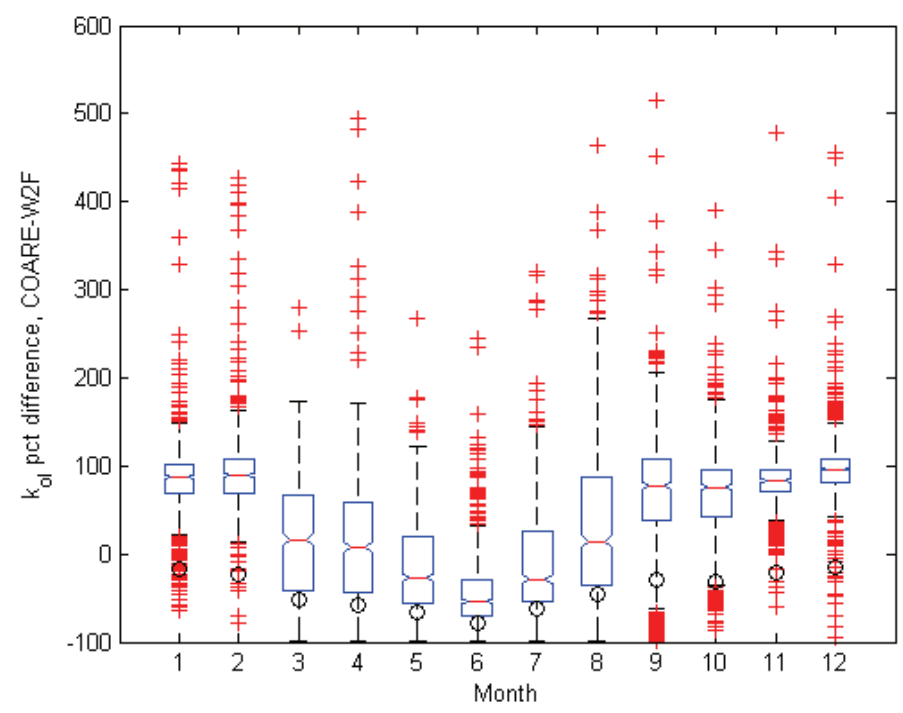

Figure 6.2: Percent difference between COARE and W2F Model PBT transfer velocity for a water-side transfer resistance limited compound, HCB (A), and an air-side transfer resistance limited compound, $\alpha-\mathrm{HCH}$ (B), for 1973 hourly meteorological conditions for Lake Ontario. W2F Model values with corrected water vapor transfer velocity are shown with box and whisker plots, while the median percent difference is shown with a circle using Eq. (6.7) in the W2F model. Extreme values in plot (A) extend to 760 - $2900 \%$ difference (beyond the scale of the figure). Boxes indicate the lower quartile, median, and upper quartile. Whiskers extend to values within 1.5 times the interquartile range. 


\subsection{Experimental}

\subsubsection{Site description}

Modified Bowen ratio flux measurements were conducted at three stations with increasing fetch under offshore flow conditions in eastern Lake Superior on 14 July 2006 on board the U.S. EPA $R / V$ Lake Guardian. Weather conditions during sampling were initially clear, then progressed to $50 \%$ cloud cover at the last station. Waves were calm to $0.3 \mathrm{~m}$. Station locations, sampling times, and meteorological variables are reported in Table 6.1. The station locations are shown in Figure 6.3 along with NOAA HYSPLIT model air parcel backward trajectories and water surface temperature from the NOAA GLSEA data product.

Table 6.1: Conditions at the three sampling stations in eastern Lake Superior on 14 July 2006, and average temperature at the upper $(8.5 \mathrm{~m})$ and lower $(1 \mathrm{~m})$ platforms.

\begin{tabular}{|c|c|c|c|c|c|c|c|c|c|}
\hline $\begin{array}{l}\text { Start } \\
\text { time, } \\
\text { EDT }\end{array}$ & $\begin{array}{l}\text { Finish } \\
\text { time, } \\
\text { EDT }\end{array}$ & Lat. & Lon. & $\begin{array}{l}\text { Fetch, } \\
\mathrm{km}^{\mathrm{a}}\end{array}$ & $\begin{array}{l}\text { Wind, } \\
\mathrm{m} \mathrm{s}^{-1}\end{array}$ & $T_{\mathrm{w}},{ }^{\circ} \mathrm{C}^{\mathrm{b}}$ & $\begin{array}{l}T_{\mathrm{a},}{ }^{\circ} \mathrm{C} \\
\text { lower }\end{array}$ & $\begin{array}{l}T_{\mathrm{a}},{ }^{\circ} \mathrm{C} \\
\text { upper }\end{array}$ & $\begin{array}{l}\text { Sensible } \\
\text { heat } \\
\text { flux, } W \\
m^{-2}\end{array}$ \\
\hline 0620 & 0750 & 46.8571 & 85.3450 & 15.7 & 3.5 & 19.3 & 19.4 & 19.5 & -1.5 \\
\hline 0922 & 1052 & 46.9974 & 85.3245 & 28.3 & 3.4 & 16.9 & 16.7 & 18.3 & -5.2 \\
\hline 1318 & 1448 & 47.2783 & 85.3099 & 58.8 & 4.6 & 15.5 & 16.1 & 17.8 & -9.0 \\
\hline
\end{tabular}

\footnotetext{
${ }^{a}$ Fetch computed based on 10-m, 6-hr back-trajectories computed using NOAA HYSPLIT Model and GIS;
}

${ }^{\mathrm{b}} R / V$ Lake Guardian log data, temperature probe located $2.7 \mathrm{~m}$ below the water surface. 


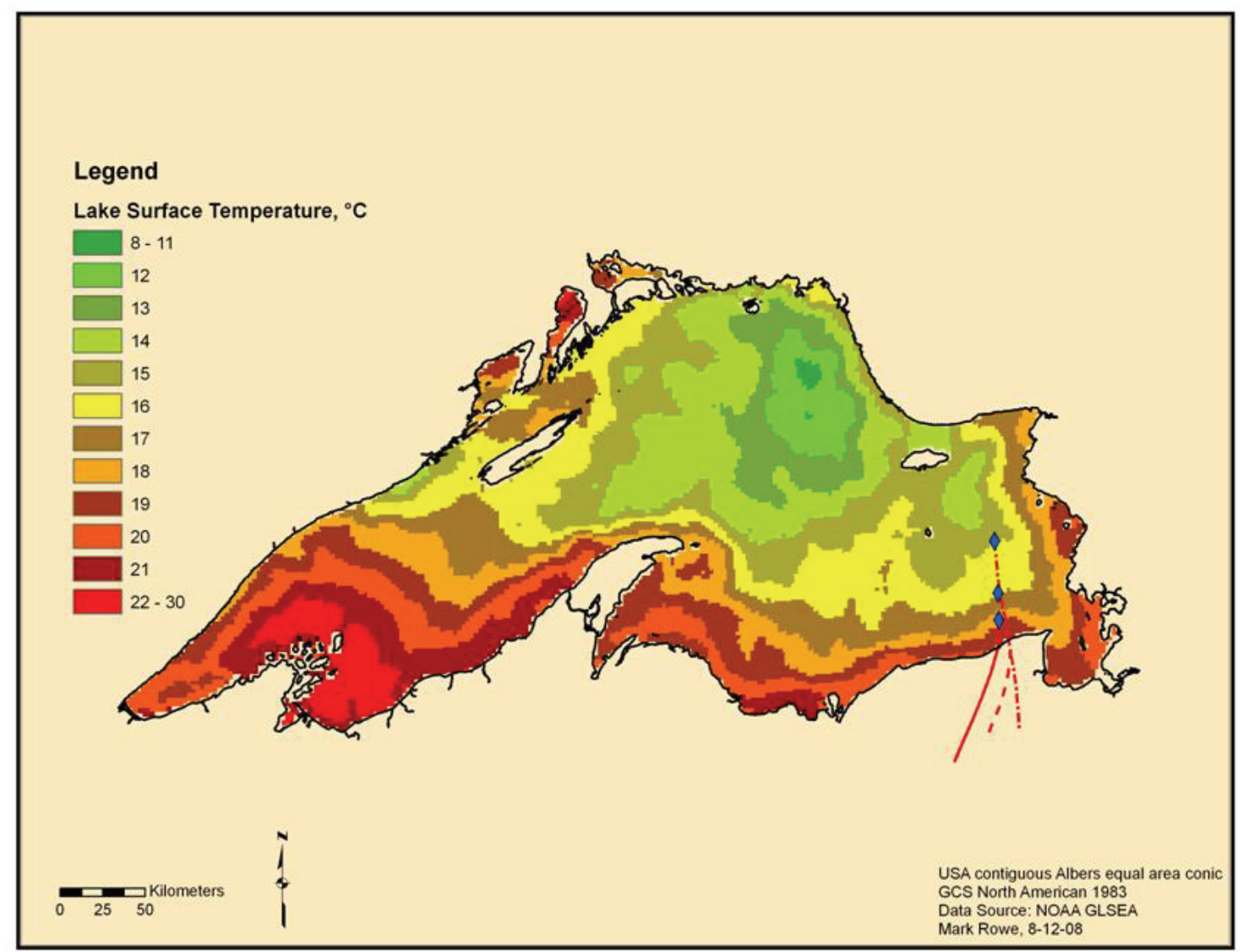

Figure 6.3: A map of Lake Superior showing the station locations (diamonds), NOAA HYSPLIT air parcel backward trajectories (lines), and NOAA GLSEA lake surface temperatures derived from NOAA polar-orbiting satellite imagery for 14 July 2006 . The lake surface temperatures indicated at the stations are $18{ }^{\circ} \mathrm{C}, 17-16^{\circ} \mathrm{C}$, and $16-15^{\circ} \mathrm{C}$ at 15,30 , and $60 \mathrm{~km}$ fetch, respectively. 


\subsubsection{Modified Bowen Ratio (MBR) flux measurements}

Equipment and methods described in detail by Perlinger et al (2005) were used here to carry out MBR flux measurements of PBTs in Lake Superior aboard the U.S. EPA research vessel Lake Guardian. Following this method, measurements were made at upper and lower platforms located at $8.5 \mathrm{~m}$ and $1 \mathrm{~m}$ above the water surface, respectively. PBT concentration, and air temperature (aspirated thermocouple) were measured at both platforms. At the upper platform, sensible heat flux was measured by eddy covariance along with six-axis ship motion, and mean temperature and humidity (Vaisala HMP45C). Eddy covariance measurements were corrected for ship motion using methods of Edson et al. (1998) and computer code provided by NOAA/ESRL. A transfer velocity, $k_{\mathrm{a} 12}$, over the layer of atmosphere between the two platforms is obtained for sensible heat by combining the difference in potential temperature between the two platforms, $\Delta \theta$, with the kinematic sensible heat flux, $\overline{w^{\prime} \theta^{\prime}}$ :

$$
k_{a 12}=\frac{\overline{w^{\prime} \theta}}{\Delta \theta}
$$

This transfer velocity is assumed to apply to all conserved scalar variables (a transport mechanism of turbulent diffusion by small eddies is assumed), and the PBT flux, $F_{\mathrm{PBT}}$, is calculated from the difference in PBT concentration, $\Delta C_{\mathrm{a}}$, between the two plaforms:

$$
F_{P B T}=k_{a 12} \Delta C_{a}=\frac{\overline{W^{\prime} \theta}}{\Delta \theta} \Delta C_{a}
$$

Mixing ratio is the conserved variable for gases. However, because pressure variation with height is negligible over the first $10 \mathrm{~m}$ of the atmosphere, concentration in $\mathrm{pg} \mathrm{m}^{-3}$, referenced to a standard temperature and pressure $\left(25^{\circ} \mathrm{C}, 1 \mathrm{~atm}\right)$, may be used directly in this calculation to obtain a flux in $\mathrm{pg} \mathrm{m}^{-2} \mathrm{~s}^{-1}$.

Flux measurements should be conducted within the constant flux surface layer if the measured flux is to be considered representative of the surface flux. A constant flux surface layer exists under conditions of stationarity, horizontal homogeneity, and a lack of sources or sinks between the measurement height and the surface. The steady-state conservation equation for PBT mass in a volume element with horizontal homogeneity in 
the $y$-dirction, neglecting source terms, vertical advection, and turbulent flux in the $x$ direction is as follows:

$$
U \frac{\partial C_{a}}{\partial x}=-\frac{\partial F_{P B T}}{\partial z}
$$

In the case of offshore flow in the coastal zone, a gradient in the $x$-direction may exist, in which case flux is expected to vary with height above the surface. However if the measurement height is sufficiently low, the flux at the platform approximates the surface flux. Fairall et al. (2006, Fig. 9) found that bulk transfer coefficients calculated from fluxes measured at 18-m height matched those of the COARE Algorithm when the IBL height was greater than $\sim 180 \mathrm{~m}$. This suggests two approaches to test whether measured fluxes are expected to represent surface fluxes: 1) estimate the IBL height and determine whether the upper measurement platform is less than $0.1 h_{\mathrm{ibl}}$, and 2) compare fluxes of sensible heat, latent heat, or momentum to those given by the COARE Algorithm, which has been calibrated and verified against many hours of open ocean flux measurements where horizontal homogeneity was assured.

\subsubsection{Chemical Analysis}

Gaseous concentration of PBTs was measured using low-flow (13 $\left.\mathrm{L} \mathrm{min}^{-1}\right)$ denuder samplers consisting of 289 sections of capillary GC columns (ZB-1, 0.530-mm inside dia., $100 \%$ PDMS, 5- $\mu$ m film, Phenomenex) packed into a deactivated stainless steel tube (250-mm long, 13-mm inside dia.). Details of design, construction, and application of the low-flow denuders are given elsewhere (Tobias et al. 2007; Rowe and Perlinger 2009a). Sample extraction, cleanup, GC analysis, and quality assurance procedures are described in detail elsewhere (Rowe and Perlinger 2009a). Analytes included hexachlorobenzene, 144 PCB congeners, PBDEs 47 and 99. A sample was collected at the upper and lower platform at each of the three stations. In addition, a sample was collected on deck in the ship's bow during 70 min. in transit from 15- to 30-km stations plus $34 \mathrm{~min}$. in transit from 30- to 60-km stations, and an additional sample during 35 min. in transit from 30 - to $60-\mathrm{km}$ stations plus $53 \mathrm{~min}$. in transit beyond the $60-\mathrm{km}$ station. A field blank was transported and stored with the samples, and opened inside the 
upper sampler housing during one sample collection period. A trip blank was transported and stored with the samples. Samples were transported by hand in a cooler on ice.

The denuders were capped and stored 19 months at $4{ }^{\circ} \mathrm{C}$ prior to extraction and analysis. A pair of blank denuders stored four years in the same refrigerator and analyzed along with the samples had $100 \pm 10 \%$ recovery of surrogate standards PCB 14, 65 , and 166 , and $\mathrm{HCB}$ mass less than $20 \%$ of these samples, providing evidence that surrogate recoveries and blank levels were not affected by storage. A calibrated and validated breakthrough model (Rowe and Perlinger 2009c) predicted $<10 \%$ breakthrough for the least retained analytes reported here (HCB and PCB 8) for sampling time up to $3 \mathrm{hr}$ at the maximum sampling temperature observed $\left(19.5^{\circ} \mathrm{C}\right)$, providing evidence that analytes were not lost to breakthrough in the $1.5 \mathrm{hr}$ sample collection times used here, for which 0 $\%$ breakthrough was predicted. Breakthrough was also not predicted for any of the surrogate standards, although low recovery was observed for some surrogate standards in the samples. Surrogate standards PCB 14, 65, and 166, spiked into denuders prior to sampling, were recovered $28 \pm 4 \%, 75 \pm 4 \%$, and $96 \pm 6 \%$ (median \pm range), respectively. Because the method is well characterized and validated (Rowe and Perlinger 2009a), breakthrough of analytes during sampling was not predicted, and evidence exists that samples were not affected by storage, it is likely that low recovery of surrogate PCB 14 occurred because of the hot-spike process for introduction of surrogate standards.

Although PCB 14 has similar retention characteristics to HCB in diffusion denuders, the hot-spike procedure heats the denuder inlet and deposits surrogates some distance into denuder capillaries, reducing their effective breakthrough volumes. The lowest PCB 14 recoveries occurred in denuders with greater sample volume, supporting the hypothesis that low PCB 14 recovery was caused by breakthrough. Analyte mass in blanks was $<20$ $\%$ of analyte mass in samples ( $<6 \%$ for $\mathrm{HCB}$ ), and greater than the method detection limit (Rowe and Perlinger 2009a) for all reported concentrations. Reported concentrations were blank subtracted, but not adjusted for surrogate recovery. 


\subsubsection{Error analysis}

To estimate uncertainty in measured and modeled fluxes, propagation of error analysis was conducted as:

$$
\delta F(x, y, z)=\sqrt{\left(\frac{\partial F}{\partial x} \delta x\right)^{2}+\left(\frac{\partial F}{\partial y} \delta y\right)^{2}+\left(\frac{\partial F}{\partial z} \delta z\right)^{2}}
$$

where $F(\mathrm{x}, \mathrm{y}, \mathrm{z})$ is an arbitrary function of three variables and $\delta()$ indicates the estimated uncertainty in the variable in the form of a standard deviation (Taylor 1982). This analysis assumes that the error contributions are small relative to the mean value, independent, and random.

Error analysis applied to the MBR flux measurement, Eq. (6.15), yields the following expression for relative error on the flux:

$$
\frac{\delta F_{P B T}}{F_{P B T}}=\sqrt{\left(\frac{1}{\rho C_{p} \overline{w^{\prime} \theta}}\right)^{2}+(0.2)^{2}+\left(\frac{\sqrt{2} \delta C_{a}}{\Delta C_{a}}\right)^{2}+\left(\frac{\sqrt{2} 0.1}{\Delta \theta}\right)^{2}}
$$

where the error in the sensible heat flux measurement is divided into a mean bias of $1 \mathrm{~W}$ $\mathrm{m}^{-2}$ and a relative error of $20 \%$ (Fairall et al. 2003). The estimated uncertainty of the aspirated thermocouple temperature measurement is $0.1^{\circ} \mathrm{C} . \delta \mathrm{C}_{\mathrm{a}}$ was estimated as the mean concentration multiplied by the overall method precision estimated as the nonparametric coefficient of variation (Sirois and Vet 1999) of field duplicate measurements of the same compound using the same method (Table 6.2).

Error analysis applied to the bulk flux Eq. (6.1), which is applied here to both W2F and COARE flux calculations, yields:

$\frac{\delta F_{P B T}}{F_{P B T}}=\sqrt{\left(\frac{\delta k_{o l}}{k_{o l}}\right)^{2}+\left(\frac{k_{o l} C_{a} R T_{w}}{F_{P B T} H} \frac{\delta H}{H}\right)^{2}+\left(\frac{k_{o l} R T_{w}}{F_{P B T} H} \delta C_{a}\right)^{2}+\left(\frac{k_{o l}}{F_{P B T}} \delta C_{w}\right)^{2}}$

A value of 0.3 for $\frac{\delta k_{o l}}{k_{o l}}$ was selected after the error analysis of Hoff (1994), which also seems to be a reasonable approximation of the range of measured $k_{\mathrm{ol}}$ for DMS in Blomquist et al. (2006, Fig. 1). The estimated relative error in $C_{a}$ was taken from Table 
6.2, and relative error in $C_{\mathrm{w}}$ was estimated as the relative standard deviation of the available aqueous concentration measurements (Table 6.3), with a minimum value of 0.2 if fewer than three measurements were available. Average relative difference in Henry's law constant (Set 2 - Set 1) was calculated for each PBT at the three stations and reported in Table 6.2. A value of 0.5 was selected for relative error in Henry's law constant, after Blanchard et al. (2008), which is a reasonable approximation of the differences reported in Table 6.2, although considerable variability exists among compounds.

Table 6.2: Overall method precision, expressed as the non-parametric coefficient of variation (CoV) of field duplicates, using the same denuder sampling method as in the 14 July 2006 measurements (Rowe and Perlinger 2009a). Relative difference in Henry's law constant from two sources (Set $2-$ Set 1 ) is also reported.

$\begin{array}{llll}\text { Compound } & \text { CoV } & \begin{array}{l}\text { Number of } \\ \text { duplicate pairs }\end{array} & \begin{array}{l}\text { Relative difference in } \\ \text { Henry's law constant }\end{array} \\ \text { HCB } & 0.09 & 5 & -0.79 \\ \text { PCB 8 } & 0.12 & 3 & 0.20 \\ \text { PCB 18 } & 0.12 & 5 & 0.01 \\ \text { PCB 22 } & 0.08 & 4 & 0.17 \\ \text { PCB 28 } & 0.04 & 4 & 0.53 \\ \text { PCB 34 } & 0.07^{\text {A }} & 1 & 0.09 \\ \text { PCB 110 } & 0.10 & 4 & 0.76 \\ \text { A Only one duplicate pair was available, so the relative difference was reported. }\end{array}$

\subsubsection{Ancillary data}

Inputs for the IBLTE Model include upstream, over-land air temperature, dewpoint temperature, PBT atmospheric concentration, and wind speed, as well as water surface temperature and aqueous PBT concentration. For the 15-, 30-, and 60-km stations, over land meteorological variables were averaged from meteorological stations at Sault Sainte 
Marie, Munising, and Newbury, MI. The time for the initial over-land conditions was adjusted for travel time over water using the fetch and wind speed given in Table 6.1. Over-land air temperature (dewpoint temperature) was $18.8^{\circ} \mathrm{C}\left(16.5^{\circ} \mathrm{C}\right), 23.5^{\circ} \mathrm{C}(17.6$ $\left.{ }^{\circ} \mathrm{C}\right)$, and $27.4^{\circ} \mathrm{C}\left(18.2^{\circ} \mathrm{C}\right)$; wind speed was $2.1,3.1$, and $3.7 \mathrm{~m} \mathrm{~s}^{-1}$, respectively. Water surface temperature as a function of fetch to each station was obtained by geo-referencing the NOAA GLSEA raster image, then extracting data along the NOAA HYSPLIT back trajectory using a geographic information system.

Upstream, over-land atmospheric PBT concentration was not measured. Volatilization fluxes were indicated for all PBTs, so the minimum concentration measured at the $15 \mathrm{~km}$ station was used as an estimate of the over-land concentration for input to the IBLTE Model. Available aqueous PBT concentrations are reported in Table 6.3 .

Table 6.3: PBT concentration ( $\left.\mathrm{pg} \mathrm{L}^{-1}\right)$ in filtered, near-surface $(0.5-1 \mathrm{~m})$ Lake Superior water measured by Michigan Technological University and data compiled by the IADN Project. Mean, relative standard deviation (RSD), and the number of measurements are reported.

\begin{tabular}{|c|c|c|c|c|c|c|}
\hline & $\begin{array}{l}\text { Michi } \\
2004-\end{array}$ & Tech & & IADN & ect ${ }^{b}$ & \\
\hline & Mean & RSD & $\mathrm{n}$ & Mean & RSD & $\mathrm{n}$ \\
\hline HCB & 17.3 & 0.20 & 3 & 13 & 0.09 & $14^{\circ}$ \\
\hline РСВ 8 & & & & & & \\
\hline PCB 18 & 10.1 & 0.18 & 4 & 1.6 & 0.13 & 3 \\
\hline РCB 34 & 3.3 & 0.01 & 2 & & & \\
\hline PCB 28 & 19.1 & 0.14 & 5 & & & \\
\hline PCB 22 & 11.9 & 0.54 & 2 & & & \\
\hline PCB 110 & 44.2 & 0.09 & 5 & & & \\
\hline PCB 44 & 8.0 & 0.13 & 5 & 8.8 & 0.11 & 3 \\
\hline PCB 52 & & & & 3.7 & 0.73 & 3 \\
\hline РCB 101 & 64.4 & 0.09 & 4 & 1.4 & 0.86 & 3 \\
\hline Total PCB & & & & 35 & 0.54 & 3 \\
\hline
\end{tabular}




\subsection{Results and Discussion}

To investigate whether fluxes measured at the upper platform are representative of the surface flux, sensible heat flux measured by eddy covariance was compared to sensible heat flux estimated by the COARE Algorithm using meteorological data in Table 6.1. Eddy covariance and COARE sensible heat flux agreed within the estimated measurement uncertainty at the three stations (Figure 6.4). Fairall et al. (2006) found that eddy covariance fluxes of momentum, sensible heat, and latent heat were biased low compared to COARE fluxes when the measurement height was greater than about $10 \%$

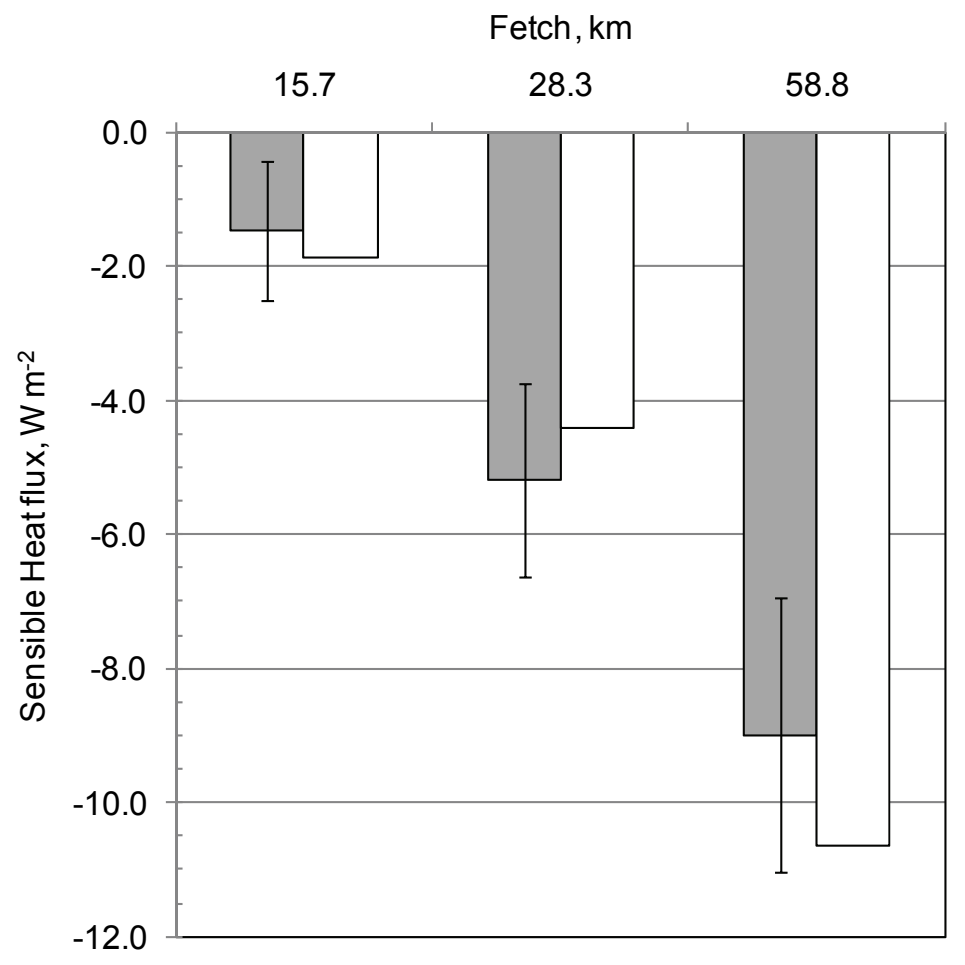

Figure 6.4: Sensible heat flux measured by eddy covariance (filled bar) and estimated by COARE Bulk Algorithm (open bar) at the three stations in Lake Superior. 
of the internal boundary layer height in coastal offshore flow under stable conditions. Modeled IBL height for the 15-, 30-, and 60-km stations was 147, 30, and $30 \mathrm{~m}$, respectively, suggesting that fluxes measured at 8.5-m height may underestimate the surface flux at 30 and $60 \mathrm{~km}$. However, the comparison in Figure 6.4 suggests that fluxes measured at $8.5 \mathrm{~m}$ were reasonably representative of surface fluxes in this case.

The influence of gas transfer model selection and uncertainty in $H$ on $k_{\mathrm{ol}}$ was considered by calculating $k_{\mathrm{ol}}$ for each compound using the meteorological conditions at each station using the two gas transfer models and two sets of $H$ (Figure 6.5). The COARE Model gave higher $k_{\mathrm{ol}}$ than the W2F Model at the $15 \mathrm{~km}$ station where water and air temperatures were equal. Stability increased with fetch at the three stations such that the COARE Model gave similar, then lower, $k_{\mathrm{ol}}$ at the 30 - and 60-km stations, respectively. Differences in $k_{\mathrm{ol}}$ caused by model selection were larger than the influence of uncertainty in $H$ on $k_{\mathrm{ol}}$ in this case. The difference in $k_{\mathrm{ol}}$ between the two models, relative to the average $k_{\mathrm{ol}}$ of the two models, was up to $53 \%$ for the conditions considered here.

PBT concentrations measured at 1-m and 8.5-m height at the 15-, 30-, and 60-km stations are presented in Table 6.4 and Figure 6.6. In most cases, concentration increased with fetch at 1-m height, which is consistent with a volatilization flux. For all PCBs except PCB 8, atmospheric concentration decreased over the course of the day at the upper platform, in apparent contradiction to indications of volatilization flux from the lake. This may be caused by a reduction in concentration over the course of the day in the mixed-layer air incident at the coast. Diel variation in atmospheric PCB concentration has been observed and attributed to photochemical transformation, growth of the mixed layer over the day, or reaction with hydroxyl radical $(\mathrm{OH})$ (Totten et al. 2002; Mandalakis et al. 2003; Macleod et al. 2007). Here, reduction in concentration at 8.5-m height increased with increasing reaction rate constant with $\mathrm{OH}$ (Figure 6.7), suggesting that reaction with $\mathrm{OH}$ may have caused a reduction in PCB concentration incident at the coast over the course of the day. Also shown in Figure 6.7 is the calculted reduction in concentration due to destruction by $\mathrm{OH}$, assuming a typical daytime, mid-latitude, continental $\mathrm{OH}$ concentration of 1 to $7 \times 10^{6}$ molecules $\mathrm{cm}^{-3}$ (Thompson 1995). The dashed lines in 
Figure 6.7 indicate that it is unlikely that destruction by $\mathrm{OH}$ over the 7-hr sampling time period can fully account for the observed reduction in concentration. Alternatively, compounds with greater hydroxyl radical reactivity may have lesser mean mixing ratio in the upper boundary layer and lower free troposphere than near the surface, resulting in dilution as the mixed layer increased in height over the day. A correlation between the reduction in mixing ratio with height in the atmosphere and $\mathrm{OH}$ reactivity is expected because sources of organic compounds are near the surface while destruction by $\mathrm{OH}$ occurs throughout the volume, and such a correlation has been observed for a variety of organic compounds (Anderson and Hites 1996). Few measurements of PBT mixing ratio have been taken above the surface, but Anderson and Hites (1996) estimated the average atmospheric vertical gradient for tri-chloro PCBs by analogy to propane, which has similar $\mathrm{OH}$ reactivity. According to their estimate, the ratio of tri-chloro $\mathrm{PCB}$ mixing ratio at $2 \mathrm{~km}$ to that at the surface is about 0.73 . This suggests that a reduction in PBT mixing ratio at the surface due to dilution, but correlated to $\mathrm{OH}$ reactivity, may occur as the mixed layer grows during the day. Neither of these phenomena alone appears large enough to account for the reduction factor of 0.6 shown in Figure 6.7 for tri-chloro $\mathrm{PCBs}$, but perhaps a combination of dilution and reaction may have caused the reduction, or other phenomena may have contributed. 


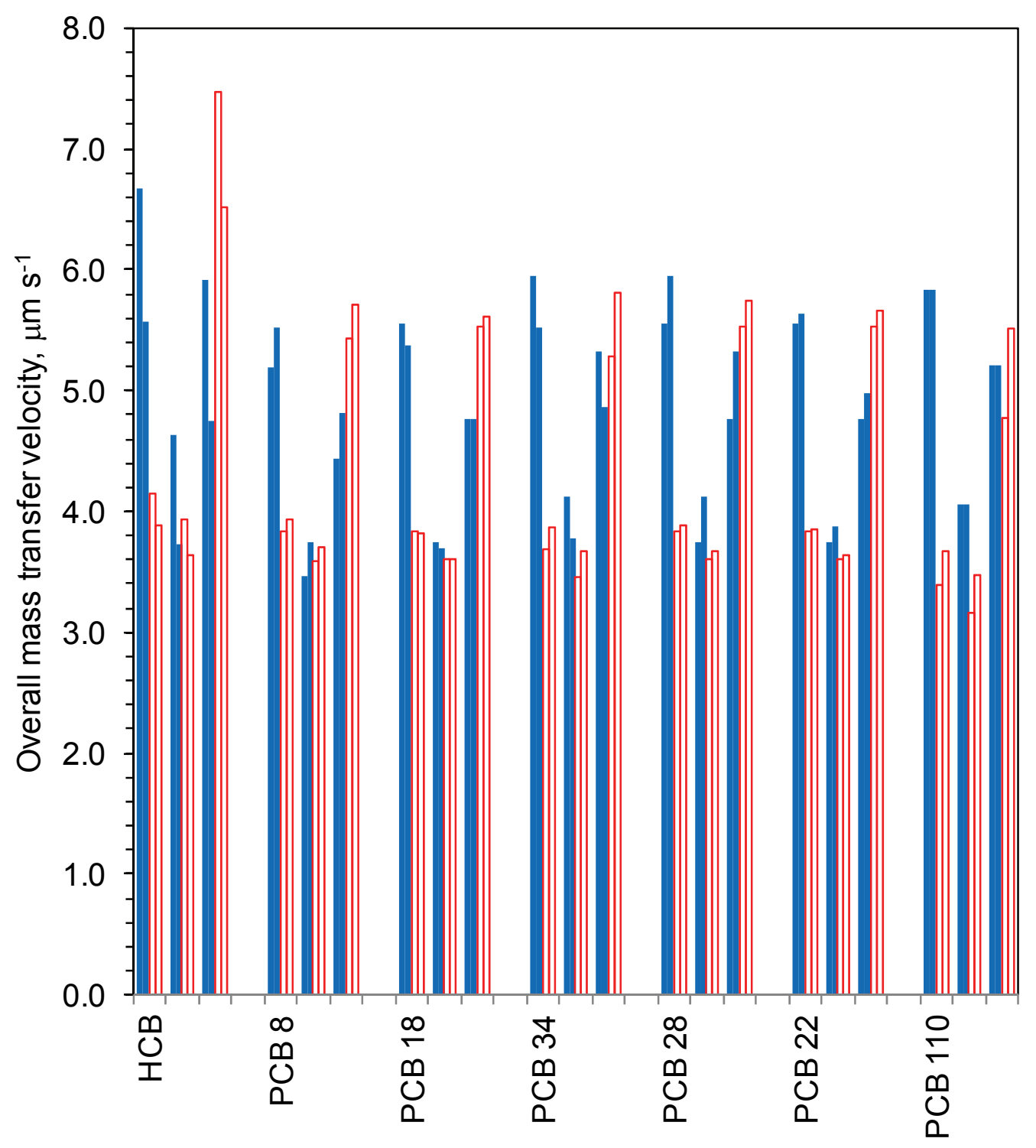

Figure 6.5: Overall mass transfer velocity, $k_{\mathrm{ol}}$, for each PBT at the 15,30 , and $60 \mathrm{~km}$ stations. Filled bars are from the COARE Algorithm with H Set 1 (left) and H Set 2 (right). Open bars are from the W2F Model. 
Table 6.4: Atmospheric PBT concentration measured at the upper (8.5-m) and lower (1m) platforms at 15-, 30-, and 60-km stations in Lake Superior, 14 July 2006 (pg m ${ }^{-3}$ at 25 ${ }^{\circ} \mathrm{C}, 1$ atm).

$\begin{array}{lllll} & \text { Height, } \mathrm{m} & 15 \mathrm{~km} & 30 \mathrm{~km} & 60 \mathrm{~km} \\ \text { HCB } & 8.5 & 58.3 & 64.8 & 60.0 \\ & 1 & 56.3 & 67.9 & 71.0 \\ \text { PCB 8 } & 8.5 & 5.5 & 5.5 & 8.2 \\ & 1 & 7.3 & 10.3 & 11.6 \\ \text { PCB 18 } & 8.5 & 9.2 & 6.8 & 5.3 \\ & 1 & 13.4 & 9.6 & 16.1 \\ \text { PCB 34 } & 8.5 & 11.7 & 4.3 & 4.4 \\ & 1 & 6.7 & 7.6 & 17.0 \\ \text { PCB 28 } & 8.5 & 4.7 & 3.7 & 2.8 \\ & 1 & 6.9 & 5.9 & 6.1 \\ \text { PCB 22 } & 8.5 & 5.7 & 5.6 & 2.2 \\ & 1 & 5.0 & 4.9 & 6.0 \\ \text { PCB 110 } & 8.5 & 3.6 & 2.7 & 3.1 \\ & 1 & 3.8 & 4.7 & 5.6\end{array}$




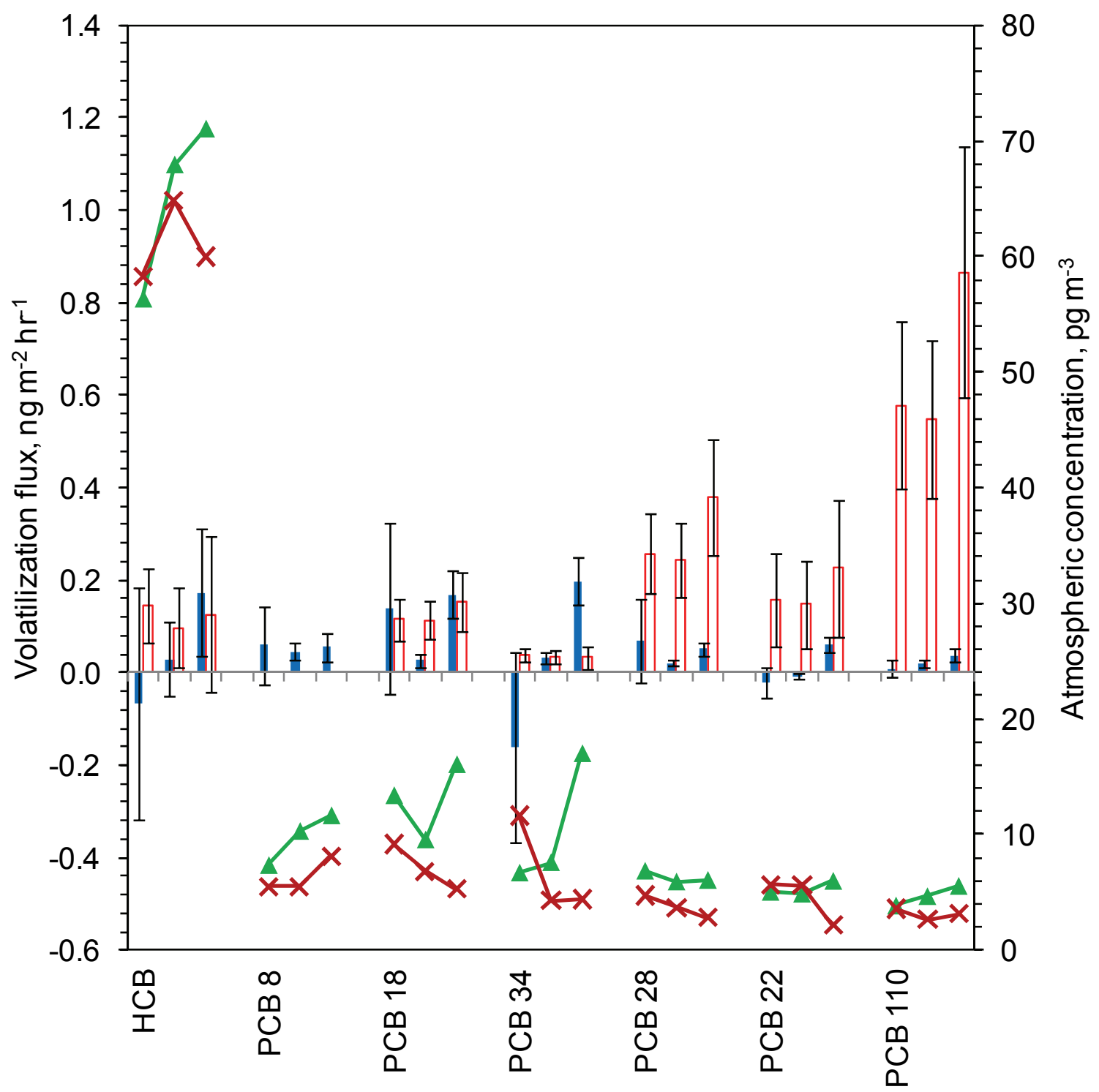

Figure 6.6: For each analyte the PBT flux and atmospheric concentration is plotted (left to right) at the 15-, 30-, and 60-km stations. The MBR flux is shown with an open bar, and the two film flux with an open bar, both with estimated uncertainty given by the error bar. The upper platform concentration is shown with an $\times$ and the lower platform concentration with a triangle. 


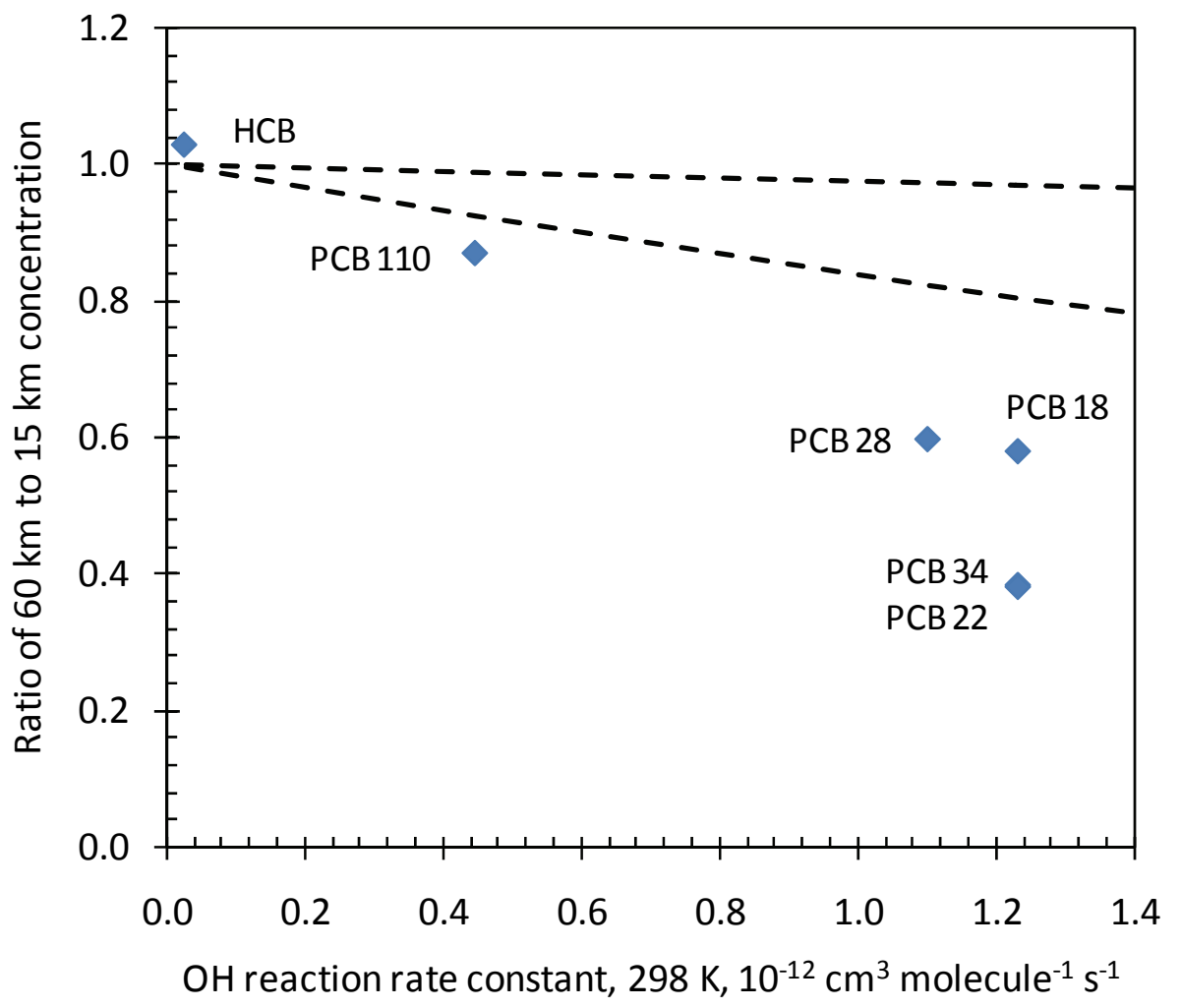

Figure 6.7: Ratio of 15-km station to 60-km station (0620-0750 to $1318-1448$ local time) PBT concentration at $8.5 \mathrm{~m}$ height versus hydroxyl radical reaction rate constant for PBTs in air over Lake Superior on 14 July 2006 (symbols). The calculated reduction in concentration by $\mathrm{OH}$-radical reaction over a 7-hr period is shown by the dashed lines for a typical range of daytime, mid-latitude, continental $\mathrm{OH}$ concentration of $1 \times 10^{6}$ (upper line) to $7 \times 10^{6}$ molecules $\mathrm{cm}^{-3}$ (lower line). 
Measured and predicted fluxes are shown in Figure 6.6. COARE fluxes (not shown) fell within the estimated uncertainty range of the W2F fluxes because they rely on the same $C_{\mathrm{w}}$ and $H$. Most of the MBR and W2F fluxes indicate net volatilization, consistent with the increase in concentration with fetch at $1-\mathrm{m}$ height. Volatilization fluxes may be expected for these compounds during the summer when Lake Superior surface water is near its warmest point in the annual cycle.

Uncertainty estimates shown in the error bars in Figure 6.6 are useful to distinguish the conditions under which MBR flux measurements were significantly different from zero, and to indicate whether or not differences between MBR and W2F fluxes are significant relative to the uncertainty. Contributions of the individual terms in Eqs. (6.18) and (6.19) to the overall relative error are given in Table 6.5 and Table 6.6. At the 30and $60-\mathrm{km}$ stations, the MBR flux is larger than the estimated uncertainty in most cases. At the $15-\mathrm{km}$ station stability was near neutral, which resulted in small temperature and concentration gradients, as well as a small sensible heat flux, all of which contributed to a large relative error in the MBR measurement at $15 \mathrm{~km}$. At 30- and $60-\mathrm{km}$, the air temperature had increased over the course of the day and water temperature decreased with fetch (Figure 6.3), which enhanced atmospheric stability, temperature gradient, sensible heat flux, and PBT gradient with fetch, conditions favorable for measurement of the flux by MBR. Measurement of the PBT gradient was the greatest single contribution to uncertainty in the MBR flux at 30 and $60 \mathrm{~km}$ in most cases, but in some cases, particularly at $60 \mathrm{~km}$, the PBT gradient and sensible heat flux contributed nearly equally to the overall uncertainty. The relative errors for $\mathrm{W} 2 \mathrm{~F}$ flux measurements may be considered rough estimates because the uncertainty in $k_{\mathrm{ol}}$ and $H$ are estimated, and few $C_{\mathrm{w}}$ measurements were available from which to estimate spatial, temporal, and measurement variability in $C_{\mathrm{w}}$. Uncertainty in $C_{\mathrm{w}}$ was the greatest single contribution to relative error in the W2F flux estimate in most cases, and may be underestimated in Table 6.6 due to the small number of available $C_{\mathrm{w}}$ measurements. The contribution of uncertainty in $H$ appears to be small for PCBs 28, 22, and 110 because of the large fugacity for these compounds resulting from the available value of $C_{\mathrm{w}}$. 
Table 6.5: Contributions to the relative error in the MBR flux measurements given by the terms in Eq. (6.18)

\begin{tabular}{|c|c|c|c|c|c|c|}
\hline & $\begin{array}{l}\text { Fetch, } \\
\text { km }\end{array}$ & $\begin{array}{l}\overline{\boldsymbol{W} \cdot \boldsymbol{\theta}} \\
\text { bias }\end{array}$ & $\begin{array}{l}\overline{\boldsymbol{w}^{\prime} \boldsymbol{\theta}} \\
\text { random }\end{array}$ & $\Delta C_{a}$ & $\Delta \theta$ & $\begin{array}{l}\text { Overall } \\
\text { relative } \\
\text { error }\end{array}$ \\
\hline \multirow[t]{3}{*}{$\mathrm{HCB}$} & 15 & 0.68 & 0.20 & 3.64 & 1.05 & 3.86 \\
\hline & 30 & 0.19 & 0.20 & 2.72 & 0.09 & 2.74 \\
\hline & 60 & 0.11 & 0.20 & 0.76 & 0.08 & 0.80 \\
\hline \multirow[t]{3}{*}{ PCB 8} & 15 & 0.68 & 0.20 & 0.60 & 1.05 & 1.40 \\
\hline & 30 & 0.19 & 0.20 & 0.28 & 0.09 & 0.41 \\
\hline & 60 & 0.11 & 0.20 & 0.49 & 0.08 & 0.54 \\
\hline \multirow[t]{3}{*}{ PCB 18} & 15 & 0.68 & 0.20 & 0.46 & 1.05 & 1.35 \\
\hline & 30 & 0.19 & 0.20 & 0.51 & 0.09 & 0.59 \\
\hline & 60 & 0.11 & 0.20 & 0.17 & 0.08 & 0.30 \\
\hline \multirow[t]{3}{*}{ PCB 34} & 15 & 0.68 & 0.20 & 0.18 & 1.05 & 1.28 \\
\hline & 30 & 0.19 & 0.20 & 0.18 & 0.09 & 0.34 \\
\hline & 60 & 0.11 & 0.20 & 0.08 & 0.08 & 0.26 \\
\hline \multirow[t]{3}{*}{ PCB 28} & 15 & 0.68 & 0.20 & 0.17 & 1.05 & 1.28 \\
\hline & 30 & 0.19 & 0.20 & 0.14 & 0.09 & 0.32 \\
\hline & 60 & 0.11 & 0.20 & 0.09 & 0.08 & 0.26 \\
\hline \multirow[t]{3}{*}{ РCВ 22} & 15 & 0.68 & 0.20 & 0.92 & 1.05 & 1.56 \\
\hline & 30 & 0.19 & 0.20 & 0.77 & 0.09 & 0.83 \\
\hline & 60 & 0.11 & 0.20 & 0.12 & 0.08 & 0.27 \\
\hline \multirow[t]{3}{*}{ РCB 110} & 15 & 0.68 & 0.20 & 1.90 & 1.05 & 2.28 \\
\hline & 30 & 0.19 & 0.20 & 0.24 & 0.09 & 0.38 \\
\hline & 60 & 0.11 & 0.20 & 0.23 & 0.08 & 0.34 \\
\hline
\end{tabular}


Table 6.6: Contributions to the relative error in the W2F flux estimates given by the terms in Eq. (6.19)

\begin{tabular}{|c|c|c|c|c|c|c|}
\hline & $\begin{array}{l}\text { Fetch, } \\
\text { km }\end{array}$ & $k_{o l}$ & $\boldsymbol{H}$ & $C_{a}$ & $C_{w}$ & $\begin{array}{l}\text { Overall } \\
\text { relative } \\
\text { error }\end{array}$ \\
\hline \multirow[t]{3}{*}{$\mathrm{HCB}$} & 15 & 0.30 & 0.34 & 0.06 & 0.33 & 0.56 \\
\hline & 30 & 0.30 & 0.66 & 0.12 & 0.47 & 0.87 \\
\hline & 60 & 0.30 & 1.12 & 0.20 & 0.65 & 1.35 \\
\hline \multirow[t]{3}{*}{ PCB 18} & 15 & 0.30 & 0.10 & 0.02 & 0.22 & 0.38 \\
\hline & 30 & 0.30 & 0.08 & 0.02 & 0.21 & 0.37 \\
\hline & 60 & 0.30 & 0.16 & 0.04 & 0.24 & 0.42 \\
\hline \multirow[t]{3}{*}{ PCB 34} & 15 & 0.30 & 0.11 & 0.01 & 0.24 & 0.40 \\
\hline & 30 & 0.30 & 0.14 & 0.02 & 0.26 & 0.42 \\
\hline & 60 & 0.30 & 0.57 & 0.08 & 0.43 & 0.78 \\
\hline \multirow[t]{3}{*}{ PCB 28} & 15 & 0.30 & 0.02 & 0.00 & 0.15 & 0.33 \\
\hline & 30 & 0.30 & 0.02 & 0.00 & 0.15 & 0.33 \\
\hline & 60 & 0.30 & 0.02 & 0.00 & 0.15 & 0.33 \\
\hline \multirow[t]{3}{*}{ PCB 22} & 15 & 0.30 & 0.03 & 0.00 & 0.57 & 0.64 \\
\hline & 30 & 0.30 & 0.03 & 0.00 & 0.57 & 0.65 \\
\hline & 60 & 0.30 & 0.04 & 0.01 & 0.58 & 0.66 \\
\hline \multirow[t]{3}{*}{ PCB 110} & 15 & 0.30 & 0.00 & 0.00 & 0.09 & 0.31 \\
\hline & 30 & 0.30 & 0.00 & 0.00 & 0.09 & 0.31 \\
\hline & 60 & 0.30 & 0.01 & 0.00 & 0.09 & 0.31 \\
\hline
\end{tabular}


The aqueous concentration was the greatest contribution to uncertainty in the W2F and COARE Model flux estimates. Clearly there are some inconsistencies in the concentrations reported in Table 6.3. Michigan Tech and IADN Project HCB and PCB 44 concentrations are in reasonable agreement. Otherwise, the Michigan Tech concentrations are approximately ten-fold greater than individual congener concentrations collected by the IADN Project, and some individual Michigan Tech congeners are greater than the total PCB concentration of the IADN Project. Measurement of aqueous PCB concentrations in Lake Superior is challenging because concentrations are near detection limits; few recent data have been reported and a recent Environment Canada sampling campaign yielded no reportable concentrations for PCBs (Personal communication, J. Waltho, Environment Canada). In an effort to obtain sufficient analyte mass, the Michigan Tech method used a large sample volume, 720 to $790 \mathrm{~L}$, compared to the $24 \mathrm{~L}$ samples used by Environment Canada (Table 6.3). The MBR flux, which does not depend on estimates of $C_{\mathrm{w}}$, can give some indication as to which of the Table 6.3 aqueous concentrations appear reasonable. Comparing MBR to W2F flux at $60 \mathrm{~km}$, where uncertainty is least, either HCB concentration could be consistent with the measured flux within the uncertainty. For PCB 18, the Michigan Tech value is a good fit to the MBR flux, while the much lower IADN value gives near-zero or negative fluxes. For the remaining PCBs the IADN Project did not report $C_{\mathrm{w}}$, and Michigan Tech $C_{\mathrm{w}}$ gave fluxes much larger than the MBR method, suggesting that lower $C_{\mathrm{w}}$, more similar to the other congener-specific concentrations reported by the IADN Project, would be more reasonable.

The IBLTE Model was applied to compare modeled to measured flux, modification in concentration, and vertical gradients in concentration near the surface. Modeled and measured modification in air temperature and vertical gradient in air temperature were in reasonable agreement (Figure 6.8), which provides a means to evaluate the treatment of vertical mixing in the atmosphere within the IBLTE Model. Modification in air temperature was slightly underpredicted, which may result from an overestimate of the IBL growth rate, an initial over-land air temperature that was not representative of the air mass sampled, or contributions to sensible heat not accounted for in the model, such as 
radiation. Modeled and measured modification in $\mathrm{HCB}$ atmospheric concentration were in good agreement, particularly at 1-m height (Figure 6.9). This analysis gives an indication that the HCB atmospheric concentration measurements, aqueous HCB concentration, Henry's law constant, COARE Gas Transfer Model, and the IBLTE Model parameterization are all in reasonable agreement.

It is interesting to consider the complex interaction between the influence of wind speed and varying water surface temperature on the fetch-dependent HCB flux (Figure 6.10). Initially, flux increases with fetch because of the acceleration of the near-surface wind speed caused by the reduction in aerodynamic roughness of water compared to land. In Figure 6.10, the change in wind speed is modeled using the empirical parameterization of Phillips and Irbe (1978). The water surface temperature decreased with increasing fetch, which caused a reduction in flux because of reduced $K_{\mathrm{aw}}$ and increased atmospheric stability. W2F fluxes were in good agreement with IBLTE Model fluxes, primarily because they both rely on the same $K_{\mathrm{aw}}$ and aqueous concentration. MBR fluxes were consistent with W2F and IBLTE Model fluxes within estimated uncertainty.

For several PCBs, the W2F flux in Figure 6.6 is much larger than the MBR flux. The IBLTE Model offers a means to evaluate which flux is more consistent with the measured modification in PBT atmospheric concentration. The ratio of modeled to measured landlake modification in PBT atmospheric concentration at 1-m height, 60-km fetch, using Set 2 Henry's law constant and Michigan Tech aqueous concentration from Table 6.3, is given in Table 6.7. Modeled modification in concentration was much greater than observed for PCBs 28, 22, and 110, even considering that the upstream, over-land atmospheric concentration may have decreased by up to a factor of two over the same time period (Figure 6.7). The observed modification in concentration is more consistent with the smaller MBR volatilization fluxes for these compounds. The discrepancy in modeled versus measured modification in concentration is also larger than what can be accounted for by the estimated uncertainty in $K_{\mathrm{aw}}$ and $k_{\mathrm{ol}}$, suggesting that the available aqueous concentrations for these compounds (Table 6.3) are too high. 
Table 6.7: Ratio of modeled to measured land-lake modification in PBT atmospheric concentration at 1-m height, 60-km fetch using Set 2 Henry's law constant and Michigan Tech aqueous concentration from Table 6.3 .

$\begin{array}{ll}\text { HCB } & 1.2 \\ \text { PCB 18 } & 2.7 \\ \text { PCB 28 } & 34.4 \\ \text { PCB 22 } & 26.7 \\ \text { PCB 34 } & 0.5 \\ \text { PCB 110 } & 80.3\end{array}$

\subsection{Conclusion}

Measurement and estimation of air-water exchange fluxes of organic toxics that are present at $\mathrm{pg} \mathrm{m}^{-3}$ concentrations in the atmosphere and at $\mathrm{pg} \mathrm{L}^{-1}$ aqueous concentrations is challenging because several measurements, each of which may have considerable uncertainty, must be combined. Here, a transect measurement approach that incorporates modified Bowen ratio flux measurements collected at stations with increasing fetch in offshore flow was combined with an internal boundary layer transport exchange model to provide an opportunity for critical evaluation of measured and estimated fluxes by quantitative comparison of measured and modeled modification in PBT atmospheric concentration with fetch at $1-\mathrm{m}$ height over the water. Significantly non-zero volatilization fluxes were measured by the MBR method for $\mathrm{HCB}$ and several $\mathrm{PCB}$ congeners. Volatilization fluxes were consistent with observed increase in concentration with fetch at 1-m height for most compounds.

Comparison of PBT transfer velocities predicted by W2F and COARE gas transfer models revealed significant differences between the two for hourly meteorological conditions representative of an annual cycle over the Great Lakes. The COARE Model is recommended over the W2F Model because it accounts for physical proesses that the W2F parameterizations do not. These results suggest that the averaging of meteorological conditions that is typically done in computing transfer velocities using the W2F model may cause bias in flux estimates through loss of the significant variation in transfer velocity that occurs on diurnal and synoptic time scales. 

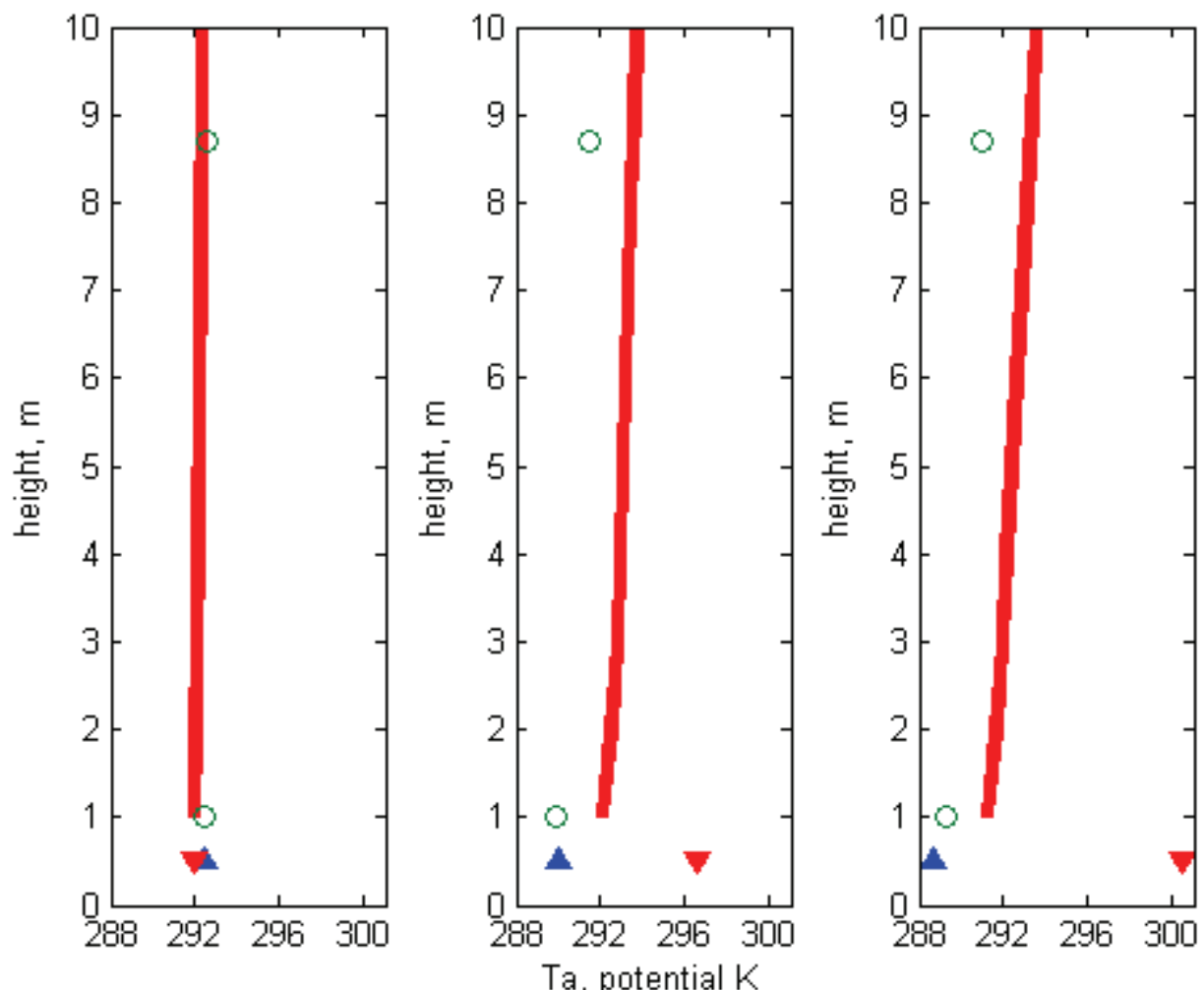

Figure 6.8: Measured (circles) and IBLTE-Modeled (line) air temperature at the 15-, 30-, and $60-\mathrm{km}$ stations (panels from left to right). The water surface temperature is plotted as an upward-pointing blue triangle, and the initial over-land air temperature as a downward-pointing red triangle. 

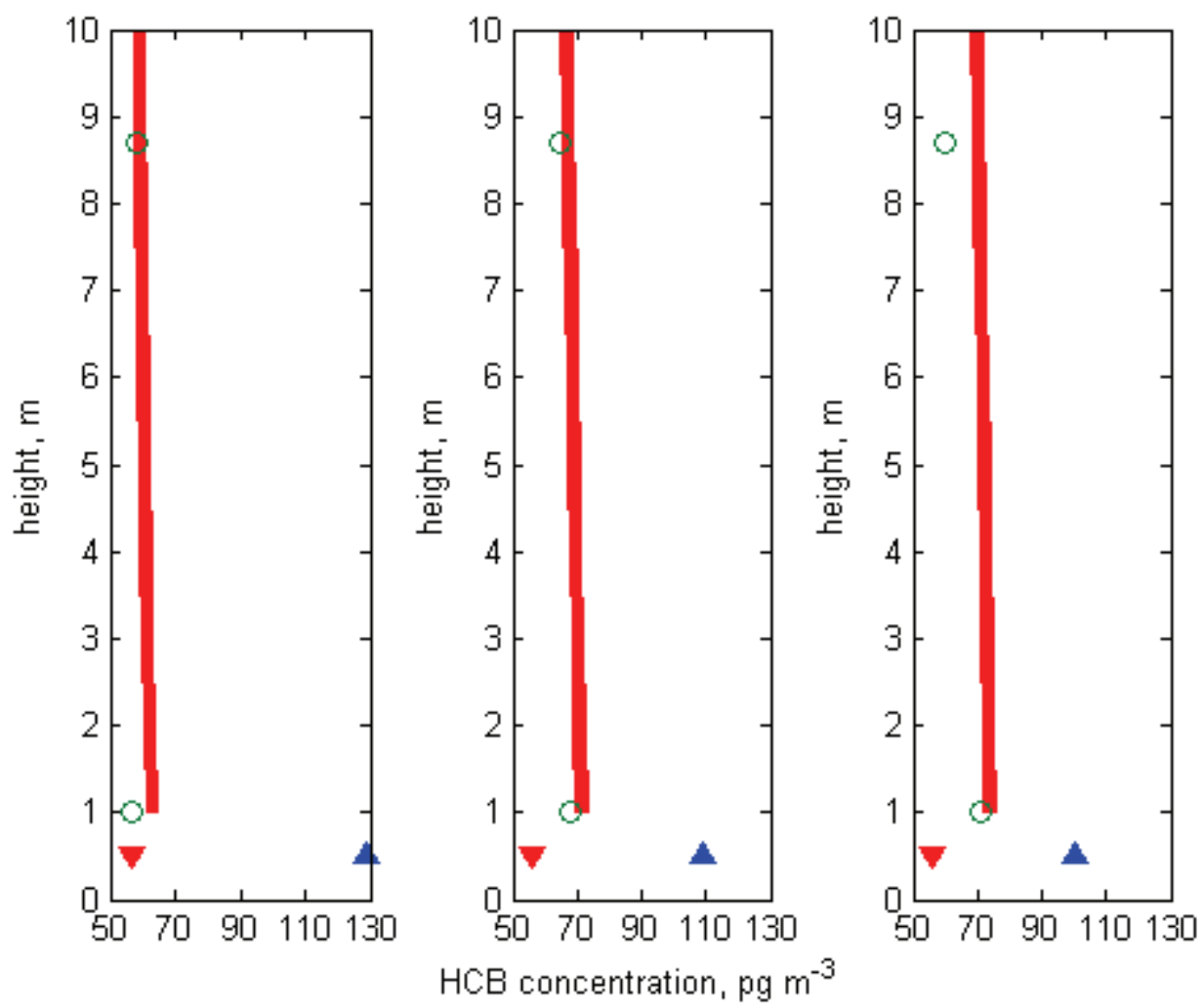

Figure 6.9: Measured (circles) and IBLTE modeled (line) HCB atmospheric concentration at the 15-, 30-, and 60-km stations (panels from left to right). The HCB concentration at equilibrium with the water surface is plotted as an upward-pointing blue triangle, and the initial over-land HCB concentration as a downward-pointing red triangle. 

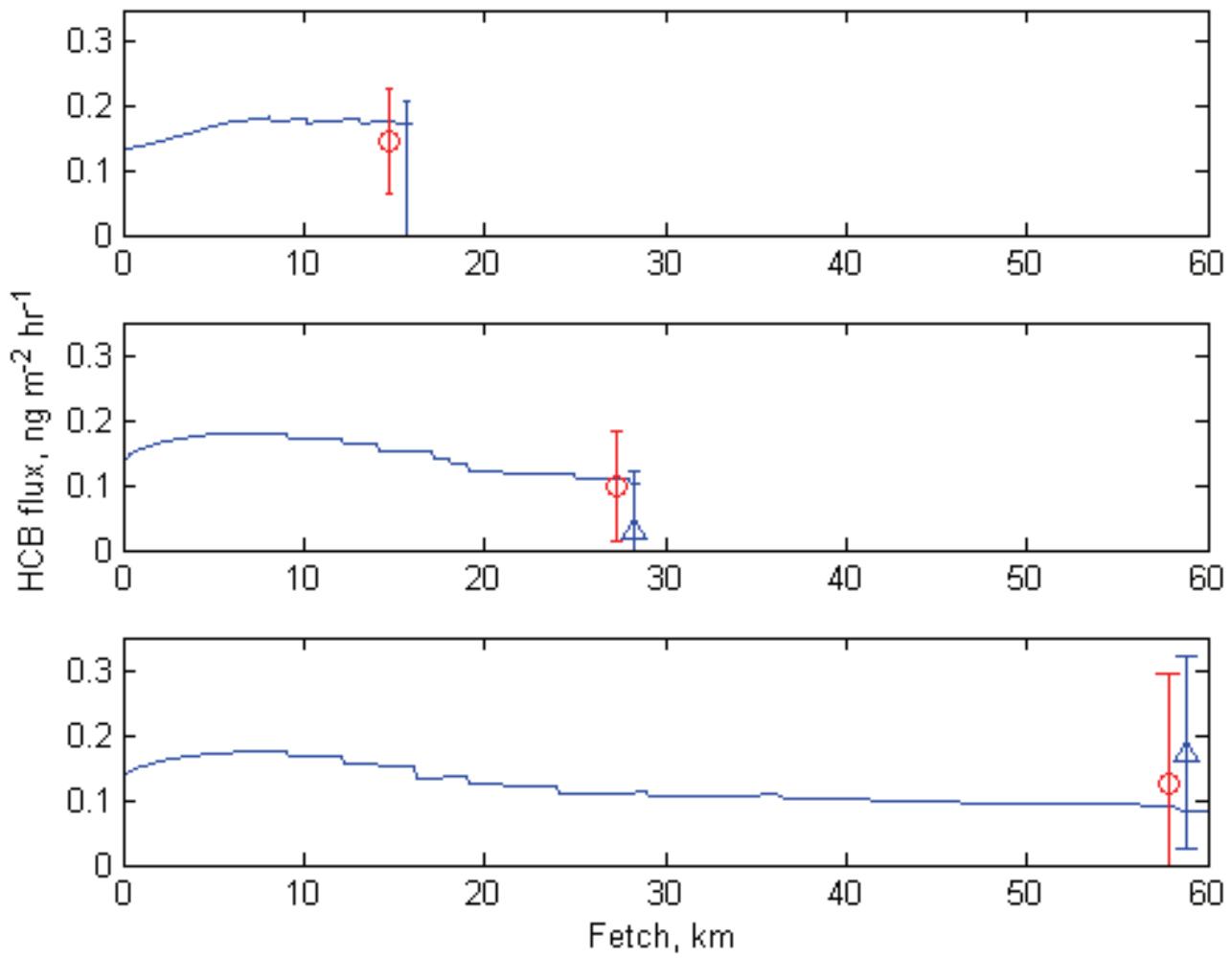

Figure 6.10: HCB flux versus fetch from the IBLTE Model for (top to bottom panels) 15$\mathrm{km}, 30-\mathrm{km}$, and $60-\mathrm{km}$ stations. Two film (circle) and MBR flux (triangle) at the station are re-plotted from Figure $\mathbf{6 . 6}$ for reference. Discontinuities in the IBLTE Model flux are caused by the finite spatial resolution of the water surface temperature data. 


\section{Conclusions and future research}

In this work, improved methods for measurement of atmospheric PBT concentrations using multicapillary denuders were developed, and the methods were applied to measurement of indoor and outdoor atmospheric PBT concentrations, as well as to measurement of PBT air-water exchange fluxes. Models were developed for prediction of collection efficiencies and artifacts in multicapillary denuders and interpretation of micrometeorological air-water exchange flux measurements in the coastal zone. These developments suggest directions for future research.

\subsection{Methods for improved precision and temporal resolution for non-polar atmospheric PBT measurements}

Application of the gas-phase cleanup method to the low-flow denuder improved precision and method detection limits for this method for non-polar PBTs. Development of the high-flow denuder, along with the gas-phase cleanup method, provided a method for non-polar PBTs that offers greater temporal resolution than the conventional highvolume sampler, and comparable precision, while offering the potential to avoid some of the artifacts in particle-gas separation and reactive losses of analytes associated with the conventional method.

The thermal extraction methods offer the ability to collect a sample in a relatively short period of time compared to solvent extraction methods. High temporal resolution sampling is useful for investigation of phenomena such as gaseous atmosphere-surface exchange and diel variations in concentration caused by surface exchange and chemical transformations. Improved understanding of these phenomena will allow for development of improved fate and transport models for PBTs. High temporal resolution sampling is also useful for location of source regions by backward trajectory analysis, which is critical to achieve further reductions in ecosystem contamination levels for legacy chemicals. For indoor air sampling, the low-flow denuder method offers reduced pump size and sample volume relative to the high volume sampler, which is advantageous for sampling in small rooms and work places. 
Several avenues of future research may lead to further improvements in the methods developed in this work. The gas-phase cleanup method is limited to non-polar and thermally stable compounds. Several classes of chemicals of emerging concern and secondary organic aerosol precursors are polar yet exhibit some volatility. A fundamental limitation of a gas-phase cleanup method is that the selectivity of the mobile phase cannot be manipulated as in solvent-based cleanup methods. One option is to perform the initial transfer from denuder to thermal desorption (TD) tube by thermal extraction, then extract the TD tube with a small volume of solvent. This would avoid the need for extraction using a large volume of solvent and evaporative concentration as in conventional

methods, while allowing for the use of conventional solvent-based cleanup methods for separation of the sample components. Transfer of the solvent extract into the analytical instrument after cleanup could be accomplished by large-volume injection. Alternatively, a method could be developed to transfer the solvent extract back into a TD tube for transfer into the analytical instrument by thermal desorption. A second option is to perform the initial extraction of the denuder by supercritical fluid extraction, which would make the method more amenable to analysis of thermally labile compounds. For the high-flow denuder, preliminary results indicated that the cordierite ceramic honeycomb substrate provided better resolution in the chromatogram than the stainless steel substrate, which may be related to reduced stationary phase bleed. Future work may follow up on use of the ceramic substrate for multicapillary denuder fabrication, which is also lower in cost, and available in longer lengths than the stainless steel honeycomb.

\subsection{Atmosphere-surface exchange flux measurements for PBTs}

Air-water exchange flux measurements for $\mathrm{HCB}$ and PCBs were conducted using the modified Bowen ratio (MBR) approach using the low-flow denuders for PBT collection with the gas-phase cleanup method. Addition of the cleanup provided improved precision and method detection limits, and allowed micrometeorological measurements of PCB fluxes to be reported for the first time.

Improvements to flux measurement methods and field experiment design could allow for critical evaluation of gas exchange velocity parameterizations in the future. The flux 
measurements reported here were conducted on the basis of opportunity using the U.S. EPA R/V Lake Guardian. Use of the Michigan Tech R/V Agassiz would allow for greater flexibility in design of field experiments. One approach that may improve the quality of MBR flux measurements using the Agassiz is to drift behind a sea anchor during sampling with engines shut off. A sea anchor is a drogue that is towed through the water and reduces the drift speed of the boat by increasing drag. This would avoid contamination of the lower platform PBT sample with engine exhaust and avoid potential contamination of the sonic anemometer data by engine vibration. Re-location of the lower platform to the bow would also reduce the potential for contamination of the lower PBT sample, although vertical motion at that location may be greater. Use of infrared gas analyzers on the upper and lower platforms would provide measurements of the water vapor and carbon dioxide fluxes and gradients, allowing for two additional means to measure the transfer velocity between the two platforms for use in the MBR method. This would avoid the limitation caused by inability to measure a temperature gradient for neutral conditions in the conventional MBR method. Finally, switching pumps between the upper and lower platforms during sampling would minimize the potential impact of bias introduced by inaccurate quantification of the pump flow rate.

Larger sample volume may allow MBR flux measurement for a greater number of analytes. The model for prediction of gaseous collection efficiency can be applied to optimize the sample time and flow rate to maximize sample volume while avoiding breakthrough. It is likely that the low-flow denuder flow rate can be increased to some extent to reduce sample collection time. Two low-flow denuders in series can be used to increase sample capacity, and both denuder sample extracts may be transferred into the same TD tube for cleanup and analysis. Collection of field duplicate samples would enhance the ability to estimate measurement precision. The high-flow denuders offer greater sample capacity than the low-flow denuders. However, the method precision was lower, and blank levels higher for the high-flow denuder method, relative to the low-flow denuder, which is a disadvantage for MBR flux measurements.

Measurement of the aqueous PBT concentration concurrently with MBR flux measurements would allow for experimental determination of the transfer velocity for 
comparison with transfer velocity parameterizations. Development of an air-water equilibrator that can operate at the sample flow rate of the denuder would allow for measurement of the atmospheric PBT concentration at equilibrium with the aqueous PBT concentration using the denuder analytical method. The equilibrator would produce air that has been equilibrated with the aqueous PBT concentration, which could then be sampled with the denuder. This would avoid the added cost of analyzing the aqueous concentration by a different method than the denuder samples, the need for knowledge of the Henry's law constant, and the need to accurately separate dissolved from sorbed PBT fractions in an aqueous sample.

Sampling at multiple stations with increasing fetch in offshore flow allows for comparison of the flux measurements with PBT atmospheric concentration modification with fetch. Ideally, an upstream sampling station at the coast would measure upstream, over-land PBT concentration, air temperature, and humidity for the over-water flux measurements for input into the IBLTE Model.

\subsection{Determination of the internal boundary layer growth rate coefficient by calibration of the IBLTE Model}

A parameterization was developed that gives the internal boundary layer (IBL) height as a function of fetch and stability given meteorological conditions incident at the coast. Reasonable agreement was obtained between the IBL growth rate coefficient, $\alpha$, obtained from calibration of the IBLTE Model to a large data set of air temperature and humidity modification from the International Field Year of the Great Lakes, 1973, (Phillips and Irbe 1978) and $\alpha$ obtained from a simplified atmospheric diffusion equation and an estimate of the atmospheric eddy diffusivity from Monin Obukhov similarity theory (MOST). However, discrepancies existed between the MOST $\alpha$ and calibrated values of $\alpha$ for some of the Phillips and Irbe classes of wind speed and air-water temperature difference. A problem with the Phillips and Irbe data is that they were classified by wind speed and air-water temperature difference, then averaged, and some of the classes covered a wide range of atmospheric stability. A further problem is that the data were in the form of absolute temperature modification, rather than modification relative to the 
initial air-water temperature difference or dewpoint temperature difference. The original Phillips and Irbe data are no longer available for re-analysis.

It may be possible to obtain data similar to the Phillips and Irbe data set from buoys, ship logs (for example the R/V Lake Guardian, passenger, or commercial ships equipped with meteorological instruments), or meteorological stations located on islands. This would provide an opportunity to classify the data by bulk Richardson number, and calculate the air temperature and dewpoint temperature modification relative to the initial value at the coast rather than in absolute terms. Such an analysis may allow for a more critical comparison between the calibrated values of $\alpha$ and the MOST values of $\alpha$ to determine if the discrepancies observed in this work were caused by the classification scheme of Phillips and Irbe or by the simplifying assumptions used in the MOST analysis. However, it would be difficult to reproduce the range of atmospheric stability and fetch of the Phillips and Irbe data set, which was obtained by installing a network of 20 data buoys in Lake Ontario for a 12-month period.

\subsection{Application of the IBLTE and COARE gas transfer models to PBT air- water exchange estimates.}

A comparison of the COARE and W2F gas exchange models showed that important differences exist between the two. Specifically, the water vapor transfer velocity parameterization commonly used with the W2F model differs by approximately a factor of two from recent micrometeorological measurements of the water vapor transfer velocity, which likely causes the W2F model to give incorrect results for air-side transfer resistance limited compounds. Additionally, buoyancy effects are neglected in the W2F model, which causes important differences between the two models when the full range of meteorological conditions representative of a typical annual cycle for the Great Lakes is considered. It would be interesting and informative to re-analyze the IADN Project flux estimates using the COARE gas exchange model.

The IBLTE Model, which incorporates the COARE gas transfer model, is capable of accounting for effects of equilibration of air with water as fetch increases as well as

effects of atmospheric stability on air-water exchange. Land-based sampling networks 
should be designed to capture the upstream, over-land PBT atmospheric concentration. If the upstream, over-land concentration is known, the IBLTE Model can be used to account for effects of both fetch and stability on net gas exchange of PBTs. 


\section{References}

Abraham, M., K. Enomoto, E. Clarke and G. Sexton (2002). Hydrogen bond basicity of the chlorogroup; hexachlorocyclohexanes as strong hydrogen bond bases. J. Org. Chem. 67: 4782-4786.

Abraham, M. H. and J. M. Al-Hussaini (2005). Solvation parameters for the 209 PCBs: calculation of physicochemical properties. J. Environ. Monit. 7: 295-301.

Abraham, M. H., S. C. Harpreet, G. S. Whiting and R. C. Mitchell (1994). Hydrogen bonding. 32. An analysis of water-octanol and water-alkane partitioning and the delta $\log$ P parameter of Seiler. J. Pharm. Sci. 83(8): 1085-1100.

Acree Jr., W. (2009). Personal communication, 28 October.

Allan, M. A. (2004). Manual for the GAW Precipitation Chemistry Programme: Guidelines, Data Quality Objectives and Standard Operating Procedures, World Meteorological Organization Global Atmosphere Watch. pp. 182.

American Sportfishing Association (2008). Sportfishing in America. pp. 12. www.asafishing.org

Anderson, P. N. and R. A. Hites (1996). OH radical reactions: the major removal pathway for polychlorinated biphenyls from the atmosphere. Environ. Sci. Technol. 30: 1756-1763.

Angevine, W., J. Hare, C. Fairall, D. Wolfe, R. Hill, W. Brewer and A. White (2006a). Structure and formation of the highly stable marine boundary layer over the Gulf of Maine. J. Geophys. Res. 111: D23S22. 10.1029/2006JD007465.

Angevine, W. M., M. Tjernstrom and M. Zagar (2006b). Modeling of the coastal boundary layer and pollutant transport in New England. J. Appl. Meteorol. 45: 137-154.

Aragon, P., J. Atienza and M. D. Climent (2000). Analysis of organic compounds in air: A review. Crit. Rev. Anal. Chem. 30(2\&3): 121-151.

Arp, H., R. Schwarzenbach and K. Goss (2008). Ambient gas/particle partitioning. 1. Sorption mechanisms of apolar, polar, and ionizable organic compounds. Environ. Sci. Technol. 42: 5541-5547.

Arp, H. P. H., R. P. Schwarzenbach and K. U. Goss (2007). Equilibrium sorption of gaseous organic chemicals to fiber filters used for aerosol studies. Atmos. Environ. 41: 8241-8252.

Atlas, E. L., S. M. Li, L. J. Standley and R. A. Hites (1993). Natural and anthropogenic organic compounds in the global atmosphere. Global Atmospheric Chemical Change. C. N. Hewitt and W. T. Sturges, Eds. New York, Elsevier Applied Science: 313-382.

Baltussen, E., C. A. Cramers and P. J. F. Sandra (2002). Sorptive sample preparation - a review. Anal. Bioanal. Chem. 373: 3-22. 
Bamford, H., D. Poster, R. Huie and J. Baker (2002). Using extrathermodynamic relationships to model the temperature dependence of Henry's Law constants of 209 PCB congeners. Environ. Sci. Technol. 36: 4395-4402.

Bandemehr, A., R. Hoff, C. H. Chan, M. Neilson, R. Hites, D. Orr and W. M. J. Strachan (1997). Technical summary of progress under the Integrated Atmospheric Deposition Network 1990-1996, U.S. EPA, Environment Canada. pp. 102.

Barro, R., J. Regueiro, M. Llompart and C. Garcia-Jares (2009). Analysis of industrial contaminants in indoor air: Part 1. Volatile organic compounds, carbonyl compounds, polycyclic aromatic hydrocarbons and polychlorinated biphenyls. J. Chromatogr. A 1216: 540-566.

Basu, I. (2000, May 2000). Analysis of PCBs, pesticides, and PAHs in Air and Precipitation Samples. version 1.2. Retrieved March 8, 2004, from http://www.msc-smc.ec.gc.ca/iadn/Resources/iu/in sampleprep00 e.html.

Beyer, A., F. Wania, T. Gouin, D. Mackay and M. Matthies (2002). Selecting internally consistent physicochemical properties of organic compounds. Environ. Toxicol. Chem. 21(5): 941-953.

Bhavsar, S. P., S. A. Jackson, A. Hayton, E. J. Reiner, T. Chen and J. Bodnar (2007). Are PCB levels in fish from the Canadian Great Lakes still declining? J. Great Lakes Res. 33: 592-605.

Bidleman, T. and L. L. McConnell (1995). A review of field experiments to determine air-water gas exchange of persistent organic pollutants. Sci. Tot. Environ. 159: $101-117$.

Bidleman, T. F., R. L. Falconer and T. Harner (1999). Particle/gas distribution of semivolatile organic compounds: Field and laboratory experiments with filtration samplers. Gas and particle phase measurements of atmospheric organic compounds. D. A. Lane, Ed. Amsterdam, Gordon and Breach Science Publishers: $39-71$.

Bidleman, T. F. and C. E. Olney (1974). High-volume collection of atmospheric polychlorinated biphenyls. Bull. Environ. Contam. Toxicol. 11(5): 442-450.

Blanchard, P., C. V. Audette, M. L. Hulting, I. Basu, K. Brice, S. Backus, H. DryfhoutClark, F. Froude, R. Hites, M. Nielson and R. Wu (2008). Atmospheric Deposition of Toxic Substances to the Great Lakes: IADN Results through 2005, U.S. EPA and Environment Canada. pp. 226.

Blanchard, P., C. V. Audette, M. L. Hulting, I. Basu, K. Brice, C. H. Chan, H. DryfhoutClark, F. Froude, R. A. Hites and M. Neilson (2004). Atmospheric Deposition of Toxic Substances to the Great Lakes: IADN Results through 2000, U.S. EPA and Environment Canada. pp. 129. www.epa.gov/grtlakes/monitoring/air/iadn/reports/IADN_1999_2000.pdf

Blomquist, B. W., C. W. Fairall, B. J. Huebert, D. J. Kieber and G. R. Westby (2006). DMS sea-air transfer velocity: Direct measurement by eddy covariance and 
parameterization based on the NOAA/COARE gas transfer model. Geophys. Res. Lett. 33: 1-4.

Bowling, D. R., A. C. Delany, A. A. Turnipseed and D. D. Baldocchi (1999).

Modification of the relaxed eddy accumulation technique to maximize measured scalar mixing ratio differences in updrafts and downdrafts. J. Geophys. Res. 104(D8): 9121-9133.

Cetin, B. and M. Odabasi (2005). Measurement of Henry's law constants of seven polybrominated diphenyl ether (PBDE) congeners as a function of temperature. Atmos. Environ. 39: 5273-5280.

Chang, S. S. and R. R. J. Braham (1991). Observational study of a convective internal boundary layer over Lake Michigan. J Atmos. Sci. 48(20): 2265-2279.

Craig, R. (1946). Measurements of temperature and humidity in the lowest 1000 feet of the atmosphere over Massachusetts Bay. Pap. Phys. Oceanogr. Meteorol. 10: 147.

Croley II, T. E. (1989). Verifiable evaporation modeling on the Laurentian Great Lakes. Water Resour. Res. 25(5): 781-792.

Croley, T. E. and T. S. Hunter (1996). Great Lakes Monthly Hydrologic Data, Great Lakes Environmental Research Laboratory, Ann Arbor, MI, ftp://ftp.glerl.noaa.gov/publications/tech_reports/glerl-083/UpdatedFiles/.

Currado, G. M. and S. Harrad (1998). Comparison of polychlorinated biphenyl concentrations in indoor and outdoor air and the potential significance of inhalation as a human exposure pathway. Environ. Sci. Technol. 32: 3043-3047.

Dachs, J., R. Lohmann, W. Ockenden, L. Mejanelle, S. Eisenreich and K. Jones (2002). Oceanic biogeochemical controls on global dynamics of persistent organic pollutants. Environ. Sci. Technol. 36: 4229-4237.

Destaillats, H., R. L. Maddalena, B. C. Singer, A. T. hodgson and T. E. McKone (2008). Indoor pollutants emitted by office equipment: A review of reported data and information needs. Atmos. Environ. 42: 1371-1388.

Dettmer, K. and W. Engewald (2002). Adsorbent materials commonly used in air analysis for adsorptive enrichment and thermal desorption of volatile organic compounds. Anal. Bioanal. Chem. 373: 490-500.

Dettmer, K. and W. Engewald (2003). Ambient air analysis of volatile organic compounds using adsorptive enrichment. Chromatographia 57: S-339-S-347.

Doskey, P. V. and A. W. Andren (1979). High-volume sampling of airborne polychlorobiphenyls with Amberlite XAD-2 resin. Analyt. Chim. Acta 110: 129138.

Draxler, R., B. Stunder, G. Rolph, A. Stein and A. Taylor (2009). HYSPLIT (Hybrid Single-Particle Lagrangian Integrated Trajectory) model, v. 4.9, www.arl.noaa.gov/HYSPLIT.php 
Drexler, H., G. Kerscher, B. Liebl and J. Angerer (2004). PCB in interiors - a relevant health risk? Gesundheitswesen 66(Suppl 1): S47-51.

Eatough, D. J. (1999). BOSS, the Brigham Young University Organic Sampling System: Determination of particulate carbonaceous material using diffusion denuder sampling technology. Gas and Particle Phase Measurements of Atmospheric Organic Compounds. D. A. Lane, Ed. Amsterdam, Gordon and Breach Science Publishers. 2: 233-285.

Edson, J. B., A. A. Hinton, K. E. Prada, J. E. Hare and C. W. Fairall (1998). Direct covariance flux estimates from mobile platforms at sea. $\underline{\text { J. Atmos. Oceanic }}$ Technol. 15: 547-562.

Ellis, D. A., J. W. Martin, A. O. De Silva, S. A. Mabury, M. D. Hurley, M. P. Sulbaek Anderson and T. J. Wallington (2004). Degradation of fluorotelomer alcohols: A likely atmospheric source of perfluorinated carboxylic acids. Environ. Sci. Technol. 38: 3316-3321.

Environment Canada (2009a). Canadian National Atmospheric Chemistry (NAtChem) Database. www.msc-smc.ec.gs.ca/natchem Meteorological Service of Canada, Toronto.

Environment Canada (2009b). http://climate.weatheroffice.ec.gc.ca/climateData/canada_e.html.

Fairall, C. (2007). Personal communication 16 May.

Fairall, C. W., L. Bariteau, A. A. Grachev, R. J. Hill, D. E. Wolfe, W. A. Brewer, S. C. Tucker, J. E. Hare and W. M. Angevine (2006). Turbulent bulk transfer coefficients and ozone deposition velocity in the International Consortium for Atmospheric Research into Transport and Transformation. J. Geophys. Res. 111: $1-19$.

Fairall, C. W., E. F. Bradley, J. E. Hare, A. A. Grachev and J. B. Edson (2003). Bulk parameterization of air-sea fluxes: updates and verification for the COARE Algorithm. J. Climate 16: 571-591.

Fairall, C. W., J. E. Hare, J. B. Edson and W. McGillis (2000). Parameterization and micrometeorological measurement of air-sea gas transfer. Boundary-Layer Meteorol. 96: 63-105.

Farrar, N. J., T. Harner, M. Shoeib, A. Sweetman and K. C. Jones (2005). Field deployment of thin-film passive air samplers for persistent organic pollutants: study in the urban atmospheric boundary layer. Environ. Sci. Technol. 39(2): 4248.

Fischer, R., R. Weller, H. Jacobi and K. Ballschmiter (2002). Levels and pattern of volatile organic nitrates and halocarbons in the air at Neumayer Station (70 $\left.{ }^{\circ} \mathrm{S}\right)$, Antarctic. Chemosphere 48: 981-992.

Fuller, E. N., P. D. Schettler and J. C. Giddings (1966). A new method for prediction of binary gas-phase diffusion coefficients. Ind. Eng. Chem. 58(5): 19-27. 
Fuzzi, S., M. O. Andraea, B. J. Huebert, M. Kulmala, T. C. Bond, M. Boy, S. J. Doherty, A. Guenther, M. Kanakidou, K. Kawamura, V. M. Kerminen, U. Lohmann, L. M. Russell and U. Poschl (2006). Critical assessment of the current state of scientific knowledge, terminology, and research needs concerning the role of organic aerosols in the atmosphere, climate, and global change. Atmos. Chem. Phys. 6: 2017-2038.

Gabrio, T., I. Piechotowski, T. Wallenhorst, M. Klett, L. Cott, P. Friebel, B. Link and M. Schwenk (2000). PCB-blood levels in teachers, working in PCB-contaminated schools. Chemosphere 40(9-11): 1055-1062.

Galarneau, E., C. Audette, A. Bandemehr, I. Basu, T. F. Bidleman, K. A. Brice, D. A. Burniston, C. H. Chan, F. Froude, R. A. Hites, M. L. Hulting, M. Neilson, D. Orr, M. F. Simcik, W. M. J. Strachan and R. M. Hoff (2000). Atmospheric deposition of toxic substances to the Great Lakes: IADN results to 1996. Toronto, ON, Canada, Environment Canada, U.S. EPA. pp. 126. www.epa.gov/grtlakes/monitoring/air/iadn/reports/IADN_1996.pdf

Garratt, J. and B. Ryan (1989). The structure of the stably stratified internal boundary layer in offshore flow over the sea. Boundary-Layer Meteorol. 47: 17-40.

Garratt, J. R. (1987). The stably stratified internal boundary layer for steady and diurnally varying offshore flow. Boundary-Layer Meteorol. 38: 369-394.

Garratt, J. R. (1990). The internal boundary layer - a review. Boundary-Layer Meteorol. 50: 171-203.

Gioia, R., L. Nizzetto, R. Lohmann, J. Dachs, C. Temme and K. Jones (2008). Polychlorinated biphenyls (PCBs) in air and seawater of the atlantic ocean: sources, trends and processes. Environ. Sci. Technol. 42: 1416-1422.

Goriaux, M., B. Jourdain, B. Tmime, J. L. Besombes, N. Marchand, A. Albinet, E. LeozGarziandia and H. Wortham (2006). Field comparison of particulate PAH measurements using a low-flow denuder device and conventional sampling systems. Environ. Sci. Technol. 40(6398-6404).

Gormley, P. G. and M. Kennedy (1949). Diffusion from a stream flowing through a cylindrical tube. Proc. Royal Irish Acad. 52A: 163-169.

Goss, K., H. Arp, G. Bronner and C. Niederer (2008). Partition behavior of hexachlorocyclohexane isomers. J. Chem. Eng. Data 53: 750-754.

Goss, K. U. (2004). The air/surface adsorption equilibrium of organic compounds under ambient conditions. Crit. Rev. Env. Sci. Tec. 34: 339-389.

Gouin, T., I. Cousins and D. Mackay (2004). Comparison of two methods for obtaining degradation half-lives. Chemosphere 56: 531-535.

Gray, K. A., M. A. Klebanoff, J. W. Brock, H. Zhou, R. Darden, L. Needham and P. Longnecker (2005). In utero exposure to background levels of polychlorinated biphenyls and cognitive functioning among school-age children. Am. J. Epidemiol. 162(1): 17-26. 
Gundel, L. A., V. C. Lee, R. R. Kariyawasam, R. K. Stevens and J. M. Daisey (1995). Direct determination of the phase distributions of semi-volatile polycyclic aromatic hydrocarbons using annular denuders. Atmos. Environ. 29(14): 17191733.

Hare, J. E., C. W. Fairall, W. R. McGillis, J. B. Edson, B. Ward and R. Wanninkhof (2004). Evaluation of the NOAA/COARE air-sea gas transfer parameterization using GasEx data. J. Geophys. Res. 109(C8).

Harman-Fetcho, J., L. McConnell, C. Rice and J. Baker (2000). Wet deposition and airwater gas exchange of currently used pesticides to a subestuary of the Chesapeake Bay. Environ. Sci. Technol. 34(8): 1462-1468.

Harner, T. and M. Shoeib (2002). Measurements of octanol-air partition coefficients $\left(\mathrm{K}_{\mathrm{OA}}\right)$ for polybrominated diphenyl ethers (PBDEs): Predicting partitioning in the environment. J. Chem. Eng. Data 47(2): 228-232.

Harner, T., M. Shoeib, M. Diamond, M. Ikonomou and G. Stern (2006). Passive sampler derived air concentrations of PBDEs along an urban-rural transect: Spatial and temporal trends. Chemosphere 64: 262-267.

Harner, T., M. Shoeib, M. Diamond, G. Stern and B. Rosenberg (2004). Using passive air samplers to assess urban-rural trends for persistent organic pollutants. 1. Polychlorinated biphenyls and organochlorine pesticides. Environ. Sci. Technol. 38(17): 4474-4483.

Harrad, S., R. Wijesekera, S. Hunter, C. Halliwell and R. Baker (2004). Preliminary assessment of U.K. human dietary and inhalation exposure to polybrominated diphenyl ethers. Environ. Sci. Technol. 38: 2345-2350.

Hassan, R., R. Scholes and N. Ash, Eds. (2005). The Millennium Ecosystem Assessment Series, Vol. 1: Ecosystems and Human Well-being: Current State and Trends. Washington, DC, Island Press.

Hierlemann, A., E. Zellers and A. Ricco (2001). Use of linear solvation energy relationships for modeling responses from polymer-coated acoustic-wave vapor sensors. Anal. Chem. 73: 3458-3466.

Hinds, W. C. (1999). Aerosol Technology. New York, John Wiley \& Sons.

Hites, R. A. (2004). Polybrominated diphenyl ethers in the environment and people: a meta-analysis of concentrations. Environ. Sci. Technol. 38(4): 945-956.

Hites, R. A., J. A. Foran, D. O. Carpenter, M. C. Hamilton, B. A. Knuth and S. J. Schwager (2004). Global assessment of organic contaminants in farmed salmon. Science 303(5655): 226-229.

Hoff, R. M. (1994). An error budget for the determination of the atmospheric mass loading of toxic chemicals in the Great Lakes. Great Lakes Res. 20(1): 229-239.

Hoh, E. and R. A. Hites (2005). Brominated flame retardants in the atmosphere of the United States. The Seventh Annual Workshop on Brominated Flame Retardants in the Environment, Gaithersburg, MD, NIST. 
Hoh, E., L. Zhu and R. A. Hites (2006). Dechlorane plus, a chlorinated flame retardant, in the Great Lakes. Environ. Sci. Technol. 40: 1148-1189.

Holsen, T. M., K. E. Noll, S. P. Liu and W. J. Lee (1991). Dry deposition of polychlorinated biphenyls in urban areas. Environ. Sci. Technol. 25: 1075-1081.

Hornbuckle, K. C., J. D. Jeremiason, C. W. Sweet and S. J. Eisenreich (1994). Seasonal variations in air-water exchange of polychlorinated biphenyls in Lake Superior. Environ. Sci. Technol. 28: 1491-1501.

Hsu, S. A. (1989). A verification of an analytical formula for estimating the height of the stable internal boundary layer. Boundary-Layer Meteorol. 48: 197-201.

Hu, D., A. Martinez and K. Hornbuckle (2008). Discovery of non-Aroclor PCB (3,3'Dichlorobiphenyl) in Chicago air. Environ. Sci. Technol. 42(21): 7873-7877.

IPCC (2007). Climate Change 2007: The Physical Science Basis. Cambridge, UK and New York, NY, USA. pp. 996.

Jantunen, L. M. and T. F. Bidleman (2006). Temperature dependent Henry's law constants for hexachlorobenzene, $\mathrm{p}, \mathrm{p}$-DDE, and components of technical chlordane and estimates of gas exchange in Lake Ontario. Chemosphere 62: 16891696.

Jeremiason, J. D., K. C. Hornbuckle and S. J. Eisenreich (1994). PCBs in Lake Superior, 1978 - 1992: Decreases in water concentrations reflect loss by volatilization. Environ. Sci. Technol. 28: 903-914.

Kaimal, J. C. and J. J. Finnigan (1994). Atmospheric Boundary Layer Flows. New York, NY, Oxford University Press.

Kaupp, H. and M. S. McLaughlan (2000). Distribution of polychlorinated dibenzo-Pdioxins and dibenzofurans (PCDD/Fs) and polycyclic aromatic hydrocarbons (PAHs) within the full size range of atmospheric particles. Atmos. Environ. 34: 73-83.

Klanova, J., P. Eupr, J. Kohoutek and T. Harner (2008). Assessing the influence of meteorological parameters on the performance of polyurethane foam-based passive air samplers. Environmental Science and Technology 42: 550-555.

Kohler, M., J. Tremp, M. Zennegg, C. Seiler, S. Minder-Kohler, M. Beck, P. Lienemann, L. Wegmann and P. Schmid (2005). Joint sealants: An overlooked diffuse source of polychlorinated biphenyls in buildings. Environ. Sci. Technol. 39: 1967-1973.

Kohler, M., M. Zennegg and R. Waeber (2002). Coplanar polychlorinated biphenyls (PCB) in indoor air. Environ. Sci. Technol. 36: 4735-4740.

Krieger, M. S. and R. A. Hites (1992). Diffusion denuder for the collection of semivolatille organic compounds. Environ. Sci. Technol. 26(6): 1551-1555.

Krieger, M. S. and R. A. Hites (1994). Measurement of polychlorinated biphenyls and polycyclic aromatic hydrocarbons in air with a diffusion denuder. Environ. Sci. Technol. 28(6): 1129-1133. 
Lee, D. H. L., I. K. Lee, K. Song, M. Steffes, W. Toscano, B. A. Baker and D. R. Jacobs (2006). A strong dose-response relation between serum concentrations of persistent organic pollutants and diabetes. Diabetes Care 29: 1638-1644.

Lee, R. G. M., H. Hung, D. Mackay and K. C. Jones (1998). Measurement and modeling of the diurnal cycling of atmospheric PCBs and PAHs. Environ. Sci. Technol. 32: 2172-2179.

Li, N., F. Wania, Y. D. Lei and G. L. Daly (2003). A Comprehensive and Critical Compilation, Evaluation, and Selection of Physical-Chemical property Data for Selected polychlorinated Biphenyls. J. Phys. Chem. Ref. Data 32(4): 1545-1590.

Li, Q. and C. Poole (2001). Selectivity equivalence of poly(dimethyldiphenylsiloxane) stationary phases for open-tubular column gas chromatography. J. Sep. Sci. 24: 129-135.

Li, Q., C. F. Poole, W. Kiridena and W. W. Koziol (2000). Chromatographic methods for the determination of the $\log \mathrm{L}^{16}$ solute descriptor. Analyst 125: 2180-2188.

Liss, P. S. and P. G. Slater (1974). Flux of gases across the air-sea interface. Nature 247: 181-184. 10.1038/247181a0.

Liu, B. Y. H. and D. Y. H. Pui (1981). Aerosol sampling inlets and inhalable particles. Atmos. Environ. 15: 598-600.

Lovkvist, P. and J. A. Jonsson (1987). Capacity of sampling and preconcentration columns with a low number of theoretical plates. Anal. Chem. 59: 818-821.

Mackay, D. and A. Yeun (1983). Mass transfer coefficient correlations for volatilization of oranic solutes from water. Environ. Sci. Technol. 17(4): 211-217.

Macleod, M., M. Scheringer, H. Podey, K. Jones and K. Hungerbuhler (2007). The origin and significance of short-term variability of semivolatile contaminants in air. Environ. Sci. Technol. 41: 3249-3253.

Mader, B. T., R. C. Flagan and J. H. Seinfeld (2001). Sampling atmospheric carbonaceous aerosols using a particle trap impactor/denuder sampler. Environ. Sci. Technol. 35(24): 4857-4867.

Mahrt, L. (1999). Stratified atmospheric boundary layers. Boundary-Layer Meteorol. 90: 375-396.

Malcolm, K., D. Woolfson, J. Russell, P. Tallon, L. McAuley and D. Craig (2003). Influence of silicone elastomer solubility and diffusivity on the in vitro release of drugs from intravaginal rings Journal of Controlled Release 90(2): 217-225.

Mandalakis, M., H. Berresheim and E. G. Stephanou (2003). Direct evidence for destruction of polychlorobiphenyls by $\mathrm{OH}$ radicals in the subtropical troposphere. Environ. Sci. Technol. 37: 542-547.

Marandino, C., W. De Bruyn, S. Miller and E. Saltzman (2009). Open ocean DMS air/sea fluxes over the eastern South Pacific Ocean. Atmos. Chem. Phys. 9: 345-356. 
McDonald, T. A. (2005). Polybrominated diphenylether levels among United States residents: Daily intake and risk of harm to the developing brain and reproductive organs. Integrated Environmental Assessment and Management 1(4): 343-354.

McGillis, W. R., J. B. Edson, C. J. Zappa, J. D. Ware, S. P. McKenna, E. A. Terray, J. E. Hare, C. W. Fairall, W. Drennan, M. Donelan, M. D. DeGrandpre, R.

Wanninkhof and R. A. Feely (2004). Air-sea $\mathrm{CO}_{2}$ exchange in the equatorial Pacific. J. Geophys. Res. 109: C08S02, doi:10.1029/2003JC002256.

Melas, D. (1989). The temperature structure in a stably stratified internal boundary layer over a cold sea. Boundary-Layer Meteorol. 48: 361-375.

Meng, F., D. Wen and J. Sloan (2008). Modelling of air-water exchange of PCBs in the Great Lakes. Atmos. Environ. 42: 4822-4835.

Mulhearn, P. (1981). On the formation of a stably stratified internal boundary-layer by advection of warm air over a cooler sea. Boundary-Layer Meteorol. 21: 247-254.

Niemi, G., D. Wardrop, R. Brooks, S. Anderson, V. Brady, H. Paerl, C. Rakocinski, M. Brouwer, B. Levinsion and M. McDonald (2004). Rationale for a new generation of indicators for coastal waters. Environ. Health. Perspect. 112: 979-986.

Nieuwstadt, F. (1984). The turbulent structure of the stable, nocturnal boundary layer. J. Atmos. Sci. 41(14): 2202-2216.

Offenberg, J. H. and J. E. Baker (1999). Aerosol size distribution of polycyclic aromatic hydrocarbons in urban and over-water atmospheres. Environ. Sci. Technol. 33(19): 3324-3331.

Perlinger, J. A. (2007). Final Report: Comparison of Technologies for PBT Flux Measurement, Michigan Technological University, U.S. EPA Great Lakes National Program Office. pp. 225.

Perlinger, J. A. (2008). Quality Assurance Project Plan: Measurement and Modeling of PBT Transport in Lake Superior, Michigan Technological University. pp. 74.

Perlinger, J. A. and M. D. Rowe (2008). Atmospheric transport and air-water exchange of hexachlorobenzene in Lake Superior. Organohalogen Compounds 70: 598-601.

Perlinger, J. A. and M. D. Rowe (2009). Semivolatile Organic Chemical Sampling and Extraction Transfer Method and Apparatus. U.S. Patent Pending.

Perlinger, J. A., D. E. Tobias, P. S. Morrow and P. V. Doskey (2005). Evaluation of novel techniques for measurement of air-water exchange of persistent bioaccumulative toxicants in Lake Superior. Environ. Sci. Technol. 39: 84118419 .

Pharma Algorithms (2006). ADME Boxes version 3.5 (ABSOLV module). www.pharma-algorithms.com/webboxes/.

Phillips, W. D. and J. G. Irbe (1978). Land-to-lake comparison of wind, temperature, and humidity on Lake Ontario during the International Field Year for the Great Lakes 
(IFYGL). Downsview, ON, Atmospheric Environment Service, Environment Canada. pp. 51.

Pich, J. (1972). Theory of gravitational deposition of particles from laminar flows in channels. J. Aerosol. Sci. 3: 351-361.

Platts, J. A., M. H. Abraham, D. Butina and A. Hersey (2000). Estimation of molecular linear free energy relationship descriptors by a group contribution approach. 2 . Prediction of partition coefficients. J. Chem. Inf. Comput. Sci 40: 71-80.

Platts, J. A., D. Butina, M. H. Abraham and A. Hersey (1999). Estimation of molecular linear free energy relation descriptors using a group contribution approach. $\underline{\text { J. }}$ Chem. Inf. Comput. Sci 39: 835-845.

Poole, C. and S. Poole (2009). Foundations of retention in partition chromatography. J. Chrom. A 1216: 1530-1550.

Poole, C. F. (2003). The Essence of Chromatography. Amsterdam, Elsevier.

Poole, S. K. and C. F. Poole (1995). Chemometric classification of the solvent properties (selectivity) of commonly used gas chromatographic stationary phases. J. Chromatogr. A 697: 425-427.

Pope, C. A. and D. W. Dockery (2006). Health effects of fine particulate air pollution: lines that connect. J. Air \& Waste Manage. Assoc. 56: 709-742.

Raymond, A. and G. Guiochon (1975). The use of graphitized carbon black as a trapping material for organic compounds in light gases before a gas chromatographic analysis. J. Chromatogr. Sci. 13(4): 173-177.

Robinson, A. L., N. M. Donahue, M. K. Shrivastava, E. A. Weitkamp, A. M. Sage, A. P. Grieshop, T. E. Lane, J. R. Pierce and S. N. Pandis (2007). Rethinking organic aerosols: semivolatile emissions and photochemical aging. Science 315(5816): $1259-1262$.

Robinson, P. E., A. M. Gregory, J. Remmers and R. Levy (1990). Trends of PCB, hexachlorobenzene, and beta-benzene hexachloride levels in the adipose tissue of the U.S. population. Environ. Res. 53: 175-192.

Rolaf van Leeuwen, F. X., M. Feeley, D. Schrenk, J. C. Larsen, W. Farland and M. Younes (2000). Dioxins: WHO's tolerable daily intake (TDI) revisited. Chemosphere 40: 1095-1101.

Rowe, A., L. Totten, M. Xie, T. Fikslin and S. Eisenreich (2007). Air-water exchange of polychlorinated biphenyls in the Deleware River. Environ. Sci. Technol. 41: 1152-1158.

Rowe, M. D. (2009). Modeling contaminant behavior in Lake Superior: A comparison of PCBs, PBDEs, and mercury. Michigan Technological University. Houghton, MI. http://gradworks.umi.com/1464086.pdf 
Rowe, M. D. and J. A. Perlinger (2008). Thermal extraction and analysis of atmospheric semivolatile organic compounds from multicapillary collection devices. Organohalogen Compounds 70: 38-41.

Rowe, M. D. and J. A. Perlinger (2009a). Gas-phase cleanup method for analysis of trace atmospheric semivolatile organic compounds by thermal desorption from diffusion denuders. J. Chromatogr. A 1216: 5940-5948. DOI:10.1016/j.chroma.2009.06.034.

Rowe, M. D. and J. A. Perlinger (2009b). Performance of a high flow rate, thermallyextractable multicapillary denuder for atmospheric semivolatile organic compound concentration measurement. Atmospheric Environment in review.

Rowe, M. D. and J. A. Perlinger (2009c). Prediction of gas collection efficiency and particle collection artifact for atmospheric semivolatile organic compounds in multicapillary denuders. J. Chromatogr. A 1217: 256-263. 10.1016/j.chroma.2009.11.049.

Rowe, M. D., J. A. Perlinger and N. R. Urban (2008). Modeling contaminant behavior in Lake Superior: A comparison of PCBs, PBDEs, and mercury. State of Lake Superior, Ecovision World Monograph Series. M. Munawar and I. F. Munawar, Eds. Burlington, Canada., Aquatic Ecosystem Health \& Management Society.

Rusina, T., F. Smedes, J. Klanova, K. Booij and I. Holoubek (2007). Polymer selection for passive sampling: A comparison of critical properties. Chemosphere 68: 13441351.

Schwarzenbach, R. P., P. M. Gschwend and D. M. Imboden (2003). Environmental Organic Chemistry. New York, Wiley Interscience.

Seinfeld, J. H. and S. N. Pandis (1998). Atmospheric Chemistry and Physics. New York, NY, John Wiley \& Sons, Inc.

Sirois, A. and R. Vet (1999). The precision of precipitation chemistry measurements in the Canadian air and precipitation monitoring network (CAPMON). Environ. Monit. Assess. 57: 301-329.

Smedman, A.-S., H. Bergström and B. Grisogono (1997). Evolution of stable internal boundary layers over a cold sea. J. Geophys. Res. 102(C1): 1091-1099.

Smith, D. (1999). Worldwide trends in DDT levels in human breast milk. Int. J. Epidemiol. 28: 179-188.

Song, W., J. C. Ford, A. Li, W. J. Mills, D. R. Buckley and K. J. Rockne (2004). Polybrominated diphenyl ethers in the sediments of the Great Lakes. 1. Lake Superior. Environ. Sci. Technol. 38(12): 3286-3293.

Sprunger, L., A. Proctor, W. Acree Jr. and M. Abraham (2007). Characterization of the sorption of gaseous and organic solutes onto polydimethyl siloxane solid-phase microextraction surfaces using the Abraham model. J. Chromatogr. A 1175: 162173. 
Stephanou, E. G. and N. E. Stratigakis (1993). Determination of anthropogenic and biogenic organic compounds on airborne particles: flash chromatographic fractionation and capillary gas chromatographic analysis. J. Chromatogr. 644: 141-151.

Strandberg, B., N. G. Dodder, I. Basu and R. A. Hites (2001). Concentrations and spatial variations of polybrominated diphenyl ethers and other organohalogen compounds in Great Lakes air. Environ. Sci. Technol. 35(6): 1078-1083.

Stull, R. B. (1988). An Introduction to Boundary Layer Meteorology. Dordrecht, The Netherlands, Kluwer Academic Publishers.

Swackhamer, D. L., B. D. McVeety and R. A. Hites (1988). Deposition and evaporation of polychlorobiphenyl congeners to and from Siskiwit Lake, Isle Royale, Lake Superior. Environ. Sci. Technol. 22(6): 664-72.

Taylor, G. (1915). Eddy motion in the atmosphere. Philosophical Transactions of the Royal Society of London. Series A, Containing Papers of a Mathematical or Physical Character 215: 1-26. www.jstor.org/stable/91100.

Taylor, J. (1982). An Introduction to Error Analysis. Sausalito, CA, University Sciences Books.

Ten Hulscher, T., L. van der Velde and W. Bruggeman (1992). Temperature dependence of Henry's law constant for selected chlorobenzenes, polychlorinated biphenyls, and polycyclic aromatic hydrocarbons. Environ. Toxicol. Chem. 11: 1595-1603.

Thompson, A. (1995). Measuring and modeling the tropospheric hydroxyl radical (OH). J. Atmos. Sci. 52(19): 3315-3327.

Tobias, D. E., J. A. Perlinger, P. S. Morrow, P. V. Doskey and D. L. Perram (2007). Direct thermal desorption of semivolatile organic compounds from diffusion denuders and gas chromatographic analysis for trace concentration measurement. J. Chromatogr. A 1140: 1-12.

Totten, L., P. Brunciak, C. Gigliotti, J. Dachs, T. Glenn IV, E. Nelson and S. Eisenreich (2001). Dynamic air-water exchange of polychlorinated biphenyls in the New York-New Jersey Harbor estuary. Environ. Sci. Technol. 35: 3834-3840.

Totten, L. A., S. J. Eisenreich and P. A. Brunciak (2002). Evidence for destruction of PCBs by the $\mathrm{OH}$ radical in urban atmospheres. Chemosphere 47: 735-746.

Tuduri, L., T. Harner, P. Blanchard, Y.-F. Li, L. Poissant, D. Waite, C. Murphy and W. Belzer (2006). A review of currently used pesticides (CUPs) in Canadian air and precipitation. Part 2: Regional information and perspectives. Atmos. Environ. 40: 1579-1589.

U.S. Department of the Interior, Fish and Wildlife Service, U.S. Department of Commerce and U.S. Census Bureau (2006). 2006 National Survey of Fishing, Hunting, and Wildlife-Associated Recreation. pp. 128.

U.S. EPA (2008). National Listing of Fish Advisories. http://epa.gov/waterscience/fish/advisories/. 
U.S. EPA and Environment Canada (2001). Integrated Atmospheric Deposition Network Quality Assurance Project Plan. Chicago IL. pp. 52.

USEPA (2002). Great Lakes Strategy 2002, http://www.epa.gov/glnpo/gls/glstoc.html. pp. 48.

Volckens, J. and D. Leith (2003). Effects of sampling bias on gas-particle partitioning of semi-volatile compounds. Atmospheric Environment 37: 3385-3393.

Wallace, J. C., I. Basu and R. A. Hites (1996). Sampling and analysis artifacts caused by elevated indoor air polychlorinated biphenyl concentrations. Environ. Sci. Technol. 30: 2730-2734.

Wanninkhof, R., J. R. Ledwell and J. Crusius (1991). Air-Water Mass Transfer. S. C. Wilhelm and J. S. Gulliver, Eds. New York, American Society of Civil Engineers: 441-458.

Weschler, C. J. and W. W. Nazaroff (2008). Semivolatile organic compounds in indoor environments. Atmos. Environ. 42: 9018-9040.

Wesely, M. L., D. H. Lenschow and O. T. Denmead (1987). Flux measurement techniques. Measurements of surface exchange and flux divergence of chemical species in the global atmosphere, Columbia University.

Whitby, K. J. (1978). The physical characteristics of sulfur aerosol. Atmos. Environ. 12: 135-159.

White, F. M. (1999). Fluid Mechanics. New York, McGraw-Hill.

Whitman, W. G. (1923). The two-film theory of gas absorption. Chem. Metal Eng. 29: 146-148.

WHO (2002). Global Assessment of the State-of-the-Science of Endocrine Disruptors, World Health Organization, http://www.who.int/ipcs/publications/new_issues/endocrine_disruptors/en/. pp. 180.

Wilford, B. H., G. O. Thomas, K. C. Jones, B. Davidson and D. K. Hurst (2008). Decabromodiphenyl ether (deca-BDE) commercial mixture components, and other PBDEs, in airborne particles at a UK site. Environ. Int. 34: 412-419.

Woolfenden, E. (1997). Monitoring VOCs in air using sorbent tubes followed by thermal desorption-capillary GC analysis: Summary of data and practical guidelines. J. Air \& Waste Manage. Assoc. 47: 20-36.

Wu, R., S. Backus, I. Basu, P. Blanchard, K. Brice, H. Dryfhout-Clark, P. Fowlie, M. Hulting and R. Hites (2009). Findings from quality assurance activities in the Integrated Atmospheric Deposition Network. J. Environ. Monit. 11(277-296). 10.1039/b810428j.

Xiao, H., H. Hung, T. Harner, Y. Lei, G. Johnston and F. Wania (2007). A flow-through sampler for semivolatile organic compounds in air. Environ. Sci. Technol. 41: 250-256. 
Yan, S., L. Rodenburg, J. Dachs and S. Eisenreich (2008). Seasonal air-water exchange fluxes of polychlorinated biphenyls in the Hudson River Estuary. Environ. Pollut. 152: 443-451.

Zhang, X., K. Rygwelski, R. Rossman, J. Pauer and R. Kreis Jr. (2008). Model construct and calibration of an integrated water quality model (LM2-Toxic) for the Lake Michigan Mass Balance Project. Ecol. Model. 219: 92-106. 


\section{Appendix A: Copyright agreements}

\section{A.1 Chapter 2 copyright agreement}

\section{JOURNAL PUBLISHING AGREEMENT}

Elsevier B.V.

\section{YOUR DETAILS}

Article:

Corresponding author:

E-mail address:

Journal:

Our Reference:

PII:

DOI:

\author{
Gas-phase Cleanup Method for Analysis of Trace Atmospheric Semivolatile \\ Organic Compounds by Thermal Desorption from Diffusion Denuders \\ Dr. Judith A. Perlinger \\ jperl@mtu.edu \\ Journal of Chromatography A \\ CHROMA350157 \\ S0021-9673(09)00911-X \\ 10.1016/j.chroma.2009.06.034
}

YOUR STATUS

I am one author signing on behalf of all co-authors of the manuscript

\section{ASSIGNMENT OF PUBLISHING RIGHTS}

I hereby assign to Elsevler B.V. the copyright in the manuscript identified above (government authors not electing to transfer agree to assign a non-exclusive licence) and any supplemental tables, lllustrations or other information submitted therewith that are intended for publication as part of or as a supplement to the manuscript (the "Article") in all forms and media (whether now known or hereafter developed), throughout the world, in all languages, for the full term of copyright, effective when and if the article is accepted for publication. This transfer includes the right to provide the Article in electronic and online forms and systems.

\section{RETENTION OF RIGHTS FOR SCHOLARLY PURPOSES}

I understand that I retain or am hereby granted (without the need to obtain further permission) rights to use certain versions of the Article for certain scholarly purposes, as described and defined below ("Retained Rights"), and that no rights in patents, trademarks or other intellectual property rights are transferred to the journal.

The Retalned Rights Include the right to use the Pre-print or Accepted Authors Manuscript for Personal Use, Internal Institutional Use and for Scholarly Posting; and the Published Journal Article for Personal Use and Internal Institutional Use.

\section{AUTHOR WARRANTIES / ETHICS AND DISCLOSURE}

I affirm the Author Warranties noted below, and confirm that I have reviewed and complied with the relevant Instructions to Authors, the Ethics in Publishing policy, and Conflicts of Interest disclosure. For further information see the journal home page or elsevier.com.

\section{Author warranties}

The article I have submitted to the journal for review is orlginal, has been written by the stated authors and has not been published elsewhere.

The article is not currently being considered for publication by any other journal and will not be submitted for such review while under review by this journal.

The article contains no Ilbellous or other unlawful statements and does not contain any materials that violate any personal or proprietary rights of any other person or entity.

I have obtained written permission from copyright owners for any excerpts from copyrighted works that are included and have credited the sources in my article.

If the article was prepared jointly with other authors, I have informed the co-author(s) of the terms of this publishing agreement and that I am signing on their behalf as their agent, and I am authorized to do so.

\section{FUNDING AGENCY REQUIREMENTS AND OTHER POLICIES}

I have also been made aware of the journal's policles with respect to funding agency requirements such as the NIH 'PublicAccess' policy, and the rapid publication 'ArticlesInPress' service. See elsevler.com for details.

For more information about the definitions relating to this agreement click here.

$\checkmark$ I have read and agree to the terms of the Journal Publishing Agreement.

16th June 2009 


\title{
A.2 Chapter 3 copyright agreement
}

\author{
Your article [CHROMA_350596] - Copyright Form Wednesday, November 18, 2009 \\ Completed \\ $1: 42: 23 \mathrm{PM}$ \\ From: support@elsevier.com \\ To: jperl@mtu.edu
}

Attachments: CHROM $350596 . \mathrm{html}(27.5 \mathrm{~KB})$

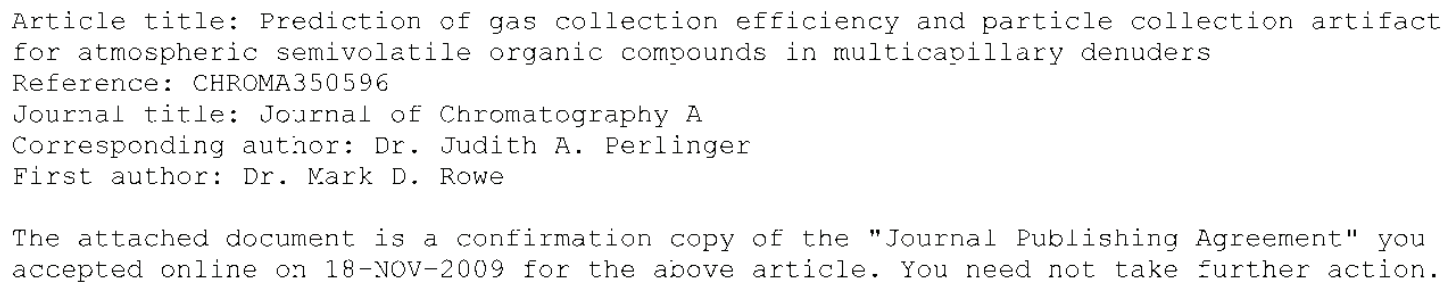




\section{A.3 Journal of Chromatography A copyright agreement details.}

The link associated with Personal Use in A.1 and A.2 leads to the following

definitions, which document the right of the author to use the work in a thesis or dissertation.

\section{DEFINITIONS}

\section{ACCEPTED AUTHOR MANUSCRIPT ("AAM")}

Author's version of the manuscript of a paper that has been accepted for publication and which may include any author-in peer review process. AAMs should not include however other publisher value added contributions such as formatting and Appropriate Bibliographic Citation and a link to the final publication (generally through the relevant DOI).

\section{APPROPRIATE BIBLIOGRAPHIC CITATION}

Authors posting Accepted Author Manuscript online may later add a citation for the Published Journal Article indicating tha may mention the journal title provided they add the following text at the beginning of the document:

"NOTICE: this is the author's version of a work that was accepted for publication in Journal of Chromatography $A$. Changes resulting from the publishing process, such as peer review, editing, corrections, structural formatting, and other quality control mechanisms may not be reflected in this document. Changes may have been made to this work since it was submitted for publication. A definitive version was subsequently published in PUBLICATION, [VOL\#, ISSUE\#, (DATE)] DOI\#"

\section{COMMERCIAL PURPOSES}

The usse or posting of articles for commercial gain including the posting by companies or their employee-authored works $\mathrm{ft}_{\mathrm{f}}$ pharmaceutical companies and physician-prescribers); commercial exploitation such as directly associating advertising wit document delivery or access; the systematic distribution to others via e-mail lists or list servers (to parties other than knc

\section{INTERNAL INSTITUTIONAL USE}

Use by the author's institution for classroom teaching at the institution (including distribution of copies, paper or electroni programs) and posting on secure Intranet sites for scholarly purposes. For authors employed by companies, the use by th

\section{PERSONAL USE}

Use by an author in the author's classroom teaching (including distribution of copies, paper or electronic), distribution of 6 personal use, use in a subsequent compilation of the author's works, inclusion in a thesis or dissertation, preparation of ot article to book-length form, or otherwise using or re-using portions or excerpts in other works (with full acknowledgment

\section{PRE-PRINT}

Author's own write-up of research results and analysis that has not been refereed, nor had any other value added to it by and the like).

\section{PUBLISHED JOURNAL ARTICLE ("PJA")}

The definitive final record of published research that appears or will appear in the journal and embodies all value-adding $\mathrm{F}$ pagination.

\section{SCHOLARLY POSTING}

Voluntary posting by an author on open Web sites operated by the author or the author's institution for scholarly purpose: servers, provided there is no Commercial Purpose involved. Deposit in or posting to Special Repositories (such as PubMed agreements between Elsevier and the repository and only consistent with Elsevier's policies concerning such repositories. connection with such posting, the Appropriate Bibliographic Citation should be used. 


\section{Appendix B: Chapter 2 supplemental information}

Table B.1: Concentration of persistent, bioaccumulative, and toxic chemicals $\left(\mathrm{pg} \mathrm{m}^{-3}\right)$ in duplicate outdoor and indoor air samples. Sample volumes and concentrations are referenced to standard conditions of $25^{\circ} \mathrm{C}, 1 \mathrm{~atm}$. Observations that fell between the $M D L$ and $Q L$ are included in italicized font. In the case of non-detect, the MDL is given in boldface font preceded by the symbol " $<$ ". Missing values indicate observations that failed the blank criterion. Air temperature and relative humidity reported in the table are means over the sample collection period.

\begin{tabular}{|c|c|c|c|c|c|c|c|c|c|c|c|}
\hline \multicolumn{2}{|l|}{$\begin{array}{l}\text { Sample location } \\
\text { Date }\end{array}$} & \multicolumn{2}{|c|}{$\begin{array}{c}\text { Outdoor } \\
\text { 4 Dec. } 2007\end{array}$} & \multicolumn{2}{|c|}{$\begin{array}{c}\text { Outdoor } \\
19 \text { Dec. } 2007\end{array}$} & \multicolumn{2}{|c|}{$\begin{array}{c}\text { DESEB } \\
\text { laboratory } \\
29 \text { Nov. } 2007\end{array}$} & \multicolumn{2}{|c|}{$\begin{array}{c}\text { DESEB } \\
\text { hallway } \\
11 \text { Dec. } 2007\end{array}$} & \multicolumn{2}{|c|}{$\begin{array}{c}\text { Dillman } \\
\text { hallway } \\
4 \text { Jan. } 2008\end{array}$} \\
\hline Volume, $\mathrm{m}^{3}$ & & 5.1 & & 20.7 & 20.8 & 3.9 & 3.8 & 19.7 & 19.3 & 2.7 & 2.6 \\
\hline Temp., ${ }^{\circ} \mathrm{C}$ & & -9.2 & -9.2 & -4.2 & -4.2 & 17.4 & 17.4 & 19.9 & 19.9 & 21.9 & 21.9 \\
\hline Rel. humidity, \% & & 75.7 & 75.7 & 83.6 & 83.6 & 28.2 & 28.2 & 24.4 & 24.4 & 11.0 & 11.0 \\
\hline $\begin{array}{l}\text { Analyte or co- } \\
\text { eluting analyte } \\
\text { group }\end{array}$ & $\begin{array}{r}\mathrm{MDL}, \\
\mathrm{Pg}\end{array}$ & \multicolumn{2}{|c|}{ Conc., $\mathrm{pg} \mathrm{m}^{-3}$} & \multicolumn{2}{|c|}{ Conc., $\mathrm{pg} \mathrm{m} \mathrm{m}^{-3}$} & \multicolumn{2}{|c|}{ Conc., $\mathrm{pg} \mathrm{m}^{-3}$} & \multicolumn{2}{|c|}{ Conc., pg $\mathrm{m}^{-3}$} & \multicolumn{2}{|c|}{ Conc., $\mathrm{pg} \mathrm{m}^{-3}$} \\
\hline PCB $4+10$ & 6.7 & 0.4 & $<0.3$ & $<0.3$ & 1.8 & $<1.3$ & $<1.3$ & $<1.8$ & $<1.8$ & $<2.5$ & $<2.6$ \\
\hline PCB 9 & 8.5 & & & 1.8 & 1.7 & 5.9 & 6.0 & $<2.2$ & $<2.2$ & 33.4 & $<3.2$ \\
\hline PCB 7 & 8.5 & $<0.4$ & $<0.4$ & $<0.4$ & 0.7 & $<1.7$ & $<1.7$ & $<2.2$ & 6.7 & 26.5 & 29.3 \\
\hline PCB 6 & 10.8 & $<0.5$ & $<0.5$ & $<0.5$ & $<0.6$ & $<2.1$ & $<2.1$ & 18.8 & 19.5 & 130.3 & 129.6 \\
\hline PCB 5 & 5.0 & $<0.2$ & $<0.2$ & $<0.3$ & $<0.3$ & $<1.0$ & $<1.0$ & 4.2 & 3.1 & 15.4 & 16.5 \\
\hline PCB 8 & 9.3 & & & 2.0 & 2.2 & & & 52.9 & 47.2 & 505.6 & 540.1 \\
\hline $\mathrm{HCB}$ & 2.3 & 54.0 & 63.3 & 55.7 & 69.2 & 49.6 & 51.0 & 101.6 & 96.6 & 174.4 & 181.2 \\
\hline PCB 18 & 9.0 & 1.4 & 1.7 & 1.5 & 2.8 & 17.0 & 20.5 & 101.1 & 91.3 & 624.0 & 678.1 \\
\hline PCB 17 & 2.4 & 0.3 & 0.6 & 0.4 & 1.2 & 2.6 & 4.6 & 24.2 & 22.6 & 267.7 & 297.4 \\
\hline PCB 12 & 8.7 & $<0.4$ & $<0.4$ & $<0.4$ & $<0.5$ & $<1.7$ & $<1.7$ & $<2.3$ & $<2.3$ & & $<3.3$ \\
\hline PCB $27+13$ & 9.9 & 0.5 & $<0.5$ & 1.0 & 1.2 & $<2.0$ & $<1.9$ & 7.0 & 8.0 & 77.5 & 79.2 \\
\hline PCB 24 & 13.1 & $<0.6$ & $<0.6$ & $<0.7$ & & & & & $<3.4$ & & \\
\hline РСB 16 & 8.4 & 1.3 & & 1.7 & 1.5 & 4.9 & 5.5 & 19.4 & 16.6 & 218.7 & 241.8 \\
\hline РCB 15 & 7.0 & $<0.3$ & $<0.3$ & 0.5 & 0.5 & 2.3 & 3.9 & $<1.8$ & 16.9 & 137.5 & 153.0 \\
\hline PCB 32 & 3.5 & 0.3 & 0.4 & 0.6 & 0.6 & 2.6 & 2.9 & $<0.9$ & 18.2 & 170.9 & 181.4 \\
\hline PCB 54 & 11.8 & $<0.6$ & $<0.6$ & & & 12.8 & 11.2 & 12.6 & 11.3 & & \\
\hline PCB 34 & 4.7 & $<0.2$ & $<0.2$ & 1.9 & 1.7 & $<0.9$ & $<0.9$ & $<1.2$ & $<1.2$ & $<1.8$ & $<1.8$ \\
\hline
\end{tabular}


Table B1: (continued)

\begin{tabular}{|c|c|c|c|c|c|c|c|c|c|c|c|}
\hline \multicolumn{2}{|l|}{$\begin{array}{l}\text { Sample location } \\
\text { Date }\end{array}$} & \multicolumn{2}{|c|}{$\begin{array}{c}\text { Outdoor } \\
\text { 4 Dec. } 2007\end{array}$} & \multicolumn{2}{|c|}{$\begin{array}{c}\text { Outdoor } \\
19 \text { Dec. } 2007\end{array}$} & \multicolumn{2}{|c|}{$\begin{array}{c}\text { DESB } \\
\text { laboratory } \\
29 \text { Nov. } 2007\end{array}$} & \multicolumn{2}{|c|}{$\begin{array}{l}\text { DESB hallway } \\
11 \text { Dec. } 2007\end{array}$} & \multicolumn{2}{|c|}{$\begin{array}{c}\text { Dillman } \\
\text { hallway } \\
\text { 4 Jan. } 2008 \\
\end{array}$} \\
\hline $\begin{array}{l}\text { Analyte or co- } \\
\text { eluting analyte } \\
\text { group }\end{array}$ & $\begin{array}{l}\text { MDL, } \\
\text { pg }\end{array}$ & Conc. & $\mathrm{pg} \mathrm{m^{-3 }}$ & Conc. & $\mathrm{pg} \mathrm{m^{-3 }}$ & Conc., & $g m^{-3}$ & Conc., & $\mathrm{g} \mathrm{m}^{-3}$ & Conc., & $\mathrm{pg} \mathrm{m^{-3 }}$ \\
\hline PCB 29 & 4.0 & $<0.2$ & $<0.2$ & $<0.2$ & $<0.2$ & $<0.8$ & $<0.8$ & $<1.0$ & $<1.0$ & & 37.7 \\
\hline PCB 26 & 5.6 & $<0.3$ & $<0.3$ & 0.4 & 0.5 & 1.3 & 1.7 & 9.1 & 8.5 & 115.4 & 126.5 \\
\hline PCB 25 & 9.0 & $<0.4$ & $<0.4$ & $<0.5$ & & $<1.8$ & 4.1 & 5.7 & 5.6 & 47.7 & 55.2 \\
\hline PCB $31+53$ & 5.4 & & 1.2 & 3.5 & 3.8 & 11.1 & 10.6 & 50.8 & 48.6 & 716.4 & 791.7 \\
\hline PCB 28 & 2.4 & & 0.6 & 1.4 & 1.7 & 6.6 & 6.5 & 31.8 & 30.6 & 516.1 & 576.5 \\
\hline PCB $33+20$ & 4.5 & $<0.2$ & $<0.2$ & 1.3 & 1.0 & 5.1 & 5.0 & 25.8 & 24.3 & 418.1 & 450.3 \\
\hline PCB 51 & 0.9 & $<0.05$ & $<0.05$ & 3.3 & $<0.05$ & $<0.2$ & $<0.2$ & 10.0 & 11.3 & 12.8 & 35.0 \\
\hline РCB 45 & 1.5 & 0.5 & 0.6 & 0.5 & 0.4 & 7.3 & 3.4 & 8.4 & 8.0 & 61.0 & 66.6 \\
\hline PCB 22 & 5.3 & & & 0.6 & 0.6 & 2.5 & 3.0 & 15.0 & 14.1 & 226.6 & 253.6 \\
\hline PCB. 46 & 7.3 & $<0.4$ & 0.6 & 0.9 & $<0.4$ & 4.6 & $<1.4$ & & & 19.4 & 20.7 \\
\hline PCB 73 & 4.8 & 2.6 & 2.6 & 1.2 & 1.1 & 35.0 & 16.9 & 27.8 & 24.2 & & \\
\hline PCB 69 & 1.0 & $<0.05$ & $<0.05$ & 0.8 & $<0.05$ & $<0.2$ & $<0.2$ & $<0.2$ & $<0.2$ & $<0.4$ & $<0.4$ \\
\hline PCB 52 + aldrin & 13.6 & 1.4 & & 2.0 & 2.0 & & & & & 127.3 & 143.6 \\
\hline PCB 48 & 5.5 & $<0.3$ & $<0.3$ & $<0.3$ & $<0.3$ & $<1.1$ & $<1.1$ & $<1.4$ & $<1.4$ & $<2.1$ & $<2.1$ \\
\hline PCB 104 & 3.4 & $<0.2$ & $<0.2$ & $<0.2$ & $<0.2$ & $<0.7$ & $<0.7$ & $<0.9$ & $<0.9$ & $<1.3$ & $<1.3$ \\
\hline PCB 75 & 1.8 & 1.2 & 1.1 & 0.2 & 0.2 & 16.6 & 7.4 & 43.3 & 10.2 & 9.2 & 11.0 \\
\hline PCB 44 & 2.0 & $<0.1$ & & 0.5 & 0.7 & 3.3 & 3.3 & 18.9 & 18.8 & 216.8 & 245.5 \\
\hline PCB $59+42$ & 1.8 & & & 0.6 & 1.1 & 19.3 & 15.8 & 13.9 & 14.7 & 108.4 & 129.9 \\
\hline PCB 35 & 6.5 & $<0.3$ & $<0.3$ & $<0.3$ & $<0.3$ & $<1.3$ & $<1.3$ & $<1.7$ & 2.0 & 12.8 & 19.3 \\
\hline РСВ. 71 & 1.9 & $<0.1$ & 0.2 & $<0.1$ & 0.3 & 0.7 & $<0.4$ & 4.2 & 4.7 & 63.3 & 72.1 \\
\hline PCB 41 & 1.6 & $<0.1$ & $<0.1$ & $<0.1$ & & 0.8 & $<0.3$ & 2.2 & 2.6 & 40.7 & 48.2 \\
\hline PCB 64 & 2.5 & $<0.1$ & 0.2 & $<0.1$ & 0.4 & 1.1 & 0.9 & 7.7 & 8.3 & 108.3 & 123.9 \\
\hline $\begin{array}{l}\text { PCB } 40+37+ \\
\text { octachlorostyrene }\end{array}$ & 4.7 & 12.6 & 14.2 & 4.7 & 5.7 & 102.9 & 94.0 & 65.4 & 65.3 & 157.6 & 190.4 \\
\hline РСB 103 & 4.2 & $<0.2$ & $<0.2$ & $<0.2$ & $<0.2$ & $<0.8$ & $<0.8$ & $<1.1$ & $<1.1$ & $<1.6$ & $<1.6$ \\
\hline PCB 100 & 8.0 & $<0.4$ & $<0.4$ & $<0.4$ & $<0.4$ & $<1.6$ & $<1.6$ & $<2.1$ & $<2.1$ & $<3.0$ & $<3.1$ \\
\hline PCB 67 & 11.6 & $<0.6$ & $<0.6$ & $<0.6$ & $<0.6$ & $<2.3$ & $<2.3$ & $<3.0$ & $<3.0$ & & \\
\hline РСB $93+63$ & 12.9 & $<0.6$ & $<0.6$ & $<0.7$ & $<0.7$ & $<2,5$ & $<2.5$ & 3.4 & 4.4 & 27.2 & 26.9 \\
\hline PCB 95 & 10.9 & $<0.5$ & $<0.5$ & $<0.6$ & & 5.2 & 5.7 & 19.7 & 19.2 & 117.8 & 140.7 \\
\hline PCB 74 & 2.4 & $<0.1$ & $<0.1$ & $<0.1$ & 0.3 & 2.1 & 1.6 & 6.8 & 7.3 & 94.9 & 110.5 \\
\hline РСВ 70 & 1.9 & $<0.1$ & $<0.1$ & $<0.1$ & 0.4 & 2.9 & 3.8 & 16.4 & 16.8 & 214.4 & 249.9 \\
\hline PCB $91+66$ & 4.0 & $<0.2$ & $<0.2$ & $<0.2$ & $<0.2$ & $<0.8$ & $<0.8$ & $<1.0$ & $<1.0$ & 175.3 & 209.2 \\
\hline PCB. $84+92+56$ & 5.2 & $<0.3$ & $<0.2$ & $<0.3$ & 0.6 & 2.4 & 2.4 & 11.2 & 12.3 & 139.6 & 164.4 \\
\hline PCB $60+101+90$ & 4.0 & $<0.2$ & $<0.2$ & $<0.2$ & 0.8 & 4.6 & 3.2 & 16.5 & 17.4 & 93.7 & 107.9 \\
\hline PCB 99 & 6.2 & $<0.3$ & $<0.3$ & $<0.3$ & 0.4 & $<1.2$ & 2.4 & 7.8 & 8.9 & 39.0 & 47.0 \\
\hline PCB $119+83$ & 7.8 & $<0.4$ & $<0.4$ & $<0.4$ & $<0.4$ & $<1.5$ & $<1.5$ & $<2.0$ & $<2.0$ & & \\
\hline
\end{tabular}


Table B1: (continued)

\begin{tabular}{|c|c|c|c|c|c|c|c|c|c|c|c|}
\hline \multicolumn{2}{|l|}{$\begin{array}{l}\text { Sample location } \\
\text { Date }\end{array}$} & \multicolumn{2}{|c|}{$\begin{array}{c}\text { Outdoor } \\
4 \text { Dec. } 2007\end{array}$} & \multicolumn{2}{|c|}{$\begin{array}{c}\text { Outdoor } \\
19 \text { Dec. } 2007\end{array}$} & \multicolumn{2}{|c|}{$\begin{array}{c}\text { DESB } \\
\text { laboratory } \\
29 \text { Nov. } 2007\end{array}$} & \multicolumn{2}{|c|}{$\begin{array}{l}\text { DESB hallway } \\
11 \text { Dec. } 2007\end{array}$} & \multicolumn{2}{|c|}{$\begin{array}{c}\text { Dillman } \\
\text { hallway } \\
\text { 4 Jan. } 2008\end{array}$} \\
\hline $\begin{array}{l}\text { Analyte or co- } \\
\text { eluting analyte } \\
\text { group }\end{array}$ & $\begin{array}{l}\text { MDL, } \\
\text { pg }\end{array}$ & \multicolumn{2}{|c|}{ Conc., $\mathrm{pg} \mathrm{m}^{-3}$} & \multicolumn{2}{|c|}{ Conc., $\mathrm{pg} \mathrm{m}^{-3}$} & \multicolumn{2}{|c|}{ Conc., $\mathrm{pg} \mathrm{m}^{-3}$} & \multicolumn{2}{|c|}{ Conc., pg m $\mathrm{m}^{-3}$} & \multicolumn{2}{|c|}{ Conc., $\mathrm{pg} \mathrm{m}^{-3}$} \\
\hline РСВ 97 & 10.4 & $<0.5$ & $<0.5$ & 0.5 & 1.2 & $<2.1$ & $<2.0$ & 4.8 & 7.0 & 30.6 & 37.4 \\
\hline РСB 87 & 4.5 & $<0.2$ & $<0.2$ & 0.2 & 0.3 & $<0.9$ & $<0.9$ & 6.3 & 5.0 & 41.7 & 49.0 \\
\hline PCB 136 & 2.6 & 1.2 & 1.0 & 0.7 & 1.1 & 18.8 & 11.5 & $<0.7$ & $<0.7$ & & $<1.0$ \\
\hline PCB 117 & 6.8 & 1.1 & & 1.4 & 1.2 & & & & & & \\
\hline PCB 115 & 0.5 & 0.3 & 0.4 & 0.4 & 0.7 & 1.3 & 1.2 & 5.3 & 5.5 & 11.3 & 13.6 \\
\hline PCB 85 & 2.1 & $<0.1$ & $<0.1$ & $<0.1$ & $<0.1$ & $<0.4$ & $<0.4$ & $<0.5$ & $<0.5$ & 18.4 & $<0.8$ \\
\hline PCB 154 & 3.9 & $<0.2$ & $<0.2$ & $<0.2$ & $<0.2$ & $<0.8$ & $<0.8$ & $<1.0$ & $<1.0$ & $<1.5$ & $<1.5$ \\
\hline PCB 110 & 3.1 & & & 0.7 & 1.0 & 12.3 & 10.2 & 15.4 & 14.4 & 81.1 & 100.1 \\
\hline PCB 81 & 14.0 & $<0.7$ & $<0.7$ & $<0.7$ & $<0.7$ & $<2.8$ & $<2.7$ & $<3.6$ & $<3.6$ & $<5.3$ & $<5.4$ \\
\hline РСВ 82 & 4.6 & $<0.2$ & $<0.2$ & $<0.2$ & $<0.2$ & $<0.9$ & $<0.9$ & $<1.2$ & $<1.2$ & $<1.7$ & $<1.8$ \\
\hline PCB 151 & 2.6 & 4.0 & 4.0 & 2.4 & 2.8 & 91.1 & 53.2 & 134.9 & 124.9 & 102.6 & 153.6 \\
\hline PCB 135 & 4.6 & $<0.2$ & $<0.2$ & $<0.2$ & $<0.2$ & $<0.9$ & $<0.9$ & $<1.2$ & $<1.2$ & 9.6 & 11.3 \\
\hline PCB 77 & 5.8 & $<0.3$ & $<0.3$ & 0.5 & 0.4 & $<1.1$ & $<1.1$ & $<1.5$ & $<1.5$ & 9.5 & 93.5 \\
\hline PCB 144 & 4.1 & 1.5 & 1.9 & 0.8 & 0.9 & 23.9 & 20.7 & 13.6 & 13.3 & & $<1.6$ \\
\hline PCB 147 & 3.1 & $<0.1$ & $<0.1$ & $<0.2$ & $<0.2$ & $<0.6$ & $<0.6$ & $<0.8$ & $<0.8$ & $<1.2$ & $<1.2$ \\
\hline PCB 149 & 5.6 & 2.0 & 2,2 & 1.4 & 1.5 & 32.7 & 23.3 & 25.9 & 24.5 & 87.6 & 108.6 \\
\hline PCB 124 & 6.8 & $<0.3$ & $<0.3$ & $<0.3$ & $<0.4$ & $<1.3$ & $<1.3$ & $<1.8$ & $<1.8$ & & \\
\hline PCB $123+107$ & 7.3 & $<0.4$ & $<0.3$ & 0.7 & 0.4 & $<1.4$ & $<1.4$ & $<1.9$ & $<1.9$ & & \\
\hline PCB 134 & 4.7 & $<0.2$ & $<0.2$ & $<0.2$ & $<0.2$ & $<0.9$ & 1.0 & $<1.2$ & $<1.2$ & & \\
\hline PCB $131+$ PCB & & & & & & & & & & & \\
\hline $118+$ PBDE 28 & 6.8 & 14.4 & 18.7 & 6.9 & 8.2 & 241.8 & 218.3 & 275.2 & 258.4 & 262.3 & 375.8 \\
\hline PCB 122 & 1.5 & & & & & & & & & & \\
\hline PCB 165 & 1.0 & 0.5 & 0.6 & 0.2 & 0.3 & 5.6 & 6.4 & 2.3 & 2.0 & & \\
\hline PCB $114+146$ & 2.0 & $<0.1$ & $<0.1$ & $<0.1$ & $<0.1$ & $<0.4$ & $<0.4$ & $<0.5$ & 1.8 & 8.1 & 9.0 \\
\hline PCB 132 & 3.9 & & & 0.4 & 0.3 & 1.9 & 2.8 & 3.1 & 2.8 & 17.8 & 22.4 \\
\hline PCB 153 & 2.9 & $<0.1$ & $<0.1$ & 0.3 & 0.3 & 1.6 & 1.1 & 4.0 & 3.9 & 45.5 & 55.2 \\
\hline PCB 179 & 6.1 & $<0.3$ & $<0.3$ & 0.7 & 0.4 & $<1.2$ & 9.9 & $<1.6$ & $<1.6$ & & \\
\hline PCB 105 & 2.0 & & & $<0.1$ & $<0.1$ & 15.9 & 16.1 & 10.0 & 9.8 & 29.6 & 38.6 \\
\hline PCB 141 & 31.3 & 2.2 & $<1.5$ & 3.1 & 2.5 & 13.2 & $<6.1$ & $<8.1$ & $<8.1$ & & \\
\hline PCB 176 & 5.2 & $<0.3$ & $<0.3$ & $<0.3$ & $<0.3$ & $<1.0$ & $<1.0$ & $<1.4$ & $<1.4$ & & 4.0 \\
\hline PCB 137 & 2.9 & $<0.1$ & $<0.1$ & $<0.1$ & $<0.1$ & & $<0.6$ & $<0.7$ & 1.0 & & \\
\hline PCB 130 & 3.4 & $<0.2$ & $<0.2$ & $<0.2$ & $<0.2$ & $<0.7$ & $<0.7$ & $<0.9$ & $<0.9$ & & \\
\hline PCB 164 & 3.8 & $<0.2$ & $<0.2$ & $<0.2$ & $<0.2$ & $<0.8$ & $<0.7$ & $<1.0$ & $<1.0$ & 3.0 & 3.9 \\
\hline PCB 138 & 5.4 & $<0.3$ & $<0.3$ & 0.7 & $<0.3$ & 1.8 & 1.6 & 3.5 & 3.3 & 27.4 & 34.8 \\
\hline PCB $163+129$ & 3.0 & $<0.1$ & $<0.1$ & $<0.2$ & $<0.2$ & $<0.6$ & $<0.6$ & $<0.8$ & $<0.8$ & 9.5 & 13.2 \\
\hline PCB 178 & 3.6 & & $<0.2$ & 1.0 & 0.7 & & & $<0.9$ & $<0.9$ & 5.8 & 7.7 \\
\hline
\end{tabular}


Table B1: (continued)

\begin{tabular}{|c|c|c|c|c|c|c|c|c|c|c|c|}
\hline \multicolumn{2}{|l|}{$\begin{array}{l}\text { Sample location } \\
\text { Date }\end{array}$} & \multicolumn{2}{|c|}{$\begin{array}{c}\text { Outdoor } \\
\text { 4 Dec. } 2007\end{array}$} & \multicolumn{2}{|c|}{$\begin{array}{c}\text { Outdoor } \\
19 \text { Dec. } 2007\end{array}$} & \multicolumn{2}{|c|}{$\begin{array}{c}\text { DESB } \\
\text { laboratory } \\
29 \text { Nov. } 2007\end{array}$} & \multicolumn{2}{|c|}{$\begin{array}{l}\text { DESB hallway } \\
11 \text { Dec. } 2007\end{array}$} & \multicolumn{2}{|c|}{$\begin{array}{c}\text { Dillman } \\
\text { hallway } \\
4 \text { Jan. } 2008\end{array}$} \\
\hline $\begin{array}{l}\text { Analyte or co- } \\
\text { eluting analyte } \\
\text { group }\end{array}$ & $\begin{array}{l}\text { MDL, } \\
\mathrm{pg}\end{array}$ & Conc. & $\mathrm{g} \mathrm{m}^{-3}$ & Conc., & $\mathrm{g} \mathrm{m}^{-3}$ & Conc. & $\mathrm{pg} \mathrm{m}^{-3}$ & Conc., & $\mathrm{pg} \mathrm{m}^{-3}$ & Conc., & $\mathrm{pg} \mathrm{m}^{-3}$ \\
\hline PCB 158 & 3.3 & $<0.2$ & $<0.2$ & $<0.2$ & $<0.2$ & $<0.7$ & $<0.7$ & $<0.9$ & $<0.9$ & 3.7 & 5.2 \\
\hline PCB 175 & 2.5 & $<0.1$ & $<0.1$ & $<0.1$ & $<0.1$ & $<0.5$ & $<0.5$ & $<0.7$ & $<0.7$ & & \\
\hline PCB 187 & 11.5 & $<0.6$ & $<0.6$ & 1.4 & $<0.6$ & $<2.3$ & $<2.3$ & $<3.0$ & $<3.0$ & 30.9 & 33.0 \\
\hline PCB 183 & 4.8 & $<0.2$ & $<0.2$ & $<0.2$ & $<0.2$ & $<0.9$ & $<0.9$ & $<1.2$ & $<1.2$ & $<1.8$ & $<1.8$ \\
\hline PCB 128 & 3.4 & $<0.2$ & $<0.2$ & $<0.2$ & $<0.2$ & $<0.7$ & $<0.7$ & 1.4 & $<0.9$ & 3.5 & 4.9 \\
\hline PCB 185 & 6.6 & 0.4 & $<0.3$ & 1.7 & $<0.3$ & & & & & 7.3 & 6.8 \\
\hline PCB 174 & 74.9 & 6.2 & $<3.6$ & 19.3 & $<3.9$ & & $<14.7$ & $<19.4$ & $<19.5$ & $<28.1$ & 37.7 \\
\hline PCB 167 & 5.6 & $<0.3$ & $<0.3$ & $<0.3$ & $<0.3$ & 1.3 & 1.2 & $<1.5$ & $<1.5$ & $<2.1$ & $<2.2$ \\
\hline PCB 202 & 33.4 & 2.4 & $<1.6$ & 5.6 & 2.2 & 14.8 & $<6.5$ & & $<8.7$ & & \\
\hline PCB 177 & 2.5 & $<0.1$ & $<0.1$ & 0.2 & $<0.1$ & $<0.5$ & $<0.5$ & $<0.7$ & $<0.7$ & 10.1 & 12.8 \\
\hline PCB 173 & 2.0 & $<0.1$ & $<0.1$ & $<0.1$ & $<0.1$ & $<0.4$ & 1.0 & 0.9 & $<0.5$ & $<0.8$ & $<0.8$ \\
\hline PCB 197 & 3.4 & 2.1 & 2.4 & 1.1 & 1.2 & 62.2 & 40.7 & 36.5 & 37.5 & 30.4 & 41.8 \\
\hline PCB 156 & 2.1 & $<0.1$ & $<0.1$ & $<0.1$ & $<0.1$ & $<0.4$ & $<0.4$ & $<0.6$ & $<0.6$ & & \\
\hline PCB 157 & 14.7 & $<0.7$ & $<0.7$ & $<0.7$ & $<0.8$ & $<2.9$ & $<2.9$ & $<3.8$ & $<3.8$ & $<5.5$ & 6.0 \\
\hline PCB 180 & 6.8 & $<0.3$ & $<0.3$ & $<0.3$ & $<0.4$ & $<1.3$ & $<1.3$ & $<1.8$ & $<1.8$ & 45.8 & 59.6 \\
\hline PCB $193+200$ & 8.5 & $<0.4$ & $<0.4$ & $<0.4$ & 0.8 & 3.9 & & $<2,2$ & & & 8.8 \\
\hline PCB 191 & 2.4 & $<0.1$ & $<0.1$ & $<0.1$ & $<0.1$ & $<0.5$ & $<0.5$ & $<0.6$ & $<0.6$ & $<0.9$ & $<0.9$ \\
\hline PBDE 47 & 17.8 & 8.4 & 14.3 & 6.4 & 8.3 & 537.6 & 387.0 & 509.9 & 549.8 & 485.3 & 616.9 \\
\hline PCB 170 & 1.9 & $<0.1$ & $<0.1$ & 0.2 & $<0.1$ & $<0.4$ & $<0.4$ & $<0.5$ & $<0.5$ & 12.9 & 17.3 \\
\hline PCB 199 & 1.9 & $<0.1$ & $<0.1$ & $<0.1$ & $<0.1$ & $<0.4$ & $<0.4$ & $<0.5$ & $<0.5$ & 18.1 & 23.3 \\
\hline PCB 190 & 2.1 & $<0.1$ & $<0.1$ & $<0.1$ & $<0.1$ & & $<0.4$ & $<0.5$ & $<0.5$ & 2.8 & 3.6 \\
\hline PCB 196 & 1.9 & $<0.1$ & $<0.1$ & $<0.1$ & $<0.1$ & $<0.4$ & $<0.4$ & $<0.5$ & $<0.5$ & 9.1 & 12.0 \\
\hline PCB 203 & 2.6 & $<0.1$ & $<0.1$ & 0.6 & 0.2 & & $<0.5$ & & & 11.8 & 14.9 \\
\hline PCB 208 & 2.4 & & $<0.1$ & 0.4 & $<0.1$ & & & & $<0.6$ & & \\
\hline PCB 189 & 3.4 & $<0.2$ & $<0.2$ & $<0.2$ & $<0.2$ & $<0.7$ & $<0.7$ & $<0.9$ & $<0.9$ & $<1.3$ & $<1.3$ \\
\hline PCB $195+207$ & 4.7 & $<0.2$ & $<0.2$ & $<0.2$ & $<0.2$ & $<0.9$ & $<0.9$ & $<1.2$ & $<1.2$ & 7.4 & 9.9 \\
\hline PCB 194 & 8.2 & & & $<0.4$ & 1.0 & 71.3 & 36.2 & & 20.0 & 10.2 & 16.8 \\
\hline РCB 205 & 2.9 & 0.6 & 0.3 & 0.8 & 0.2 & 5.4 & 5.7 & 4.4 & 3.8 & 2.6 & 4.1 \\
\hline PBDE 99 & 45.3 & & 3.8 & $<2.3$ & $<2.3$ & 461.4 & 295.0 & 119.5 & 209.6 & 27.1 & 45.8 \\
\hline PCB 206 & 2.7 & & & 0.7 & & & & & $<0.7$ & 3.1 & 3.7 \\
\hline PCB 209 & 3.9 & 0.8 & & 0.6 & 0.8 & 4.1 & 3.2 & $<1.0$ & $<1.0$ & & \\
\hline
\end{tabular}


Figure B.1: (next page) Chromatograms of co-located outdoor air samples. The upper chromatogram was processed through the gas-phase cleanup method while the lower chromatogram was not. Analytes and co-eluting analyte groups are identified in the upper panel. 


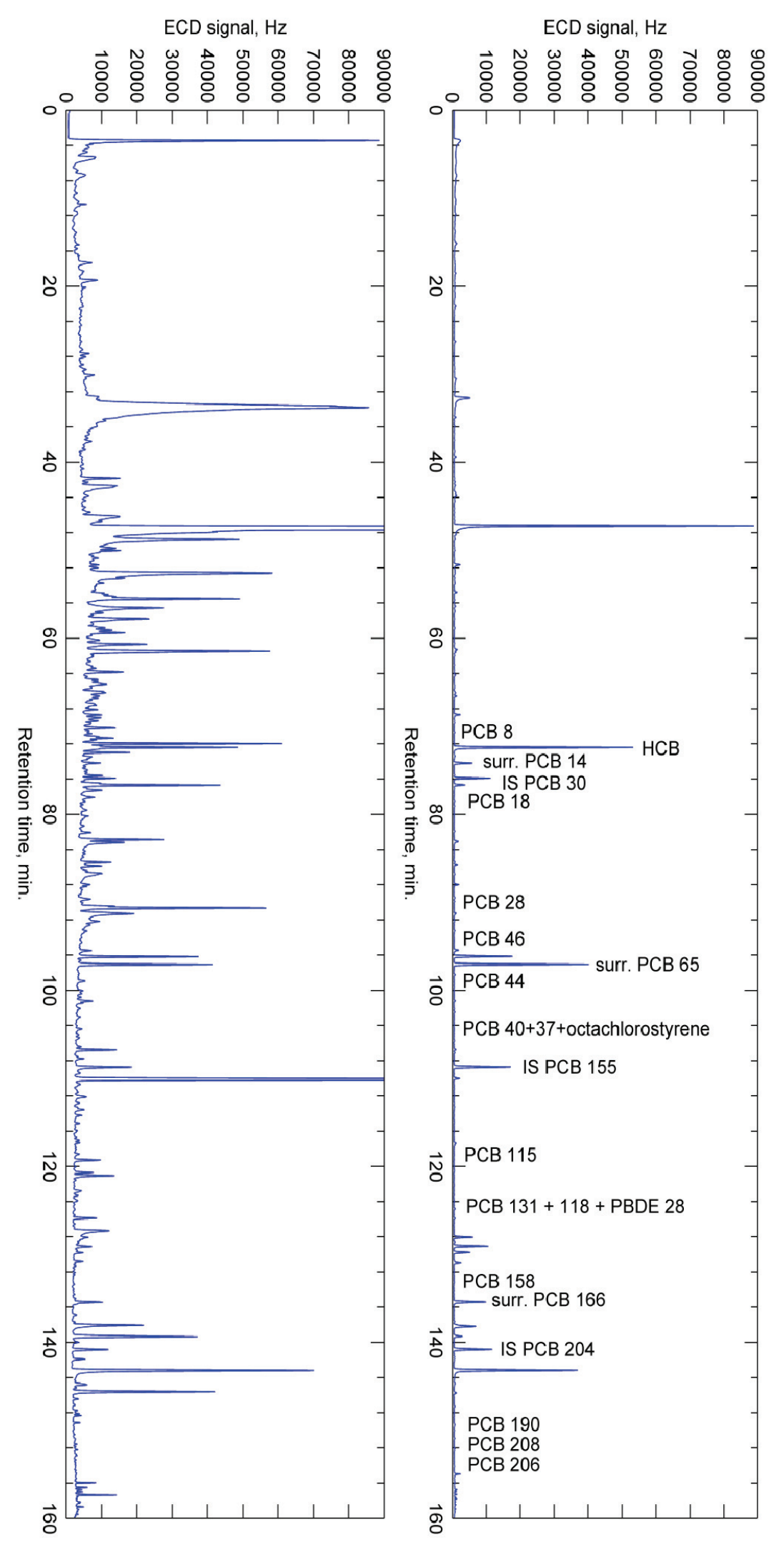




\section{Appendix C: Chapter 3 supplemental information}

\section{Detailed description of the collection efficiency model}

\section{Prediction of gas-phase collection efficiency.}

Collection efficiency for open tubular and packed-bed sorptive samplers can be described using chromatographic theory (for example, Baltussen et al. 2002; Xiao et al. 2007). Calculations were conducted on a single capillary in a denuder. The predicted breakthrough volume for a single capillary was then multiplied by the number of capillaries in the denuder to obtain the gaseous breakthrough volume for the denuder.

From an equilibrium point of view, retention volume can be obtained from the geometry of the capillary and the liquid-gas partition coefficient for the analyte at the sample collection temperature:

$$
\begin{gathered}
k=K / \beta \\
V_{r}=V_{0}(1+k)
\end{gathered}
$$

where $K=$ liquid-gas (stationary phase) partition coefficient, $\beta=$ phase ratio (mobile phase volume/stationary phase volume), $k=$ capacity factor, $V_{\mathrm{r}}=$ retention volume, $V_{0}=$ mobile phase retention volume (void volume of the capillary). If mass transport were infinitely fast, the instantaneous collection efficiency would change from $100 \%$ to $0 \%$ when sample volume equals retention volume. However, because of limited mass transport in the mobile and stationary phases, there is a mass transport zone of finite length, and breakthrough occurs over a period of time. Various expressions are available to estimate the shape of the breakthrough front as a function of the number of theoretical plates. For an open tubular capillary, the theoretical plate height can be described using the Golay Equation (as in Poole 2003, p. 34):

$$
H=\frac{2 D_{g}}{u}+\frac{\left(1+6 k+11 k^{2}\right)}{96(1+k)^{2}} \frac{d^{2} u}{D_{g}}+\frac{2 k}{3(1+k)^{2}} \frac{d_{f}^{2} u}{D_{s}}
$$




$$
N=L / H
$$

where $H=$ theoretical plate height, $u=$ gas velocity in the capillary, $D_{\mathrm{g}}=$ analyte diffusivity in the gas, $k=$ retention factor, $d=$ capillary internal diameter, $d_{\mathrm{f}}=$ stationary phase film thickness, $D_{\mathrm{s}}=$ analyte diffusivity in the stationary phase, $N=$ number of theoretical plates, and $L=$ capillary length. Pressure drop corrections to $H$ included in Poole (2003) were $<1 \%$ and were not included. The Golay Equation requires knowledge of analyte diffusivity in both the gas and stationary phases. Gas-phase diffusivity was estimated as a function of analyte molecular mass and molar volume (Fuller et al. 1966). Diffusivity of the analyte in the stationary phase is more difficult to estimate. An empirical expression for diffusivity of large organic molecules in silicone elastomer as a function of analyte molecular mass was reported by Malcolm et al. (2003):

$$
\log (D s)=-0.0068 M-4.0738
$$

where $D_{\mathrm{s}}=$ analyte diffusivity in silicone elastomer at $37^{\circ} \mathrm{C}, \mathrm{cm}^{2} \mathrm{~s}^{-1}$, and $M=$ analyte molecular mass, $\mathrm{g}_{\text {mole }}{ }^{-1}$. The PDMS stationary phase used in our diffusion denuders is a silicone elastomer. Rusina et al. (2007) measured diffusivity of four PAH compounds in PDMS at $25^{\circ} \mathrm{C}$, and reported values from 10 to 24 -fold less than those given by Eq. (C5) at $37^{\circ} \mathrm{C}$. Decreasing $D_{\mathrm{s}}$ by a factor of 100 from the value given by Eq. C5, to simulate lesser diffusivity at sample collection temperatures below $25^{\circ} \mathrm{C}$, resulted in $<1 \%$ change in $H$. Thus, the model is not sensitive to uncertainty in $D_{\mathrm{s}}$ for these denuders.

By employing the number of theoretical plates estimated in Eq. C4 in any of a number of expressions available in the literature, the retention volume can be reduced to obtain breakthrough volume. Simple expressions are available that give the instantaneous breakthrough volume assuming a Gaussian front shape (Raymond and Guiochon 1975). However, these expressions can give unrealistic results (negative breakthrough volume) for samplers with a low number of theoretical plates and low $K_{\mathrm{pdms}}$. A more useful definition of breakthrough than the instantaneous collection efficiency is the integral breakthrough fraction, $b t$, defined as the ratio of analyte mass that passed through the sampler uncollected to the total analyte mass that entered the sampler. This is the breakthrough fraction that can be measured in a sorptive sampling experiment, for 
example by using a backup denuder in series with the sampling denuder. Lövkvist and Jönsson (1987) derived an expression for estimating the integral breakthrough fraction:

$$
\begin{gathered}
b t=\frac{\tau-1}{\tau} \Phi\left(N^{\frac{1}{2}} \frac{\tau-1}{\tau^{\frac{1}{2}}}\right)+\frac{\tau+1}{\tau} \exp (2 N) \Phi\left(-N^{\frac{1}{2}} \frac{\tau+1}{\tau^{\frac{1}{2}}}\right) \\
\tau=\frac{t}{t_{r}}=\frac{V}{V_{r}}
\end{gathered}
$$

where $b t=$ integral breakthrough fraction (fraction of total analyte mass entering the sampler that passed through the sampler), $t, V=$ sampling time or volume, $t_{\mathrm{r}}, V_{\mathrm{r}}=$ retention time or volume, and $\Phi()=$ integral of the normal distribution. The expression of Lövkvist and Jönsson was derived based on a mass balance using assumptions that are representative of gas-liquid sorptive sampling: a linear distribution isotherm, constant inlet concentration, and low theoretical plate numbers. Lövkvist and Jönsson also provided a simplified approximate form of their breakthrough expression that can be solved explicitly for the breakthrough volume. The curve fitting constants are given for specific values of $b t$ (up to 0.1). The approximate expression was used by Baltussen (2002). However, if breakthrough volumes are required for a breakthrough fraction greater than 0.1 , for example in comparing predicted breakthrough volumes to experimental breakthrough volumes, the Lövkvist and Jöhnsson expression can be solved iteratively for the value of $V$ that gives the desired $b t$. Eq. C6 was used here rather than the approximate form.

\section{Temperature-dependent $K_{\mathrm{pdms}}$ from the solvation parameter model}

We obtained temperature-dependent solvent descriptors for PDMS through analysis of data reported by Li et al. (2000). Measured solvent descriptors were reported by Poole and Poole (1995) at one temperature only $\left(121.4^{\circ} \mathrm{C}\right)$, while Li et al. (2000) reported solvent descriptors for determination of retention factors at $140,120,100,80$, and $60^{\circ} \mathrm{C}$. Retention factor, $k$, is related to $K$ and the phase ratio, $\beta$, as $k=K / \beta$ (Eq. C1). Thus, $K_{\mathrm{pdms}}$ was obtained by adding $\log (\beta)=1.9$ to the values of $c$ reported by Li et al., where $\beta$ was

calculated from nominal column dimensions. The solvent descriptors of $\mathrm{Li}$ et al. were 
then linearly regressed against inverse absolute temperature to provide a means to estimate solvent descriptors at other temperatures. Regression results are given in Table 1. The slope of $s$ was not significantly different from zero $(P=0.66)$ over the temperature range tested, so the mean of the five measurements is given as the intercept. The other slopes and intercepts were significantly different from zero $(P<0.002)$, had relative standard error values of $<8 \%$, and coefficients of determination $>0.98$ (Table 1). The regression parameters reported in Table 1, combined with available methods to estimate solute descriptors for any molecule, provide a means to estimate temperature dependent $K_{\text {pdms, }}$, and thus breakthrough fraction, for any organic compound.

\section{Prediction of particle transmission efficiency}

Particle losses in a denuder can occur at two locations: 1) along the length of the capillaries by diffusion and sedimentation, 2) at the entrance to the capillaries where the flow is split across the ends of the capillary walls. The Gormley-Kennedy model for diffusion to the walls of a tube (Gormley and Kennedy 1949) was used to estimate particle losses by diffusion along the length of the capillaries:

$$
h=\frac{\pi L D_{p}}{2 Q}
$$

for $\mathrm{h}<0.0156$

$$
f_{t D}=1-4.07 h^{\frac{2}{3}}+2.4 h+0.446 h^{\frac{4}{3}}
$$

for $\mathrm{h}>0.0156$

$f_{t D}=0.8191 \exp (-7.314 h)+0.0975 \exp (-44.6 h)+0.0325 \exp (-114 h)$

where $h$ is computed from other variables as defined in Eq. C9, $L=$ capillary length, $D_{\mathrm{p}}$ $=$ particle diffusivity, $Q=$ volumetric flow rate, and $f_{\mathrm{tD}}=$ ratio of outlet to inlet particle concentration (fraction transmitted). During the measurements reported here, the lowflow denuders were oriented horizontally during sampling, and particles in them are thus subject to sedimentation, while the high-flow denuders were oriented vertically. Particle 
loss along the capillary length by sedimentation was included for low-flow denuders using the method of Pich (1972).

Particle loss on the ends of the capillary walls was predicted using a single-fiber collection efficiency model for filters (Hinds 1999, p.190) modified for application to multicapillary denuders as follows. An equivalent fiber diameter for the low-flow denuder was calculated by dividing the solid area of the denuder cross-section by the summed length of capillary cell walls assuming geometries of close-packed cylinders (low-flow) or hexagons (high-flow):

$$
d_{f}=\frac{\left(A_{d}-N_{c} A_{o c}\right)}{1.732 N_{c}}\left(\frac{A_{d}}{0.866 N_{c}}\right)^{-0.5}
$$

where $d_{f}$ is fiber diameter, $N_{c}$ is the number of capillaries in the denuder, $A_{o c}$ is the open area of a single capillary, and $A_{d}$ is the cross-sectional area of the denuder. For the highflow denuder, the foil thickness used to make the stainless steel honeycombs was known to be 0.002 inches. The overall fraction transmitted through the denuder was calculated by modifying the expression for a fiber filter to consider collection on a two-dimensional surface (the capillary ends):

$$
f_{t}=\left(1-E_{\Sigma} \alpha\right)^{n} f_{t D} f_{t S}
$$

where $E_{\Sigma}$ is the single fiber collection fraction per unit fiber length for impaction, interception, diffusion, sedimentation as defined by Hinds (1999, p.196), $\alpha$ is the solid area fraction of the denuder, $n$ is the number of sections in the denuder ( $n=1$ for the lowflow denuder, $n=2$ for the high-flow denuder), and $f_{t s}$ is the fractional transmission for sedimentation along the length of the tube. 
Table C.1: Solute descriptors for the compounds used in GC measurements of $K_{\text {pdms. }}$.

$\begin{array}{llllll} & \boldsymbol{E} & \boldsymbol{S} & \boldsymbol{A} & \boldsymbol{B} & \boldsymbol{L} \\ \mathrm{HCB}^{\mathrm{a}} & 1.490 & 0.990 & 0.000 & 0.000 & 7.390 \\ \alpha-\mathrm{HCH}^{\mathrm{b}} & 1.45 & 1.20 & 0 & 0.47 & 7.34 \\ \mathrm{Y}^{\mathrm{HCCH}}{ }^{\mathrm{b}} & 1.45 & 1.28 & 0 & 0.50 & 7.57 \\ \mathrm{PCB} \mathrm{18}{ }^{\mathrm{c}} & 1.75 & 1.35 & 0.00 & 0.17 & 7.480 \\ \mathrm{PCB} \mathrm{28}{ }^{\mathrm{c}} & 1.76 & 1.33 & 0.00 & 0.15 & 7.904 \\ \mathrm{PCB} \mathrm{44}{ }^{\mathrm{c}} & 1.90 & 1.48 & 0.00 & 0.15 & 8.312 \\ \mathrm{PCB} \mathrm{65}{ }^{\mathrm{c}} & 1.89 & 1.48 & 0.00 & 0.15 & 8.288 \\ \mathrm{PBDE} 2{ }^{\mathrm{d}} & 2.15 & 1.78 & 0.00 & 0.32 & 9.92 \\ { }^{\mathrm{a}} \text { (Sprunger et al. 2007) } \\ { }^{\mathrm{b}} \mathrm{C}, \mathrm{A}, \mathrm{B} \text {, and } L \text { (Goss et al. 2008), } E \text { (Abraham et al. 2002) } \\ { }^{\mathrm{C}} \text { (Abraham and Al-Hussaini 2005) } \\ { }^{\mathrm{d}} \text { (Pharma Algorithms 2006, group contribution method) }\end{array}$


Table C.2: Solvent descriptors for PDMS and dry octanol from several sources are presented, including the number of compounds in the calibration data set. Reported uncertainties are given in parentheses.

\begin{tabular}{llllllllll} 
& $\mathbf{T},{ }^{\circ} \mathbf{C}$ & Phases & $\boldsymbol{c}$ & $\boldsymbol{e}$ & $\boldsymbol{s}$ & $\boldsymbol{a}$ & $\boldsymbol{b}$ & $\boldsymbol{l}$ & $\mathbf{n}$ \\
$\mathrm{T}^{\mathrm{a}}$ & 25 & dry PDMS-gas & -0.032 & 0 & 0.209 & 0.409 & 0 & 0.860 & $41-63$ \\
$\mathrm{H}^{\mathrm{b}}$ & 25 & dry PDMS-gas & 0.18 & -0.05 & 0.21 & 0.99 & 0.10 & 0.84 & 32 \\
& & & $(0.13)$ & $(0.18)$ & $(0.20)$ & $(0.23)$ & $(0.23)$ & $(0.03)$ & \\
$\mathrm{S}$ & 25 & dry PDMS-gas & -0.045 & -0.197 & 0.493 & 1.271 & 0.347 & 0.856 & 64 \\
& & & $(0.025)$ & $(0.109)$ & $(0.128)$ & $(0.170)$ & $(0.147)$ & $(0.016)$ & \\
$\mathrm{S}^{\mathrm{c}}$ & 25 & \multirow{2}{*}{ wet PDMS-gas } & -0.045 & 0.053 & 0.639 & 1.096 & 0.650 & 0.763 & 78 \\
& & & $(0.095)$ & $(0.108)$ & $(0.146)$ & $(0.154)$ & $(0.183)$ & $(0.028)$ & \\
$\mathrm{A}$ & 25 & dry octanol-gas & -0.120 & -0.203 & 0.560 & 3.560 & 0.702 & 0.939 & \\
$\mathrm{~L}$ & 120 & dry PDMS-gas & -0.136 & 0 & 0.207 & 0.185 & 0 & 0.504 & 59 \\
& & & $(0.015)$ & & $(0.009)$ & $(0.021)$ & & $(0.003)$ & \\
$\mathrm{P}$ & 121.4 & dry PDMS-gas & -0.194 & 0.024 & 0.190 & 0.125 & 0 & 0.498 & 39
\end{tabular}

T: Table 1 regression; H: (Hierlemann et al. 2001), S: (Sprunger et al. 2007), A: (Abraham and Al-Hussaini 2005); L: (Li et al. 2000); P: (Poole and Poole 1995).

${ }^{a}$ The number of compounds varied at each of the five temperatures at which Li et al. measured $K_{\mathrm{pdms}}$

${ }^{\mathrm{b}}$ Hierlemann et al. found $e$ and $b$ to be statistically insignificant.

${ }^{\mathrm{C}}$ There was a typographical error in Sprunger et al., the correct value of $c$ is given above (Acree Jr. 2009). 
Table C.3: Sample collection conditions for gaseous breakthrough fraction measurements.

\begin{tabular}{|c|c|c|c|c|c|}
\hline $\begin{array}{l}\text { Sample } \\
\text { ID }^{\text {a }}\end{array}$ & Date & Location $^{c}$ & $\begin{array}{l}\text { Temperature, }{ }^{\circ} \mathrm{C} \text {, } \\
\text { avg (min, } \max )\end{array}$ & $\begin{array}{l}\text { Relative humidity, \% } \\
\text { avg (min, max) }\end{array}$ & $\begin{array}{l}\text { Sample } \\
\text { volume, } \\
\mathrm{m}^{3}\end{array}$ \\
\hline $\mathrm{H} 1 \mathrm{~A}, \mathrm{~B}$ & $5 / 19 / 2008$ & $\mathrm{OE}$ & $4.5 \quad(3.0,6.3)$ & $79.3 \quad(75.0,83.0)$ & 56.8 \\
\hline $\mathrm{H} 2 \mathrm{~A}, \mathrm{~B}$ & $7 / 17 / 2008$ & $\mathrm{OE}$ & $13.6(12.2,15.4)$ & $99.7(98.2,100.0)$ & 111.6 \\
\hline $\mathrm{H} 3 \mathrm{~A}, \mathrm{~B}$ & $7 / 29 / 2008$ & $\mathrm{OE}$ & $24.9(23.4,25.8)$ & $71.8 \quad(68.8,75.4)$ & 73.1 \\
\hline $\mathrm{H} 4 \mathrm{~A}, \mathrm{~B}$ & $8 / 5 / 2008$ & OD & $24.1(22.9,25.2)$ & $52.5(46.6,60.2)$ & 66.3 \\
\hline $\mathrm{H} 5^{\mathrm{b}}$ & $6 / 24 / 2008$ & OD & $11.8(11.4,12.2)$ & $94.6(93.1,96.1)$ & 67.9 \\
\hline $\mathrm{H} 6^{\mathrm{b}}$ & $6 / 25 / 2008$ & OD & $20.0(18.8,21.1)$ & $74.2(66.1,81.7)$ & 76.8 \\
\hline L1A,B & $11 / 29 / 2007$ & ID & $17.4(17.2,17.6)$ & $28.2(26.0,29.6)$ & 5.1 \\
\hline L2A,B & $12 / 4 / 2007$ & OD & $-9.2(-12.3,-5.4)$ & $75.7 \quad(59.4,86.8)$ & 20.7 \\
\hline L3A, B & $12 / 11 / 2007$ & ID & $19.9(19.8,20.1)$ & $24.4 \quad(23.4,26.8)$ & 3.9 \\
\hline$L 4 A, B$ & $12 / 19 / 2007$ & OD & $-4.2(-3.0,-5.1)$ & $83.6 \quad(76.4,89.9)$ & 19.7 \\
\hline L5A,B & $1 / 4 / 2008$ & II & $21.9(21.4,22.0)$ & $11.0(10.8,11.9)$ & 2.7 \\
\hline L6A,B & $1 / 17 / 2008$ & OD & $-10.0(-14.2,-6.4)$ & $80.1 \quad(51.6,93.3)$ & 22.0 \\
\hline \multicolumn{6}{|c|}{${ }^{a}$ Sample identification code: high-flow $(H)$, low-flow $(L)$, duplicate samples $(A, B)$. } \\
\hline \multicolumn{6}{|c|}{${ }^{\mathrm{b}}$ Ceramic honeycomb denuder } \\
\hline
\end{tabular}


Table C.4: Mean properties of log-normal ambient aerosol size distributions and predicted particle transmission for each aerosol mode through the high-flow and lowflow denuders.

\begin{tabular}{|c|c|c|c|c|}
\hline Aerosol class & $\begin{array}{l}\text { Mass conc. }\left(C_{\mathrm{p}}\right) \\
\mu \mathrm{g} \mathrm{m}^{-3} \text { a }\end{array}$ & $\begin{array}{l}\text { Size range, } \\
\mu m^{a}\end{array}$ & $\begin{array}{l}f_{t} \text {, high-flow } \\
\text { denuder }^{b}\end{array}$ & $\begin{array}{l}f_{\mathrm{t}} \text {, low-flow } \\
\text { denuder }^{\mathrm{b}}\end{array}$ \\
\hline Rural & & & & \\
\hline Nucleation & 0.04 & $0.01-0.10$ & 0.93 & 0.90 \\
\hline Accumulation & 4.6 & $0.08-1.28$ & 0.98 & 0.97 \\
\hline $\begin{array}{l}\text { Coarse particle } \\
\text { Urban }\end{array}$ & 24.0 & $1.30-28.20$ & 0.93 & 0.42 \\
\hline Nucleation & 0.7 & $0.01-0.13$ & 0.93 & 0.91 \\
\hline Accumulation & 38.1 & $0.07-1.49$ & 0.98 & 0.97 \\
\hline Coarse particle & 30.5 & $1.16-27.71$ & 0.93 & 0.44 \\
\hline
\end{tabular}


Table C.5: Root mean square (RMS) error for comparison of predicted with measured breakthrough fraction, $b t$, for low-flow and high-flow diffusion denuders.

All data

Relative humidity $\leq 70 \%$

Relative humidity $>70 \%$

RMS difference between duplicate measurements

\begin{tabular}{llll} 
Low-flow & \multicolumn{2}{l}{ High-flow } \\
RMS & & RMS & \\
error & $\mathrm{n}$ & error & $\mathrm{n}$ \\
0.05 & 28 & 0.10 & 23 \\
0.05 & 23 & 0.11 & 8 \\
0.01 & 5 & 0.09 & 15 \\
0.05 & 13 & 0.05 & 7
\end{tabular}




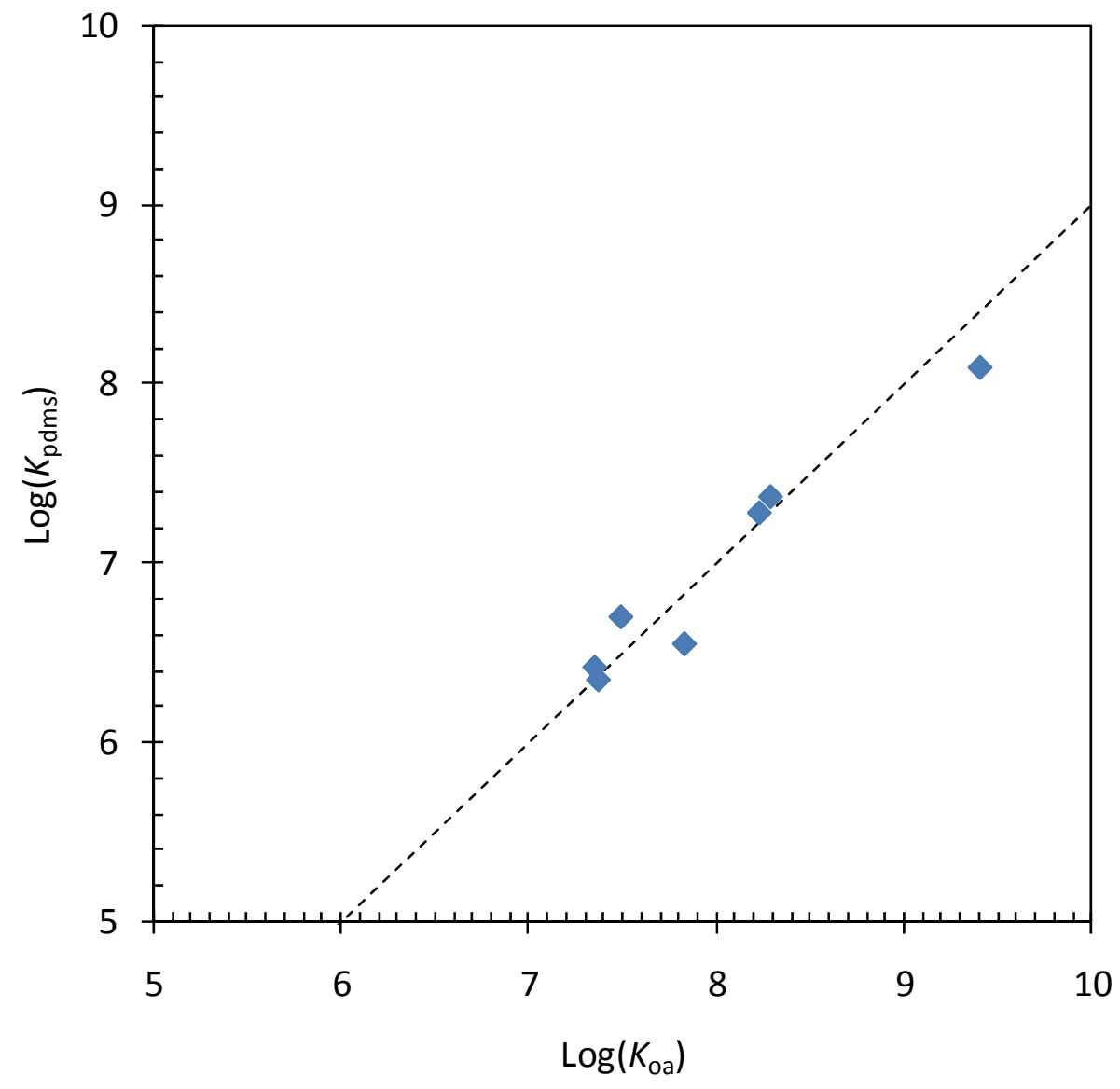

Figure C.1: $\log \left(K_{\text {pdms }}\right)$ measured using gas chromatography versus $\log \left(K_{\text {oa }}\right)$ at $25^{\circ} \mathrm{C}$ for the compounds listed in Table 3.3. The relationship $\log \left(K_{\mathrm{pdms}}\right)=\log \left(K_{\mathrm{oa}}\right)-1$ is plotted using a dashed line. 


\section{Appendix D: Chapter 4 supplemental information}
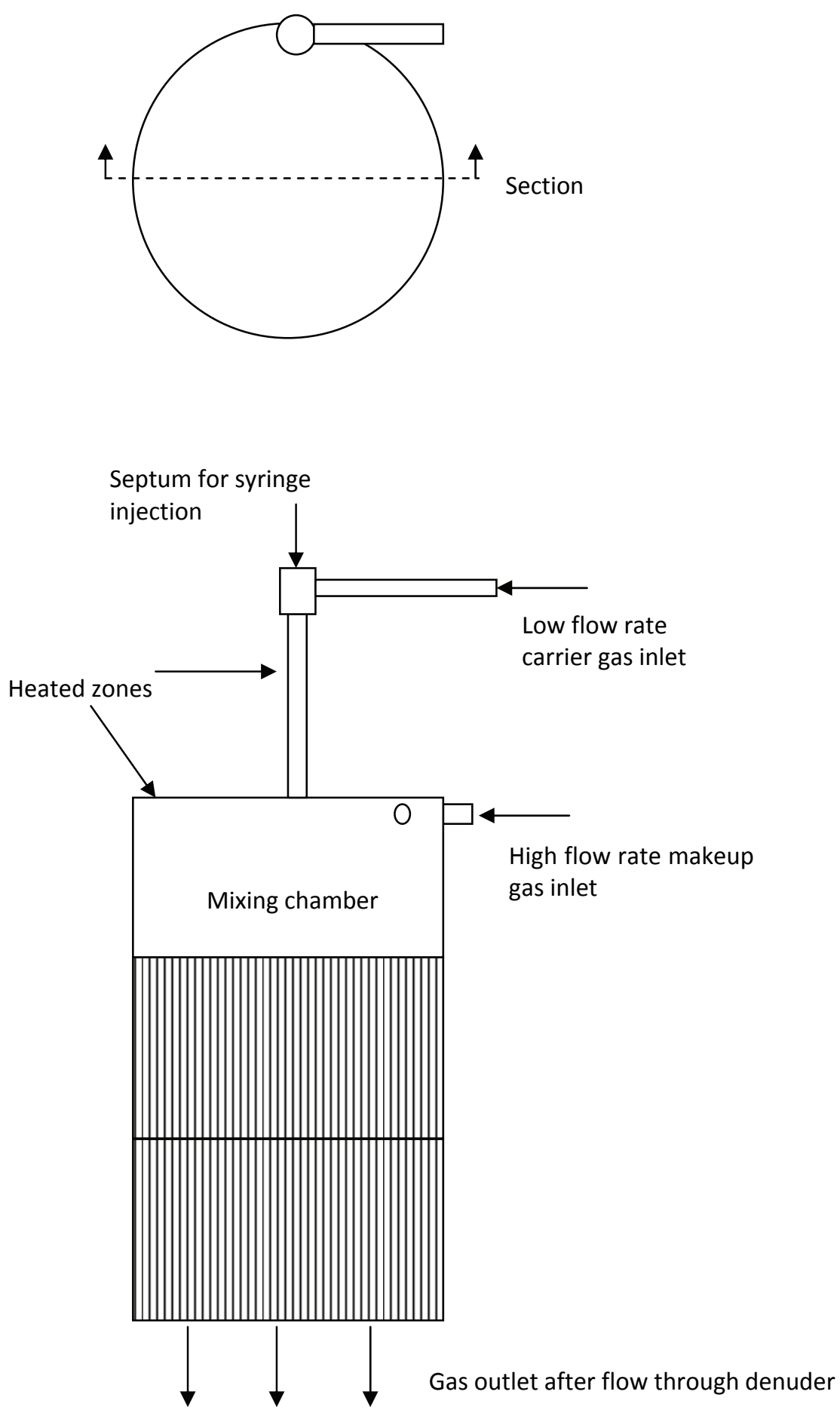

Figure D.1: Schematic illustration of the high-flow denuder hot-spike device. 


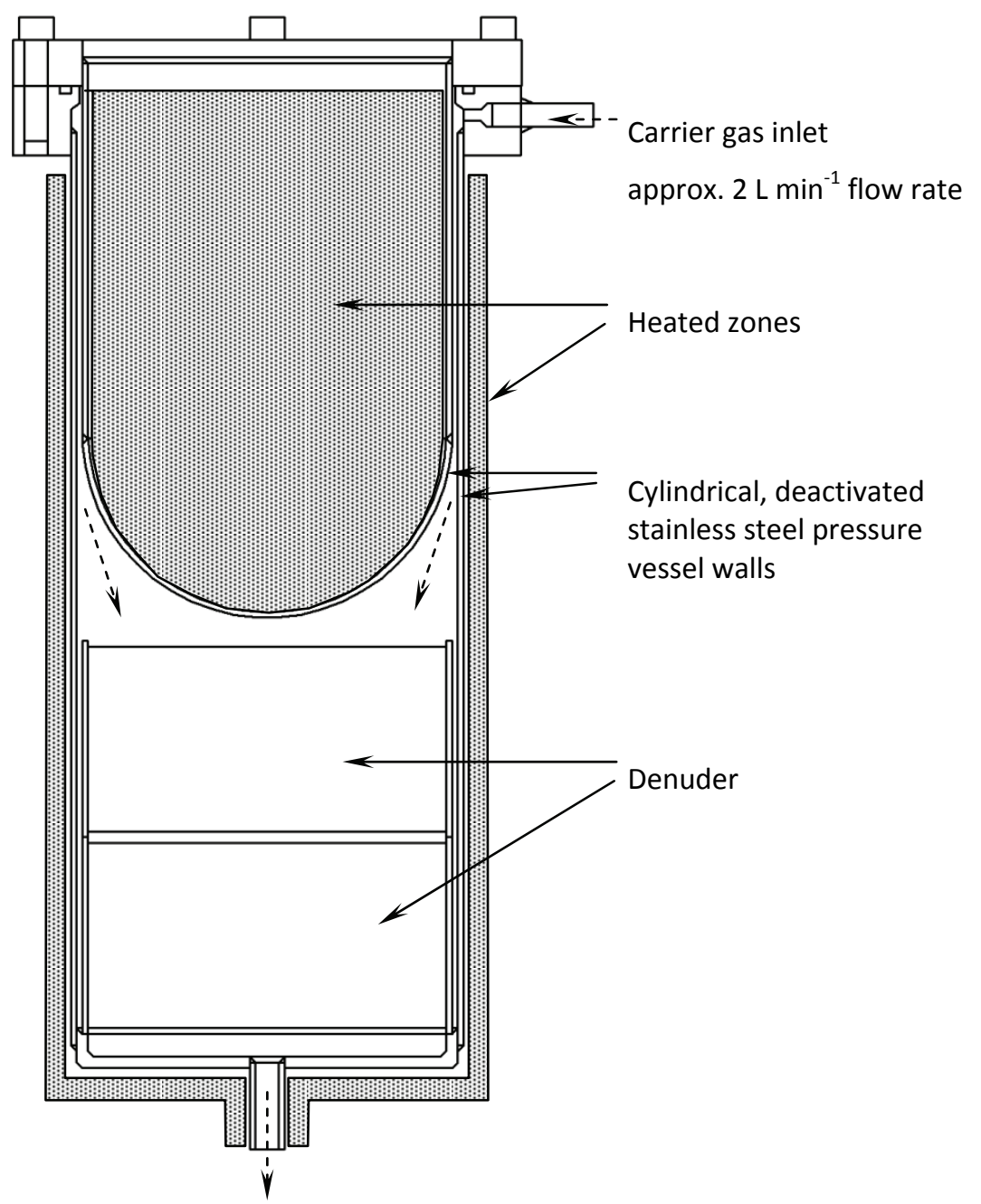

Carrier gas outlet to thermal desorption tube

Figure D.2: Schematic longitudinal cross-section of the analyte transfer apparatus (ATA). 
Table D.1: Concentration of atmospheric persistent, bioaccumulative, and toxic chemicals (pg m${ }^{-3}$ at $25^{\circ} \mathrm{C}, 1$ atm.) ${ }^{a}$

\begin{tabular}{|c|c|c|c|c|c|c|c|c|c|c|}
\hline \multicolumn{2}{|l|}{$\begin{array}{l}\text { Sample location } \\
\text { Date }\end{array}$} & \multicolumn{2}{|c|}{$\begin{array}{l}\text { Eagle Harbor, } \\
\text { MI } \\
19 \text { May } 2008\end{array}$} & \multicolumn{2}{|c|}{$\begin{array}{l}\text { Houghton, } \\
\text { MI } \\
24 \quad 25 \\
\text { Jun. } 2008\end{array}$} & \multicolumn{2}{|c|}{$\begin{array}{c}\text { Eagle Harbor, } \\
\text { MI } \\
17 \text { Jul. } 2008\end{array}$} & \multirow[t]{2}{*}{$\begin{array}{c}\begin{array}{c}\text { Eagle } \\
\text { Harbor, Ml }\end{array} \\
\text { 29 Jul. } 2008 \\
73.1\end{array}$} & \multicolumn{2}{|c|}{$\begin{array}{l}\text { Houghton, } \\
\text { MI } \\
5 \text { Aug. } 2008\end{array}$} \\
\hline Volume, $\mathrm{m}^{3}$ & & 56.8 & 59.0 & 67.9 & 76.8 & 109.4 & 111.6 & & 70.1 & 66.3 \\
\hline Temp., ${ }^{\circ} \mathrm{C}$ & & 4.5 & 4.5 & 11.8 & 20.0 & 13.6 & 13.6 & 24.9 & 24.1 & 24.1 \\
\hline Rel. humidity, \% & & 79.3 & 79.3 & 94.6 & 74.2 & 99.7 & 99.7 & 71.8 & 52.5 & 52.5 \\
\hline $\begin{array}{l}\text { Analyte or } \\
\text { co-eluting analyte } \\
\text { group }\end{array}$ & $\begin{array}{r}\mathrm{MDL}, \\
\mathrm{pg}\end{array}$ & Conc., & $g^{-3}$ & Conc & $g m^{-3}$ & Conc. & $\mathrm{pg} \mathrm{m}^{-3}$ & Conc., $\mathrm{pg} \mathrm{m}^{-3}$ & Conc., & $\mathrm{g} \mathrm{m}^{-3}$ \\
\hline PCB $4+10$ & 29.5 & $<0.5$ & $<0.5$ & $<0.4$ & 1.4 & & 0.7 & $<0.4$ & $<0.4$ & $<0.4$ \\
\hline РСВ 9 & 19.8 & 1.0 & 1.4 & $<0.3$ & $<0.3$ & $<0.2$ & $<0.2$ & 3.2 & $<0.3$ & $<0.3$ \\
\hline PCB 7 & 24.0 & $<0.4$ & $<0.4$ & $<0.4$ & $<0.3$ & $<0.2$ & $<0.2$ & $<0.3$ & $<0.3$ & $<0.4$ \\
\hline РCB 6 & 22.1 & $<0.4$ & $<0.4$ & 6.6 & 10.9 & 10.1 & 7.9 & 5.1 & 6.1 & 6.8 \\
\hline PCB 5 & 15.4 & $<0.3$ & $<0.3$ & $<0.2$ & 0.5 & $<0.1$ & $<0.1$ & $<0.2$ & $<0.2$ & $<0.2$ \\
\hline PCB 8 & 37.1 & $<0.7$ & $<0.6$ & 2.2 & 12.2 & 0.9 & 0.7 & 2.2 & 4.1 & 4.1 \\
\hline $\mathrm{HCB}$ & 9.3 & 55.7 & 69.2 & 68.5 & 95.9 & 104.9 & 78.0 & 66.4 & 66.7 & 69.0 \\
\hline РCB 18 & 49.0 & $<0.9$ & & 7.6 & 19.2 & 4.1 & 2.6 & 5.6 & 9.0 & 9.0 \\
\hline РСВ 17 & 10.7 & $<0.2$ & $<0.2$ & 2.0 & 6.5 & 1.0 & 0.8 & 2.0 & 3.4 & 3.3 \\
\hline PCB 12 & 20.2 & $<0.4$ & $<0.3$ & $<0.3$ & $<0.3$ & $<0.2$ & $<0.2$ & $<0.3$ & $<0.3$ & $<0.3$ \\
\hline PCB $27+13$ & 26.2 & $<0.5$ & $<0.4$ & $<0.4$ & $<0.3$ & 0.3 & $<0.2$ & 0.4 & 0.6 & 0.8 \\
\hline PCB 24 & 8.0 & $<0.1$ & $<0.1$ & $<0.1$ & $<0.1$ & $<0.1$ & $<0.1$ & $<0.1$ & $<0.1$ & 0.1 \\
\hline РСB 16 & 8.6 & $<0.2$ & $<0.1$ & 0.8 & $<0.1$ & $<0.1$ & $<0.1$ & $<0.1$ & $<0.1$ & $<0.1$ \\
\hline РСВ 15 & 25.5 & 0.6 & $<0.4$ & $<0.4$ & $<0.3$ & $<0.2$ & $<0.2$ & $<0.3$ & $<0.4$ & $<0.4$ \\
\hline РCB 32 & 9.2 & $<0.2$ & $<0.2$ & 0.6 & $<0.1$ & 0.5 & $<0.1$ & & $<0.1$ & 2.5 \\
\hline РСВ 54 & 23.3 & $<0.4$ & $<0.4$ & $<0.3$ & $<0.3$ & $<0.2$ & 2.4 & $<0.3$ & $<0.3$ & $<0.4$ \\
\hline PCB 34 & 14.8 & $<0.3$ & $<0.3$ & & 0.8 & $<0.1$ & $<0.1$ & $<0.2$ & $<0.2$ & 0.6 \\
\hline РСВ 29 & 17.0 & $<0.3$ & $<0.3$ & $<0.2$ & 5.1 & $<0.2$ & $<0.2$ & $<0.2$ & $<0.2$ & $<0.3$ \\
\hline РСВ 26 & 13.3 & $<0.2$ & $<0.2$ & 0.5 & $<0.2$ & $<0.1$ & $<0.1$ & 0.5 & $<0.2$ & 1.2 \\
\hline PCB 25 & 8.4 & $<0.1$ & $<0.1$ & $<0.1$ & $<0.1$ & $<0.1$ & $<0.1$ & 0.2 & 0.4 & 0.5 \\
\hline PCB $31+53$ & 22.1 & $<0.4$ & $<0.4$ & 2.1 & 13.1 & $<0.2$ & 0.8 & 2.0 & $<0.3$ & 7.2 \\
\hline PCB 28 & 9.8 & & $<0.2$ & 1.5 & 8.6 & 0.7 & 0.5 & 1.4 & $<0.1$ & 5.2 \\
\hline PCB $33+20$ & 28.0 & $<0.5$ & $<0.5$ & 1.1 & 6.0 & 0.4 & $<0.3$ & 0.9 & $<0.4$ & $<0.4$ \\
\hline PCB 51 & 21.5 & $<0.4$ & $<0.4$ & $<0.3$ & 0.7 & $<0.2$ & $<0.2$ & $<0.3$ & $<0.3$ & $<0.3$ \\
\hline РСB 45 & 44.8 & $<0.8$ & $<0.8$ & $<0.7$ & 10.8 & $<0.4$ & $<0.4$ & $<0.6$ & $<0.6$ & 1.0 \\
\hline
\end{tabular}


Table D.1: (continued)

\begin{tabular}{|c|c|c|c|c|c|c|c|c|c|c|}
\hline $\begin{array}{l}\text { Sample location } \\
\text { Date }\end{array}$ & & \multicolumn{2}{|c|}{$\begin{array}{c}\text { Eagle Harbor, } \\
\text { MI } \\
19 \text { Apr. } 2008\end{array}$} & \multicolumn{2}{|c|}{$\begin{array}{c}\text { Houghton, } \\
\text { MI }\end{array}$} & \multicolumn{2}{|c|}{$\begin{array}{l}\text { Eagle Harbor, } \\
\qquad \mathrm{MI}\end{array}$} & $\begin{array}{c}\text { Eagle } \\
\text { Harbor, MI } \\
29 \text { Jul. } 2008\end{array}$ & \multicolumn{2}{|c|}{$\begin{array}{l}\text { Houghton, } \\
\text { MI }\end{array}$} \\
\hline $\begin{array}{l}\text { Analyte or } \\
\text { co-eluting analyte } \\
\text { group }\end{array}$ & $\begin{array}{r}\mathrm{MDL} \\
\mathrm{PB}\end{array}$ & Conc. & $\mathrm{gg} \mathrm{m}^{-3}$ & Cono & $\mathrm{g} \mathrm{m}^{-3}$ & Conc. & $\mathrm{g} \mathrm{m}^{-3}$ & Conc., $\mathrm{pg} \mathrm{m}^{-3}$ & Conc. & $\mathrm{g} \mathrm{m}^{-3}$ \\
\hline PCB 22 & 57.1 & $<1.0$ & $<1.0$ & 0.7 & 4.2 & $<0.5$ & $<0.5$ & 1.3 & 3.0 & 2.9 \\
\hline PCB 46 & 11.0 & $<0.2$ & $<0.2$ & & 0.6 & $<0.1$ & & $<0.2$ & $<0.2$ & 0.3 \\
\hline PCB 73 & 7.5 & $<0.1$ & $<0.1$ & $<0.1$ & $<0.1$ & & $<0.1$ & $<0.1$ & $<0.1$ & $<0.1$ \\
\hline PCB 69 & 34.3 & $<0.6$ & $<0.6$ & $<0.5$ & $<0.4$ & $<0.3$ & $<0.3$ & $<0.5$ & $<0.5$ & $<0.5$ \\
\hline PCB 52 & 11.6 & $<0.2$ & $<0.2$ & 1.1 & 6.3 & $<0.1$ & $<0.1$ & 1.1 & $<0.2$ & 3.7 \\
\hline PCB 48 & 12.9 & 5.9 & $<0.2$ & $<0.2$ & $<0.2$ & 4.1 & 3.5 & $<0.2$ & $<0.2$ & 0.5 \\
\hline PCB 49 & 51.5 & $<0.9$ & $<0.9$ & $<0.8$ & 4.4 & $<0.5$ & $<0.5$ & $<0.7$ & 3.3 & 3.3 \\
\hline PCB 75 & 36.8 & $<0.6$ & $<0.6$ & $<0.5$ & $<0.5$ & $<0.3$ & $<0.3$ & $<0.5$ & $<0.5$ & $<0.6$ \\
\hline PCB 44 & 37.0 & $<0.7$ & $<0.6$ & 1.1 & 6.6 & 0.8 & 0.4 & $<0.5$ & 3.8 & $<0.6$ \\
\hline PCB $59+42$ & 12.8 & $<0.2$ & 0.4 & 0.7 & 3.3 & 0.3 & $<0.1$ & 1.0 & 2.2 & 2.1 \\
\hline PCB 35 & 5.7 & $<0.1$ & 0.4 & & 0.4 & 0.3 & $<0.1$ & 0.2 & $<0.1$ & $<0.1$ \\
\hline PCB 71 & 15.0 & $<0.3$ & $<0.3$ & & 1.3 & $<0.1$ & $<0.1$ & $<0.2$ & 1.8 & 1.7 \\
\hline PCB 41 & 7.5 & $<0.1$ & $<0.1$ & 0.3 & 0.9 & $<0.1$ & $<0.1$ & 0.2 & $<0.1$ & $<0.1$ \\
\hline PCB 64 & 7.0 & $<0.1$ & 0.2 & 0.4 & 2.6 & 0.3 & 0.2 & 0.6 & 1.8 & 1.8 \\
\hline $\begin{array}{l}\text { PCB } 40+37+ \\
\text { octachlorostyrene }\end{array}$ & 13.7 & 0.5 & 0.8 & 1.0 & 2.5 & 1.1 & 0.7 & 1.5 & $<0.2$ & 1.6 \\
\hline PCB 103 & 8.4 & $<0.1$ & $<0.1$ & $<0.1$ & $<0.1$ & $<0.1$ & 0.2 & $<0.1$ & $<0.1$ & $<0.1$ \\
\hline PCB 100 & 11.4 & $<0.2$ & $<0.2$ & $<0.2$ & $<0.1$ & $<0.1$ & $<0.1$ & $<0.2$ & $<0.2$ & $<0.2$ \\
\hline PCB 67 & 11.8 & $<0.2$ & $<0.2$ & $<0.2$ & $<0.2$ & $<0.1$ & $<0.1$ & $<0.2$ & 0.3 & $<0.2$ \\
\hline PCB $93+63$ & 26.2 & $<0.5$ & $<0.4$ & $<0.4$ & $<0.3$ & $<0.2$ & $<0.2$ & $<0.4$ & $<0.4$ & $<0.4$ \\
\hline PCB 95 & 11.6 & $<0.2$ & 0.3 & 1.4 & 7.8 & 0.5 & & 1.3 & 5.2 & 5.5 \\
\hline PCB 74 & 7.9 & 0.2 & $<0.1$ & 0.3 & 1.8 & $<0.1$ & 0.2 & $<0.1$ & $<0.1$ & $<0.1$ \\
\hline PCB 70 & 9.9 & $<0.2$ & $<0.2$ & 1.2 & 6.3 & 0.2 & $<0.1$ & $<0.1$ & 1.0 & 1.8 \\
\hline PCB $91+66$ & 61.4 & $<1.1$ & $<1.0$ & $<0.9$ & $<0.8$ & $<0.6$ & $<0.6$ & $<0.8$ & $<0.9$ & $<0.9$ \\
\hline PCB $84+92+56$ & 26.8 & $<0.5$ & $<0.5$ & 0.9 & $<0.3$ & $<0.2$ & $<0.2$ & $<0.4$ & 2.8 & $<0.4$ \\
\hline PCB $60+101+90$ & 22.4 & $<0.4$ & $<0.4$ & 1.1 & 6.0 & $<0.2$ & $<0.2$ & $<0.3$ & $<0.3$ & 4.3 \\
\hline РСВ 99 & 6.1 & $<0.1$ & $<0.1$ & 0.4 & 2.1 & $<0.1$ & $<0.1$ & $<0.1$ & $<0.1$ & $<0.1$ \\
\hline PCB $119+83$ & 14.0 & $<0.2$ & $<0.2$ & $<0.2$ & 0.8 & $<0.1$ & $<0.1$ & $<0.2$ & 0.2 & 0.3 \\
\hline PCB 97 & 32.5 & $<0.6$ & $<0.6$ & 0.6 & $<0.4$ & $<0.3$ & $<0.3$ & $<0.4$ & $<0.5$ & $<0.5$ \\
\hline PCB 87 & 11.3 & 0.4 & $<0.2$ & $<0.2$ & 0.7 & 1.9 & 0.5 & $<0.2$ & $<0.2$ & $<0.2$ \\
\hline PCB 136 & 12.1 & $<0.2$ & 0.4 & 0.3 & 0.3 & 1.0 & $<0.1$ & 7.5 & 4.6 & 5.0 \\
\hline PCB 117 & 10.6 & $<0.2$ & $<0.2$ & 1.1 & 2.6 & $<0.1$ & $<0.1$ & $<0.1$ & 0.5 & 0.5 \\
\hline PCB 115 & 9.0 & $<0.2$ & $<0.2$ & $<0.1$ & 0.3 & $<0.1$ & $<0.1$ & $<0.1$ & $<0.1$ & $<0.1$ \\
\hline PCB 85 & 7.9 & $<0.1$ & $<0.1$ & $<0.1$ & $<0.1$ & $<0.1$ & $<0.1$ & $<0.1$ & $<0.1$ & $<0.1$ \\
\hline
\end{tabular}


Table D.1: (continued)

\begin{tabular}{|c|c|c|c|c|c|c|c|c|c|c|}
\hline $\begin{array}{l}\text { Sample location } \\
\text { Date }\end{array}$ & & \multicolumn{2}{|c|}{$\begin{array}{c}\text { Eagle Harbor, } \\
\text { MI }\end{array}$} & \multicolumn{2}{|c|}{$\begin{array}{c}\text { Houghton, } \\
\text { MI }\end{array}$} & \multicolumn{2}{|c|}{$\begin{array}{c}\text { Eagle Harbor, } \\
\text { MI }\end{array}$} & $\begin{array}{c}\text { Eagle } \\
\text { Harbor, MI } \\
29 \text { Jul. } 2008\end{array}$ & \multicolumn{2}{|c|}{$\begin{array}{c}\text { Houghton, } \\
\text { MI }\end{array}$} \\
\hline $\begin{array}{l}\text { Analyte or } \\
\text { co-eluting analyte } \\
\text { group }\end{array}$ & $\begin{array}{r}\text { MDL, } \\
\mathrm{pg}\end{array}$ & Cone., & $\mathrm{g} \mathrm{m}^{-3}$ & Conc & $\mathrm{g} \mathrm{m}^{-3}$ & Conc. & $\mathrm{g} \mathrm{m}^{-3}$ & Conc., pg m ${ }^{-3}$ & Conc. & $\mathrm{og} \mathrm{m}^{-3}$ \\
\hline PCB 154 & 9.1 & 0.2 & $<0.2$ & $<0.1$ & $<0.1$ & $<0.1$ & $<0.1$ & $<0.1$ & $<0.1$ & $<0.1$ \\
\hline PCB 110 & 8.2 & $<0.1$ & $<0.1$ & $<0.1$ & $<0.1$ & $<0.1$ & $<0.1$ & $<0.1$ & $<0.1$ & $<0.1$ \\
\hline PCB 81 & 9.2 & $<0.2$ & $<0.2$ & $<0.1$ & $<0.1$ & $<0.1$ & $<0.1$ & 0.1 & $<0.1$ & $<0.1$ \\
\hline PCB 82 & 10.2 & $<0.2$ & 0.3 & $<0.2$ & & $<0.1$ & 0.1 & $<0.1$ & 0.3 & 1.0 \\
\hline PCB 151 & 14.2 & $<0.3$ & $<0.2$ & 1.1 & 1.6 & $<0.1$ & $<0.1$ & $<0.2$ & $<0.2$ & $<0.2$ \\
\hline PCB 135 & 7.7 & $<0.1$ & $<0.1$ & $<0.1$ & $<0.1$ & $<0.1$ & $<0.1$ & 0.2 & 0.6 & 0.4 \\
\hline PCB 77 & 8.8 & $<0.2$ & $<0.1$ & & 0.6 & $<0.1$ & 0.6 & $<0.1$ & $<0.1$ & $<0.1$ \\
\hline PCB 144 & 7.9 & $<0.1$ & $<0.1$ & $<0.1$ & $<0.1$ & 0.3 & $<0.1$ & $<0.1$ & $<0.1$ & $<0.1$ \\
\hline PCB 147 & 8.5 & $<0.2$ & $<0.1$ & $<0.1$ & $<0.1$ & $<0.1$ & $<0.1$ & $<0.1$ & $<0.1$ & $<0.1$ \\
\hline PCB 149 & 10.2 & $<0.2$ & 0.4 & 0.6 & 2.7 & $<0.1$ & $<0.1$ & 1.0 & $<0.1$ & 3.1 \\
\hline PCB 124 & 7.4 & $<0.1$ & $<0.1$ & $<0.1$ & 0.1 & $<0.1$ & $<0.1$ & $<0.1$ & 0.1 & 0.5 \\
\hline PCB $123+107$ & 19.9 & $<0.3$ & $<0.3$ & $<0.3$ & 0.3 & $<0.2$ & $<0.2$ & $<0.3$ & $<0.3$ & $<0.3$ \\
\hline PCB 134 & 11.4 & $<0.2$ & $<0.2$ & $<0.2$ & 0.4 & $<0.1$ & $<0.1$ & $<0.2$ & 0.2 & 0.4 \\
\hline $\begin{array}{l}\text { PCB } 131+118+ \\
\text { PBDE } 28\end{array}$ & 93.0 & $<1.6$ & $<1.6$ & 1.7 & 4.1 & 2.0 & $<0.8$ & 2.2 & $<1.3$ & $<1.4$ \\
\hline PCB 122 & 9.4 & $<0.2$ & $<0.2$ & $<0.1$ & $<0.1$ & $<0.1$ & 0.3 & $<0.1$ & $<0.1$ & $<0.1$ \\
\hline PCB 165 & 8.2 & $<0.1$ & $<0.1$ & $<0.1$ & $<0.1$ & $<0.1$ & $<0.1$ & $<0.1$ & $<0.1$ & $<0.1$ \\
\hline PCB $114+146$ & 15.6 & $<0.3$ & $<0.3$ & $<0.2$ & 0.3 & $<0.1$ & $<0.1$ & $<0.2$ & 0.4 & 0.4 \\
\hline PCB 132 & 8.3 & $<0.1$ & $<0.1$ & 0.2 & 1.1 & 0.2 & 0.1 & 0.3 & 1.0 & 1.0 \\
\hline PCB 153 & 8.5 & $<0.2$ & 0.3 & 0.3 & 1.5 & 0.4 & 0.2 & 0.5 & 2.0 & 1.9 \\
\hline PCB 179 & 9.4 & $<0.2$ & $<0.2$ & $<0.1$ & 0.2 & $<0.1$ & $<0.1$ & $<0.1$ & 0.3 & 0.3 \\
\hline PCB 105 & 13.9 & $<0.2$ & $<0.2$ & $<0.2$ & 1.0 & 0.3 & 0.2 & & 1.0 & 0.9 \\
\hline PCB 141 & 8.3 & & & $<0.1$ & 0.5 & & $<0.1$ & 0.2 & 0.5 & 0.5 \\
\hline PCB 176 & 11.7 & $<0.2$ & $<0.2$ & $<0.2$ & $<0.2$ & $<0.1$ & $<0.1$ & $<0.2$ & $<0.2$ & $<0.2$ \\
\hline PCB 137 & 8.3 & $<0.1$ & $<0.1$ & $<0.1$ & $<0.1$ & $<0.1$ & $<0.1$ & $<0.1$ & 0.2 & $<0.1$ \\
\hline PCB 130 & 10.3 & $<0.2$ & $<0.2$ & $<0.2$ & $<0.1$ & $<0.1$ & $<0.1$ & $<0.1$ & $<0.1$ & $<0.2$ \\
\hline PCB 164 & 7.8 & $<0.1$ & $<0.1$ & $<0.1$ & $<0.1$ & $<0.1$ & $<0.1$ & $<0.1$ & $<0.1$ & $<0.1$ \\
\hline PCB 138 & 10.0 & $<0.2$ & $<0.2$ & 0.3 & 1.6 & 0.4 & 0.3 & 0.5 & 2.1 & 1.9 \\
\hline PCB $163+129$ & 15.3 & $<0.3$ & $<0.3$ & $<0.2$ & 0.4 & $<0.1$ & $<0.1$ & $<0.2$ & 0.5 & 0.4 \\
\hline PCB 178 & 8.6 & $<0.2$ & $<0.1$ & $<0.1$ & $<0.1$ & $<0.1$ & $<0.1$ & $<0.1$ & $<0.1$ & $<0.1$ \\
\hline PCB 158 & 6.4 & $<0.1$ & $<0.1$ & $<0.1$ & 0.2 & 0.1 & 0.1 & 0.1 & 0.3 & 0.2 \\
\hline PCB 175 & 6.2 & $<0.1$ & $<0.1$ & $<0.1$ & $<0.1$ & $<0.1$ & $<0.1$ & $<0.1$ & $<0.1$ & $<0.1$ \\
\hline PCB 187 & 7.3 & $<0.1$ & $<0.1$ & $<0.1$ & 0.4 & 0.1 & 0.1 & 0.2 & 0.7 & 0.7 \\
\hline PCB 128 & 7.2 & $<0.1$ & $<0.1$ & $<0.1$ & 0.2 & $<0.1$ & $<0.1$ & $<0.1$ & 0.4 & 0.3 \\
\hline
\end{tabular}


Table D.1: (continued)

\begin{tabular}{|c|c|c|c|c|c|c|c|c|c|c|}
\hline \multicolumn{2}{|l|}{$\begin{array}{l}\text { Sample location } \\
\text { Date }\end{array}$} & \multicolumn{2}{|c|}{$\begin{array}{l}\text { Eagle Harbor, } \\
\text { MI } \\
19 \text { Apr. } 2008 \\
\end{array}$} & \multicolumn{2}{|c|}{\begin{tabular}{l} 
Houghton, \\
\multicolumn{1}{c}{ MI } \\
$24 \quad 25$ \\
June 2008 \\
\end{tabular}} & \multicolumn{2}{|c|}{$\begin{array}{c}\text { Eagle Harbor, } \\
\text { MI } \\
17 \text { Jul. } 2008\end{array}$} & $\begin{array}{c}\text { Eagle } \\
\text { Harbor, MI } \\
29 \text { Jul. } 2008 \\
\end{array}$ & \multicolumn{2}{|c|}{$\begin{array}{l}\text { Houghton, } \\
\text { MI } \\
5 \text { Aug. } 2008\end{array}$} \\
\hline $\begin{array}{l}\text { Analyte or } \\
\text { co-eluting analyte } \\
\text { group }\end{array}$ & $\begin{array}{r}\mathrm{MDL}, \\
\mathrm{pg}\end{array}$ & \multicolumn{2}{|c|}{ Conc., $\mathrm{pg} \mathrm{m}^{-3}$} & \multicolumn{2}{|c|}{ Conc., $\mathrm{pg} \mathrm{m}^{-3}$} & \multicolumn{2}{|c|}{ Conc., pg m $\mathrm{m}^{-3}$} & \multirow{2}{*}{$\begin{array}{r}\text { Conc., } \mathrm{pg} \mathrm{m}^{-3} \\
0.4\end{array}$} & \multicolumn{2}{|c|}{ Conc., pg m } \\
\hline PCB 185 & 7.5 & $<0.1$ & $<0.1$ & $<0.1$ & 0.2 & 0.2 & 0.2 & & & \\
\hline PCB 174 & 10.5 & $<0.2$ & $<0.2$ & $<0.2$ & 0.3 & $<0.1$ & $<0.1$ & $<0.1$ & 0.4 & 0.4 \\
\hline PCB 167 & 9.6 & & & & & & & 0.6 & $<0.1$ & $<0.1$ \\
\hline PCB 202 & 13.6 & & & $<0.2$ & $<0.2$ & $<0.1$ & & $<0.2$ & 0.7 & 0.8 \\
\hline PCB 177 & 7.4 & $<0.1$ & $<0.1$ & $<0.1$ & $<0.1$ & $<0.1$ & $<0.1$ & $<0.1$ & 0.2 & 0.2 \\
\hline PCB 173 & 5.9 & $<0.1$ & $<0.1$ & $<0.1$ & $<0.1$ & $<0.1$ & $<0.1$ & $<0.1$ & $<0.1$ & $<0.1$ \\
\hline PCB 156 & 6.8 & $<0.1$ & $<0.1$ & $<0.1$ & $<0.1$ & $<0.1$ & $<0.1$ & $<0.1$ & 0.1 & 0.1 \\
\hline PCB 172 & 10.1 & $<0.2$ & 1.2 & $<0.1$ & $<0.1$ & $<0.1$ & $<0.1$ & $<0.1$ & $<0.1$ & $<0.2$ \\
\hline PCB 157 & 7.1 & $<0.1$ & $<0.1$ & $<0.1$ & $<0.1$ & $<0.1$ & $<0.1$ & $<0.1$ & $<0.1$ & $<0.1$ \\
\hline PCB 180 & 7.3 & 0.3 & 0.4 & $<0.1$ & 0.3 & $<0.1$ & $<0.1$ & 0.1 & 0.6 & 0.5 \\
\hline PCB $193+200$ & 15.9 & $<0.3$ & $<0.3$ & $<0.2$ & $<0.2$ & $<0.1$ & 0.2 & $<0.2$ & $<0.2$ & $<0.2$ \\
\hline PCB 191 & 36.2 & $<0.6$ & $<0.6$ & $<0.5$ & $<0.5$ & $<0.3$ & $<0.3$ & $<0.5$ & $<0.5$ & $<0.5$ \\
\hline PCB 170 & 7.5 & $<0.1$ & $<0.1$ & $<0.1$ & $<0.1$ & $<0.1$ & $<0.1$ & $<0.1$ & 0.2 & 0.1 \\
\hline PCB 199 & 7.2 & $<0.1$ & $<0.1$ & $<0.1$ & 0.1 & $<0.1$ & $<0.1$ & $<0.1$ & 0.2 & 0.2 \\
\hline PCB 190 & 6.1 & $<0.1$ & $<0.1$ & $<0.1$ & $<0.1$ & $<0.1$ & $<0.1$ & $<0.1$ & $<0.1$ & $<0.1$ \\
\hline PCB 196 & 8.5 & $<0.1$ & $<0.1$ & $<0.1$ & $<0.1$ & $<0.1$ & $<0.1$ & $<0.1$ & 0.2 & $<0.1$ \\
\hline PCB 203 & 6.3 & $<0.1$ & $<0.1$ & $<0.1$ & $<0.1$ & $<0.1$ & $<0.1$ & $<0.1$ & $<0.1$ & $<0.1$ \\
\hline PCB 208 & 6.1 & $<0.1$ & $<0.1$ & $<0.1$ & $<0.1$ & $<0.1$ & $<0.1$ & $<0.1$ & $<0.1$ & $<0.1$ \\
\hline РCB 189 & 31.9 & $<0.6$ & $<0.5$ & $<0.5$ & $<0.4$ & $<0.3$ & $<0.3$ & $<0.4$ & $<0.5$ & $<0.5$ \\
\hline РCB $195+207$ & 35.7 & $<0.6$ & $<0.6$ & $<0.5$ & $<0.5$ & $<0.3$ & $<0.3$ & $<0.5$ & $<0.5$ & $<0.5$ \\
\hline $\begin{array}{l}\text { PCB } 194+\text { PBDE } \\
100\end{array}$ & 30.9 & $<0.5$ & & & & 1.9 & 2.2 & & & 12.2 \\
\hline PCB 205 & 6.4 & $<0.1$ & $<0.1$ & $<0.1$ & $<0.1$ & 0.2 & 0.2 & 0.4 & $<0.1$ & 0.7 \\
\hline РСВ 206 & 6.4 & $<0.1$ & $<0.1$ & $<0.1$ & $<0.1$ & $<0.1$ & $<0.1$ & $<0.1$ & $<0.1$ & $<0.1$ \\
\hline PCB 209 & 22.5 & $<0.4$ & $<0.4$ & $<0.3$ & $<0.3$ & $<0.2$ & $<0.2$ & $<0.3$ & $<0.3$ & $<0.3$ \\
\hline
\end{tabular}

${ }^{a}$ Observations that fell between the MDL and QL are given in italicized font. In the case of non-detect, the MDL is given in boldface font preceded by the symbol " $<$ ". Missing values indicate observations that failed the blank criterion. PBDE 47 and 99 were included as analytes but were not reported because of persistent blank failures. PBDE 28 and 100 are indicated as co-eluting interferences with analytes, but were not included in the calibration standards. Air temperature and relative humidity are means over the sample collection period. 
Table D.2: Paired analyte groups for comparison of concentrations measured by highflow denuder to IADN Project high-volume samples.

\begin{tabular}{|c|c|c|c|}
\hline High-flow denuder & IADN Project & High-flow denuder & IADN Project \\
\hline PCB $4+10$ & $4+10$ & PCB $91+66$ & $66^{b}$ \\
\hline РСВ 9 & $7+9^{a}$ & РCB $84+92+56$ & $92+84^{b}$ \\
\hline PCB 6 & 6 & PCB $60+101+90$ & $101^{b}$ \\
\hline PCB 8 & $8+5^{a}$ & PCB 99 & 99 \\
\hline $\mathrm{HCB}$ & $\mathrm{HCB}$ & PCB $119+83$ & $83^{b}$ \\
\hline РСВ 18 & 18 & РСВ 97 & 97 \\
\hline РСВ 17 & $15+17^{\mathrm{a}}$ & РСB 87 & 87 \\
\hline РСВ 12 & 12 & PCB 85 & 85 \\
\hline PCB $27+13$ & $13^{b}$ & РCB 110 & 110 \\
\hline PCB 16 & 16 & РCB 81 & 81 \\
\hline РСВ 32 & 32 & РCB 135 & $135+144^{a}$ \\
\hline РСВ 26 & 26 & РCB 77 & 77 \\
\hline PCB $31+53$ & $31^{b}$ & РСВ 149 & $123+149^{a}$ \\
\hline PCB 28 & 28 & PCB $114+146$ & $114^{\mathrm{b}}$ \\
\hline PCB $33+20$ & $33^{b}$ & PCB 132 & $132+153+105^{\mathrm{a}}$ \\
\hline РCB 45 & 45 & PCB 138 & $163+138^{a}$ \\
\hline РСВ 22 & 22 & РCB 128 & 128 \\
\hline PCB 52 & 52 & РCB 174 & 174 \\
\hline РСB 48 & 48 & РCB 156 & 156 \\
\hline РСB 49 & 49 & РCB 172 & 172 \\
\hline PCB $59+42$ & $42^{b}$ & РCB 157 & 157 \\
\hline PCB 71 & $41+71^{a}$ & РCB 180 & 180 \\
\hline РСВ 64 & 64 & РСB 170 & $170+190^{a}$ \\
\hline PCB 100 & 100 & РCB 199 & 199 \\
\hline РСB 95 & 95 & РCB 205 & 205 \\
\hline PCB 74 & 74 & РCB 206 & 206 \\
\hline PCB 70 & $70+76^{a}$ & & \\
\hline
\end{tabular}

${ }^{\text {a }}$ PCB congeners resolved in the high-flow method were added to match the IADN analyte group.

${ }^{\mathrm{b}}$ One or two co-eluting congeners in the high-flow method were not included in the IADN method. 